\title{
Intimal hyperplasia in human vascular grafts : a study in peripheral bypasses and arteriovenous fistulas
}

Citation for published version (APA):

Hofstra, L. (1995). Intimal hyperplasia in human vascular grafts : a study in peripheral bypasses and arteriovenous fistulas. [Doctoral Thesis, Maastricht University]. Datawyse / Universitaire Pers Maastricht. https://doi.org/10.26481/dis.19950602lh

Document status and date:

Published: 01/01/1995

DOI:

10.26481/dis.19950602/h

Document Version:

Publisher's PDF, also known as Version of record

\section{Please check the document version of this publication:}

- A submitted manuscript is the version of the article upon submission and before peer-review. There can be important differences between the submitted version and the official published version of record.

People interested in the research are advised to contact the author for the final version of the publication, or visit the DOI to the publisher's website.

- The final author version and the galley proof are versions of the publication after peer review.

- The final published version features the final layout of the paper including the volume, issue and page numbers.

Link to publication

\footnotetext{
General rights rights.

- You may freely distribute the URL identifying the publication in the public portal. please follow below link for the End User Agreement:

www.umlib.nl/taverne-license

Take down policy

If you believe that this document breaches copyright please contact us at:

repository@maastrichtuniversity.nl

providing details and we will investigate your claim.
}

Copyright and moral rights for the publications made accessible in the public portal are retained by the authors and/or other copyright owners and it is a condition of accessing publications that users recognise and abide by the legal requirements associated with these

- Users may download and print one copy of any publication from the public portal for the purpose of private study or research.

- You may not further distribute the material or use it for any profit-making activity or commercial gain

If the publication is distributed under the terms of Article $25 \mathrm{fa}$ of the Dutch Copyright Act, indicated by the "Taverne" license above, 
INTIMAL HYPERPLASIA IN HUMAN VASCULAR GRAFTS A STUDY IN PERIPHERAL BYPASSES AND ARTERIOVENOUS FISTULAS 



\section{INTIMAL HYPERPLASIA IN HUMAN VASCULAR GRAFTS}

A study in peripheral bypasses and arteriovenous fistulas

\section{PROEFSCHRIFT}

ter verkrijging van de graad van doctor aan de Rijksuniversiteit Limburg te Maastricht, op het gezag van de Rector Magnificus, Prof. mr. M.J. Cohen, volgens het besluit van het College van Dekanen, in het openbaar te verdedigen op vrijdag 2 juni 1995 om 14.00 uur

door

Leonard Hofstra

geboren te Emmen op 25 juni 1963

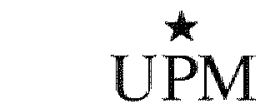

UHVIVERSTAIRE PERS MAASTRHCHT 


\section{Promotores}

Prof. dr. P.J.E.H.M. Kitslaar

Prof. dr. A.P.G. Hoeks

\section{Co-promotores}

Dr. J.H.M. Tordoir

Dr. M.J.A.P. Daemen

\section{Beoordelingscommissie}

Prof. dr. R.S. Reneman (voorzitter)

Prof. dr. J.W. Arends

Prof. dr. B. Eykelboom (Rijksuniversiteit Utrecht)

Prof. dr. N. Westerhof (Vrije Universiteit Amsterdam)

Prof. dr. H.J.J. Wellens

\section{CIP-DATA KONINKLIJKE BIBLIOTHEEK, DEN HAAG}

Hofstra, Leonard

Intima $\|$ hyperplasia in human vascular grafts; a study in peripheral bypasses and arteriovenous fistulas / Leonard Hofstra, - Manstricht: Universitaire Pers Maastricht. "III. Thesis Rijksuniversiteit Limburg Maastricht. - With ref. With summary in Dutch.

ISBN $90-5278-190-7$

Subject headings: intimal hyperplasia / human yascular grafts / fistulas.

Layout: Karin Scheele, A Point, Maastrichi

Production: Datawyse, Maastricht

Financial support by the Netherlands Heart Foundation and the Netherlands Kidney Foundation for the publication of this thesis is gratefully acknowledged. 


\section{CONTENTS}

page

Preface

INTRODUCTION

Chapter 1 General introduction

Chapter 2 The development of intimal hyperplasia after vascular reconstruction in humans

MATERIALS AND METHODS

Chapter 3 Vessel Wall Doppler Tracking: A new techmique to assess vessel wall elastic properties

Chapter $4 \quad$ Short-term variations in elastic properties of a muscular artery in humans

ELASTIC PROFILES OF PERIPHERAL BYPASSES AND GRAFT ARTERIOVENOUS FISTULAS IN HUMANS

Chapter 5 Assessment of inhomogeneities in elastic properties of in situ and reversed saphenous vein grafts in humans

Chapter 6 Elastic properties of PTFE and saphenous vein bypass grafts in humans

Chapter 7 Mismatch in elastic properties around anastomoses of interposition grafts for hemodialysis access

Chapter 8 The dimensions and elastic properties of human saphenous vein grafted into the arterial circulation are stable with time 
MECHANICAL INFLUENCES ON THE OCCURRENCE OF INTIMAL HYPERPLASIA IN PERIPHERAL BYPASSES AND GRAFT ARTERIO-VENOUS FISTULAS IN HUMANS

Chapter 9 Anastornotic intimal hyperplasia in prosthetic arterio-venous fistulas for hemodialysis is associated with high shear rate and not with mismatch in elastic properties

Chapter 10 The influence of mismatch in elastic properties and flow on the occurrence of stenotic intimal thickening in peripheral bypass grafts in humans; a prospective analysis

Chapter 11 High shear rate mediated denudation inhibits proliferation in human stenotic tissue derived from AV fistulas and peripheral bypass grafts

\section{GENERAL DISCUSSION}

Chapter 12 Mechanical and flow characteristics affecting intimal hyperplasia in peripheral bypasses and graft arteriovenous fistulas in humans

Summary

Samenvatting

Dankwoord

Curriculum vitae

List of publications 


\section{PREFACE}

The studies presented in this thesis are part of a larger research program, conducted in the Cardiovascular Research Institute Maastricht (CARIM). In that program attention is focused on studying the elastic properties of medium sized arteries in patients with a high risk of developing atherosclerosis, like hypertensive and diabetic patients, to gain more insight in the pathogenesis of vascular disease. Vessel Wall Doppler Tracking, a non-invasive method to assess the elastic properties of large vessels, is one of the techniques used and has been developed in the Department of Biophysics of our University.

We have used this system to investigate a different vascular problem, that is the occurrence of stenoses in peripherall bypass grafts and arterio-venous fistulas used for hemodialysis. Patency and function of these vascular conduits are jeopardized by the development of a stenosis due to intimal hyperplasia, mainly occurring at the anastomoses. A difference in elastic properties between graft and native vessels ('compliance mismatch') and unphysiologic flow conditions (shear rate) are possible contributing factors in the development of the stenotic lesions. In this thesis we have attempted to clarify the role of mismatch in ellastic properties around anastomoses in the development of intimal hyperplasia in peripheral bypasses and graft arteriovenous fistulas in humans in a prospective way. Furthermore, the influence of flow characteristics on intimal thickening was studied.

When we started our studies in 1991, quantitative mechanical information on bypass grafts and AV fistulas was scarce. Therefore, we first studied the mechanical profiles of different graft materials in both types of reconstructions. The elastic properties and flow characteristics were assessed two weeks after construction at defined sites in the graft and in the inflow and outflow vascular segments in patients who underwent femorodistal bypass surgery for stage II-IV occlusive arterial disease of the legs and in patients with a graft arteriovenous fistula for hemodialysis access. The initial mechanical and flow profiles were correlated with the occurrence of intimal hyperplasia during follow-up. This allowed a prospective analysis of the influence of mismatch in elastic properties and flow characteristics on intimal hyperplasia. Finally, the extent and distribution of cellular proliferation in stenotic lesions, surgically derived from these patients was studied in relation to local flow characteristics, in order to obtain insight in the direct coupling between flow and intimal proliferation. 
Research on this subject has recently been continued, by investigating the velocity profiles in arteries with a new ultrasound technique. For the first time, in vivo shear rate measurements in humans can be performed, allowing investigation of the effect of shear rate on the development of intimal hyperplasia in humans. Investigations with this new system may further unravel the influence of mechanical factors on the development of intimal hyperplastic lesions in vascular reconstructions in humans. 


\section{GENERAL INTRODUCTION}

The treatment of lower limb ischaemia is one of the major clinical problems encountered in vascular surgery. After the first implantation of a saphenous vein graft as a bypass to reestablish distal perfusion of the lower limb in 1949, major technical progress has been made in bypassing peripheral occlusive atherosclerotic lesions'. Nowadays, femoro-pedal bypasses are performed with the use of the in situ technique, and femoro-crural bypasses are constructed using prosthetic graft material, to achieve limb salvage in patients previously considered inoperable ${ }^{2-18}$. Despite these technical improvements ${ }^{19-21}$, peripheral bypasses are often complicated by the development of stenoses, mainly due to intimal hyperplasia. When a saphenous vein is grafted into the arterial circulation, generalized intimal thickening occurs, but to a limited extent ${ }^{22 \cdot 29}$. However, sometimes, locally, the process of intimal thickening is uncontrolled and leads to the formation of focal stenotic lesions ${ }^{16,17,30-34}$. Intimal hyperplasia often occurs at the anastomoses or in the areas adjacent to the anastomoses ${ }^{33-39}$ and leads to deterioration of graft flow and eventually to occlusion in about $20-30 \%$ of cases in the first year after operation ${ }^{2,3,16,17,36,37,40}$. Graft occlusion often necessitates surgical repair of the bypass graft and may result in loss of the graft. Another type of vascular reconstruction, the arteriovenous fistula for hemodialysis ${ }^{41}$, is even more susceptible to develop intimal hyperplasia, with a $50-60 \%$ incidence of stenosis in the first postoperative year ${ }^{42-45}$. Since hemodialysis patients depend on a proper functioning of the fistula, hemodynamically important stenoses always necessitate surgical correction or transluminal angioplasty. These interventions result in a mean hospital stay of one month per patient each year, illustrating the financial consequences and the impact of this clinical problem on the daily life of hemodialysis patients ${ }^{42,45}$. Another major clinical problem related to intimal hyperplasia is restenosis after percutaneous transluminal coronary angioplasty (PTCA) in patients with severe coronary artery disease. Restenosis due to intimal thickening occurs within three months in approximately $30-40 \%$ of patients after PTCA, results in recurrence of symptoms, and often necessitates reintervention ${ }^{46-54}$.

Because of the profound clinical impact of intimal hyperplasia after vascular reconstruction, extensive research has been performed in the last two decades to increase our understanding of the biology of this vascular response. Immunologic reactions ${ }^{55-69}$, platelet aggregation after vascular injury ${ }^{59,60,70-72}$, a large varielty of growth factors ${ }^{30,51}$ and different mechanical factors ${ }^{73,74}$ have been implicated as playing a role in the development of stenoses after vascular reconstruction. 
The studies presented in this thesis concentrate on the role of different mechanical factors, such as compliance mismatch and unphysiological shear rate, on the occurrence of intimal hyperplasia. Our hypothesis that compliance mismatch between graft and native vessels is one of the factors contributing to the development of intimal hyperplasia is based on the observation, that intimal thickening very often develops at the site of the anastomoses ${ }^{34,35,38,42,45,75.77}$. A possible mechanism may be a difference in compliance between graft and host vessel, occurring within a very short vessel segment, resulting in excessive mechanical stretching at the site of the anastomosis. Mechanical stretch may induce vessel wall injury, initiating a reparative response which results in intimal thickening ${ }^{73,78}$. Another physical factor affecting intimal growth is shear stress, i.e. shear rate times local viscosity. In one of the first studies evaluating the effect of varying levels of shear rate on the vessel wall, endothelial cell denudation was observed when the vessel wall was exposed to excessive high shear rate levels ${ }^{79,80}$. Therefore, it was suggested that high shear rate induces a hemodynamic injury of the vessel wall, initiating a vascular response to injury. This hypothesis was supported by observations in an animal study, investigating the influence of varying flow velocities on the occurrence of intimal hyperplasia at the venous anastomosis and the efferent vein of graft $\mathrm{AV}$ fistulas. A higher incidence of intimal hyperplasia was observed in areas with the highest flow velocities ${ }^{81,82}$. On the other hand, numerous investigations in different animal models demonstrated increased intimal thickening in low shear rate regions $^{74,83-89}$. Therefore, the current opinion is that the development of intimal thickening occurs in areas with low shear rate conditions.

\section{AIM OF THE STUDY}

In this thesis we have attempted to investigate prospectively the influence of mechanical factors, mismatch in elastic properties and shear rate, on the occurrence of intimal hyperplasia in peripheral bypass grafts and graft AV fistulas. One of the main advantages of studying the influence of mechanical factors in these 'models" is that peripheral bypass grafts and AV fistulas are easily accessible to the techniques used in this thesis. Morcover, the inclusion of the two different types of vascular reconstruction allows the investigation of mechanical factors on intimal hyperplasia in conditions of normal physiologic arterial flow (peripheral bypass) and very high flow (arteriovenous fistula). Our hypothesis is that (sub)-occlusive intimal hyperplasia in peripheral bypasses or AV fistulas occurs in areas of low shear rates. In addition, we hypothesize that an increased mismatch in elastic properties between graft and native vessels is associated with the occurrence of peri-anastomotic intimal hyperplasia. To test these hypotheses, a stepwise approach is used, which is reflected by the siructure of the thesis. 


\section{OUTLINE OF THE THESIS}

After an introduction of the problem of intimal hyperplasia following vascular reconstructions in humans (chapter 2 ), the thesis is divided in three different sections:

\section{MATERIALS AND METHODS}

In this section Vessel Wall Doppler Tracking (VWDT), the method used to measure diameter and distension of vessel segments is described and evaluated (chapter 3). Furthermore, the results of repeated measurements of the elastic properties of the common femoral artery in humans are reported (chapter 4). Especially, intra-individual variation in elastic behavior in relation to blood pressure was evaluated.

\section{ELASTIC PROFILES OF PERIPHERAL BYPASSES AND GRAFT AV FISTULAS IN HUMANS}

Since quantitative information on the in vivo mechanical profiles of peripheral bypass grafts and AV fistulas in humans was not available, we started to measure the elastic properties of different graft materials and the adjacent native vessels. The goal of these studies was to quantify mismatch in elastic properties around anastomoses and to obtain mechanical profiles along the graft. In addition, we tried to identify clues for the predisposition of intimal hyperplasia to develop at the site of the anastomoses. In chapter 5 the assessment of mechanical profiles of 'in situ' and 'reversed' saphenous vein bypass grafts are reported. The goal of this study was to compare the mechanical profiles of the in situ and the reversed saphenous vein peripheral bypass graft and to obtain insight in possible inhomogeneities in elastic properties around anastomoses. In chapter 6 a comparison is made between elastic profiles of poly-tetra-fluoro-ethylene (PTFE) prosthesis and reversed saphenous vein bypass grafts in the femorodistal position. In chapter 7 the differences in mismatch in elastic properties around the venous and arterial anastomoses of graft arteriovenous fistulas for hemodialysis are reported. Chapter 8 describes the dimensions and elastic properties of saphenous vein femorodistal grafts during the first 6 months after implantation. The goal of this study was to investigate possible functional or structural adaptation with time of the saphenous vein when grafted into the arterial circulation.

\section{MECHANICAL INFLUENCES ON THE DEVELOPMENT OF INTIMAL HYPERPLASIA IN PERIPHERAL BYPASSES AND GRAFT AV FISTULAS IN HUMANS}

The occurrence of stenoses due to intimal hyperplasia in the peripheral bypass grafts and the arteriovenous fistulas, respectively, was correlated with the initial mechanical profiles and flow characteristics as reported in chapter 5-7. The goal of these studies was to prospectively analyse the influence of mechanical factors, flow and perianastomotic mismatch in elastic properties, on the occurrence of intimal thickening. 
The results of these studies are reported in chapter 9 (AV fistulas) and 10 (peripheral bypasses). In chapter 11 the assessment of intimal DNA synthesis in surgically harvested stenotic lesions in relation to flow and endothelial cell coverage of the lumen is reported. The goal of that study was to investigate a possible link between peak shear rate and cell proliferation in human stenotic lesions. In addition, the influence of the presence of endothelial cells on intimal proliferation was studied. 


\section{REFERENCES}

1. Kunlin J. Le traitment de l'arterite obliterante par la greffe veneuse. Arch Chir Mal Coeur $1949 ; 42: 371-372$.

2. Harris PL, How TV, Jones DR. Prospectively randonized clinical trial to compare in situ and reversed saphenous vein grafts for femoropopliteal bypass. Br J Surg 1987; 74:252-255.

3. Harris RW, Andros G, Dulawa LB, Oblath RW, Apyan R, Salles-Cunta S. The transition to "in situ" vein bypass grafts. Surg Gynecol Obstet 1986; 163:21.28.

4. Harris PL, Veith FJ, Shanik GD, Nott D, Wengerter KR, Moore DJ. Prospective randomized comparison of in situ and reversed infrapopliteal vein grafts. Br J Surg 1993: 80:173-176.

5. Acher CW, Turnipseed WD. In situ distal saphenous vein bypass using the intraluminal valve-disnuption technique. Arch Surg 1985; 120:933-936.

6. Baird RJ, Tutassaura H, Hiyagishima RT. Saphenous vein bypass graft to arteries of the ankle and foot. Amn Surg 1970; 172:1059-1063.

7. Batson RC, Sottiurai VS. Nonreversed and in situ grafts. Clinical and experimental observations. Ann Surg 1985; 201:771-779.

8. Buchbinder D, Rolins DL, Verta. MJ, et al. Early experiance with in situ saphenous vein bypass for distal arterial reconstruction. Surgery 1986; 99:350-356.

9. Buchbinder D, Singh JK, Karmody AM, Leather RP, Shah DM. Comparison of patency rate and structural changes of in situ and reversed vein artarual bypass. J Surg Res 1987: $30.213-222$.

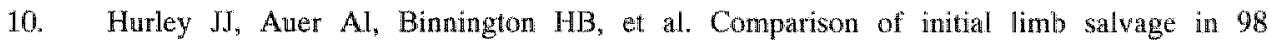
consecutive patients with either reversed autogenous or in situ vein bypass graft procedures. Am J Surg 1985; 150:777-781.

11. Leather RP, Shah DM, Chang BB, Kaufman JL. Resurrection of the in situ saphenous vein bypass. 1000 cases later. Anm Surg 1988; 208:435-442.

12. Leather RP, Shah DM, Karmody AM. Infrapopliteal arterial bypass for limb salvage: Increased patency and utilization of the saphenous vein used "in situ". Surgery 1981; 90:1000-1008.

13. Najmaldin A, Clifford PC, Farrands PA, Campbell. M.J, Chant AD, Webster JH. The succes of in situ vein grafting: Early results in comparison with the reversed vein technique. Eur $J$ Vasc Surg 1987; 1:165-168.

14. Prendiville EJ, Yeager A, ODonnell TF, et al. Long-term results with the above-knee popliteal expanded polytetrafluoroethylene graft. $J$ Vasc Surg 1990; 11.517-524.

15. Shah DM, Buchbinder D. Modified technique to produce valwular incompetence in in situ saphenous wein arterial bypass. Arch Surg 1981; 116:356-358.

16. Taylor LM, Edwards JM, Phinney ES, Porter JM. Reversed wein bypass to infrapopliteal arteries. Ann Surg 1987; 205:90-97.

17. Taylor LM, Edwards JM, Porter JM. Present status of rewersed vein bypass grafting: Five-year results of a modern series. IVasc Surg 1990; 11.193-206.

18. Taylor RS, Loh A, McFarland RJ, Cox M, Chester JF. Improved teclnique for polytetrafluoroethylene bypass grafting: long-term results using anastomotic veiru patches. BF J Surg 1992 ; 79:348-354.

19. Tyrrell MR, Chester JF, Vipond MN, Clarke GH, Taylor RS, Wolfe JHN, Experimental ewidence to support the use of interposition vein collars/patches in distal PTFE anasiomoses. Eur J Vasc Surg 1990; 4:95-101.

20. Tyrrell MR, Wolfe $\mathbb{H H N}$. New prosthetic venous collar anastomotic teclonique: combining the best of other procedures. Br J Surg 1991; 78:1016-1017.

21. Veith FJ, Gupta SK, Ascer E, et al. Six year prospective multicenter randomized comparison of autologous saphenous vein and polytetrafuoroethylene grafts in infrainguinal arterial reconstructions. J Vasc Surg 1986; 3:104-114. 
22. Cambria RP, Brewster DC, Hasson J, Megerman J, Wanock DF, Abbott WM. The ewolution of morphologic and biomechanical changes in reversed and in situ vein grafts. Ann Surg 1987; 205:167-174.

23. Dilley R, McGeachie JK, Prendergaist FJ. A review of the histologic changes in vein-to-artery grafts, with particular reference to intimal hyperplasia. Arch Surg 1988; 123:691-696.

24. Fuchs JCA, Mitchener JS, Hagen PO. Postoperative changes in autologous vein grafts. Ann Siurg 1978; 188:1-15:

25. Dilley RJ, McGeachie JK, Tennant M. Vein to artery grafts: a morphological and histochemical study of the histogenesis of intimal hyperplasia. Aust $N Z J$ Surg 1992; 62:297-303.

26. Adcoek GD, Adcock OT, Wheeler JR, et al. Arterialization of reversed autogenous vein grafts: Quantitative light and electron microscopy of canine jugular vein grafts harvested and implanted by standard or improved techniques.J Vasc Surg 1987; 6:283-295.

27. Dobrin PB, Littooy FN, Golan J, Blakeman B, Fareed J. Mechanical and histological changes in canine vein grafts, $J$ Surg Res 1988; 44:259-265.

28. Milroy CM, Scott DJA, Beardt JD, Horrocks M, Bradfield JWB. Histological appearances of the long saphenous vein. I Pathology 1989; 159:311-316.

29. Zacharias RK, Kirkman TR, Clowes AW. Mechanisms of healing in synthetic grafts. I Vasc Surg $1987 ; 6: 429-436$.

30. Clowes AW, Reidy MA. Prevention of stenosis after vascular reconstruction: Pharmacologic control of intimal hyperplasia - A review. $J$ Vasc Surg 1991; 6:885-891.

31. Szilagy DE, Elliot JP, Hageman JH, Smith RF, Daall'olmo CA. Biologic fate of autogenous vein implants as arterial substitutes. Ann Surg 1973; 178:232-246.

32. Echave V, Koomick AR, Haimov M, Jacobson JH. Intimal hyperplasia as a complication of the use of the polytetrafluoroethylene graft for femoral-popliteal bypass. Surgery 1979; 86:791 798 .

33. Madras PN, Johnson WR, Ward CA. Enhancement of thrombus formation by vascular prostheses. Can J Surg 1980; 23:544-546.

34. Madras PN, Ward CA, Johnson WR, Singh PL. Anastomic byperplasia. Surgery 1981; 90:922-923.

35. Imparato AM, Bracco A, Eun Kim G, Zeff R. Intimal and neointimal fibrous proliferation causing faillure of arterial reconstructions. Surgery 1972; 72:1007-1017.

36. Berkowitz HD, Fox $\mathrm{AD}$, Deaton $\mathrm{DH}$. Reversed vein graft stenosis: Early diagnosis and management. J Vasc Surg 1992; 15:130-142.

37. Berkowitz HD, Greenstein S, Barker CF, Perloff LJ. Late failute of reversed vein bypass grafts. Ann Surg 1989; 210:782-786.

38. LoGerfo FW, Quist WC, Nowak MD, Crawshaw HM. Haudenschild CC. Downstream. anastomotic hyperplasia. A mechanism of fallure in Dacron arterial grafts. Ann Surg 1983; 797:479-483.

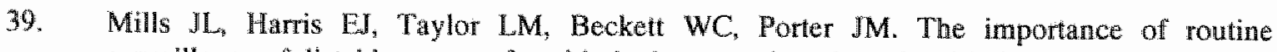
surveillance of distal bypass grafts with duplex scanning: A study of 379 reversed vein grafts. IVasc Sturg 1990; 12.379-389.

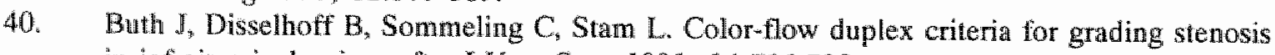
in infrainguinal wein grafts. $J$ Vasc Surg $1991 ; 14: 716-728$.

41. May J, Tiller D, Johnson J, Stewart J, Ross Sheil AG. Saphenous-vein arteriovenous fistula in regular dialysis treatment. New Eng J Med 1969; 280:770.

42. Swedberg SH, Brown BG, Sigley R, Wight TN, Gordon D, Nicholls SC. Intimal fibromuscular hyperplasia at the venous anastomosis of PTFE grafts in hemodialysis patients. Circulation $1989 ; 80: 1726-1736$. 
43. Tordoir JHM, Herman JM, Kwan TS, Diderich PM. Long-term follow-up of the pollytetrathoroethylene (PTFE) prosthesis as an arteriovenous fistula for hemodialysis. Fur I Vaso Surg $1988 ; 2: 3-7$.

44. Windus DW. Permanent vascular access: a nephrologist's view. Am J Kidney Dis 1903; 21:457-471.

45. Jenkins AMcL, Buist TAS, Glover SD. Medium-term follow-up of forty autogenous vein and forty polytetrafluorethylene (Gore-Tex) grafts for vascular access. Surgery 1980; 88:667-672.

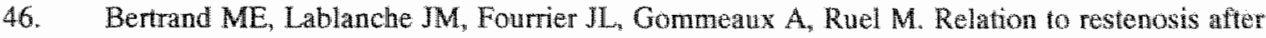
percutaneons transluminal coronary angioplasty to vasomotion of the dilated coronary arterial segment. Am J Cardiol 1989; 63:277-281.

47. Vlietstra RE, Holmes DR, Rodeheffer RJ, Baily KR. Consequences of restenosis after coronary angioplasty. Int I Cardiol 1991; 31:143-148.

48. Waller BF, Pinkerton CA, Orr CM, Slack JD, VanTassel JW, Peters T. Restenosis 1 to 24 months after climically succesful coronary ballon angioplasy: $A$ necropsy study of 20 patients. $J$ Am Coll Cardiol 1991; 17:58b-70b.

49. Serruys PW, Foley DP, Kirkheide RL, King III SB. Restenosis revisited: Insights provided by quantifative coronary angiography. Am Heart J 1993; 126:1243-1267.

50. Serruys PW, Breeman A. Coronary angioplasty - Long-term follow-up results and detection of restenosis: guidelines for aviation cardiology. Eur Heart J 1992; $13: 76 \mathrm{~h}-88 \mathrm{~h}$.

51. Liu MW, Roubin GS, King III SB. Restenosis after coronary angioplasty. Potential biologic determinants and role of intimal hyperplasia. Circulation 1989; 79:1374-1387.

52. Liu MW, Berk BC. Restenosis following coronary balloon angioplasty. Role of smooth muscle cell proliferation. Trends Cardiovasc Med 1991; 1:107-111.

53. Serruys PW, Luyten HE, Beatt KJ, et al. Incidence of restenosis after successful coronary angioplasty: a time-related phenomenon. Circulation 1988; 77:361-371.

54. McBride W, Lange RA, Hillis LD. Restenosis after successful coronary angioplasty. Pathophysiology and prevention. New Eng J Med 1988; 318:1734-1737.

55. Bewilacqua MP, Nelson RM. Sellectins. J Clin Inwes: 1993; 91:379-387.

56. Badimon JJ, Fuster $\mathrm{V}$, Chesebro $\mathrm{JH}$, Badimon L. Coronary atherosclerosis. A multifactorial disease. Circulation 1993; 87:I13-1176.

57. Farber HW, Beer DJ. Restricted secretion of a T-lymfocyte chemotactic cytokine by serotonin-stimulated cultured aortic endothelial cells. Circ Res 1991, 69:257-265.

58. Fitzmaurice M, Ratliff NB. Immunoglobulin deposition in atherosclerotic aortocoronary saphenous vein grafts. Arch Pathol Lab Med 1990" 114.388-393.

59. Fuster V, Badimon L, Badimon JJ, Chesebro IH. Mechanisms of disease: The patliogenesis of coronary artery disease and the acute coronary syndromes (First of wo parts). New Eng $J$ Med 1992; 326:242-250.

60. Fuster $\mathrm{V}$, Badimon $\mathrm{L}$, Badimon JJ, Chesebro JH. Mechanisns of disease: The pathogenesis of coronary artery disease and the acute coronary syndromes (Second of two parts). New Eng $J$ Med 1992; 326:310-318.

61. Garrati KN, Edwards WD, Kaufmann URS, Whetstra RE, Holmes DR, Differential histopathology of primary atherosclerotic and restenotic lesions in coronary arteries and saphenous vein bypass grafts: Analysis of tissue obtained from 73 patients by directional atherotomy. J Am Coll Cardiol 1991; 17:442-448.

62. Hansson GK, Holm J, Holm S, Fotev Z, Hedrich HJ, Fingerle $\$. T lymphocytes inhibit the vascular response to injury. Proc Natl Acad Sci U S A 1991; 88:10530-10534.

63. Mantovani A, Dejana $\mathbb{E}$. Cytokines as communication signals between leukocytes and endothelial cells. Immunol Today 1989; 10:370-375.

64. McEwer RP. Selectins: Novel receptors that mediate leukocyte adlhesion during inflammation. Thrombosis Haemostasis 1991; 65:223-228. 
65. Nelken NA, Coughlin SR, Gordon $\mathrm{D}$, Wilcox $\mathbb{N}$. Monocyte chemoattractant protein-1 in human atheromatous plaques. I Clin Invest 1991; 88:1121-1127.

66. Pan XM, Nelken NA, Colyvas $N_{1}$ Rapp JH. Inhibition of injury induced intimal byperplasia. by sardiasin in rats. $J$ Vasic $\$$ urg $1992 ; 15: 693-698$.

67. Ricevut G, Mazzone A, Pasoti D, de Servi S, Specchia G. Role of granulocytes in endothelial jnjury in coronary heart disease in humans. Atherosclerosis 1991; 91:1-14.

68. Chan $\mathbb{P}$, Muno E, Patel M, et al. Cellular biology of human intimal hyperplastic stenosis. Eur IVasc Surg 1993; 7:129-135.

69. Ross. R. The pathogenesis of atherosclerosis: a perspective for the 1990s. Nature 1993; $362: 80 \%-809$.

70. Okadome K, Yukizane T, Mii S, Fukuda A, Sugimachi $K$. Correlation of longterm results of femoropopliteal autogenous vein grafts with shear stress variation. In situ or reversed graft? $J$ Cardiovasc Surg Torino 1989; 30:932-935.

71. Karino T, Goldsmith HL. Role of blood cell-wall interactions in thrombogenesis and atherogenesis: a microrheological study. Biorheology $1984 ; 21 ; 587-601$.

72. Yukizance $T$, Okadome K, Eguchi H, Muto $Y$, Sugimachi K. Isotopic study of the effects of platelets on development of intimal thickening in autologous vein grafts in dogs. Br J Surg 1991: 78:297-302.

73. Abbott WM, Megerman J, Hasson JE, LTtalien G, Warmock DF "Effect of compliance mismatch on vascular graft patency. $J$ Vosc Surg $1987 ; 5: 376-382$.

74. Kohler TR, Jawien A. Flow affects development of intimal hyperplasia after arteriall injury in rats. Arterioscler Thromb 1992; 12:963-971.

75. Baird RN, Abbott WM. Pulsatile blood-flow in arterial grafts. Lancet 1976; October 30:948-950.

76. Ark van der PD, Smakman JGJ. De rol van plaatjesaggregatie bij hart- en vaatziekten. Deel 3: Welke winst kan men verwachten wan een platjesaggregatie-remmende therapie? Janssen Nieuws 1990; 5:47-50.

77. Mills JL, Fujitani RM, Taylor SM. The characteristics and anatomic distribution of lesions that cause reversed vein graft failure: a five-year prospective study. J Vasc Surg 1993; 17:195-204.

78. Abbott WM, Megerman J. Adaptive responses of arteries to grafting. $J$ Vasc Surg 1989; 9:377-379.

79. Fry DL. Acute vascular endothelial changes are associated with increased blood velocity gradients. Circ kes 1908; 22:105-197.

80. Fry DL. Certain chemorheologic considerations regarding the blood vascular interface with particular reference to coronary artery disease. Circulation 1969; XXXIX and XI.IW38-IV59.

81. Fillinger MF, Reinitz ER, Schwartz RA, Resetarits DE, Paskanik AM, Bredenberg CE. Beneficiall effects of banding on venous intimal-medial hyperplasia in arteriovenous loop grafts. Am J Surg 1989; 158:87.94.

82. Fillinger MF, Reinitz ER, Schwartz RA, et al. Graft geometry and venous intimal-medial hyperplasia in arteriovenous loop grafts. J Vasc Surg 1990; 11.556-566.

83. Kohler TR, Kirkman TR, Kraiss LW, Zierler BK, Clowes AW. Increased blood flow inhibits neointimal hyperplasia in endothelialized vascular grafts. Circ Res 1997; 69:1557-1565.

84. Asakura T, Karino T. Flow patterns and spatial distribution of atherosclerotic lesions in human coronary arteries. Circ Res 1990; 66:1045-1066.

85. Bassiouny HS, White $\mathrm{S}$, Glagov $\mathrm{S}$, Choi E, Giddens DP, Zarins CK. Anastomotic intimal hyperplasia: Mechanical injury or flow induced. $J$ Vasc Surg 1992; 15:708-717.

86. Friedman MH. Some atherosclerosis may be a consequence of the normal adaptive response to shear. Atheroscierosis 1990, 82:193-196.

87. Friedman MH, Bargeron CB, Deters OJ, Hutchins GM, Mark FF. Correlation between wall shear and intimal thickness at a coronary artery branch. Atherosclerosis $1987 ; 68: 27-33$. 
88. Kamiya A, Ando J, Shibata M, Masuda H. Roles of fluid shear stress in physiological regulation of vascular structure and function. Biorheology $1988,25: 271-277$.

89. Kamiya A, Togawa T. Adaptive regulation of wall shar stress to flow change in the canine carotid artery. Am J Physiol 1980; 239:H14 H21. 



\section{CHAPTER 2}

\section{THE DEVELOPMENT OF INTIMAL HYPERPLASLA AFTER VASCULAR RECONSTRUCTION IN HUMANS}

\section{INTRODUCTION}

Intimal hyperplasia has first been described in 1906 by Carrell", who transplanted a vein into the arterial circulation and observed intimal thickening at the site of the anastomoses. Nowadays, intimal hyperplasia is considered as the response of a vessel wall to injury. It is the main cause for obstructive complications in the first year following almost every type of vascular intervention. Stenoses due to intimal hyperplasia may develop after PTCA (30-40\%) $)^{2-9}$, after coronary artery bypass grafting $(25 \%)^{10}$, in peripheral artery bypass surgery $(25 \%)^{11-26}$ and after the construction of a vascular access for hemodialysis $(50 \%)^{27-31}$. Knowledge on the biology of this process may help in developing therapeutic strategies to prevent this frequent complication after vascular intervention.

\section{MORPHOLOGY}

The development of an intimal hyperplastic lesion has been very well described in animal models, especially in the balloon injury model in the rat ${ }^{32-34}$. In this model, a large artery is denudated by passage of an inflated balloon, introduced by a catheter. In the response to this injury which leads to intimal thickening, three different stadia are recognized ${ }^{34}$. The first stage starts as soon as 24 hours after injury and is characterized by the replication of vascular smooth muscle cells (VSMC) in the media of the damaged arterial wall. In the second stage, these smooth muscle cells migrate from the media to the intima, with a peak between the third and fourth day. In the final stage of the process, VSMC replicate in the intima with a maximum at day 4-7. Furthermore, the intimal VSMC start producing matrix material like collagen, elastin and proteoglycans ${ }^{35}$. The thickening of the intima proceeds up to the $12 \mathrm{th}$ week after injury, due to the production of extracellular matrix and volume increase of the intimal VSMC. After this period, the lesion remains stable. Histologic studies evaluating the morphology of intimal hyperplasia in humans showed that VSMC and extracellular matrix are also prominent in the lesions. This suggests that the biology of intimal hyperplasia in humans and animals may be similar ${ }^{8,36-38}$. However, some observations suggest that differences may be present between the development of intimal thickening in humans and in animals. First of all, evaluation of cell proliferation in human 
stenotic lesions, regarded as the key event in the development of intimal thickening in animals ${ }^{39-43}$, provided conflicting results. In studies investigating proliferation in restenotic tissue after PTCA, both high and low proliferation indices were observed ${ }^{44-46}$. In stenotic lesions, surgically derived from arterio-venous fistulas of hemodialysis patients high proliferation rates have been observed ${ }^{46}$. A second point is that administration of agents, like heparin or ACE-inhibitors ${ }^{27,47-56}$, decrease the extent of intimal thickening in animals. The effect of these agents in humans when administered locally or systemically is currently under investigation. Systemic administration has shown no benificial effect so far ${ }^{57.58}$.

\section{FACTORS INFLUENCING INTIMAL HYPERPLASIA}

\section{Peri-anastomotic mismatch in elastic properties and intimal thickening}

When two vessels with different elastic properties are anastomosed, an abrupt change in elastic properties occurs within a very short vessel segment. The peri-anastomotic difference in elastic properties is often called compliance mismatch. The suggested link between compliance mismatch and anastomotic intimal hyperplasia sterns from many observations that intimal hyperplasia in peripheral arterial bypass grafts and graft AV fistulas develops at the site of the anastomose ${ }^{29,30,59-64}$. A mismatch in elastic properties may affect intimal hyperplasia in at least 3 different ways ${ }^{61,65.72}$. First, a mismatch in elastic properties leads to a point of excessive mechanical stretching, which may result in vessel wall injury and initiate a vascular reponse resulting in intimal thickening ${ }^{73}$. A second mechanism may be the positive influence of excessive cyclic stretching on replication of VSMC and production of extra-cellular matrix (ECM) ${ }^{33,74-79}$. In vitro studies demonstrated that VSMC start to produce ECM and to replicate when they are subjected to high levels of distension. This phenomenon seems to be more pronounced in VSMC derived from veins as compared to arterial VSMC ${ }^{74}$. Animal studies demonstrated that intimal thickening in vein grafts is associated with increased tangential stress ${ }^{80-83}$. A third mechanism may be the influence of compliance on flow characteristics $^{34,85}$. Flow studies demonstrated that a sudden increase in compliance is associated with enhanced particle residence time, flow stasis and separation, suggesting low shear conditions. A sudden decrease in compliance was not associated with these unfavourable flow conditions. In humans a sudden increase in compliance is observed in the carotid bulb, where also enhanced particle residence time, reversal of flow and flow separation have been observed ${ }^{86}$. Since the carotid bulb is a predilection site for the occurrence of atherosclerosis, one might postulate that disturbed flow and increased particle residence time are associated with the development of an atherosclerotic plaque.

In animal studies evaluating the effect of compliance mismatch, lower patency rates in grafts with a low compliance were observed ${ }^{65}$. However, a direct effect of compliance mismatch on intimal thickening at the anastomoses of grafts has never been demonstrated. This may be due to the absence of occlusive intimal hyperplasia in animal models ${ }^{87-89}$. In humans, lower patency rates are found in stiff prosthetic grafts 
as compared to more compliant venous grafts. However, a prospective study investigating the effect of compliance mismatch around anastomoses on the occurrence of intimal thickening has never been conducted due to the absence of techniques able to quantify elastic properties around anastomoses in vivo in humans ${ }^{90,91}$. With the introduction of Vessel Wall Doppler Tracking ${ }^{92}$ the assessment of elastic properties at defined sites in the graft and the native arterial system has become possible. This allows the calculation of compliance mismatch around the anastomoses of human grafts $^{93,94}$.

\section{Blood flow characteristics and intimal thickening}

Flow is an important modulator of vascular structure and function, probably by affecting the function of the endothelium ${ }^{95-102}$. Due to their location at the interface of blood and arterial wall, endothelial cells are exposed to pulsatile pressure and flow, generated by the beating heart. Although the magnitude of the tangential acting shear forces is smaller than the transmural forces imposed by variations in pressure, it is recognized that oscillations in shear forces have an important effect on the structure and function of the vessel wall. The shape and structure of endothelial cells can be modified by changing shear rate levels ${ }^{103.108}$. Furthermore, the release of vaso-active substances and growth factors by the endothelium seems to be affected by changes in the level of shear rate ${ }^{109-119}$. The crucial role of the endothelial cells in mediating structural changes in response to modulation of flow levels was demonstrated by Langille, who found a $21 \%$ decrease in rat carotid artery diameter after reduction of flow in arteries with a normal endothelial cell lining ${ }^{120,121}$. In denudated arteries no structural adlaptations to reduced flow were observed. However, shear rate dependent functional and structural changes in the vessel wall have also been observed in the absence of endothelium ${ }^{95,122}$, suggesting that the VSMC's beneath the endothelium also have the ability to sense differences in flow.

The effect of varying levels of shear rate on intimal thickening has been studied extensively in animals ${ }^{123-125}$. The first studies conducted in this field suggested that high shear rate levels have an injuring effect on the endothelial cell (EC) layer, thereby inducing a vascular response ${ }^{126,127}$. High shear rate levels resulted in endothelial cell edema, deformation and eventually in EC erosion. These early observations are supported by a study investigating the occurrence of intimal hyperplasia in graft AV fistulas in dogs in relation to flow velocities. More intimal thickening was observed in areas with the highest flow velocities ${ }^{118,129}$. However, the current opinion is that increased intimal thickening occurs in areas of low shear rates $86,97,99,122,130-133$. This has been observed in at least two different models. In the balloon catheter injury model, increased flow velocities are associated with a decrease in intimal-medial thickening ${ }^{124}$. Also in models based on the placement of a prosthetic graft in the arterial system, increased flow velocities resulted in decreased intimal thickening ${ }^{123}$. Studies on flow models based of the human carotid bifurcation showed that in the carotid bulb, just opposite to the flow divider, low shear rate levels are present, illustrated by flow separation, enhanced particle residence time and reversal of flow. This part of the 
carotid artery is predisposed to the development of atherosclerotic disease in contrast to the relatively disease free flow divider, where a high shear rate is present. This suggests an inhibiting effect of high shear rate on intimal thickening ${ }^{86}$.

\section{Influence of flow on growth factors release}

The pathways by which flow acts on on the vessel wall are still unknown, but an essential role in signal transduction is attributed to $\mathrm{EC}^{68,115,134-142}$. In a flow model in rabbit iliac arteries it was shown that an increase in flow resulted in release of NO and vasodilatation ${ }^{110}$. The administration of a specific potassium channel antagonist blocked the flow mediated vasodilatation and NO release, suggesting that the signal transduction pathway underlying flow mediated vasodilatation may be the activation of a potassium channel on the endothelium cell membrane. The observation that increased flow results in a release of NO by endothelial cells was confirmed in a cell culture study, using bovine aortic $\mathrm{EC}^{109}$. Besides a vasodilatory effect of an increase in NO production with increasing shear rate, increased NO release may also result in a reduction of platelet adherence and aggregation ${ }^{143,144}$. In a similar model it was shown that fluid shear stress modulates intracellular calcium concentration in vascular endothelial cells. A transient increase in free calcium concentration was observed after increasing shear rates to a certain level ${ }^{145}$. The increase in free calcium concentration was proportional to the increase in shear rate, suggesting an important role of calcium in the signal transduction pathway, underlying flow mediated responses of the vessel wall. The shear rate dependent release of growth factors by endothelial cells is reflected by a varying expression of multiple growth factor related genes when wall shear rate is changed. A possible mechanism underlying the increased expression of growth factor genes may be a recently described shear rate induced transcription factor ${ }^{146}$, which may not only regulate the expression of platelet derived growth factor (PDGF) genes, but also of tissue plasminogen activator, intracellular adhesion molecule 1 (ICAM-1) and transforming growth factor B1 (TGF-B1). For instance, a shear dependent release of PDGF $B$ mRNA has been observed in cultured human umbilical vein endothelial cells (HUVEC) ${ }^{1 / 4}$. Of interest is that the release of PDGF B mRNA increased when shear stress increased from 0 to $6 \mathrm{dyn} / \mathrm{cm}^{2}$, then gradually declined to a minimum at a shear stress level of $31 \mathrm{dyn} / \mathrm{cm}^{2}$ and increased again when shear stress rose to $50 \mathrm{dyn} / \mathrm{cm}^{2}$. Since PDGF is a mitogen and a potent vasoconstrictor, one may speculate that a certain level of shear stress is associated with a minimum release of PDGF by endothelial cells, resulting in vasodilatation and inhibition of VSMC growth. In addition, these data indicate that in both low and high shear stress conditions, increased expression of PDGF may occur, possibly resulting in promotion of VSMC growth ${ }^{147.48}$. The stimulatory effects of both high and low flow on growth factor release like PDGF may explain the apparent discrepancy in the literature that both high and low shear rates are associated with increased vascular growth.

So far, it is unclear whether the signal transduction pathways of shear rate on vascular function ate more susceptible to mean shear rate or to pulsatile variations in shear rate. In most models the effect of mean shear rate on intimal thickening was studied, since 
this can be calculated from the Haagen-Poiseuille formula ${ }^{123,124}$. However, some studies show evidence that the temporal shear rate gradient (value between the minimum and maximum value of shear rate within a cardiac cycle) is of more importance than the mean level of shear. First, in an in-vitro study it was shown that in regions of low mean shear rate but with large temporal gradients, the endothelial cells structure is heavily affected in that region ${ }^{149}$. Endothelial cells migrated away from these sites with the remaining cells starting to divide at a high rate. This suggests that this flow mediated response of endothelial cells is determined by the temporal gradient in wall shear rate rather than the mean level of shear. In a study evaluating the possible mechanisms leading to post-stenotic dilatation, it was shown that the mean level of shear was very low in these areas, but the temporal gradient was high ${ }^{102}$. This also suggests that the shear rate gradient may be more important in modifying vascular function and structure than the mean level of shear rate. A recently published study showed that the development of anastomotic intimal hyperplasia decreases temporal gradients of shear rate at the site of the stenosis ${ }^{150}$. This suggests that the development of intimal thickening in the anastomotic area may be at least in part an adaptive response in order to decrease high wall shear rate gradients and supports the concept that the gradient in shear rate may be the regulatory factor rather than a certain mean level of shear rate. 


\section{RERERENCES}

1. Camel A. Resulats eloignes de la transplantation des veines sur les arteres. Rev De Chir 1910; 41.987.

2. Bertrand $\mathrm{ME}_{\mathrm{s}}$ Lablanche $\mathrm{JM}_{\mathrm{B}}$, Fourrier $\mathrm{JL}_{\text {, }}$ Gonmeaux $\mathrm{A}$, Ruel M. Relation to restenosis after percutaneous transiuminal coronary angioplasty to wasomotion of the dilated coronary arterial segment. Am I Cardiol 1989; 63:277-281.

3. Vlietstra $\mathbb{R E}$, Holmes $D R$, Rodeheffer $\mathrm{RJ}_{3}$ Baily KR. Consequences of restenosis after cononary angioplasty. Int I Cardiol 1991; $31: 143-148$.

4. Waller BF, Pinkerton CA, Or CM, Slack JD, VanTassel JW, Peters T. Restenosis 1 to 24 months after clinically succesful coronary ballon angioplasy: A necropsy study of 20 patients. I Am Coll Cardiol 1991; 17,58b-70b.

5. Serruys ['W, Foley DP, Kirkheide RL, King III SB. Restenosis revisited: Insights provided by quantitatuve coronary angiography. Am Hearr $f$ 1993; 126:1243-1267.

6. Serruys PW, Breman A. Coronary angioplasty - Long-tem follow-up resulis and detection of restenosis: guidelines for aviation cardiology. Eur Heart $J$ 1992; 13:76h-88h.

7. Liu MW, Roubin OS, King III SB. Restenosis after coronary angioplasty. Potential biologic determinants and role of intimal hyperplasia. Circulation 1989; 79:1374-1387.

8. Liu MW, Berk BC. Restenosis following coronary balloon angioplasty. Role of smooth muscle cell proliferation. Trends Cardiovasc Med 1991; 1:107-111.

9. Serruys PW, Luyten HE, Beatt KJ, et al. Incidence of restenosis after successful coronary angioplasty: a time-related phenomenon. Circulation 1988; $77.361-371$.

10. The Veterans Administration Coronary Bypass Surgery Cooperative Study Group. Eleven-year survival in the veterans administration randomized trial of coronary bypass surgery for stable angina. New Eng J Med 1984; 311:1333-1339.

11. Harris PL, How TV, Jones DR. Prospectively randomized clinical trial to compare in situ and reversed saphenous vein grafts for femoropopliteal bypass. Br f Surg 1987; 74:252-255.

12. Harris RW, Andros G, Dulawa LB, Oblath RW, Apyan R, Salles-Cunha S. The transition to "in situ" wein bypass grafts. Surg Gynecol Obstet 1986; 163:21-28.

13. Harris PL, Veith FJ, Shanik GD, Nott D, Wengerter KR, Moore DJ. Prospective randomized comparison of in situ and reversed infrapopliteal vein grafts. Br J Surg 1993; 80:173-176.

14. Acher $C W$, Tumipseed WD. In sim distal saphenous vein bypass using the intraluminal valve-disruption technique. Anch Surg 1985; 120:933-936.

15. Baird RI, Tutassan ra $H$, Hiyagishima RT. Saphenous vein bypass graft to arteries of the ankle and foot. Amn Surg 1970; 172:1059-1063.

16. Batson RC, Sotturai VS. Nonreversed and in situ grafts. Clinical and experimental observations. Am Surg 1985; 201:771-779.

17. Buchbinder D, Rolins DL, Verla MJ, ef al. Early experiance with in situ saphenous vein bypass for distal arteriat reconstruction. Surgery 1986; $99: 350-356$.

18. Buclubinder D, Singh JK, Karmody AM, Leather RP, Shah DM. Comparison of patency rate and structural changes of in situ and reversed vein anterial bypass. I Surg Res 1981; $30.213-222$.

19. Hurley Ji, Auer AI, Binnington $\mathrm{HB}$, et al. Comparison of initial limb salvage in 98 consecuive pattients with either reversed autogenous or in situ wein bypass graft procedures. Am I Surg 1985; 150:777-781.

20. Najmaldin A, Cliford PC, Farrands PA, Campbell MJ, Chant AD, Webster JH. The succes of in situ wein grafting: Early results in comparison with the reversed vein lechnique. Eur $J$ Vasc Surg 1987; 1:165-168.

21. Leather RP, Shah DM, Karmody AM. Infrapopliteal arterial bypass for limb salvage: Increased patency and utilization of the saphenous vein used "in situ". Surgery 1981; 90:1000-1008. 
22. Prendiville EJ, Yeager A, ODonnell TF, et al. Long-tern resuls with the above-knee popliteal expanded polyterrafluoroethylene graft. I Vasc Surg $1990 ; 11.517-524$.

23. Shalh DM, Buchbinder D. Modified technique to produce valvular incompetence in in situ saphenous vein arterial bypass. Arch Surg 1981; 116.356-358.

24. Taylor LM, Edwards JM, Phinney ES, Porter JM. Reversed vein bypass to infrapopliteal arteries. Ann Surg 1987:205:90-97.

25. Taylor LM, Edwards IM, Porter JM. Present status of rewersed veín bypass grafting: Five-year results of a modern series. $J$ Vasc Surg 1990; 11:193-206.

26. Taylor RS, Loh A, McFarland RJ, Cox M, Chester JF. Iraproved technique for polytetrafluom roethylene bypass grafting: long-term results using anastomotic vein patches. Br.J Surg 1992; $79: 348-354$.

27. Endean ED, Kispert JF, Martin $\mathrm{KW}$, O'Conner $\mathrm{W}$. Intimal hyperplasia is reduced by omithine decarboxilase inhibition. I Surg Res 1991; 50:634-637.

28. Tordoir JHM, Herman JM, Kwan TS, Diderich PM. Long-ferm follow-up of the polytetrafluoroethylene (PTFE) prosthesis as an arteriovenous fistula for hemodialysis. Eur J Vasc Surg $1988 ; 2: 3-7$.

29. Swedberg SH, Brown BG, Sigley R, Wight TN, Gordon D, Nicholls SC. Intimall fibromuscular hyperplasia at the venous anasiomosis of PTFE grafts in hemodialysis patients. Circularion 1989; $80: 1726-1736$.

30. Jenkins AMcL, Buist TAS, Glover SD. Medium-term follow-up of forty autogenous vein and forty polytetrafluorethylene (Gore-Tex) grafts for vascular access. Surgery 1980; 88:667-672.

31. Windus DW. Permanent vascular access: a nephrologist's view. Am J Kidney Dis 1993; $21: 457-471$.

32. Boonen HCM, Schiffers PMH, Fazzi GE, Janssen GMJ, Daemen MJAP, Mey do JGR. DNA symthesis in isolated arteries. Kinetics and structural consequences. Am I Physiol 1991; 260. HIT-H8.

33. Clowes AW, Clowes MM, Fingerle J, Reidy MA. Kinetics of cellular proliferation after arterial injury. V.Role of acute distension in the induction of smooth muscle cell proliferation. Lab Invest 1989; 60.360-364.

34. Clowes AW, Reidy MA, Clowes MM. Mechanisms of stenoses after arterial injury. Lab Innest 1983:49:208-215.

35. Nikkari TN, Jarvelainen HT, Wight TN, Ferguson M, Clowes AW. Smooth muscle cell expression of extracellular matrix genes after arterial injury. Am J Pathol 1994; 144:1348-1356.

36. Garratt KN, Edwards WD, Kaufmann URS, Vhietstra RE, Holmes DR. Differential bistopathology of primary atherosclerotic and restenotic lesions in coronary arteries and saphenous vein bypass grafts: Analysis of tissue obtained from 73 patients by directional atherotony. I Am Coll Cardiol 1991; 17:442-448.

37. Ueda $M$, Becker $A E$, Fujimoto T, Tsukada T. The early phenomena of restenosis following percutaneous transluminal coronary angioplasty. Eur Hear $J$ 1991; 12:937-945.

38. Sayers $\mathrm{RD}$, Jones L, Varty $\mathrm{K}$, et al. The histopathology of infrainguinal vein graft stenoses. Eur J Vasc Surg 1993; 7:16-20.

39. Schwart RM, Campbel] GR, Campbell JH. Replication of smooth muscle cells in vastular disease. Circ Res 1986; 58:427-444.

40. Schwartz SM. Common mechanisms of cell proliferation in hypertension and atherosclerosis. In: Zanchetti $\mathrm{A}_{0}$ Tarazi RC, eds. 7th ed. New York: Elsevier Science Publishers, 1986:454-464.

41. Schwartz SM, Liaw L. Growth control and morphogenesis in the development and pathology of arteries. J Cardiovasc Pharmacol 1993; $21: 531-549$.

42. Gordon D, Schwartz SM. Cell proliferation in human atherosclerosis. Trends Cardiowasc Med 1991; January/February:24-28. 
43. Schwartw CJ, Valente Al, Sprague EA, Kelly JL, Nerem RM. The pathogenesis of fitheroselerosis: An overview. Clin Cardiol 1991; 14:1-16.

44. OBrien ER, Alpers $\mathrm{CE}_{*}$ Stewant $\mathrm{DK}$, el al. Proliferation in primary restenotic coronary atherectomy tissue. Impilications for antiproliferative therapy. Circ Res $1993 ; 73: 223-231$.

45. Pickering JG, Weir L, Jekanowski J, Kearny MA, Isner JM. Proliferative activity in peripheral and coronary atherosclerotic plaque among patients undergoing percutaneous revascularisation. J Clin Invest 1993; 91:1469-1480.

46. Rehkter $M$, Nicholls $S_{n}$ Ferguson $M_{*}$ Gordon $D$. Cell proliferation in human arteriovenous fistulas use for hemodialysis. Arterioscler Thromb 1993; 13:609-617.

47. Kouchi $Y$, Esato $K, O$ Hara $M$, Zempo N. Effect of prostaglandin 2 analogue TRK-100 on the suppression of intimal fibrous prohferation. I Vasc Surg 1992; 16:232-238.

48. Kranzhöfer R, Schirmer J, Schömig A, et al Suppresion of neointimal thickening and smooth muscle cell proliferation after atterial injury in the rat by inhibitors of $\mathrm{Na}+\mathrm{H}+$ exchange. Circ Res $1993 ; 73: 264-268$.

49. Mitsuka M, Nagae M, Berk BC. Nat-H+ exchange inhibitors decrease neointimal formation after rat carotid injury. Effects on smooth muscle cell migration and proliferation. Circ Res $1993 ; 73: 269-275$.

50. Powell JS, Clozel JP, Muller RKM, et all. Inhibtors of angiotensin-converting enzyme prevent myointimal proliferation after vascular injury. Science 1989; 245:186-188.

51. Powell IS, Rouge M, Muller RK, Baumgartner HR. Cilazapril suppresses myointimal proliferation after vascular injury: effects on growth factor induction in wascular smooth muscle cells. Basic Res Cardiot 1991, 86:65-74.

52. Vashiht R, Sian M, Fuanks PJ, OMalley MK. Long-term reduction of intimal hyperplasia by the selective alpha-1 adrenergic antagonist doxazosin. Br J Surg 1992; 79:1285-1288.

53. Wilson NV, Salisbury JR, Kakkar VV. Effect of low molecular weight heparin on intimal hyperplasia. Br J Surg 1991; 78:1381-1383.

54. Clowes AW, Clowes MM. Kinetics of cellular proliferation after arterial injury. IV. Heparin inhibits rat smooth muscle mitogenesis and migration. Circ Res 1986; 58.839.845.

55. Dryjski M., Mikat E, Bjornsson TD. Inhibition of intimal hyperplasia after arterial injury by heparins and heparinoid. $J$ Vasc Surg 1988; 8:623-633.

56. Clowes AW, Clowes MM, Vergel SC, et al. Heparin and cilazaprill together inhibit injury-induced intimal hyperplasia. Hypertension 1991; 18:1/65-1/69.

57. The MERCATOR Study Group. Does the new angiotensin convering enzym inhibitor cilazepril prewent restenosis after percutaneous transluminal coronary angioplasty? Circulation 1992; $86: 100-110$

58. Jackson CL. Animal models of restenosis. Trends Cardiovasc Med 1094; 4:122-130.

59. Imparato AM, Bracco A, Eun Kim G, Zeff R. Intimal and neoimtimal fibrous proliferation causing failure of arterial reconstructions. Surgery 1972; 72:1007-1017.

60. Baird RN, Abbott WM. Pulsatile blood-flow in arterial grafts. Lancet 1976; October 30:948-950.

61. Kidson IG, Abbott WM. Low compliance and arterial graft acclusion. Circulation 1978; 58:11-14.

62. LoGerfo FW, Quist WC, Nowak MD, Crawshaw HM, Haudenschild CC. Downstream anastomotic hyperplasia. A mechanism of failure in Dacron arterial grafts. Ann Surg 1983; 197:479-483.

63. Madras PN, Ward CA, Johnson WR, Singh PI. Anastomic hyperplasia. Surgery 1981; $90: 922-923$.

64. Mills JL, Fujitani RM, Taylor SM. The characteristics and anatomic distribution of lesions that cause reversed vein graft failure: a tive-year prospective study. I Vasc Surg 1993; 17:195-204.

65. Abbott WM, Megerman I. Adaptive responses of arteries to grafting. J Vasc Surg 1989; $9: 377.379$ 
66. Kinley $\mathrm{CE}$, Marble AE, Eng P. Compliance: A continuing problem with wascular grafts. $y$ Cardiovas Surg 1980; 21:163-170.

67. Laogun AA, Gosling RG. In vivo arterial compliance in man. Clin Phys Physiol Meas 1982; $3: 201-212$.

68. Levenson J, Simon AC, Bouthier JD, Benetos A, Safar ME. Post-synaptic alpha-blockade and brachial artery compliance in essential hypertension. J Hypertens 1984; $2: 37-41$.

69. Schmitz-Rixen T, Megeman $\mathrm{J}$, Anderson JM, et al. Longterm study of a compliant biological vascular graft. Eur J Vasc Surg 1991; 5:149-158.

70. Okuhn SP, Conmelly DP, Calakos N, Ferrell L, Man-Xiang P, Goldstone J. Does compliance mismatch alone cause neointimal hyperplasia? J Vasc Surg 1989; 9:35-45.

71. Bassiouny HS, White $S$, Glagov $\mathrm{S}$, Choi $\mathrm{E}$, Giddens DP, Zarins CK. Anastomotic intimal hyperplasia: Mechanical injury or flow unduced. J Vasc Surg 1992; 15:708-717.

72. Pourdeyhimi B, Wagner D. On the correlation between the failure of vascular grafts and their structural and material properties: A criticall analysis. J Biomed Mat Res 1986; 20.375-409.

73. Pevec WC, LTtalien GJ, Megerman J, Cambria RP, Abbott WM. Abmormal wall strain at distal end-to-side anastomoses. Ann Vasic Surg 1993; 7:14-20.

74. Predel HG, Yang Z, Von Segesser L, Turina M, Buhler FR, Luscher TF. Implications of pulsatile stretch on growth of saphenous vein and mammary artery smooth muscle. Lancet $1992 ; 340: 878-879$.

75. Sottiurai VS, Kollross P, Glagov S, Zarins CK, Mathews MB. Morphologic alteration of cultured arterial smooth muscle cells by cyclic stretching. I Surg Res $1983 ; 35.490-497$.

76. Sottiurai VS, Sue SL, Feinberg II EL, Bringaze WL, Tran AT, Batson RC. Distal anastomotic intimal hyperplasia: Biogenesís and etiology. Eur J Vasc Surg 1988; $2: 245 \cdot 256$

77. Leung DYM, Glagov S, Mathews MB. Cyclic stretching stimulates synthesis of matrix components by arterial smooth muscle cells in witro. Science $1976 ; 191: 475477$.

78. Leung DYM, Glagov S, Mathews MB. Elastin and collagen accumulation in rabbit ascending. aorta and pulmonary trunk during postnatal growtli. Correlation of cellular synthetic response with medial tension. Circ Res 1977; 41:316-323.

79. Sumpio BE, Banes AJ, Levin LG, Johnson G. Mechanical stress stimulates aortic endothelial cells to proliferate. $J$ Vasc Surg 1987; 6:252-256.

80. Zwolak RM, Adams MC, Clowes AW. Kinetics of vein grafl hyperplasia: Association with tangential stress. IV Vasc Surg 1987; 5:126-136.

81. Dobrin PB, Littooy FN, Golan J, Blakeman B, Fareed J. Mechanical and histological changes in canine vein grafts. $J$ Surg Res 1988; 44:250-265.

82. Dobrin PB, Littooy FN, Endean $\mathbb{E D}$. Mechanical factors predisposing 10 intimal hyperplasia and medial thickening in autogenous vein grafts. Surgery 1989; 105:393 400 .

83. Dobrin PB. On the roles of deformation, tension, and wall stress as critical stimuli eliciting myointimal/medial hyperplasia. J Vasc Surg 1991; 581-582.

84. Stewart SFC, Lyman DJ. Effects of a vascular graft/natural artery compliance mismatch on pusatile flow. I Biomech 1992; 25:297-310.

85. Ojha M Cobbold RS, Johnston KW. Hemodymamics af a side tomend proximal arterial anastomosis model. I Vasc Surg 1993; 17:646-655.

86. Zarins CK, Giddens DP, Bharadvaj BK, Sottiurai VS, Mabon RF, Glagow S. Carotid bifurcation atherosclerosis. Quantitative correlation of plaque localization with flow velocity profiles and wall shear stress. Circ Res 1983; 53.502-514.

87. McBride W, Lange RA, Hillis LD. Restenosis after swccessful coronary angioplasty. Pathophysiology and prevention. New Eng J Med 1988; 318:1734-1737.

88. Wu MH, Shi Q, Sauwage LR, et al. The direct effect of graft compliance mismatch per se on development of host arterial intimal hyperplasia at the anastomotic interface. Ann Vasc Surg 1993; 7:156-168. 
89. Ferrel M, Fuster $\mathrm{V}$, Gold HK, Chesebro $\mathbb{H}$. Choosing appropriate experimental animal model for the prevention of restenosis. Circulation 1992; 85:1630-1631.

90. Mozersky DJ, Summer DS, Hokanson DE, Strandness DE. Transcutaneous measurement of the elastic properties of the human femoral artery. Circulation $1972 ; X 7 L \mathrm{~V}: 948-955$.

91. Lye CR, Sumner DS, Hokanson DE, Strandness DE. The transcutaneous measurement of the elastic properties of the human saphenous wein femoropopliteal bypass graft. Surg Gynecol Obstet 1975; 141:891-895.

92. Hoeks APG Brands PI, Smeets FAM, Reneman RS. Assessment of distensibility of superficial arteries. Utrasound Med Biol 1990; 16:121-128.

93. Hofstra L, Bergmans DCJ, Hoeks APG, Tordoir JHM, Kitslaar PJEHM. Assessment of inhomogeneities in elastic properties of in situ and reversed saphenous vein grafts in humans. Eur J Vasc Surg 1994; 100:100-105.

94. Hofstra L, Bergmans DCCI, Hoeks APG, Kitslaar PJEHM, Leunissen KML, Tordoir JHM. Mismatch in elastic properties around anastomoses of interposistion grafts for hemodialysis access. JASN 1994; 45.45-55.

95. Bevan JA, Joyce EH, Wellman GC. Flow-dependent dilation in a resistance artery still occurs after endothelium removal. Circ Res 1988; 63:980-985.

96. Kamiya $A_{4}$ Togawa $T$. Adaptive regulation of wall shear stress to flow change in the canine carotid artery. An I Physiol 1980; 239:HI4-H21.

97. Zarins CK, Bomberger RA, Gagov S. Local effects of stenoses: Increased tlow velocity inhibits atherogenesis. Circulation 1981; 64:11221-11227.

98. Cashin WL, Sanmarco ME, Nessim SA, Blankenhorn DH. Accelerated progression of atherosclerosis in coronary vessels with minimal lesions that are bypassed. New Eng $J \mathrm{Med}$ $1984 ; 311: 824 \% 828$

99. Asakura T, Karino T. Flow patterns and spatial distribution of atherosclerotic lesions in human coronary arteries. Circ Res $1990 ; 66: 1045-1066$.

100. Kamiya A, Ando J, Shibata $M$, Masuda $H$. Roles of fluid shear stress in physiological regulation of wascular structure and function. Biorheology 1988; 25:271-277.

101. LaBarbera M. Principles of design of fluid transport systems in zoology. Science 1990; 249:992-999.

102. Ojha M. Johnston KW, Cobbold RS. Evidence of a possible link between poststenotic dilatation and wall shear stress. J Vasc Surg 1990; 11:127-135.

103. Nerem RM. Vascular fluid mechanics, the arterial wall, and atherosclerosis. $f$ Biomech Eng 1992: 114:274-282.

104. Nerem RM, Girurd PR. Herodynamic influences on vascular endothelial biology. Toxicologic Pathology 1990 : 18:572-582.

105. Cambria RP, Megerman J, Abbott WM. Endothelial preservation in reversed and in situ autogenous wein grafts. Avin Surg 1985; 202.50-55.

106. Nerem RM, Harrison DG, Taylor WR, Alexander RW. Hemodynamics and vascular endothelial biology. I Cardiovasc Pharmacol 1993; 21:s6-silo.

107. Langille BL, Graham JJ, Kim D, Gotlieb AL. Dynamics of shear induced redistribution of Factin in endothelial cells in vivo. Arterioscler Thromb 1991; 6:1814-1820.

108. Langille BL, Reidly M, Kline R. Injury and repair of endothelium at sites of flow disturbances near abdominal aortic coarctations in rabbits. Arterioscler Thromb 1988; 6:146-154.

109. Buga GM, Gold ME, Fukuto JM, Ignarro L.J. Shear stress-induced release of nitric oxide from endothelial cells grown on beads. Hypertension 1991; 17:187-193.

110. Cooke JP, Rossitch E, Andon NA, Loscalzo J, Dzau VJ. Flow activates an endothelial potassium charnel to rellease an endogenous nitrovasodilator. J Clin Invest 1991; 88:1663-1671. 
11. Ralevic $V$, Milner $P$, Hudlicka $O$, Kristek F, Burnstock $G$. Substance $P$ is teleased from the endothelim of normal and capsaicin-treated rat hind-limb vasculature, in viwo, by increased flow. Circ Res 1990; 66:1178-1183.

112. Rubanyi GM, Freay AD, Kauser $K$, Johns A, Harder DR. Mechanoreception by the endothelium: Mediators and mechanisms of pressure- and flow-induced vascular responses. Blood Vessels 1990; 27:246-257.

113. Tesfamariam B, Colhen RA. Inhibition of adrenergic vasoconstriction by endothelial cell shear stress. Circ Res 1988; 63:720-725.

114. Hsieh HJ, Li NQ, Frangos JA. Shear stress increases endothelial platelet-derived growth factor mRMA levels. Am I Physiol 1991; 260:H642-H646.

115. Lischer TF. Endothelial control of vascular tone and growth. Clin Exp Hypertens 1990 ; $12: 897-902$.

116. Melkumyants AM, Balashov SA, Khayutin VM. Endothelium dependent control of arterial diameter by blood viscosity. Cardiovasc Res 1989;: 23:741.747.

117. Olesen SP, Clapham DE, Davies PF. Hemodynamic shear stress activates a $\mathrm{K}+$ current in vascular endothelial cells. Nature 1988:331:168-170.

118. Werner GS, Wiegand V, Kreuzer H. Effect of acetylcholine on arterial and venous grafts and coronary arteries in patients with coronary artery disease. Eur Heart 1 1990; 11:127-137.

119. Wermer GS, Wiegand V, Tebbe U, Kreuzer $\mathbb{H}$. Contrary effects of acetylcholine on coronary arteries and aortocoronary venous grafts in man. Eur Heart $J 1989 ; 10.86-91$.

120. Langille $\mathrm{BL}$, O'Donnell $\mathrm{F}$. Reductions in arterial diameter produced by chronic decreases in blood flow are endothelium-dependent. Science 1986; 231:405-407.

121. Langille BL, Bendeck MP, Keeley FW. Adaptations of carotid arteries of young and mature rabbits to reduced carotid blood flow. Am J Physiol 1989; 256:H931-H939.

122. Sterpetti AV, Cucina A, Santoro $\mathbb{L}$, Cardillo B, Cavallaro A. Modulation of arterial smooth muscle cell growth by hemodymamic forces. Eur J Vasc Surg 1992; 6:16-20.

123. Kohler TR, Kirkman TR, Kraiss LW, Zierler BK, Clowes AW. Increased blood flow inhibits neointimal hyperplasia in endothelialized vascular grafts. Circ Res 1991; 69:1557-1565.

124. Kohler TR, Jawien A. Flow affects development of intimal hyperplasia after arterial injury in rats. Arterioscler Thromb 1992; 12:963-971.

125. Morinaga K, Eguchi H, Miyazaki T, Okadone K, Sugimachi K. Development and regression of intimall thickening of arterially transplanted autologous vein grafts in dogs. J Vasc Surg 1987; 5:719.730.

126. Fry DL. Acute vascular endothelial changes are associated with increased blood velocity gradients. Circ Res 1968: 22:165-197.

127. Fry DL. Certain chemotheologic considerations regarding the blood vascular interface with particular reference to coronary artery disease. Circulation 1969; XXXIX and XI:IV38IV59.

128. Fillinger MF, Reinitz ER, Schwartz RA, Resetarits DE, Paskanik AM, Bredenberg. CE. Beneficial effects of banding on venous intimal-medial hyperplasia in arteriovenous loop grafts. Am J Surg 1989; 158:87-94.

129. Fillinger MF, Reinitz ER, Schwartz RA, et al. Grafi geometry and venous intimal-medial hyperplasia in arteriovenows loop grafts. I Vasc Surg 1990; 11.556-560.

130. Rittgers SE, Karayannacos PE, Guy JF, al al. Velocity distribution and intimal proliferation in autologous vein grafts in dogs. Circ Res 1978; 42:792-801.

131. Zarins $C K$, Zatina MA, Giddens DP, Ku DN, Glagov $S$. Shear stress regulation of antery lumen diameter in experimental atherogenesis. J Vasc Surg 1987; 5:413-420.

132. Friedman MH. Some atherosclerosis may be a consequence of the normal adaptive response to shear. Aherosclerosis 1990; 82:193-196.

133. Friedman MH, Bargeron CB, Deters OJ, Hutchins GM, Mark FF. Correlation between wall shear and intimal thickness at a coronary artery branch. Atherosclerosis 1987; 68:27-33. 
134. Koo EWY, Gotlieb AI. Endothelial stimulation of intimal cell proliferation in a porcine aortic orgen culture. Am I Pathot 1989; $134.497-503$.

135. Luscher TF. Imbalance of endothelium-derived relaxing and contracting factors. A new concept in hypertension? Am $J$ Hypertens 1990; 3:317-330.

136. Luscher TF, Diederich D, Siebeenman P, Lehman K, Stulz P, Von Segesser L, Yang Z,Turina

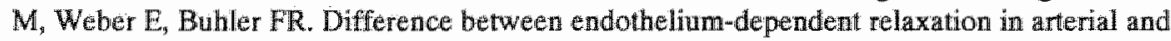
venous coronary bypass grafis. New Eng $J$ Med 1988; 319:462-467

137. Ludmer PL, Selwyn AP, Shook TL, ef al. Paradoxical wasoconstriction induced by acetylcholine in atherosclerotic cononary arteries. New Eng $J$ Med 1986; 315:1046-1051.

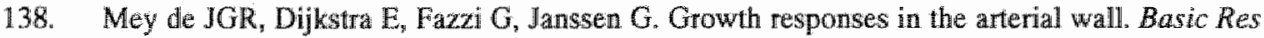
Cardial 1991; 86:13-17.

139. Mey de JGR, Dijkstra EH, Vrijdag MIJE. Endothelium reduces DNA synthesis in isolated arteries. Am I Physial 1991; 260:H1-H7.

140. Mey de JGR, Uitendaal MP, Boonen HCM, Schiffers PMH, Fazzi GE. Growth responses in isolated elastic, muscular and resistance-sized arterial segments of the rat. Blood Vessels 1991; 28:372-385.

141. Vanhoutte PM, Shimokawa H. Endothelium-derived rellaxing factor and coronary vasospasm. Circulation 1989; 80:1-9.

142. Vanhoutte PM, Varbeuren TJ, Webb RC. Local modulation of adrenergic nsuroeffector interaction in the blood vessel wall. Physiol Rev 1981; 61:151-215.

143. Furchgott RF, Vanhoutte PM. Endothelium-derived relaxing and contracting factors. FASEB J 1989; 3:2007-2018.

144. Linder L, Kiowski W, Bühler FR, Lüscher TF. Indirect evidence for release of endothelium-derived relaxing factor in buman forearm circulation in vivo. Blunted response in essential hypertension. Circulation 1990; 81:1762-1767.

145. Shen J, Luscinskas FW, Conolly A, Dewey CF, Gimbrone MA. Fluid shear stress modulates cytosolic free calcium in wascular endothelial cells. Am I Cell Physiol 1992; 31:c384-c390.

146. Resnick N, Collins T, Atkinson W, Bonthron DT, Dewey CF, Gimbrone MA. Platelet-derived growth factor $B$ chain contains a cis-acting fluid shear-stress-responsive element. Proc Nat Acad Sci U S A 1993; 90:4591-4595.

147. Nabel EG, Yang $Z$, Liptay $S$, et al. Recombinant platelet-derived growth factor $B$ gene expression in porcine arteries induce intimal hyperplasia in vivo. J Clin Invest 1993; 91:1822-1829.

148. Taubman $M B^{2}$, Rollins $B J$, Poon $M$, et al. JE mRNA accumulates rapidly in aortic injury and in platelet-derived growth factor-stimulated vascular smooth muscle cells. Circ Res 1992; $70.314-325$.

149. DePaola N, Gimbrone MA, Davies PF, Dewey CF. Vascular endothelium responds to fluid shear stress gradients. Arterioscler Thromb 1992; 12:1254-1257.

150. Ojha M. Wall shear stress temporal gradient and anastomotic intimal hyperplasia. Circ Res $1994 ; 74: 1227-1231$. 


\title{
VESSEL WALL DOPPLER TRACKING: A NEW TECHNIQUE TO ASSESS VESSEL WALL COMPLIANCE
}

\author{
L Hofstra, EJM Ermers, APM Langeveldt, APG Hoeks, PJEHM Kitslaar \\ Adapted from the Journal of Vascular Technology, 1993; 17:65-68
}

\begin{abstract}
Background. To obtain insight in the pathogenesis of atherosclerosis and intimal thickening, information on mechanical arterial vessel wall properties is necessary. Methods. A Vessel Wall Doppler Tracking (VWDT) system, based on ultrasound Mmode detection in combination with computerized data-acquisition on a PC, was developed in our laboratory. This system transcutaneously measures vessel diameter and diameter change during a successive number of heartbeats. From these parameters and simultaneously recorded pulse pressure using Dinamap, relative distension (RD), distensibility coefficient ( $\mathrm{DC}=$ relative distension per unit of pressure) and crosssectional compliance ( $\mathrm{CC}=$ area increase per unit of pressure) can be calculated. $\mathbb{R D}$ and $\mathrm{DC}$ are measures of mechanical stress exerted on the vessel wall, $\mathrm{CC}$ is a measure of the capacity of the vessel to store blood volume during cardiac cycle.

Results. We studied the vessel wall characteristics in the right common femoral artery in 41 healthy subjects (mean age: 39 , range: $24-70$ years, 19 male and 22 female). Diameter was significantly higher $(p<0.01)$ in males $(9.95 \pm 0.40 \mathrm{~mm})$ than in females $(8.49 \pm 0.22 \mathrm{~mm})$. CC was also significantly higher $(\mathrm{p}<0.05)$ in the male group $(0.837 \pm$ $\left.0.096 \mathrm{~mm}^{2} / \mathrm{kPa}\right)$ than in the female group $\left(0.604 \pm 0.044 \mathrm{~mm}^{2} / \mathrm{kPa}\right)$. RD did not differ significantly between males $(3.4 \pm 0.3 \%)$ and females $(3.8 \pm 0.3 \%)$. In DC no significant differences between males $\left(7.4 \pm 0.810^{-3} \mathrm{kPa}^{-1}\right)$ and females $\left(7.4 \pm 0.810^{-3} \mathrm{kPa}^{-1}\right)$ was found. Diameter, RD and $\mathrm{CC}$ did not change with age.

Conclusion. We conclude that VWDT is a valuable tool for establishing arterial vessel wall characteristics. The capacity of the common femoral artery to transport blood is higher in males than in females but the mechanical stress on the arterial vessel wall does not differ. These data suggest that VWDT might be of clinical relevance e.g. in bypass surveillance and early detection of atherosclerosis.
\end{abstract}




\section{INTRODUCTION}

The compliance of large conduit arteries, like the carotid and femoral arteries, play an important role in buffering phasic changes in pressure and flow during the cardiac cycle. This results in a gradual transition from phasic flow close to the heart to a more continuous flow in peripheral arteries.

From a pathogenetic and possibly diagnostic point of view it is important to study elastic properties of arteries. For instance hypertension and diabetes mellitus, which are major risk factors in the development of atherosclerosis ${ }^{1,2}$, are associated with a decrease in compliance and distensibility of arteries ${ }^{3-1.5}$. An established technique to assess compliance of arteries, is the measurement of pulse wave velocity (PWV) ${ }^{3,4,8,15}$. Stiffening of arteries leads to an increase in pulse wave velocity ${ }^{3,8}$. This provides information on the global compliance in a defined segment of an artery. However, an increased PWV allows no distinction between plaque formation and general stiffening of the arterial segment investigated.

Vessel Wall Doppler Tracking (VWDT) is a new system to assess local elastic properties of superficial arteries ${ }^{16}$. This ultrasound system combines B-mode and processing of radio frequency (RF) signals to measure arterial diameter and diameter change during a cardiac cycle. In this article a description of the technique is presented. Furthermore, the preliminary results of measurements of compliance and distensibility of the common femoral artery, obtained in 41 presumed healthy volunteers, are reported.

\section{METHODS}

The VWDT-system consists of an echo-dopplersystem (ATL ULTRAMARK IV), a memory module and a Personal Computer. The vessel of interest is visualized in Bmode, to obtain anatomical and structural information of the vessel. A cursor line is positioned perpendicular to the arterial walls (Figure 1). A number (2048) of sequential lines, based on the received and non-processed radiofrequency (RF) signals, are digitized and temporarily stored in a memory ${ }^{16}$. Each line is transferred to a personal computer. The first digitized RF-line is displayed on the computer screen, allowing the operator to identify the anterior and posterior wall of the vessel. Two sample volumes, indicated by boxes, are placed on the anterior and posterior wall, respectively (Figure 2). The distance between the boxes corresponds with the diameter of the artery. The selected signal segments are subjected to Doppler-signal processing yielding a displacement signal with a high resolution. Based on the detected displacement of the walls, the positions of the sample volumes, representing the anterior and posterior wall, are updated for each subsequent line. Thus the position of the sample volume is linked with the vessel wall structure and follows the position of the walls (tracking). The process is triggered by an ECG-signal, which facilitates the detection of the maximum (systolic) and minimum (diastolic) arterial diameter within a cardiac cycle. The minimum diameter after an ECG trigger is considered as the initial diameter. The 
difference between maximum and minimum diameter gives the change in diameter during a cardiac cycle. The result of a typical recording is shown in figure 3 . The values of the parameters obtained during 3-5 heartcycles are averaged as shown in table I. During the measurements pulse pressure recordings (i.e. the difference between systolic and diastolic pressure) were obtained at the left arm with the use of an automated cuff device (Dinamap ${ }^{\mathbb{R}}$ ).

Figure 1: B-mode image of the common femoral artery (left panel). The cursor line is positioned perpendicular to the vessel. In M-mode the displacement of the artery wall can be observed. Arrows indicate the anterior (top) and posterior (bottom) wall of the conmon femoral artery.

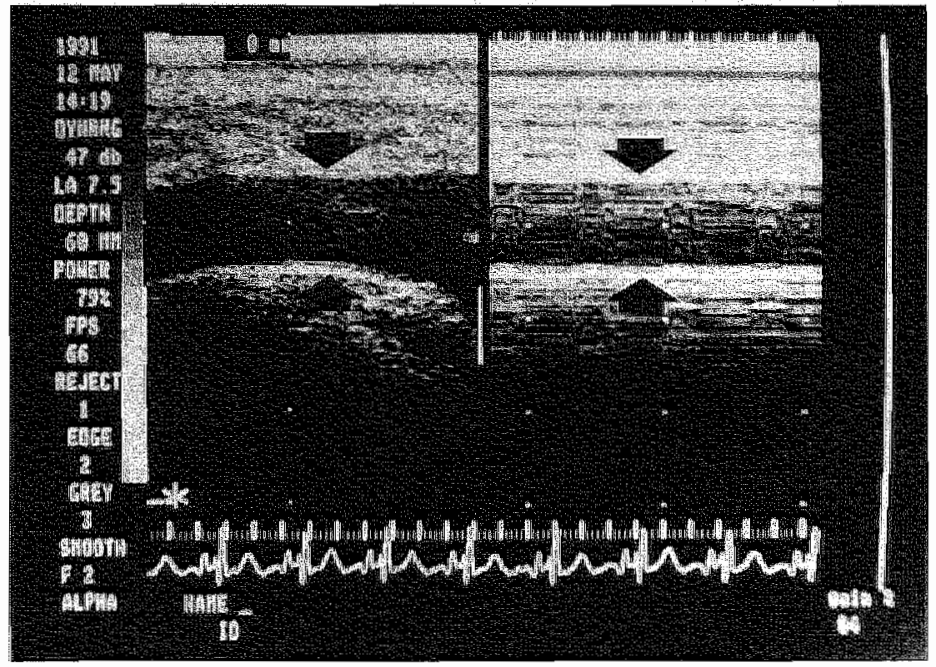

Figure 2: The digitized RF-signal of the first acquired line. The anterior (left arrow)and posterior wall (right arrow) are identified and covered by samplemvolumes indicated by the boxes.

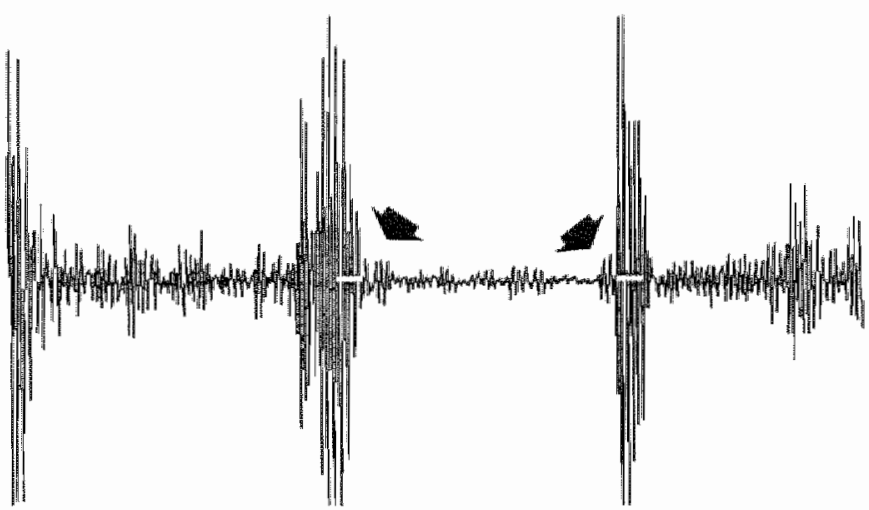


Figure 3: Displacement waveforms of the anterior (top) and posterior (middle) wall of the common femoral artery. This results in the distension waveform (bottom), where a cross indicates the occurence of an ECG-trigger.

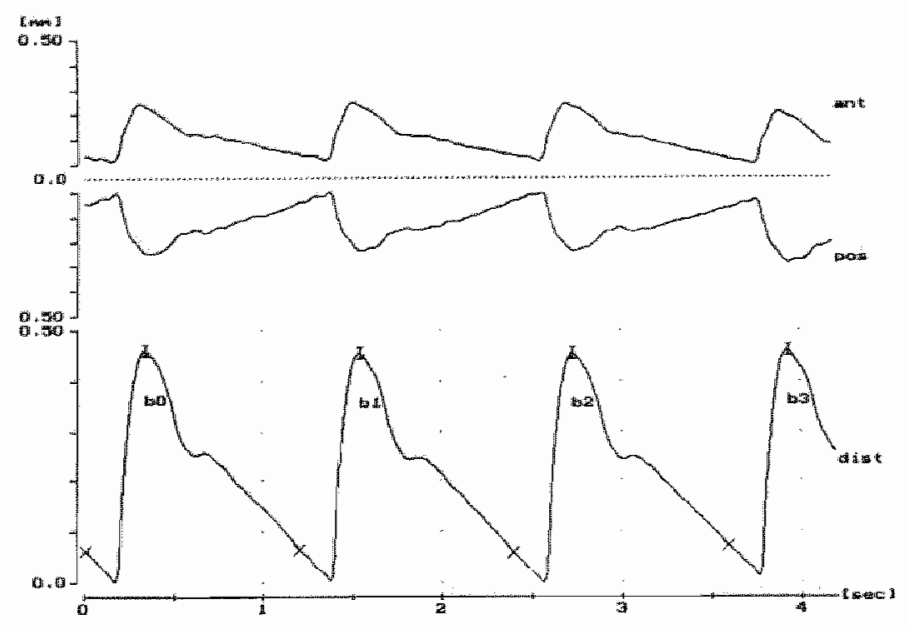

Table I: Parameters derived from the distension waveform (see fig 3). The parameter values obtained during 4 successive cardiac cycles are averaged.

\begin{tabular}{lccc}
\hline Beat & Diameter(mm) & Distension $(\mu \mathrm{m})$ & Relative Distension (\%) \\
\hline 0 & 9.25 & 543 & 5.9 \\
1 & 9.23 & 520 & 5.6 \\
2 & 9.21 & 565 & 6.1 \\
3 & 9.29 & 481 & 5.2 \\
\hline mean & 9.25 & 527 & 5.7 \\
std dev & 0.04 & 36 & 0.41 \\
\hline
\end{tabular}


From diameter, diameter change and simultaneously recorded pulse pressure the crosssectional compliance $\left(\mathrm{CC}, \mathrm{mm}^{2} / \mathrm{kPa}\right.$ ), distensibility coefficient (DC, $1 / \mathrm{kPa}$ ) and relative distension ( $\mathrm{RD}, \%$ ) can be calculated, using the following equations:

$$
\mathrm{CC}=\pi \frac{\Delta \mathrm{D} * \mathrm{D}}{2 \Delta \mathrm{P}}
$$

$\mathrm{DC}=\frac{2 \Delta \mathrm{D} / \mathrm{D}}{\Delta \mathrm{P}}$

$$
\mathrm{RD}=\Delta \mathrm{D} / \mathrm{D} * 100
$$

$(\mathrm{D}=$ diameter, $\Delta \mathrm{D}=$ diameter change and $\Delta \mathrm{P}=$ pulse pressure). The cross-sectional compliance is the cross-sectional area increase per unit of pressure, which is a measure of the capacity of the vessel to store blood volume during the cardiac cycle. The distensibility coefficient is the fractional diameter increase per unit of pressure, representing the stress-strain relationship of the arterial wall. Relative distension is the percentage diameter increase during the cardiac cycle.

The subjects, 19 male and 22 female, were measured in the supine position after an acclimatization period of 20 minutes. The measurements took place in a climatized laboratory, with a constant temperature of $24^{\circ} \mathrm{C}$. There were no significant differences in age and smoking habits between the male and female volunteers (Student t-test).

The right common femoral artery was measured three times in each subject within 20 minutes. From these measurements, the median value of each parameter was used in this study to diminish the influence of outliers.

\section{RESULTS}

In all subjects, wisualization of the common femoral artery was easily possible. A summary of the results is given in table II and III. Diameter and CC were significantly higher in the male group as compared to the female group (Student t-test, p<0.05). In DC no difference could be found between the groups. RD was slightly higher in the female group as compared to the male group. Linear regression analysis revealed a significant negative correlation for $\mathrm{CC}(r=-0.52, \mathrm{p}<0.05)$ and $\mathrm{DC}(\mathrm{r}=-0.56, \mathrm{p}<0.05)$ with age in the female group. $\mathrm{RD}$ in the female volunteers and all parameters in the male group lacked a significant correlation with age. 
Table II: Arterial dimeter, relative distension (RD), distensibility coefficient (DC), crosssectional compliance $(C C$ ) and pulse pressure for the male and the female group (mean $\pm S E$ ). Diameter and $\mathrm{CC}$ are significanty higher in the male group as compared to the female group (Sudent T-test).

\begin{tabular}{|c|c|c|c|}
\hline Parameter & Male & Female & P-value \\
\hline Diameter (mm) & $9.95(0.41)$ & $8.49(0.22)$ & 0.01 \\
\hline $\operatorname{RD}(\%)$ & $3.42(0.31)$ & $3.83(0.32)$ & 0.36 \\
\hline $\mathrm{DC}\left(10^{-3} / \mathrm{kPa}\right)$ & $7.4 \quad(0.76)$ & $7.4 \quad(0.76)$ & 0.98 \\
\hline $\mathrm{CC}\left(\mathrm{mm}^{2} / \mathrm{kPa}\right)$ & $0.837 \quad(0.097)$ & $0.604 \quad(0.064)$ & 0.05 \\
\hline $\begin{array}{l}\text { Pulsepressure } \\
\text { (mmHg) }\end{array}$ & $51 \quad(3.1)$ & $56 \quad(2.4)$ & 0.25 \\
\hline
\end{tabular}

Table III: Correlations of $\mathrm{DC}, \mathrm{CC}$ and $\mathrm{RD}$ with age for the male and the fermale group, calculated with the use of linear regression analysis. $(*=$ significant correlation, $p<0.05)$.

\begin{tabular}{lll}
\hline & Male & Female \\
\hline DC & -0.06 & $-0.56^{*}$ \\
CC & 0.25 & $-0.52^{*}$ \\
RD & -0.12 & -0.38 \\
\hline
\end{tabular}

\section{DISCUSSION}

VWDT is a new technique, where visualization in $\mathrm{B}$-mode is combined with off-line data procassing. Based on B-mode imaging structural unformation about arteries, like plaque formation and distance to the bifurcations, can be obtained. Plaque formation in the vessel wall, probably influencing the elastic properties can be identified. B-mode imaging is also very helpful in longitudinal studies, where it is of importance to define the exact site of measurement in the subsequent sessions. Using landmarks, like the bifurcations and anastomoses, this can be achieved ${ }^{16}$. 
Off-line data-processing has the advantage to identify carefully the position of the vessel wall reflections representing the anterior and posterior wall ${ }^{16}$. Doppler tracking provides the required high resolution necessary to assess compliance and distensibility accurately.

The preliminary data obtained from the common femoral artery in 41 healthy volunteers, show differences between male and female. Cross-sectional Compliance (CC), which is a measure of the capacity of the vessel to store blood volume during the cardiac cycle, is larger in the male group than in the female group. This is due to a difference in diameter rather than a difference in local elastic properties of the vessel, which is represented by $R D$ and $D C$.

In the female group a significant decrease with age in compliance and distensibility of the common femoral artery was found. In the male group no significant relation with age was shown. Some authors demonstrated age-related changes in elastic properties of large arteries ${ }^{8,15,17}$. In most studies a decrease in compliance with increasing age was reported. Laogun ${ }^{15}$ reported a difference in age related changes in aortic compliance between male and female. Male aortic compliance was found to decrease steadily between 20 and $50 \mathrm{yrs}$ of age. On the other hand, compliance of the aorta in females showed hardly any decrease with age between 20 and 45 yrs., but a sharp fall was found between 45 and 50 yrs.. Our data also show a difference in age-related changes in compliance between male and female. This could be the effect of the difference in hormonal status between male and female before menopause.

VWDT is a promising new technique to assess accurately the local vessel wall properties of arteries. This system could become of great value to study compliance and distensibility in hypertensive and diabetic subjects, and to obtain more insight in the pathogenetic mechanisms resulting in the development of atherosclerosis. Furthermore, attention can be paid to vessel wall characteristics of venous grafts used as a bypass conduit in peripheral revascularisation, to get a better understanding in the occurrence of stenotic lesions, often leading to tailure of bypasses.

\section{APPLICATION OF VWDT IN VASCULAR SURGERY}

In vascular surgery, saphenous vein grafts are often used in the construction of a bypass in order to reestablish flow to the lower limb. The occurrence of stenotic lesions in peripheral bypass grafts is a major threat to the function of the vascular conduit and often necessitates reintervention, leading to morbidity and hospitalisation of patients undergoing this kind of surgery. One of the causes for the occurrence of stenosis may be a difference in elastic properties between the venous graft and the native arterial system (mismatch). Quantitative data on the peri-anastomotic differences in elastic properties are scarce, which may be attributed to the lack of a suitable system to assess elastic properties at defined sites in the vascular system. With the 
introduction of VWDT, measurements of elastic properties at pre-defined sites are possible, due to the help of the B-mode image. This facilitates the positioning of the cursor line perpendicular to the vessel walls. Since the anastomoses of peripheral bypasses provide a useful landmark on the B-mode image, assessment of elastic properties at pre-defined sites in the graft and native arterial system is possible. Therefore, in theory VWDT is a suitable system to assess spatial changes in vessel wall elastic properties around anastomoses of vascular reconstructions. Also the calculation of mismatch in elastic properties around anastomoses may be possible. This provides insight to the possible contribution of mismatch in elastic properties to the development of stenosis in vascular reconstructions such as peripheral bypasses. 


\section{REFERENCES}

1. Brand FN, Abbot RD, Kannel WB. Diabetes, intermittent claudication, and risk of cardiovascular events. The Framingham study. Diabeies $1989 ; 38: 504-509$.

2. Rutan GH, Kuller LH, Neaton JD, Wentworti DN, McDonald RH, McFate-Smith W. Mortality associated with diastolic bypertension and isolated systolic hypertension anong men screened for Multiple Risk Intervention Trial. Circulation 1988; 77:504-514.

3. Avolio AP, Deng FQ, Li WQ, al Effects of aging on arterial distensibility in populations with high and low prevalence of hypertension: comparion between urban and rural communities in China. Circularion 1985; 71:202-210.

4. Ting CT, Chang MS, Wang SP, Chiang BN, Yin FCP. Regionall pulse wave velocities in hypertensive and normotensive humans. Cardiovasc Res 1990; 24:865-872.

5. Latureni S, London GM, Safar ME. Increased response of the brachial arterial diameter to norepinephrine in essential hypertension: Preliminary report. J Hypertens 1986; 4:237-239.

6. Levenson J, Pithois-Merli I, Simon A. Mechanical factors in large artery disease and antihypertensive drugs. Am J Cardiol 1990;66:39C-42C

7. Levy BI, Benessiano J, Poitevin P, Safar ME. Endothelium-dependent mechanical properties of the carotid artery in Wistar-Kyoto and spontaneously hypertensive rais. J Hypertens 1989 ; 7:5116 5119 .

8. Avolio AP, Chen SG, Wang RP, Zhang CL, $L i M F$, O'Rourke MF. Effects of aging on changing arterial compliance and left ventricular load in a northern chinese urban community. Circulation 1983; 68:50-58.

9. O'Rourke MF. Arterial stiffness, systolic blood pressure, and logical treatment of arteriall hypertension. Hypertension 1990; 15:339-347.

10. Asmar AG, Brunel PC, Pannier BM, Lacolley PJ, Safar ME. Arterial distensibility and ambulatory blood pressure monitoring in essential hypertension. Am I Cardiol 1988; 61:1066-1070.

11. Simon AC, Levenson J, Bouthier JD, Maarek B. Haemodynamic basis of early modifications of the large arteries in borderline hypertension. J Hypertens 1987; $5: 179-184$.

12. Scarpello JHB, Martin TRP, Ward JD. Ultrasound measurements of pulse-wave velocity in the peripheral arteries of diabetic subjects. Clin Sci 1980; 58:53-57.

13. Oxlund H, Rasmussen LM, Andreassen TT, Heickendorff L. Increased aortic stiffness in patients with type I (insulin-dependent) diabetes mellitus. Diabetologia 1989; 32:748-752.

14. Caims SA. Woodcock JP, Marshall AJ. Early arterial lesions in maturity onset diabetes mellitus detected by an ultrasound technique. Diabetotogia 1978; 4:107-111.

15. Lagon AA, Gosling RG. In wivo arterial compliance in man. Clin Phys Phystol Meas 1982; 3:201-212.

16. Hoeks APG, Brands PJ, Smeets FAM, Reneman RS. Assessment of distensibility of superficial arteries. Ultrasound Med Bial 1990; 16:121-128.

17. Reneman RS, Merode van $T$, Hick P, Muytjens AMM, Hoeks APG. Age-retated changes in carotid artery wall properties in men. Ultrosound Med Blol 1986; 12:465-47\%. 



\section{SHORT-TERM VARIATION IN ELASTIC PROPERTIES OF A MUSCULAR ARTERY IN HUMANS}

L Hofstra, JM Willigers, NC Schaper, FC Huvers, ADM Kester, PJEHM Kitslaar, APG Hoeks

Adapted from Clinical Science 1994;86:567-574

\section{ABSTRACT}

Background. Information on the interaction between mechanical strain and elastic properties of large arteries could give insight in the origin of hemodynamic vascular injury, possibly resulting in formation of atherosclerotic plaques. Intra-individual variation in elastic properties of muscular arteries, measured using non-invasive techniques, has been observed. This variation could be due to changes in blood pressure, since elastic properties of muscular arteries are strongly non-linear.

Methods. The objective of the present study was to evaluate variability in elastic properties of a muscular artery over a time period up to one hour. Furthermore the relation between changes in elastic properties and alterations in blood pressure was studlied. With a non-invasive high resolution ultrasound technique diameter and distension of the femoral artery were assessed in repeated measurements in 10 healthy volunteers (mean age: $27 \pm 2.9$ years) in resting conditions during 40-60 minutes. Simultaneously intra-arterial blood pressure of the contralateral common femoral artery and heart rate were recorded. From distension and pulse pressure, distension pressure ratio (DPR) was calculated, a measure for the compliance. For each parameter the variation coefficient (VC) was computed.

Results. In all subjects a considerable variation was found in distension (mean VC $14.8 \%$ ) but not in pulse pressure (mean VC $3.7 \%$ ). The expected positive correlation between pulse pressure and distension was absent in 8 subjects. As a consequence, large intra-individual variation was found in DPR (mean VC 15.3\%). When plotted as function of time, gradual fluctuations in DPR were observed. In the majority of the subjects no correlation between diastolic pressure and diameter was observed. Therefore the non-linear relation between diastolic diameter and distension cannot explain the observed variation in DPR.

Conclusions. In resting conditions femoral artery elastic properties in humans show large intra-individual variation with time. This variation cannot be explained by alterations in diastolic diameter, suggesting active vessel wall behavior to be responsible 
for the variability. Due to the variability of DPR in this large artery, a single measurement cannot give a proper characterization of the elastic properties.

\section{INTRODUCTION}

Due to their visco-elastic properties, large conduit arteries play an important role in buffering phasic changes in pressure and flow during the cardiac cycle ${ }^{1.3}$. Comprehension of the interaction between mechanical strain and elastic characteristics of the arterial wall is essential to get more insight in the aetiology of arterial degenerative disease due to hemodynamic vascular injury ${ }^{4-8}$. Variability in elastic behavior of large muscular arteries measured with the use of non-invasive techniques has been demonstrated. A wide range of individual values for stiffness has been reported for both the brachial and femoral artery ${ }^{9}$. Moreover, significant intra-individual variations in elasticity of the aorta and the brachial artery, calculated from pulse-wave velocity, have been reported ${ }^{10,11}$. These observed variations can be explained by the non-linear relationship between blood pressure and elastic properties ${ }^{12-14}$. An elevation of mean blood pressure leads to a decrease in compliance of an artery. Intra-arterial measurements of blood pressure in the brachial artery demonstrated considerable variation, even in resting conditions ${ }^{15-17}$, and could possibly explain the observed variation in elastic behavior. Another explanation could be the modification of elastic properties by vaso-active substances or the central nerve system ${ }^{13,18}$. Recent research revealed that the dimensions of large muscular arteries, like the common femoral artery, are influenced by vaso-active substances such as angiotensin, norepinephrin and atrial natriuretic factor $^{19.24}$. Furthermore, there is evidence of the existence of a local renin-angiotensin system (RAS) in large arteries ${ }^{19,25,26}$. An increase in compliance of the carotid artery was found after the local application of ACE-inhibitors ${ }^{27}$. Different pressure compliance curves were found for the same segment of the femoral artery in one dog measured several times during one month under the same conditions ${ }^{13}$. This indicates that spontaneous changes in elastic behavior of a large muscular vessel can occur. So far it is unclear whether the reported variation in elastic properties of large arteries can be attributed solely to alterations in blood pressure or is the result of changes in vasomotor tone.

The present study was designed to evaluate variability in elastic behavior of a large muscular artery in resting condition in man. Furthermore, the effect of alterations in blood pressure on elastic properties was studied. Repeated measurements of diameter and distension of the femoral artery were performed during 45 minutes and simultaneously blood pressure was recorded in a beat to beat fashion. In this period considerable spontaneous variation in pressure can be expected ${ }^{15-17}$. The femoral artery was choosen, because this vessel is prone to develop atherosclerotic lesions. Moreover, this part of the arterial tree is easily accessible for as well the ultrasound technique used as the intra-arterial measurement of blood pressure. 


\section{MATERIALS AND METHODS}

Vessel Wall Doppler Tracking (VWDT) ${ }^{28,29}$ was used to measure diameter and distension. The VWDT-system consists of an echo Doppler system (Ultramark IV, Advanced Technology Laboratories) with a $7.5 \mathrm{MHz}$ sector probe, a memory module and a Personal Computer. The vessel of interest is visualized in B-mode to obtain anatomical and structural information. A cursor line, representing the angle of investigation is positioned perpendicular to the arterial walls. A number (2048) of sequential nonprocessed RF lines are digitized and temporarily stored in the memory module for processing afterwards. The signal as function of depth of the first digitized RF line is displayed on the computer screen. From the shape and the position in depth of the reflections the operator can identify the anterior and posterior walls. Two sample volumes, indicated by boxes, are placed on the anterior and posterior wall, respectively. The distance between both boxes reflects the initial diameter of the artery (Figure 1).

Figure 1: The digitized RF signal of the first line acquired. From the shape and position in depth the operator can identify the position of the anterior and posterior wall. The walls are marked with (white) boxes representing the sample volumes used by the tracking program. The distance between the boxes reflects the initial diameter.

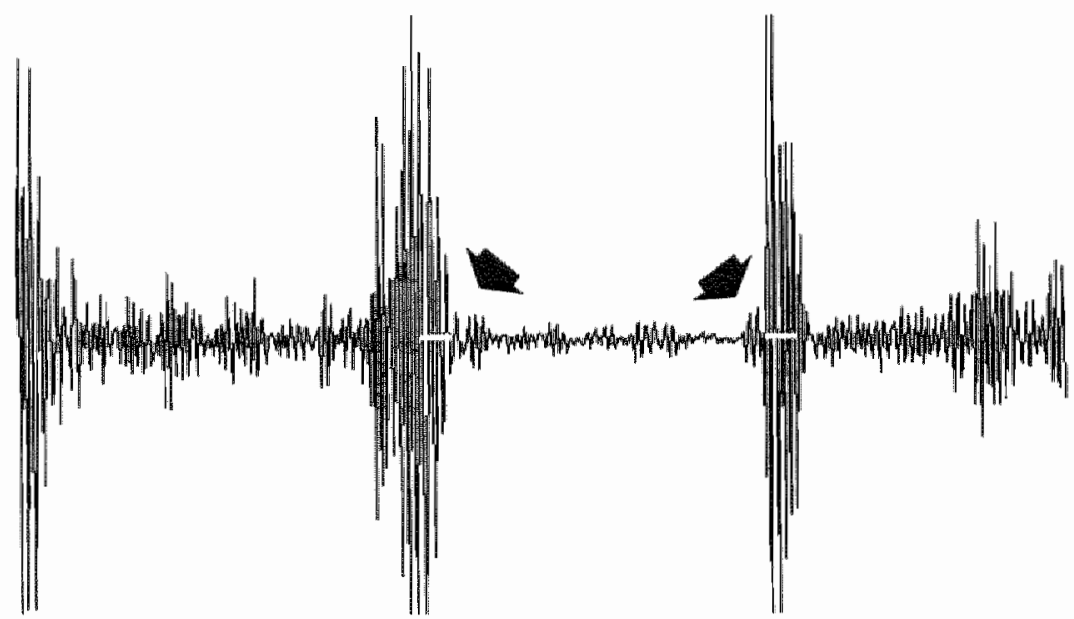


Analysis of the signal behavior within the sample volumes as function of time yields the change in vessel wall position (displacement waveform). The position of the sample volume is updated according to the detected displacement to ensure that for processing the same signall segment will be evaluated. The difference between the displacement waveforms of the anterior and posterior walls gives the change in diameter (distension) as function of time. The process is triggered by an electrocardiograph (ECG) signal, which facilitates the detection of the maximum (systolic) and minimum (diastolic) arterial diameter within a cardiac cycle. The difference between maximum and minimum diameter is considered as distension. The result of a typical recording of a distension waveform is shown in figure 2 . In the present study the averaged values of diameter and distension values during a recording time of 4 seconds were used.

Figure 2: Displacement waveforms of the anterior (top tracing) and posterior (middle tracing) wall of the common femoral artery. This results in the distension waveform (bottom tracing), where a cross indicates the occurrence of an ECG trigger.

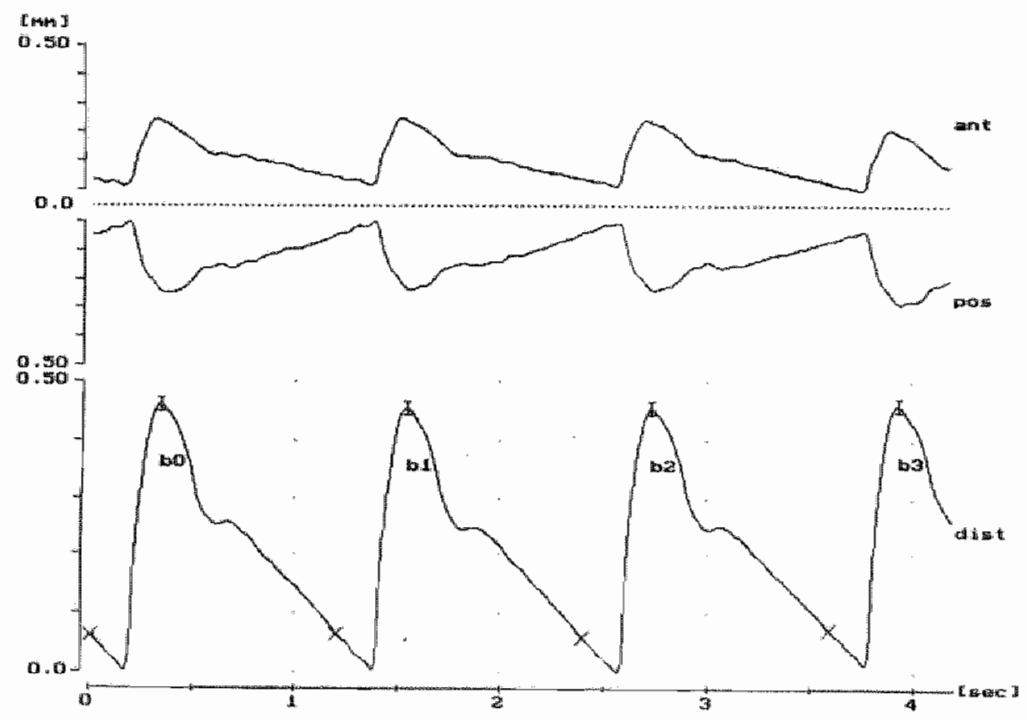

Intra-arterially blood pressure data were obtained simultaneously in the contralateral common femoral artery at a site corresponding with the position of the ultrasound measurements. We decided not to perform these measurements at the ipsilateral side, since introduction of a catheter could influence the elastic properties of the artery. A 20 Gauge rigid catheter (Arrow, Reading, USA) was introduced in the contralateral femoral artery after local anasthesia with $2 \%$ lidocaine. Via a fluid filled line, the catheter was connected with a pressure transducer (Baxter Pressure Set Uniflow 43$600 \mathrm{~F}$, Uden, The Netherlands). The resonance frequency of this system ranges from 
$18-20 \mathrm{~Hz}$, which is sufficient to provide acceptable dynamic responses. During the measurements of the distension, pressure data were simultaneously recorded and digitized at a sample frequency of $250 \mathrm{~Hz}$.. Pulse pressure was defined as the difference between the maximum and minimum value of pressure within $300 \mathrm{~ms}$ of the ECG-trigger (i.e. difference between peak systolic and end diastolic pressure). From distension ( $\triangle \mathrm{D}$ in $\mu \mathrm{m}$ ) and simultaneously recorded pulse pressure $(\Delta \mathrm{P}$ in $\mathrm{mmHg}$ ), the distension pressure ratio (DPR) was calculated using the following equation:

$$
\text { Distension Pressure Ratio }(D P R)=\frac{\Delta D}{\Delta P}
$$

This simple equation gives a measure for the compliance of the vessel.

The study was performed on 10 healthy volunteers ( 9 male, 1 female, age $27( \pm 2.9)$ (mean $( \pm S D)$ ) without a history of cardiovascular disease. All subjects were normotensive and clinically free of vascular symptoms. None of them used medication affecting cardiovascular behavior. The study was approved by the medical ethical committee of our hospital and each subject gave written informed consent.

\section{STUDY DESIGN}

All subjects were investigated at 14.00 am after they had used a light meal. They abstained from nicotine and caffeine before the investigation. The ultrasound investigations were carried out in a climatized room $\left(24^{\circ} \mathrm{C}\right)$ with the subjects in the supine position. After an acclimatization phase of 20 minutes, the subjects were measured during 38-70 minutes (mean: $52 \pm 10 \mathrm{~min}$.) with a mean sample interval of $77 \pm 15$ seconds. During the measurements, the echo transducer was constantly kept in place by the operator to avoid changes in measured values due to locall inhomogeneities in compliance ${ }^{30}$. The common femoral artery dimensions were measured $2-3$ centimeters proximal to the femoral bifurcation. All measurements were performed by the same operator.

\section{ANALYSIS}

To calculate the correlation between the different parameters, the Pearson correlation coefficient was used. A p-value $<0.05$ was accepted as level of statistical significance. The values for pulse pressure and distension for each subject are presented as mean and standard deviation. As a measure of variation, the variation coefficient of the parameters was calculated using the following equation: 


\section{RESULTS}

In all subjects a wide range of values for distension was found. (Table $\mathbb{I}$ ). The large variation in distension of the common femoral artery is illustrated by a mean variation coefficient of $14.8 \%$ for the whole group. In most subjects the variation coefficient of distension was approximately four times the variation coefficient of pulse pressure (mean $3.7 \%$ ).

Table I

\begin{tabular}{|c|c|c|c|c|c|c|c|c|c|c|}
\hline \multirow[b]{2}{*}{ Subj. } & \multirow[b]{2}{*}{$\mathrm{n}$} & \multicolumn{3}{|c|}{ Pulse pressure (mmHg) } & \multicolumn{3}{|c|}{ Distension $(\mu \mathrm{m})$} & \multicolumn{3}{|c|}{ DPR ( $(\mu \mathrm{m} / \mathrm{mmHg})$} \\
\hline & & mean & sd & $\mathrm{vc}(\%)$ & mean & sd & $\operatorname{ve}(\%)$ & mean & sd & $\mathrm{vc}(\%)$ \\
\hline 1 & 35 & 73.5 & 2.4 & 3 & 391 & 51.6 & 13 & 5.32 & 0.68 & 13 \\
\hline 2 & 39 & 63.2 & 1.6 & 3 & 221 & 18.9 & 9 & 3.50 & 0.32 & 9 \\
\hline 3 & 31 & $\$ 5.6$ & 2.9 & 5 & 540 & 112.9 & 21 & 9.70 & 1.88 & 19 \\
\hline 4 & 45 & 60.9 & 3.0 & 5 & 396 & 49.3 & 13 & 6.51 & 0.79 & 12 \\
\hline 5 & 55 & 72.3 & 1.4 & 2 & 354 & 50.6 & 14 & 4.88 & 0.72 & 15 \\
\hline 6 & 54 & 73.0 & 1.3 & 2 & 536 & 53.3 & 10 & 7.35 & 0.81 & 11 \\
\hline 7 & 40 & 60.3 & 1.5 & 2 & 361 & 60.1 & 17 & 6.00 & 1.09 & 18 \\
\hline 8 & 34 & 61.9 & 4.9 & 8 & 484 & 83.6 & 17 & 7.90 & 1.71 & 22 \\
\hline 9 & 48 & 66.8 & 2.1 & 3 & 364 & 58.7 & 16 & 5.45 & 0.89 & 16 \\
\hline 10 & 29 & 49.4 & 1.9 & 4 & 209 & 38.9 & 19 & 4.23 & 0.77 & 18 \\
\hline MEAN & & 63.7 & 2.3 & 3.7 & 386 & 57.8 & 14.8 & 6.14 & 1.04 & 15.3 \\
\hline
\end{tabular}

As an example, the relation between pulse pressure and distension of subject 1 is displayed in figure 3. As is illustrated in figure 3, a single value of pulse pressure can lead to different values of distension. No correlation $(\mathrm{r}=0.25,95 \%$ confidence interval: $-0.09-0.54$ ) was found between pulse pressure and distension in this subject. Only in 2 of the remaining subjects a positive correlation between pulse pressure and distension was found. In 3 subjects a negative correlation and in 5 subjects no correlation was found (Table II).

To evaluate a possible shift in the pressure diameter relation due to changes in diastolic pressure, diastolic pressure and diastolic diameter were correlated. In only 2 subjects could a positive correlation between these parameters be observed. In 1 subject a negative correlation was found and in 7 no correlation was observed (Table II). This indicates that an increase in diastolic pressure does not necessarily lead to an increase in diastolic diameter. To evaluate the effect of changes in diastolic pressure on elastic properties, the correlation between diastolic pressure and distension was 
calculated. In 7 subjects a negative correlation between diastolic pressure and distension was observed and in 3 subjects no correlation between these parameters was demonstrated.

Table II

\begin{tabular}{|c|c|c|c|c|c|c|c|c|c|c|c|c|}
\hline \multirow{3}{*}{$\frac{\text { Subj. }}{1}$} & \multicolumn{3}{|c|}{$\rho(\Delta \mathrm{P}$, dist $)$} & \multicolumn{3}{|c|}{$p$ (Pdia, diam) } & \multicolumn{3}{|c|}{$\rho($ Pdia dist $)$} & \multicolumn{3}{|c|}{$\rho($ diam, dist $)$} \\
\hline & \multirow{2}{*}{$\begin{array}{c}\rho \\
0.25\end{array}$} & \multicolumn{2}{|c|}{$\begin{array}{l}95 \% \text { conf. } \\
\text { interval }\end{array}$} & \multirow{2}{*}{$\begin{array}{l}\rho \\
0.15\end{array}$} & \multicolumn{2}{|c|}{$\begin{array}{l}95 \% \text { conf. } \\
\text { interval }\end{array}$} & \multirow{2}{*}{$\begin{array}{c}\rho \\
\frac{-0.45}{}\end{array}$} & \multicolumn{2}{|c|}{$\begin{array}{l}95 \% \text { conf. } \\
\text { interval }\end{array}$} & \multirow{2}{*}{$\frac{\rho}{-0.60}$} & \multicolumn{2}{|c|}{$\begin{array}{c}95 \% \text { conf. } \\
\text { interval }\end{array}$} \\
\hline & & -0.09 & 0.54 & & -0.20 & 0.46 & & -0.68 & -0.13 & & -0.78 & -0.33 \\
\hline 2 & -0.09 & -0.39 & 0.23 & -0.29 & -0.55 & 0.03 & -0.26 & -0.53 & 0.06 & 0.03 & 0.29 & -0.34 \\
\hline 3 & 0.41 & 0.06 & 0.67 & -0.21 & .0 .53 & 0.16 & -0.25 & -0.55 & 0.12 & -0.35 & -0.62 & 0.01 \\
\hline 4 & 0.30 & 0.15 & 0.43 & 0.09 & -0.07 & 0.24 & -0.46 & -0.57 & -0.33 & 0.12 & -0.04 & 0.27 \\
\hline 5 & -0.14 & -0.28 & 0.00 & 0.62 & 0.52 & 0.70 & -0.51 & -0.61 & -0.39 & -0.28 & -0.41 & -0.14 \\
\hline 6 & -0.57 & -0.73 & -0.35 & -0.30 & -0.52 & -0.03 & -0.77 & -0.86 & -0.63 & 0.32 & 0.05 & 0.54 \\
\hline 7 & -0.26 & -0.41 & -0.10 & 0.16 & 0.00 & 0.32 & -0.53 & -0.64 & -0.40 & -0.35 & -0.48 & -0.19 \\
\hline 8 & -0.24 & -0.40 & -0.07 & 0.33 & 0.16 & 0.48 & -0.48 & -0.60 & -0.33 & -0.71 & -0.79 & -0.61 \\
\hline 9 & 0.01 & -0.14 & 0.15 & -0.15 & -0.29 & 0.00 & -0.14 & -0.28 & 0.01 & -0.60 & -0.69 & -0.49 \\
\hline 10 & 0.16 & -0.22 & 0.50 & 0.07 & -0.30 & 0.43 & -0.41 & -0.76 & -0.05 & -0.61 & -0.80 & -0.31 \\
\hline
\end{tabular}

Figure 3: The relation between pulse pressure and distension of subject 1. This graph shows that an equal pulse pressure can lead to different distensions. The correlation coefficient between the parameters is not significant for this subject $(r=0.25,95 \%$ confidence-interval: $0.09-0.54)$.

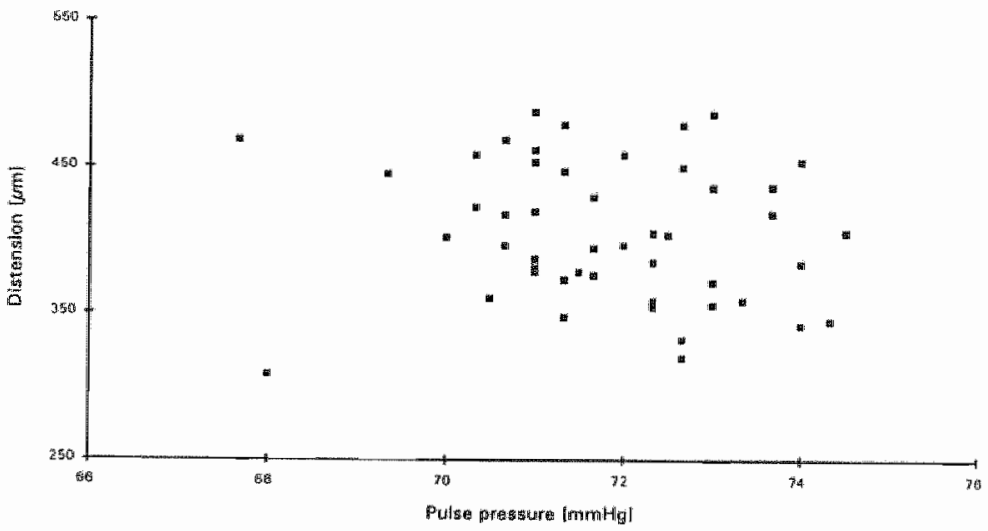


Correcting alterations in distension for pulse pressure changes (distension pressure ratio, equation 1) did not result in the expected reduction of the variation. For the whole group a mean variation coefficient for DPR of $15.3 \%$ was found. A typical graph of DPR as a function of time of subject 5 is shown in figure 4 . The graph suggests that the variation is not at random but is characterized by a gradual fluctuation with time. Between heart rate, a marker for sympathetic activity, and distension no correlation was found (data not shown).

Figure 4: The distension pressure ratio (DPR, eq. 1 ) values of the femoral artery of subject 5 plotted as function of time. The pattern suggests a gradual fluctuation in time.

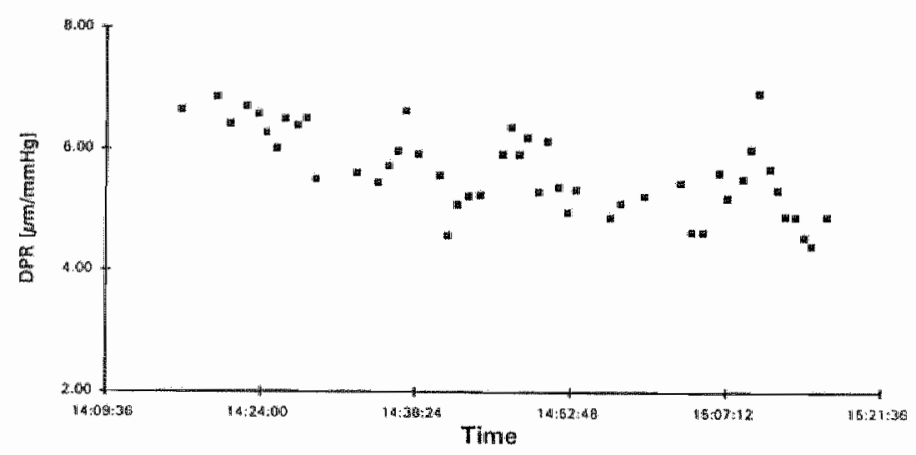

\section{DISCUSSION}

The goal of this study was to evalute variability in elastic behavior of the common femoral artery in relation to changes in blood pressure. Spontaneous intra-individual variation in distension of this artery was found in all subjects, illustrated by an average variation coefficient of $14.8 \%$, while the variation in pulse pressure was considerably lower (mean VC 3.7\%).

Part of the variation in distension possibly originated from intra-observer variation or changes in experimentation circumstances. To eliminate this variation as much as possible, we optimized operator as well as subject conditions. The measurements were performed by one and the same experienced operator. During the whole length of the experiment, the transducer was constantly positioned at the same segment of the common femoral artery, 2-3 centimeter proximal from the femoral bifurcation. This measure was necessary to avoid changes in compliance due to local inhomogeneities 
in elastic properties ${ }^{30}$. The use of B-mode imaging facilitated the positioning of the cursor line using the bifurcation as a landmark. The measurements were performed in a quiet and climatized room $\left(24^{\circ} \mathrm{C}\right)$ after an acclimatization period of at least 20 minutes. It is most likely that the variation in DPR, as reported in this study, originates from alterations in local mechanical behavior of the vessel wall rather than changes in circumstances or intra-observer variation.

One of the limitations of this study might be the correlation of blood pressure of the contralateral femoral artery with distension values of the ipsilateral femoral artery. However, it is likely that the values of pressure and the configuration of the pressure signal are equal at both sites, since intensity and timing of pulse wave reflection will have the same effect at both sites.

In previous reports the change in cross-section per unit of pressure, the cross-sectional compliance, was used as a measure for compliance. Diameter is included in this equation ${ }^{30}$. In our data hardly any variation was observed in diameter (VC: $3 \%$, data not shown), indicating that the changes in elastic properties of the femoral artery result from changes in distension over cardiac cycles rather than diastolic diameter changes. Therefore, it was decided to use a simple equation to represent the compliance, the distension pressure ratio.

Since pulse pressure is the force leading to the pulsatile distension of the arteriall wall a positive correlation is expected between these two parameters at equal diameter values. In only 2 of the 10 subjects a positive correlation between pulse pressure and distension was found and in 3 subjects even a negative correlation was observed. Consequently, a large intra-individual variation was found in the distension pressure ratio (DPR) calculated from distension and pulse pressure, as illustrated in figures 3 and 4. This observation can be explained by the non-linear relationship between pressure and distension of an artery ${ }^{13,14,31,32}$ as is diagrammatically represented in figure 5. This figure shows that an equal pulse pressure occurring at different levels of diastolic pressure can lead to quite different values of distension. In our data, only for a minority of the subjects investigated, could a positive correlation between diastolic diameter and diastolic pressure be observed. Thus, an increase in diastolic pressure is not necessarily followed by an increase in diastolic diameter, indicating that a shift in the pressure distension curve does not occur. This suggests that passive changes in elastic behavior due to changes in blood pressure, cannot explain the observed lack of correlation between pulse pressure and distension. Therefore, the large observed variation in DPR cannot be attributed to changes in blood pressure. 
Figure 5: Diagrammatic representation of the relation between pressure and diameter. Since this relation is non-linear an equal pulse pressure may lead to a different distension (d1, d2) for a varying diastolic pressure (PD1, PD2).

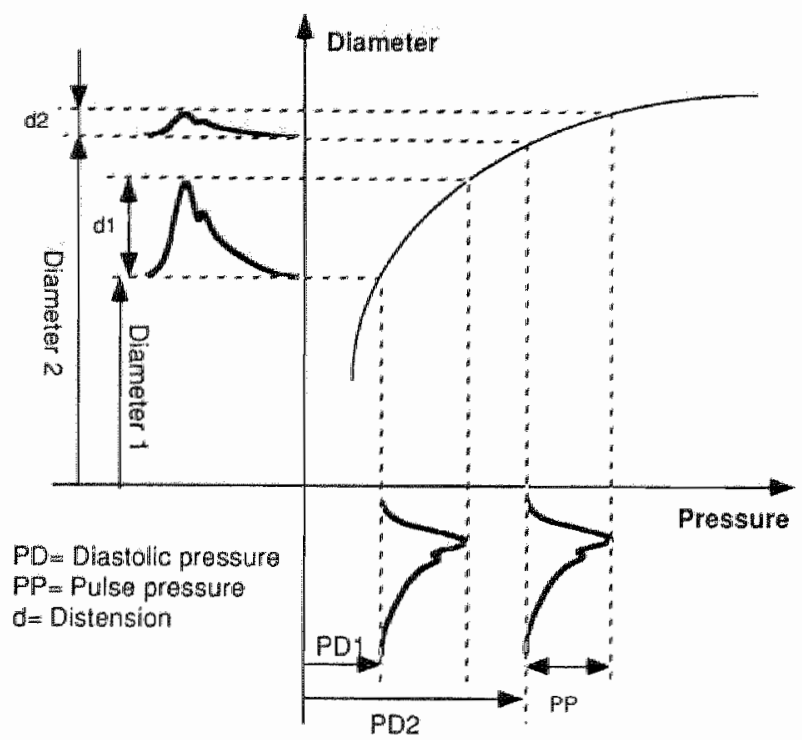

Figure 6: Hypothetical pressure-diameter curves of the same vessel at two different moments. Due to a different elastic behavior, equal pullse and diastolic pressure values can lead to different distension values.

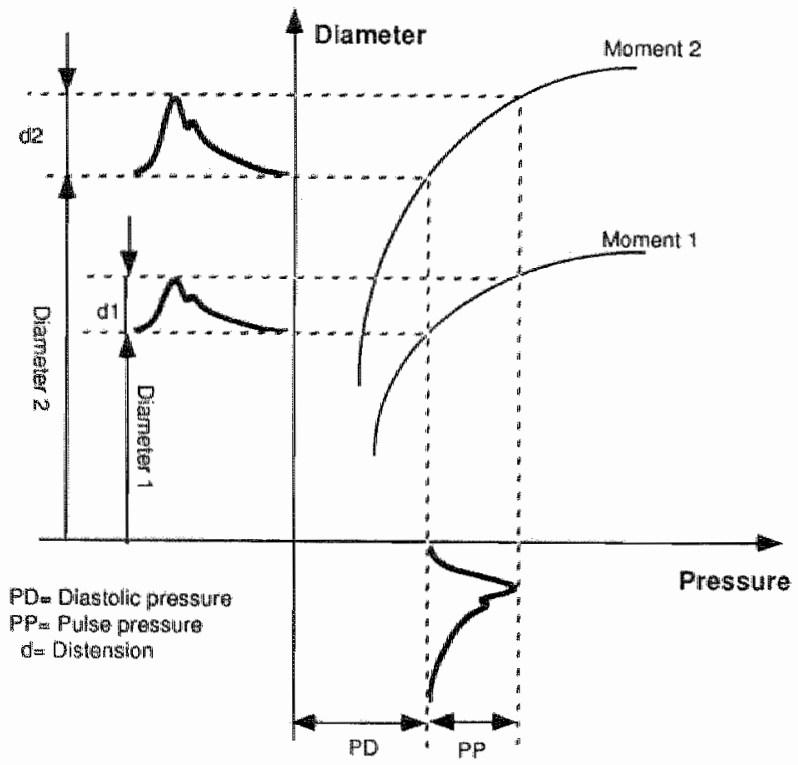


Figure 7: Pressure-distension curves obtained for two different heart beats of subject 1. Only the leading part of the curve (i.e. the early systolic phase) is presented in the graph. Despite equal diastolic pressure, diastolic diameter and pulse pressure, distinct curves are found, indicating variation in elastic behavior of the vessel at different moments.

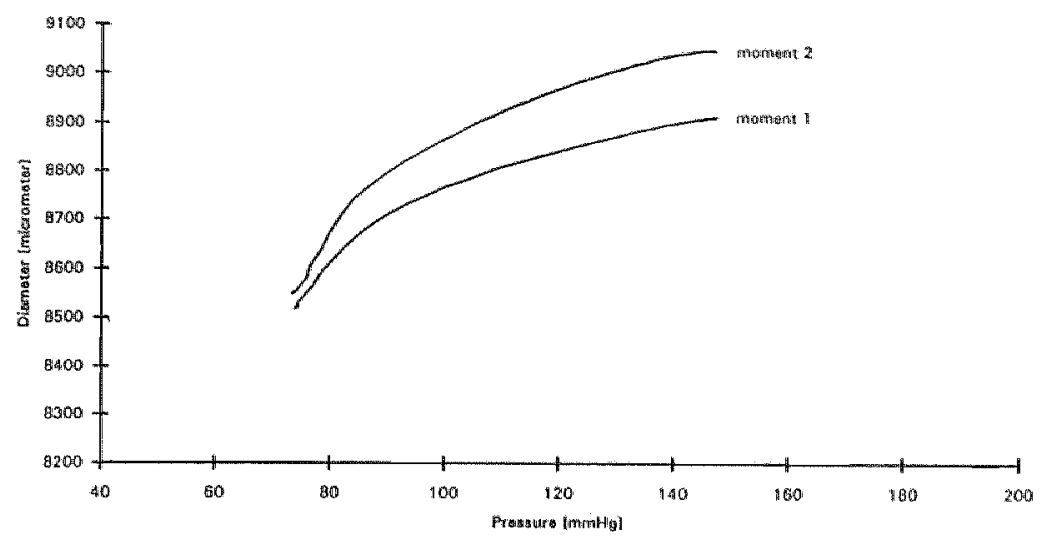

Differences in pressure-compliance curves for a femoral artery, obtained by repeated measurements in a single dog under established conditions, have been reported by Megerman ${ }^{13}$. The consequence of a change in the pressure distension relation is illustrated in figure 6 . This figure shows that for two different heartbeats unchanged diastolic and pulse pressure values can lead to different distension values due to a change in the pressure distension relation. Changes in pressure compliance curves, indicating alterations in vascular tone, can fully explain the lack of a positive correlation between pulse pressure and distension. Two instantaneous pressure distension curves of subject 1 at two different moments are depicted in figure 7 , indicating that the pressure distension relation of the femoral changes in a relatively short period of time (interval between the curves: 5 minutes).

Alterations in vascular tone ${ }^{32}$ can be the effect of a varying influence of vaso-active substances ${ }^{13,33,34}$ and/or the central nervous system ${ }^{18,24}$. The endothelial cell layer plays an important role in local regulation of vascular tone ${ }^{19,21,35-40}$. Increase in shear forces, exerted on the endothelium, leads to EDRF (NO) release ${ }^{41,42}$ and to an inhibition of adrenergic constriction ${ }^{43}$. Both mechanisms lead to vasodilation. It has been hypothesized, and it is now widely accepted, that arteries tend to maintain the shear forces that are sensed by the endothelial layer, at a constant value ${ }^{44,45}$. An increase in shear stress leads to a structural increase in artery diameter resulting in a return of the shear forces to base line values. The alterations in elastic properties, as found in our study, might 
be a functional regulation mechanism to maintain shear stress values at a constant level. This is supported by our finding that in diameter hardly any variation was found. According to the Hagen-Poisseille formula, mean shear stress is strongly diameter dependent $\left(t \sim 1 / d^{4}\right)$, and therefore slight changes in diameter have a profound effect on shear stress. Of interest in this respect is the negative correlation between diastolic pressure and distension found in all subjects, while no correlation was found between diastolic pressure and diastolic diameter. This indicates, that in response to diastolic pressure increase a contraction of smooth muscle cells occurs, to prevent an increase in diameter. At the same time, this contraction leads to stiffening of the vessel explaining the negative correlation between diastolic pressure and distension.

Another important control mechanism is the local renin-angiotensin system (RAS) ${ }^{19,46}$. The central RAS has a short term effect on changes in blood pressure and vascular tone. The local RAS probably is of importance in long term regulation of pressure and vasomotor tone $^{25}$. The gradual fluctuation of DPR as depicted in figure 4, suggests a short term regulation mechanism.

The extensive influence of the sympathetic nerve system on brachial artery distensibility has been demonstrated in a group $(n=10)$ of normal subjects ${ }^{47}$. A decrease in distension of the brachial artery was found after applying contra-lateral cooling (cold pressor). However, an increase in pulse pressure was observed, measured at the middle finger of the ipsilateral hand, indicating a decrease in compliance. Kawasaki also found an increase in stiffness of the brachial artery after the application of cold at the contralateral hand 9 . Heart rate can be used as a measure of sympathetic activity ${ }^{48}$. In the present data we found no correlation between heart rate and DPR, suggesting that the sympathetic nerve system does not play a crucial role in the variation of the elastic properties of the common femoral artery in resting conditions.

A recent study reported a $40 \%$ increase in compliance of the radial artery in hypertensive subjects after the infusion of papaverine ${ }^{49}$. These data support our observation, that in a muscular artery compliance values can undergo considerable changes. The new information of the present study is that elastic properties of the common femoral artery, represented by the DPR, change considerably in resting conditions, without the administration of vaso-active substances. The implication of this finding is that this large muscular artery in a healthy subject cannot be characterized by a single measurement of distension or DPR. Another way to arrive at a better characterization of the elastic properties of this type of artery might be by the use of provocation tests, like the administration of nitroglycerine, the cold pressor test, or a reactive hyperaemia test $^{49}$. This might give a better insight in the mechanical response of a large muscular artery and probably results in a better characterization of the vessel. 
In conclusion, our data demonstrate that the elastic properties of the common femoral artery cannot be considered constant in a young population investigated under resting conditions. Changes in blood pressure cannot explain the observed variation. This suggests that active mechanisms play a role in these changes rather than passive mechanisms. The physiologic implications of the observed variation in elastic properties are unclear, and cannot be concluded from this study. More research in this field is necessary to elicit the function of active mechanical behavior ${ }^{50}$ of large muscular arteries.

\section{ACKNOWLEDGEMENT}

We thank Dr G. Ramsay, Department of General Surgery, Academic Hospital Maastricht, for providing us with advice in writing the manuscript. 


\section{RETERENCES}

1. Cox RH. Blood flow and pressure propagation in the canine femoral artery. J Biomech 1970; $3: 131-149$.

2. Klanchar M, Tarbell JM, Wang DM. In vitro study of the influence of radial wall motion on stuer stress in an elastic tube model of the auta. Circ Res 1990; 66:1624-1635.

3. ORourke $\mathbb{M E}$. Steady and pulsatile energy losses in the systemic circulation under normal conditions and in simulated arterial disease. Cardiowasc Res 1967; 1.313-326.

4. Nerem RM. Vascular fluid mechanics, the arterial wall, and atherosclerosis. $J$ Biomech Eng $1992 ; 114: 274-282$.

5. Nerem RM, Girard PR. Hemodynamic influences on vascular endothelial biology. Toxicologic Pathology 1990; 18:572-582.

6. Bondjers $\mathrm{O}$, Glukhova M, Hansson GK, Postnov YV, Reidy MA, Schwartz SM. Hypertension and atherosclerosis. Cause and effect. or wo effects with one unknown cause? Circulation $1991 ; 84:$ V12-V16.

7. Karino T, Goldsmith HL. Role of blood cell-wall interactions in thrombogenesis and atherogenesis: a microrheological sfudy. Biorheology 1984; 21:587-601.

8. Ross R. The pathogenisis of atherosclerosis - An update. New Eng J Med 1986; 314:488-499.

9. Kawasaki T, Sasayama S, Yagi SI, Asakawa T, Hirai T. Non-invasive assessment of the age related changes in stiffness of major branches of the human arteries. Cardiovasc Res 1987; $21: 678-687$.

10. Wright JS, Cruickshank JK, Kontis S, Dore C, Gosling $\mathbb{R G}$. Aortic compliance measured by non-invasive doppler ultrasound: description of a method and its reproducibility. Clin Sci $1990 ; 78: 463-468$.

11. Kontis $S$, Gosling RG. On-line doppler ultrasound measurement of aortic compliance and its repeatability in normal subjects. Clin Phys Physiol Meas 1989; 10:127-135.

12. ORourke MF. Arterial stiffness, systolic blood pressure, and logical treatment of arterial hypertension. Hypertension 1990; 15:339-347.

13. Megerman J, Hasson JE, Warnock DF, LItalien GJ, Abbott WM. Noninvasive measurements of: nonlinear arterial elasticity. Am J Physiol 1986; 250:H181-H188.

14. Hayoz $D_{3}$ Rutschmann $B$, Perret F, et al. Conduit artery compliance and distensibility are not necessarily reduced in hypertension. Hyperiension 1992; 20:1-6.

15. Imholz BPM, Settels JJ, Meiracker van der $\mathrm{AH}$, Wesseling $\mathrm{KH}$, Wieling W. Non-invasive continuous finger blood pressure measurement during orthostatic stress compared to intralarterial pressure. Cardiowasc Res 1990; 24:214-221.

16. Llema RN, Meiracker van den AH, Imholz BPM, et al. Comparison of Finapres non-invasive beat-1o-beat finger blood pressure with intrabrachial artery pressure during and after bicycle ergometry. I Hypertens $1989 ; 7: 558-559$.

17. Parati $G$, Casadei $R$, Gropelli A, Di Rienzo $M$, Mancia G. Comparison of finger and intria-arterial blood pressure monitoring at rest and during laboratory testing. Hypertension $1989 ; 13: 647.655$

18. Vanhoutte $\mathrm{PM}$, Verbeuren TJ, Webb RC. Local modulation of adrenergic neuroeffector interaction in the blood vessel wall. Physiol Rev 1981; 61:151-215.

19. Dzau VJ, Safar ME. Large conduit arteries in hypertension: role of the vascular renin-angi* otensin system. Circulation 1988; 77:947-954.

20. Simon AC, Levenson JA, Levy BY, Bonthier JE, Peronneau PP, Safar ME. Effect of nitroglycerin on peripheral large arteries in hypertension. $\mathrm{Br} J \mathrm{Cl}$ in Pharmac 1982; $14: 241.246$

21. Levy BI, Benessiano J, Poitevin P, Safar ME. Endothelium-dependent mechanical properties of the carotid artery in Wistar-Kyoto and spontaneously hypertensive rats. J Hypertens 1989; $7.5116-5119$. 


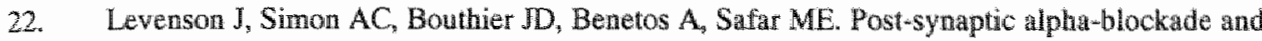
brachial artery compliance in essential hypertension. $J$ Hypertens $1984 ; 2.3741$.

23. Laurent $S$, London GM, Safar ME. Increased response of the brachial arterial diarneter to norepinephrine in essential hypertension: Preliminary report. $J$ Hyperiens $1986: 4: 237-239$.

24. Bolton TB. Mechanisms of action of iransmitters and other substances on smooth muscle. Physial Rev 1979; 59:606-695.

25. Dzau VJ. Short- and long-term determinants of cardiovascular function and therapy: contribution of circulating and tissue renin-angiotensin systems. I Cardiovasc Phamacol 1989:14.51-S5.

26. Krieger JE, Dzau VJ. Molecular biology of hypertension. Hypertension $1991 ; 18: 13-117$.

27. Levy $\mathrm{BI}$, Benessiano J, Poitevin $\mathrm{P}$, Safar ME. Angiotensin-converting enzym inhibition and compliance of the carotid artery in normotensive and hypertensive rats $J$ Him Hypertens 1989; 3.557-\$62.

28. Hoeks APG, Brands PJ, Smeets FAM, Reneman RS. Assessment of distensibility of superficial arteries. Ultrasound Med Biol 1990; 16:121-128.

29. Hofstra L, Ermers EJM, Langeveld APM, Hoeks APG, Kitslaar PJEHM. Vessel Wall Doppler Tracking: A new technique to assess vessel wall compliance. $J$ Vasc Tech 1993; 17:65-68.

30. Reneman RS, Merode van T. Brands PJ, Hoeks APG. Inhomogeneities in arterial wall properties under normal and pathological conditions. $J$ Hypertens 1992; 10:S35-S39.

31. Armentano R, Simon A, Levenson J, Chau NP, Megnien JL, Pichel R. Mechanical pressure versus intrinsic effects of hypertension on large arteries in humans. Hypertension 1991; 18:657-664.

32. Dobrin PB. Mechanical properties of arteries. Physiol Rev 1987; 58:397-460.

33. Dobrin PB, Rovick A.A. Influence of vascular smooth muscle on contractile mechanics and elasticity of arteries. Am J Physiol 1969; 217:1644-1651.

34. Vatner SF, Pagani M, Manders WT, Pasipoularides AD. Alpha adrenergic vasoconstriction and nitroglycerin vasodilation of large coronary arteries in the concious dog. I Clin Invest 1980 ; $65: 5-14$.

35. Rubanyi GM, Freay AD, Kauser $K$, Johns A, Harder DR. Mechanoreception by the endothelium: Mediators and mechanisms of pressure- and flow-induced vascular responses. Bload Vessels 1990; 27:246-257.

36. Olesen SP, Clapham DE, Davies PF. Hemodynamic shear stress activates a $\mathrm{K}+$ current in vascular endothelial cells. Nature 1988; 331:168-170.

37. Furchgott RF, Vanhoutte PM. Endothelium-derived relaxing and contracting lactors. FASEB $J 1989 ; 3: 2007-2018$.

38. Asmar AG, Brunel PC, Pannier BM, Lacolley PJ, Safar ME. Arterial distensibility and ambulatory blood ptessure monitoring in essential bypentension. Am $f$ Cardiol 1988; 61:1066-1070.

39. Luscher TF. Imbalance of endothelium-derived relaxing and contracting factors. A new concept in hypertension? Am J Hypertens 1990; 3:317-330.

40. Ralevic V, Milner P, Hudlicka $O$, Kristek F, Bunstock G. Substance $P$ is released from the endothelium of nomal and capsaicin-treated rat hind-limb vasculature, in vivo, by increased flow. Circ Res 1990; 66:1178-1183.

41. Cooke $\mathbb{I P}$, Rossitch $\mathbb{E}$, Andon NA, Loscalzo J, Dzau VJ. Flow activates an endothelial potassium channel to release an endogenous nitrovasodilator. $J$ Clin Inves: 1991; 88:1663-1671 .

42. Buga GM, Gold ME, Fukuto IM, Ignarro LJ. Shear stress-induced release of nitric oxide from endothelial cells grown on beads. Hypertension 1991; 17:187 193.

43. Tesfamariam B, Cohen RA. Inhibition of adrenergic vasoconstriction by endothelial cell shear stress. Circ Res 1988; 63:720-725. 
44. Langille $B L$, O'Donnell $F$. Reductions in arterial diameter produced by chronic decreases in blood flow are endothelum-dependent. Science 1986:231:405-407.

45. Zarins CK, Zatina MA, Giddens DP, Ku DN, Glagov S. Shear stress regulation of artery lumen diameter in experimental atherogenesis. I Vase Surg 1987; 5:413-420.

46. Dza VI, Gibbons $\mathrm{GH}$, Praft RE. Molecular mechavisms of vascular renin-angiotensin system in myointimal hyperplasid. Hypertension 1991; 18:11100-II105.

47. Kurvers HAJM, Hofstra L, Hoeks APG, Wildenberg Van De FAJM, Kitslaar PJEHM, Jacobs MHHM. Sympathetic dysfunction in Sudeck's dystrophy assessed by Vessel Wall Echo Tracking. Eur $J$ Clin Invest 1992; 22:A8.

48. Fluckiger JP, Gremaud $G$, Waeber $B$, ef al Measurement of sympathetic nerve activity in the unanesthetized rat. I Appl Physiol 1989; 67:250-255.

49. Trazzi $S$, Omboni $S$, Santucciu $C$, Parati $G$, Mancia $G$. Variability in arterial diameter and compliance: compliance modulation reserve. I Hypertens 1992; 10.541-S43.

50. Kon V, Harris RC, Ichikawa I. A regulatory role for large vessels in organ circulation. I Clin Invest $1990 ; 85: 1728-1733$. 


\title{
CHAPTER 5
}

\section{ASSESSMENT OF INHOMOGENEITIES IN ELASTIC PROPERTIES OF IN SITU AND REVERSED SAPHENOUS VEIN GRAFTS IN HUMANS}

\author{
L Hofstra, DCJJ Bergmans, APG Hoeks, JHM Tordoir, PJEHM Kitslaar \\ Adapted from the European Journal of Vascular Surgery 1994; 8: 670-676
}

Wimer of the European Society of Vascular Surgery prize 1.993

for the best clinical paper

\section{ABSTRACT}

Background. In vascular surgery controversy remains concerning the optimal technique for the implantation of the saphenous vein graft to bypass peripheral atherosclerotic lesions. In comparison with the reversed graft, the in situ graft provides theoretical hemodynamic advantages due to its natural taper and the preservation of endothelial cell function.

Methods. Elastic properties of newly implanted in situ ( $\mathbb{S}$, $n=11)$ and reversed (RV, $\mathrm{n}=21$ ) saphenous grafts were studied with the use of Vessel Wall Doppler Tracking. From diameter, diameter change and simultaneously recorded pulse pressure, distensibility coefficient (DC) representing the intrinsic elastic properties and compliance coefficient (CC), a hemodynamic parameter, were calculated. In order to obtain a mechanical profile, the parameters were assessed in defined sites in the graft and native arterial system.

Results. In the $R V$ group the reversal of the grafts resulted in a difference in diameter around the proximal anastomoses $(7.4 \mathrm{vs} 4.3 \mathrm{~mm}, \mathrm{p}<0.01)$ and from proximal to distal (4.3 vs $5.9 \mathrm{~mm}, p<0.01$ ) in the grafts; around the distal anastomoses no differences in diameter were observed. Due to the natural taper of the in situ grafts, diameter decreased from proximal to distal in the grafts $(4.5 \mathrm{vs} 3.2 \mathrm{~mm}, \mathrm{p}<0.05$ ) and no size differences were found around the anastomoses. In the RV group a decrease was observed in DC from proximal to distal in the grafts. Around the anastomoses no differences in DC were apparent. In the IS group no change in DC was found from proximal to distal in the grafts; around the distal anastomoses a decrease in DC was observed. In the RV group a decrease in CC, representing the hemodynamic capacity, was observed in the proximal anastomoses $\left(0.25 \mathrm{vs} 0.09 \mathrm{~mm}^{2} / \mathrm{kPa}, \mathrm{p}<0.01\right)$. From proximall to distal in the graft and around the distal anastomoses no differences were 
found in hemodynamic capacity. In the IS group no change in hemodynamic capacity was observed around the proximal anastomoses and distal anastomoses. However, a decrease in the value of this parameter from proximal to distal in the grafts was found $\left(0.07 \mathrm{v} \$ 0.04 \mathrm{~mm}^{2} / \mathrm{kPa}, \mathrm{p}<0.05\right)$.

Conclusions. These results demonstrate that the elastic properties of newly inserted human saphenous vein grafts are comparable with native artery elastic properties. In contrast to the in situ technique, a mismatch in hemodynamic capacity is apparent around the proximal anastomoses using the reversed technique, indicating hemodynamic benefit in proximal anastomoses of in situ grafts. However, an important decrease in hemodynamic capacity is present in the in situ graft, whereas this parameter remains stable in the reversed grafts, suggesting intrinsic hemodynamic advantage in reversed grafts.

\section{INTRODUCTION}

The autologous saphenous vein is the material of choice to bypass atherosclerotic lesions in the superficial femoral, popliteal and crural arteries. Knowledge on the mechanical characteristic of grafts could be useful for various reasons. Controversy exists concerning the optimum technique for the implantantion of these grafts ${ }^{1-5}$. In theory, the in situ technique has advantages over the reversed technique. Due to its natural taper, the in situ graft offers a better diameter match around both the proximal and distal anastomoses as compared to the reversed graft, probably resulting in a better management of pulsatile flow. Total graft performance might therefore be better in in situ grafts leading to an improvement of distal perfusion ${ }^{6}$. Another important advantage of the in situ technique may be the protection of endothelial cell function due to the preservation of the vasa vasorum ${ }^{7}$. An intact endothelium inhibits platelet adherence and could maintain better mechanical control due to the release of relaxing factors ${ }^{8-10}$. Investigation of the mechanical characteristics of in situ and reversed grafts may verify these claims in favour of the in situ technique.

A second motive to study graft mechanical characteristics is the alleged relation between intimal hyperplasia and compliance mismatch around the anastomoses. Compliance mismatch between artery and graft leads to a region of excessive mechanical stretch, possibly resulting in wall injury ${ }^{11,12}$, a major event in the initiation of intimal hyperplasia ${ }^{13}$. In addition, a mismatch in compliance leads to flow disturbance and flow separation, both associated with increased intimal thickening ${ }^{14,15}$. Abbot demonstrated a decrease in patency rates in bypasses with low compliance in a canine model $^{11}$. However, occlusions of these grafts were not related to the presence of intimall thickening.

Measurements of compliance of saphenous vein grafts in humans have been performed in the past with the use of an ultra-sonic phase locked echo-tracking system. In a comparison of in situ and reversed saphenous vein grafts, slightly higher compliance values were found in in situ grafts ${ }^{1}$. However, in that study as well as in previous reports no information was provided on the definition of the sites of measurements of 
compliance ${ }^{16-18}$. This could possibly be the result of the limitations of the technique used. Furthermore, no information was provided on the differences in compliance around the anastomoses. This information is essential to get more insight in the influence of compliance mismatch around the anastomoses on the development of intimal hyperplasia. The values for compliance in saphenous vein grafts as found in these studies, were considerably lower as compared to native artery compliance values, implying a poor hemodynamic performance of the saphenous vein graft when subjected to arterial pressure.

Recently a new technique, Vessel Wall Doppler Tracking (VWDT), was developed to assess compliance and distensibility of large vessels and grafts ${ }^{19}$. An important advantage of VWDT over other techniques is that anatomical information can be obtained, allowing exact definition of the site of measurement. In addition, measurements of elastic properties of vessels situated as deep as $6 \mathrm{~cm}$ below the skin surface can be performed, permitting measurements of reversed bypass grafts in the anatomical positions. The aim of the present study was to assess the mechanical properties of newly inserted in situ and reversed saphenous vein grafts at defined sites in the graft and native arteries in order to obtain a mechanical profile. Furthermore, differences in elastic properties around the anastomoses were studied.

\section{MATERIALS AND METHODS}

\section{Patients}

Eligible for this study were patients undergoing a femoro-distal bypass operation with the use of autologous saphenous vein. Indications for operation were disabling claudication, restpain and/or ulceration. Before the elastic properties of the graft were measured, a Duplex scan was performed to test the proper functioning of the graft. Patients with evidence of graft related stenosis were excluded from this study. The detection of a stenotic lesion was based on generally accepted Duplex criteria ${ }^{20,21}$. The existence of stenotic lesions may lead to early pulse wave reflections ${ }^{22,23}$, probably disturbing the determination of a normal mechanical profile, by increasing pulse pressure proximal from the stenotic lesion.

\section{Measurements of the elastic properties}

The elastic properties of the graft and host artery were assessed with the use of Vessel Wall Doppler Tracking (VWDT). A detailed description of this system is given elsewhere (chapter 3 and 4) ${ }^{19,24}$. From distension (in $\mu \mathrm{m}$ ), diameter (in $\mathrm{mm}$ ) and simultaneously recorded blood pressure (Finapres, in $\mathrm{kPa}$ ) RD, DC and $\mathrm{CC}$ were calculated. Relative distension (RD) gives the fractional diameter increase. The distensibility coefficient (DC) represents the local stress-strain relationship of the arterial wall and is a measure for the local intrinsic elastic properties of the vessel. The compliance coefficient represents the capacity of the vessel to store blood volume during a cardiac cycle ${ }^{25}$. From each recording, containing information of $3-5$ heartbeats, the average values of the different parameters were used in this study. The 
variation coefficient within the recordings was always less than $5 \%$. In a previously conducted study, we observed short-term variations in the elastic properties of the common femoral artery in young healthy subjects ${ }^{26}$. The variation coefficients of elastic parameters like DC and CC ranged from $10-15 \%$ in this medium-sized muscular artery. These variations are probably caused by the contractile state of the vascular smooth muscle cells and probably contribute to the maintenance of pressure and flow homeostasis. In the common carotid artery, an artery of the elastic type, the variation coefficient was found to be between $5-10 \%$. So far, we do not know wether these short-term variations also occur in diseased vessels or saphenous vein grafts. However, the variations in vascular tone in diseased vessels and saphenous vein grafts are probably limited, and certainly do not exceed variations as observed in healthy muscular arteries. Although a variation coefficient of $5-1.0 \%$ has to be considered, we believe the measurements performed in the grafts are valid.

Figure 1: Sites of measurement in the graft and in- and outflow arterial segments.

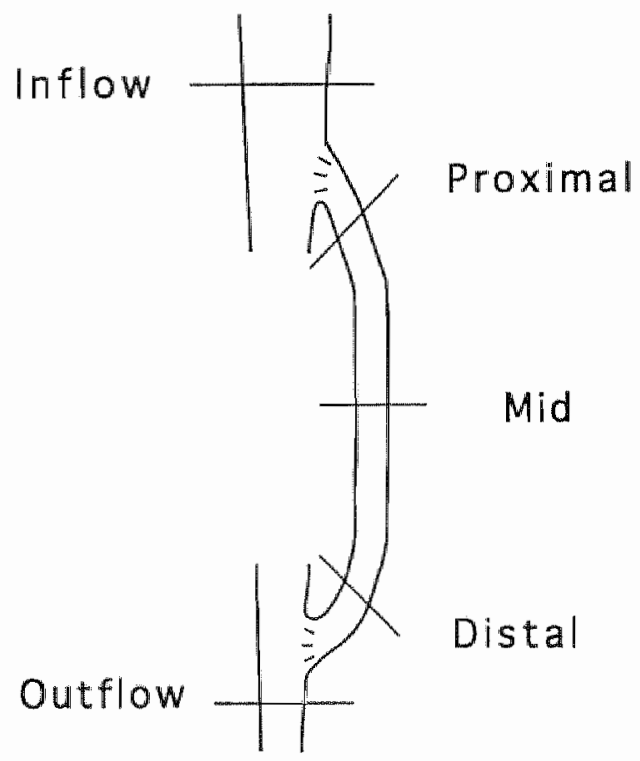

The Finapres device has been walidated for blood pressure values in the brachial artery of healthy volunteers ${ }^{27}$. However, a validation study comparing Finapres and intraarterial blood pressure values at the lower limb in patients with diseased vessels has not been reported so far. We therefore decided to assess the elastic properties of the common femoral artery in a group of patients $(n=20)$ with severe atherosclerotic lesions in the lower limb. DC and $C C$ values were calculated with the use of pulse pressure values obtained at the middle finger using Finapres and intra-arterially 
obtained pulse pressure values at the common femoral artery. Consistently, DC and CC values were higher when Finapres values were used in the calculation of these parameters (mean DC 8.1 vs $6.010^{-3} / \mathrm{kPa}$ and mean CC: 0.331 vs $0.238 \mathrm{~mm}^{2} / \mathrm{kPa}$ ). Regression analysis revealed an excellent correlation between the two ways to calculate DC and CC (for DC: $\mathrm{r}=0.93, \mathrm{p}<0.001$ and for $\mathrm{CC}: \mathrm{r}=0.91, \mathrm{p}<0.001$ ). We therefore considered the use of Finapres values in the calculation of $D C$ and $C C$ justified. In each graft measurements were performed proximal $(1 \mathrm{~cm}$ distal to the proximal anastomosis), in the middle segment, and distal $(1 \mathrm{~cm}$ proximal to the distal anastomosis). The inflow artery was measured $1 \mathrm{~cm}$ proximal to the proximal anastomosis, the outflow artery $1 \mathrm{~cm}$ distal to the distal anastomosis (Figure 1).

Patients were measured in the supine position after an acclimatisation period of 20 minutes. All patients gave a written informed consent before entering the study. The study was approved by the medical ethical committee of our Hospital.

\section{ANALYSIS}

Data are presented as medians and $25 \mathrm{th}$ and 75 th percentile intervals. Within the groups the values of $R D, D C, C C$ and diameter measured at the defined sites in the graft and in- and outflow arterial segment, respectively, were compared using the Wilcoxon signed rank test. Since patients were not randomly assigned to either of the groups, a direct comparison of in situ and reversed grafts at the defined sites was not performed. A p-value of less than 0.05 was accepted as level of statistical significance.

\section{RESULTS}

The patient characteristics of both groups are summarized in Table I. Surprisingly, in the in situ group most patients were female, in contrast to the reversed group. Of importance is the large fraction of proximal anastomoses on the superficial femoral artery in the in situ group. The values of diameter, RD, DC and CC for the reversed and in situ group are summarized in table II and depicted in figure 2. 
Table I: Patuent characteristics.

\begin{tabular}{|c|c|c|c|}
\hline \multirow[b]{2}{*}{ Wolle } & $\begin{array}{c}\text { Reversed VSM } \\
\qquad(\mathbb{N}=21)\end{array}$ & \multicolumn{2}{|c|}{$\begin{array}{l}\text { In Situ } \\
(\mathrm{N}=11)\end{array}$} \\
\hline & $(76.2 \%)$ & 3 & $(27.3 \%)$ \\
\hline Female & $(23.8 \%)$ & 8 & $(72.7 \%)$ \\
\hline Age & $71.1 \quad(S D 8.8)$ & 72.6 & $(S D 7.3)$ \\
\hline Diabetic & $3 \quad(14.3 \%)$ & 2 & $(18.2 \%)$ \\
\hline \multicolumn{4}{|l|}{ Clinical stage: } \\
\hline III & $(28.6 \%)$ & 2 & $(18.2 \%)$ \\
\hline III & $(38.1 \%)$ & 3 & $(27.3 \%)$ \\
\hline IV & $(33.3 \%)$ & 6 & $(54.4 \%)$ \\
\hline \multicolumn{4}{|l|}{ Proximal Anastomosis : } \\
\hline Common Femoral Artery & $(66.7 \%)$ & 3 & $(27.3 \%)$ \\
\hline Superficial Femoral Artery & $(33.3 \%)$ & 8 & $(72.7 \%)$ \\
\hline \multicolumn{4}{|l|}{ Distal. Anastomosis : } \\
\hline Popliteal Artery (above knee) & $(19.0 \%)$ & 2 & $(18.2 \%)$ \\
\hline Popliteal Artery (below knee) & $(42.9 \%)$ & 2 & $(18.2 \%)$ \\
\hline Crural & $(38.1 \%)$ & 6 & $(54.5 \%)$ \\
\hline Pedal & $0 \quad(0.0 \%)$ & 1 & $(9.1 \%)$ \\
\hline
\end{tabular}

Table II: Values (medians and 25 th and 75 th percentile interval) for diameter (DI), relative distension (RD), distensibility coefficient (DC) and compliance coefficient (CC) assessed at defined sites in the graft and in and outflow arterial system for the reversed and in situ grafts.

\begin{tabular}{|c|c|c|c|c|c|}
\hline & lnflow & Proximal & Mid & Distal & Outfllow \\
\hline \multicolumn{6}{|l|}{ DI (mm): } \\
\hline Reversed & $7.4(5.5 .9 .9)$ & $4.3(3.2-5.7)$ & $53(4.4-60)$ & $5.9(4.6-6.8)$ & $4.8(3.2 .5 .3)$ \\
\hline In situ & $5.7(4.8-7.7)$ & $4.5(3.9-5.6)$ & $4.1(3.6-5.5)$ & $32(2.6-4.3)$ & $3.5(2.4-6.8)$ \\
\hline \multicolumn{6}{|l|}{$\operatorname{RD}(\%)$} \\
\hline Reversed & $26(1.7-3.7)$ & $3.8(2.11-4.6)$ & $1.9(1.3-3.5)$ & $1.6(1.1 \cdot 2.7)$ & $1.6(1.1-2.6)$ \\
\hline In situ & $3.1(2.5-4.8)$ & $2.9(2.2-3.5)$ & $4.8(3.2-6.6)$ & $2.9(1.7-4.6)$ & $1.7(0.5-3.4)$ \\
\hline \multicolumn{6}{|c|}{$\mathrm{DC}\left(10^{\circ} / \mathrm{kPa}\right)$} \\
\hline Reversed & $5.3(2.6-7.2)$ & $5.8(3.8-9.8)$ & $3.7(2.2 .5 .3)$ & $2.8(1.9-4.1)$ & $2.9(1.7-4.1)$ \\
\hline In situ & $4.7(3.4-8.3)$ & $4.2(3.0 \times 7.9)$ & $7.4(4.2-11.3)$ & $5.2(3.2-7.4)$ & $2.5(0.8-4.4)$ \\
\hline \multicolumn{6}{|c|}{$\mathrm{OC}\left(\mathrm{mm}^{2} / \mathrm{kPa}\right):$} \\
\hline Reversed & $0.26(0.16-0.71)$ & $0.09(0.05-0.16)$ & $0.07(0.05-0.13)$ & $0.07(0.05-0.09)$ & $0.03(0.02-0.04)$ \\
\hline In situ & $0.15(0.09-0.40)$ & $0.08(0.06 \times 0.14)$ & $0.11(0.05-0.28)$ & $0.04(0.03-0.06)$ & $0.02(0.01-0.05)$ \\
\hline
\end{tabular}


Figure 2: Bar graphs showing the results of measurement of diameter (DI), relative distension (RD), distensibility coefficient (DC) and compliance coefficient (CC) measured at the proximal (Prox), mid (Mid) and distal (Dist) segments of the grafts and in the inflow (Inff) and outflow (Outf) arterial segments ( $\ldots *-$, , p<0.05, Wilcoxon signed rank test).
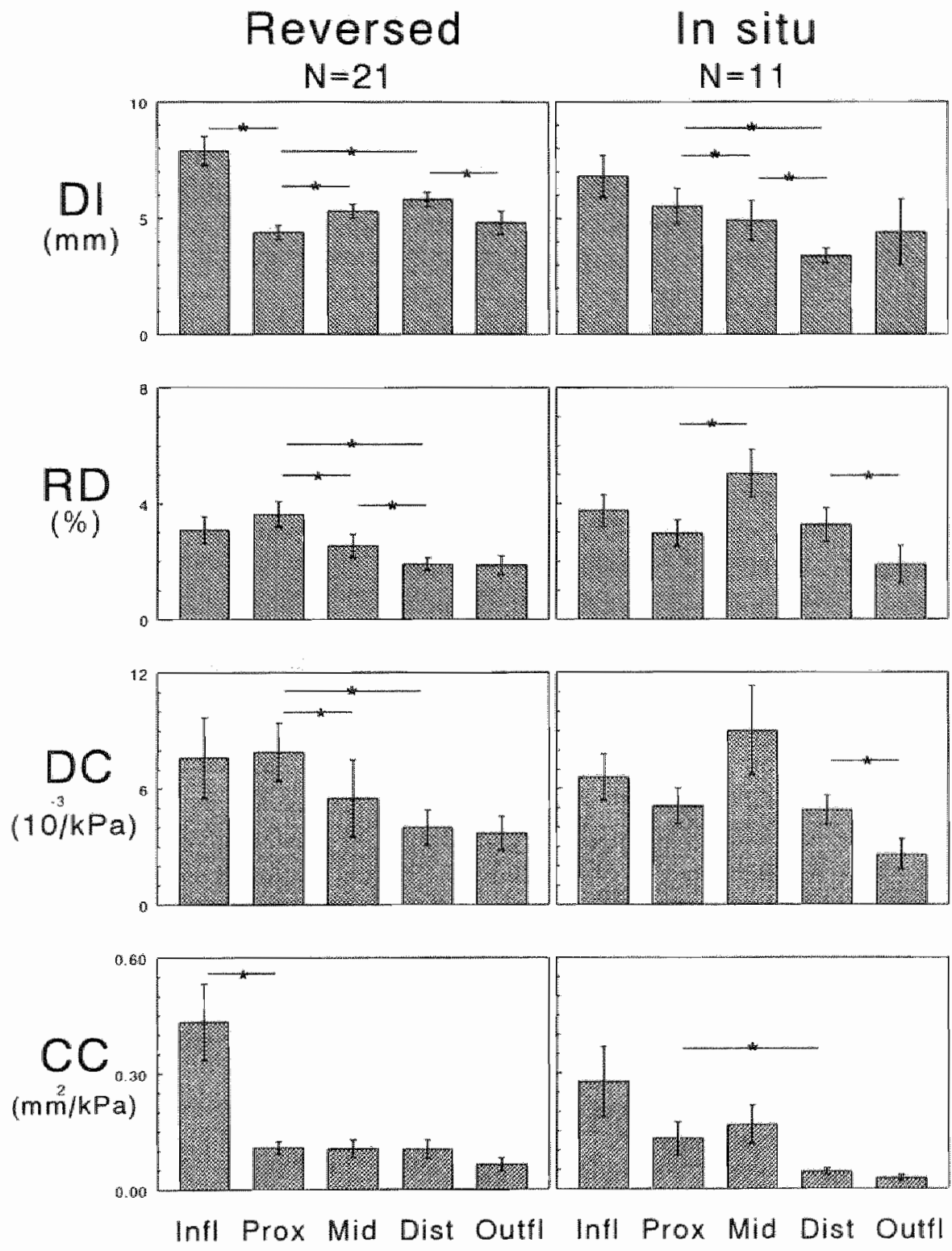
Reversed group. The proximal graft diameter $(4.3 \mathrm{~mm})$ was smaller as compared to the diameter of the arterial inflow segments $(7.4 \mathrm{~mm}, \mathrm{p}<0.05)$. The effect of reversed tapering is illustrated by a gradual increase in diameter from proximal $(4.3 \mathrm{~mm})$ to distal $(5.9 \mathrm{~mm}, \mathrm{p}<0.05)$ in these grafts. A difference in diameter was observed around the distal anastomoses (5.9 in the distal part of the grafts vs $4.8 \mathrm{~mm}$ in the arterial outflow segments, $\mathrm{p}<0.05$ ). No significant differences in RD were found between the proximal graft segments $(2.6 \%)$ as compared to the inflow segments $(3.8 \%)$. A gradual decrease in RD was found from proximal $(3.8 \%)$ to distal $(1.6 \%, \mathrm{p}<0.05)$ in the grafts. Around the distal anastomoses no significant difference in RD could be observed. For DC a similar pattern was found; no significant difference in DC around the proximal anastomoses, a gradual decrease in DC from proximal $\left(5.810^{-3} \mathrm{kPa}^{-1}\right)$ to distal $\left(2.810^{-3} \mathrm{kPa}^{-1}, \mathrm{p}<0.05\right)$ in the grafts and no significant difference around the distal anastomoses. The compliance coefficient (CC) was larger in the inflow arterial segments $\left(0.26 \mathrm{~mm}^{2} / \mathrm{kPa}\right)$ as compared to the proximal segments of the grafts $(0.09$ $\left.\mathrm{mm}^{2} / \mathrm{kPa}, \mathrm{p}<0.05\right)$. CC remained stable from proximal to distal in the grafts. Around the distal anastomoses no significant differences in $\mathrm{CC}$ were apparent.

In situ group. No significant difference in diameter was observed between the arterial inflow segments $(5.7 \mathrm{~mm})$ and the proximal segments of the graft $(4.5 \mathrm{~mm})$ but a decrease in diameter was found from proximal $(4.5 \mathrm{~mm})$ to distal $(3.2 \mathrm{~mm}, \mathrm{p}<0.05)$ in the grafts, illustrating the natural taper of in situ grafts. Around the distal anastomoses no significant size differences were found. Around the proximal anastomoses no significant differences were apparent in RD and DC. In the course of the vein graft an increase in RD was found between the proximal segments of the grafts and the middle segments $(2.9$ vs $4.8 \%, \mathrm{p}<0.05)$. In the distal segments of the graft the median values for $\mathrm{RD}$ and $\mathrm{DC}$ were higher as compared to the arterial outflow segments. In $\mathrm{CC}$ no significant difference was observed between the proximal segments and the arterial inflow segments. A decrease in $\mathrm{CC}$ was apparent from proximal to distal in the grafts $\left(0.08 \mathrm{vs} 0.04 \mathrm{~mm}^{2} / \mathrm{kPa}, \mathrm{p}<0.05\right)$. Around the distal anastomoses no significant differences in $\mathrm{CC}$ were found.

\section{DISCUSSION}

The aim of this study was to obtain profiles of elastic characteristics of newly implanted in situ and reversed saphenous vein grafts. The major finding of this study is the proper elastic properties of the saphenous vein, when subjected to arterial pressure. Along the entire length of either the in situ or reversed graft the strain and the intrinsic elastic properties of the saphenous vein, represented by RD and DC respectively, were comparable with native artery elastic properties. This is in contrast with most studies evaluating saphenous vein mechanical function in the arterial system. In a canine model low passive compliance values of saphenous vein grafts, when subjected to arterial pressures, have been reported ${ }^{28}$. In a study evaluating compliance in in situ and reversed saphenous vein grafts in humans with the use of a phase-locked 
echo tracking system the values of compliance were found to be half those of native arteries". However, no direct comparison was made between elastic properties of the graft and the native arteries, which could explain the differences between their observations and ours. Lüscher demonstrated a diminished endothellum dependent relaxation to acetylcholine (ACH) in human vein grafts as compared to internal mammary artery response, suggesting endothelial cell dysfunction of grafted saphenous veins $^{29}$. This could possibly lead to a reduction in endothelium derived relaxing factor release resulting in smooth muscle contraction. A recent study reported a diminished endothelium dependent relaxation to $\mathrm{ACH}$ in newly implanted vein grafts indicating endothelial cell. dysfunction. However, in that study a pieservation of endothelium dependent relaxation to other agents was demonstrated ${ }^{30}$. The preservation of active control of the endothelium on relaxation of grafts subjected to arterial pressures is in concordance with our finding that the elastic properties of the saphenous vein under these conditions are good. Most of our patients were investigated within 14 days after operation. Whether the proper elastic properties of the saphenous vein can be maintained with time is unclear. A longitudinal study is needed to elucidate this issue ${ }^{28,31}$.

The assessment of elastic profiles in the reversed and in situ vein grafts provided valuable information. In the reversed vein grafts the reversal resulted in diameter mismatch around the proximal anastomoses and an increase in diameter along tho grafts from proximal to distal. For $\mathrm{RD}$ and $\mathrm{DC}$, representing the strain and intrinsic elastic properties of the graft respectively, comparable values were found in the proximal segments and the arterial inflow segments. However, RD and DC values of the proximal segments were higher as compared to distal values. This suggests a compensatory mechanism for the small diameter of the proximal segments in order 10 achieve a sufficient hemodynamic capacity in this part of the graft. This is supported by the finding that along the grafts a remarkable stable pattern was found in $\mathrm{CC}$. This compensatory mechanism could be initiated by an increased flow velocity in the narrow proximal segment of the grafts ${ }^{32}$. Elevations in shear stress caused by a high flow velocity leads to a release of relaxing factors (c.g. EDRF) by the endothelium ${ }^{33}$. These relaxing factors may change the local intrinsic elastic properties by altetations in vascular smooth muscle tone resulting in higher $\mathrm{RD}$ and $\mathrm{DC}$ values in the narrow proximal segments as compared to the distal segments.

The mismatch in compliance around the proximal anastomoses of reversed grafts thas to be attributed solely to the diameter reduction, since intrinsic elastic properties of the proximal part of the grafts are sufficient. In reports evaluating sites of stenoses in reversed bypass grafts, $40 \%$ of stenotic lesions were found in the proximal part of the graft, just distal to the anastomosis ${ }^{37,38}$. This might be explained by our finding, that an abrupt decrease in cross-sectional compliance is present in the proximal anastomoses of reversed vein grafts. However, a prospective study is needed to clarify the exact relation between compliance mismatch around the proximal anastomoses of reversed vein grafts and occurrence of stenotic lesions at this site. The mismatch in diameter 
between the distal graft segments and the outflow arteries is due to the reversed tapering of the saphenous vein. Since no difference in $\mathrm{CC}$ was found around the distal anastomoses, the observed diameter mismatch probably will not have major hemodynamic consequences.

In the in situ vein grafts a congruent transition in elastic properties from inflow segment to the proximal segment of the graft was observed. In diameter as well as in $\mathrm{RD}, \mathrm{DC}$ and $\mathrm{CC}$ no significant differences were found between these sites. The strain and intrinsic elastic properties of the proximal graft segments, represented by RD and DC respectively, are comparable with the values of these parameters in the reversed group. This implicates that the gradual transition in $C C$ has to be attributed to a diameter match rather than differences in intrinsic elastic properties. The congruent pattern in $\mathrm{CC}$ around the proximal anastomosis suggests hemodynamic benefit. The in situ group demonstrated a decline in $\mathrm{CC}$ from proximal to distal in the graft. This is in contrast to the stable pattern of $\mathrm{CC}$ in the reversed graft, indicating intrinsic hemodynamic advantage of reversed vein grafts compared to the in situ graft. In both the in situ as the reversed vein graft the total hemodynamic performance of a graft seems to be restricted by its narrowest segment.

Part of the differences in profiles of in situ and reversed grafts in the present study may originate from differences in proximal and distal anastomotic levels between the groups. In the in situ group, the majority of the proximal anastomoses were constructed at the superficial femoral artery level, resulting in a proper diameter match around the proximal anastomosis. Since $\mathrm{CC}$ is strongly diameter dependent, this might partly explain the absence of a difference in $\mathrm{CC}$ between arterial inflow segment and proximal graft segment in the in situ group. Relatively more of the distal anastomoses in the in situ group were constructed at crural and pedal level, limitting total graft performance.

The use of pulse pressure values obtained with the use of Finapres may be a limitation of the present study. Our validation study revealed consistently higher DC and CC values calculated with the Finapres derived pulse pressures as compared to values calculated using intra-arterially obtained pulse pressures at the common femoral artery in a group of patients with severe atherosclerotic lesions of the lower limb. As a consequence, the values for $\mathrm{DC}$ and $\mathrm{CC}$ in the present study probably overestimate the actual compliance and distensibility. In the comparison of $D C$ and $C C$ values within the graft, this difference does not play a significant role, since for different sites in the same graft an equal pulse pressure is likely. The main advantage of the Finapres device compared to other non-invasive techniques to measure blood pressure is that beat-to-beat information is provided. In bypass patients, blood pressure may vary considerably due to sudden changes in cardiac performance and therefore beat-to-beat information instead of fragmentarily sphygmomanometric recordings is preferable.

In conclusion, the present study demonstrates that the intrinsic elastic properties of newly inserted saphenous vein grafts are comparable with native artery elastic properties. In contrast to the in situ grafts, compliance mismatch was found around the 
proximal anastomoses of reversed grafts which has to be attributed entirely to differences in diameter caused by the reversal of the graft. This finding suggests hemodynamic benefit of the proximal anastomoses of in situ grafts. Allong the graft a remarkable stable pattern in compliance was observed in the reversed graft, whereas the in situ graft showed an important decrease in compliance, indicating intrinsic hemodynamic advantage of the reversed graft. Prospective studies are needed to study the effect of inhomogeneities in elastic properties of saphenous vein grafts on graft complications such as intimal hyperplasia. 


\section{REFERENCES}

1. Harris PL, How TV, Jones DR. Prospectively randomized clinical trial to compare in situ and reversed saphenous wein grafts for femoropopliteal bypass. Br J Surg 1987; 74:252-255.

2. Harris RW, Andros G, Dulawa LB, Oblath RW, Apyan R, Salles-Cunha S. The transition to "in situ" vein bypass grafts. Surg Gynecol Obstet 1986; 163.21-28.

3. Levther RP, Shath DM, Chang BB, Kaufman IL. Resturrection of the in situ saphenous vein bypass. 1000 cases later. Ann Surg 1988; 208:435-442.

4. Buchbinder D, Rolins DL, Verta MJ, et all. Early experiance with in situ saphenous vein bypass for distal arterial reconstruction. Surgery 1986; $99: 350 \cdots 356$.

5. Hartis PI, Veith FJ, Shanik GD, Not D, Wengerter KR, Moore DI. Prospective randomized comparison of in situ and reversed infrapopliteal vein grafts. $B r d$ Surg 1993, 80:173-176.

6. ORourke MF. Steady and pulsatile energy losses in the systemic circulation under normal conditions and in simulated arterial disease. Cardiovasc Res 1967; 1:313-326.

7. Cambria RP, Megerman J, Abbott WM. Endothelial preservation in reversed and in situ autogenous vein grafts. Ann Surg 1985; 202.50-55.

8. Lüscher TF. Endothelial control of vascular tone and growth. Clin Exp Hypertens 1990; 12.897 .902 .

9. Dzau VJ, Safar ME. Large conduit arteries in hypertension: role of the vascular renin-angiotensin system. Circulation 1988; 77:947.954.

10. Laurent $\mathrm{S}$, London GM, Safar ME. Increased response of the brachial arteriall diameter to norepinephrine in essentiall hypertension: Preliminary report. $J$ Hypertens 1986; 4:237-239.

11. Abbott WM, Megerman J, Hasson JE, Lltalien G, Warnock DF. Effect of compliance mismatch on vascular graft patency. $J$ Vasc Surg 1987; 5.376-382.

12. Bassiouny HS, White $S$, Glagov S, Choi E, Giddens DP, Zarins CK. Anastomotic intimal hyperplasia: Mechanical injury or flow induced. J Vasc Surg 1992; 15:708-717.

13. Clowes AW, Reidy MA. Prevention of stenosis after vascular reconstruction: Pharmacologic control of intimal hyperplasia - A review. J Vasc Surg 1991; 6:885-891.

14. Stewart SFC, Lyman DJ. Effects of a vascular graft/natural artery compliance mismatch on pusatile flow. I Biomech 1992; 25:297-310.

15. Kohler TR, Kirkman TR, Kraiss LW, Zierler BK, Clowes AW. Increased blood flow inhibits neointimal hyperplasia in endothelialized wascular grafts. Circ Res 1991; 69:1557-1565.

16. Hokanson DE, Strandness DE. Stress-strain characteristics of various arterial grafts. Surg Gynecol Obstet $1968 ; 57.60$.

17. Hokunson DE, Mozersky DJ, Sumner DS, Strandness DE A phase-locked echo tracking system for recording arterial diameter changes in vivo. J Appl Physiol 1972; 32:728-733.

18. Lye CR, Sumner DS, Hokanson DE, Strandness DE. The transcutaneous measurement of the elastic properties of the human saphenous vein fenoropopliteal bypass graft. Surg Gynecol Obstet 1975; 141:891-895.

19. Hoeks APG, Brands PJ, Smeets FAM, Reneman RS. Assessment of distensibility of superficial arteries. Ultrasound Med Biol 1990; 16:121-128.

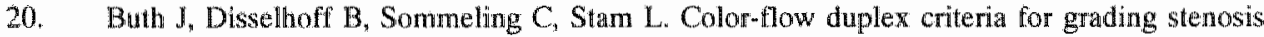
in infrainguinal wein grafts. $J$ Vasc Surg $1991 ; 14: 716-728$.

21. Chang BB, Leather RP, Kaufman JL, Kupinski AM, Leopold PW, Shah DM. Hemodynamic characteristics of failing infrainguinal in situ vein bypass. $J$ Vasc Surg $1990 ; 12: 596-600$.

22. ORourke MF. Systolic blood pressure: arterial compliance and early wave reflection, and their modification by antihypertensive therapy. I Hum Hypertens 1989; 3:47-52.

23. Kelly RP, Gibbs HH, O'Rourke MF, et al. Nitroglycerin has more favourable effects on left ventricular afterload than apparent from measurement of pressure in a peripheral artery. Eur Heart I 1990; 11:138-144. 
24. Horstra L, Ermers EJM, Langeveld APM, Hoeks APG, Kitslaar PJEHM. Vessell Wall Doppler Tracking: A new technique to assess vessel wall compliance. $J$ Vasc Tech $1993 ; 17,65-68$.

25. Reneman RS, Merode van T, Brands PJ, Hoeks APG. Inhomogeneities in arteriall wall properties under normal and pathological conditions. J Hypertens 1992; 10.535-539.

26. Hofstra L, Willigers JM, Huvers FC, et all. Short-term variations in elastic properties of a muscular artery in humans. Clin Sci 1993; 50:472-480.

27. Imbolz BPM, Settels JJ, Meiracker varu der $\mathrm{AH}$, Wesseling $\mathrm{KH}$, Wieling $\mathrm{W}$. Non-invasive continuous finger blood pressure neasurement during orthostatic stress compared to intra-arterial pressure. Cardiovasc Res $1990 ; 24: 214-221$.

28. Dobrin PB, Littooy FN, Golan J, Blakeman B, Fareed J. Mechanical and histological changes in canine vein grafts. I Surg Res 1988; 44:259-265.

29. Lüscher TF, Diederich D, Siebeenman $R$, et al. Difference between endothelium-dependent relaxation in arterial and venous coronary bypass grafts. New Eng $J$ Med 1988; 319:462-467.

30. Ishii T, Okadome $\mathrm{K}$, Komori K, Odashiro T, Sugimachi $\mathrm{K}$. Natural course of endotheliun-dependent and -independent responses in atogenous femoral veins grafted into the arterial circulation of the dog. Circ Res 1993; 72:1004-1010.

31. Abbott WM, Megerman J. Adaptive responses of arteries to grafting. J Vasc Surg 1989; 9.377-379.

32. Belkin $M$, Mackey $W C$, McLaughlin $R$, Umphrey SE, ODonnell TF. The variation in vein graft flow velocity with luminal diameter and outflow level. J Vasc Surg 1992; 15:991-999.

33. Cooke JP, Rossitch E, Andon NA, Loscalzo J, Dzau VI. Flow activates an endothelial potassium channel to release an endogenous nitrovasodilator. $J$ Clin Invest $1991 ; 88: 1663-16$. 71 .

34. Buga GM, Gold ME, Fukuto JM, Ignarro $\mathbb{L}$ J. Sthear stress-induced release of nitric oxide from endothelial cells grown on beads. Hypertension 1991; 17:187-193.

35. Olesen SP, Clapham DE, Davies PF. Hemodynamic shear stress activates a $K+$ current in vascular endothelial cells. Nature 1988; 331:168-170.

36. Rubanyi GM, Freay AD, Kauser K, Johns A, Harder DR. Mechanoreception by the endothelium: Mediators and mechanisms of pressure- and flow-induced vascular responses. Blood Vessels 1990; 27:246-257.

37. Berkowitz HD, Greenstein S, Barker CF, Perloff LJ. Late failure of reversed vein bypass grafts. Ann Surg 1989; 210:782-786.

38. Berkowitz HD, Fox AD, Deaton DH. Reversed vein graft stenosis: Early diagnosis and management. J Vase Surg 1992; 15:130-142. 



\title{
MECHANICAL PROFILES OF POLY TETRA-FLUORO- ETHYLENE AND SAPHENOUS VEIN ARTERIAL BYPASS GRAFTS IN HUMANS
}

\author{
L Hofstra, DCJJ Bergmans, APG Hoeks, JHM Tordoir, and PJEHM Kitslaar. \\ (submitted)
}

\begin{abstract}
Background. Mechanical conditions, like peri-anastomotic mismatch in elastic properties, may be associated with the occurrence of stenosis in peripheral bypass grafts. Quantitative in vivo information on elastic properties in peripheral bypass grafts in humans is scarce. We studied peri-anastomotic elastic properties of poly-tetra-fluoroethylene (PTFE) grafts and reversed saphenous vein grafts with a new ultrasound technique.
\end{abstract}

Methods. In 15 patients with a PTFE bypass graft and 15 matched patients with a reversed saphenous vein bypass graft, the diameter and distension of vessel segments was determined at defined sites in the graft and native arterial system with the use of Vessel Wall Doppler Tracking. From diameter and distension we calculated relative distension (RD in \%) and cross-sectional area-increase (AI in $\mathrm{mm}$ ) for all.

Results. AI and RD values were hugher in the saphenous vein grafts as compared to the PTFE grafts for both the proximal and the distal graft segments $(p<0.05)$. Higher RD and AI values were found in the proximal segments of PTFE grafts as compared to the distal segments $(\mathrm{p}<0.05)$. In both the reversed saphenous vein and PTFE grafts a decrease Al was observed from the inflow artery to the proximal graft segment $(p<0.05)$. No differences in AI and RD were found around the distal anastomosis of the saphenous vein grafts. In contrast, considerable increase in AI and RD was observed from the distal graft segment to the outflow artery in the PTFE grafts.

Conclusions. Local strain and cross-sectional area increase were higher in the proximal graft segments of PTFE grafts as compared to the distal graft segments. A possible explanation may be that the proximal PTFE graft segment is passively distended by the inflow artery, which is supported by the finding that a positive correlation between distension of the inflow arterial segments and distension of the proximal graft segments was observed $(r=0.69, p=0.01)$. 


\section{INTRODUCTION}

The implantation of a bypass graft in the peripheral arterial circulation in order to reestablish sufficient flow to the lower limb may lead to vascular regions where sudden changes in elastic properties are present, especially at the site of the anastomo$\operatorname{ses}^{1.7}$. Differences in elastic properties around the anastomoses, have been associated with the occurrence of intimal hyperplasia at these sites 8.14 . Peri-anastomotic differences in elastic properties may lead to a point of excessive mechanical stretching at the anastomoses leading to vessel wall injury, which may initiate a vascular response. Despite general acceptance of the compliance mismatch theory among vascular surgeons, no conclusive studies have been reported demonstrating a correlation between mismatch and the development of stenoses'. Attempts to evaluate the effect of mismatch in elastic properties between graft and native vessels on intimal hyperplasia in animal models have failed to demonstrate an association, which may be explained by the fact that occlusive intimal hyperplasia does not develop in animals ${ }^{15.17}$. Investigation of a possible association between mismatch in elastic properties and intimal hyperplasia in humans has been hampered by the lack of a suitable system to assess elastic properties at defined sites around the anastomoses of the grafts in vivo ${ }^{18,19}$. As a consequence, quantitative information on dimensions and elastic properties around the anastomoses is scarce.

With the introduction of Vessel Wall Doppler Tracking (VWDT), distension parameters of large vessels can be assessed at predefined sites ${ }^{20,21}$. This system includes B-mode imaging, which allows selection of sites for measurements with acceptable accuracy. We investigated mechanical profiles of newly inserted polytetrafluoroethylene (PTFE) and saphenous vein bypass grafts in humans with the use of VWDT. Attention was focused on the assessment of elastic properties around anastomoses to obtain insight in the differences in elastic properties around the anastomoses of the PTFE and saphenous vein bypass grafts. In addition, peak systolic velocity was measured at the same defined sites in the vascular conduit and native arteries.

\section{MATERLALS AND METHODS}

\section{Patients}

Patients with arterial insufficiency of the lower extremity as manifested by disabling claudication, restpain and/or tissue loss and receiving a PTFE or reversed saphenous vein femorodistal bypass graft were considered candidates for our study. The PTFE and reversed saphenous vein group were matched for sites of anastomosis and clinical stage (Table I). The patients with reversed saphenous vein bypass grafts were selected from a group of 32 consecutive patients. The function of the graft was tested with the use of a Duplex scan before the patients entered the study. Patients with evidence of graft related stenosis were excluded from this study, since a stenosis could alter the hemodynamics of the graft by influencing pulse wave reflections ${ }^{22}$. Fifteen consecutive patients with a PTFE graft and 15 matched patients with a reversed saphenous vein 
graft entered the study. Patients were not randomly assigned to either PTFE or reversed vein implantation. The choice for either PTFE or reversed saphenous vein graft was based on the quality of the veins suitable for grafting and/or the site of the distal anastomoses. Thin-walled ringed $6 \mathrm{~mm}$ PTFE grafts were used (Goretex, Flagsiaff, Arizona, USA). Both types of grafts were implanted using standard techniques and were inserted in an end-to-side fashion with running $6 \times 0$ Prolene sutures.

Table I: Patient characteristics of the PTFE and reversed saphenous vein group. The distribution of proximal and distal anastomoses, of special importance in this mechanical study, is equal.

\begin{tabular}{|c|c|c|}
\hline & PTFE $(n=15)$ & Reversed $(n=15)$ \\
\hline Male & 13 & 12 \\
\hline Female & 2 & 3 \\
\hline Age $($ Yrs $\pm S D)$ & $68(7.0)$ & $67(7.3)$ \\
\hline Diabetic & 6 & 5 \\
\hline \multicolumn{3}{|l|}{ Clinical stage: } \\
\hline II & 7 & 7 \\
\hline III & 4 & 3 \\
\hline IV & 4 & 5 \\
\hline \multicolumn{3}{|l|}{ Proximal Anastomosis : } \\
\hline Common Femoral Artery & 15 & 15 \\
\hline \multicolumn{3}{|l|}{ Distal Anastomosis : } \\
\hline Popliteal Artery (above knee) & 7 & 7 \\
\hline Popliteal Artery (below knee) & 4 & 4 \\
\hline Crural & 4 & 4 \\
\hline
\end{tabular}




\section{Measurements of the elastic properties}

The dirnensions and distension parameters of the graft and native artery were assessed with the use of Vessel Wall Doppler Tracking (VWDT). A detailed description of this system is given elsewhere (chapter 3 and 4 ) ${ }^{20,21}$. From distension (in $\mu \mathrm{m}$ ) and diameter (in mm), the following parameters were calculated:

Relative Distension $(R D)=\frac{\Delta D}{D} * 100 \%$

Area - Increase $(A D)=\frac{\pi \Delta d * D}{2}$

Relative distension (RD) gives the local strain of the vessel wall. Area-increase (AI) represents the capacity of the vessel to store and to release temporarily blood volume during the cardiac cycle ${ }^{23}$. Usually these parameters are expressed per unit of pressure, resulting in the distensibility coefficient and compliance coefficient respectively. Noninvasive assessment of pressure values is possible at the finger (Finapres, volumeclamp technique) or at the arm (Dynamap, automatic cuff device). These system have been validated with intra-arterially obtained pressures at the brachial artery, showing good correlations ${ }^{24}$. However, the estimation of pulse pressure values in the peripheral bypass from pressure values obtained at the finger or the arm in order to calculate compliance and distensibility in the graft is questionable. First of all we do not know to what extent the pulsatile character of pressure changes over diseased vessel segments. Furthermore, the systolic pressure values may change when a small caliber vessel, like the reversed saphenous vein is anastomosed to a large caliber vessel like the femoral artery. The anastomoses may serve as a reflection point, leading to unpredictable behavior of pressure ${ }^{25-27}$. Since invasive assessment of pressure at different sites in the graft is not acceptable, we decided not to express local strain and area-increase per unit of pressure in this study. To investigate the ability of the VWDT system to detect small distensions of vessels, we tested the system in an in vitro setting. A proper distension waveform was obtained with distension values as low as $1 \mathrm{~mm}^{2}$. This indicates that expected low distension values in PTFE grafts can be properly measured with the use of Vessel Wall Doppler Tracking.

In each graft measurements were performed proximal $(1 \mathrm{~cm}$ distal to the proximal anastomosis), in the middle segment, and distal $(1 \mathrm{~cm}$ proximal to the distal anastomosis). The inflow artery was measured $1 \mathrm{~cm}$ proximal to the proximal anastomosis, the outflow artery was measured $1 \mathrm{~cm}$ distal to the distal anastomosis (Figure 1). Proper selection of the sites of measurements was performed with the use of repeated B-mode imaging. Systolic and diastolic pressure were monitored, using a Finapres device (Ohmeda 2300, Ohmeda Monitoring Systems, Englewood, Colorado, USA), in order to have insight in the general hemodynamic condition of the patients. 
Patients showing an unstable hemodynamic condition during the measurements were excluded from the study, since changes in mean pressure might affect the local elastic properties.

Figure 1: Sites of measurements in the graft and in- and outflow arterial segments.

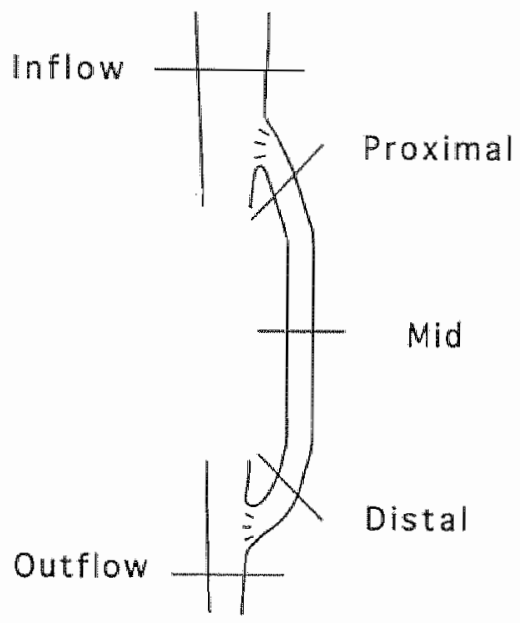

\section{Measurement of peak systolic velocity (PSV)}

The use of Duplex ultrasound in the detection of distension and diameter allowed assessment of blood stream velocity at the same predefined sites in the graft and the inflow and outflow arterial segments. Peak systolic velocity was measured by placement of a Doppler sample midstream, with an angle of $60^{\circ}$. Patients were measured in the supine position after an acclimatisation period of 20 minutes. All patients gave a written informed consent before entering the study. The study was approved by the institutional medical ethical committee.

\section{ANALYSIS}

Data are presented as medians and $25^{\text {th }}$ and $75^{\text {th }}$ percentile intervals. Within the groups the values of diameter, distension, $\mathrm{RD}$, and Al measured at the defined sites in the graft and in the in- and outflow arterial segments, respectively, were compared using the Wilcoxon-signed-rank test. Between the groups the values of the parameters measured at the defined sites were compared using the Mann-Whitney test. To investigate correlations between different parameters, linear regression analysis was used. A p-value of less than 0.05 was accepted as level of statistical significance. 


\section{RESULTS}

The patient characteristics of both groups (Table I) were comparable. Of importance in this mechanical study are the sites of proximal and distal anastomoses. Matching for site of proximal and distal anastomoses resulted in an equal distribution of proximal as well as distal anastomotic sites in the groups. The values of diameter, distension, RD, AI and PSV of the PTFE and the reversed saphenous vein group are summarized in table II and depicted in figures 2 and 3.

Table II: Values for diameter (DI), distension (DIST), relative distension (RD), areaincrease (Al) and peak systolic velocity (PSV) measured at the inflow- and outflow arterial segments and proximal, mid and distal graft segments in the PTFE and reversed saphenous vein group. Data are presented as medians and $25^{\text {th }}$ and $75^{\text {th }}$ intervals.

\begin{tabular}{|c|c|c|c|c|c|}
\hline & Inflow & Proximal & Mid & Distal & Outtlow \\
\hline \multicolumn{6}{|l|}{$\mathrm{Dl}(\mathrm{mm}):$} \\
\hline PTIFE & $7.9(6.7-10.4)$ & $4.9(4.8-5.4)$ & $5.1(4.8-5.3)$ & $4.8(4.6-5.3)$ & $4.7(2.7-5.4)$ \\
\hline Reversed & $8.6(7.1-11.2)$ & $4.1(3.1-5.6)$ & $5.4(4.1-6.1)$ & $6.0(4.6-6.8)$ & $4.9(3.5 \% 5.3)$ \\
\hline \multicolumn{6}{|l|}{$\operatorname{DIST}(\mu \mathrm{m})$} \\
\hline PTFE & $167(140-282)$ & $96(17-1 \| 2)$ & $18(14-39)$ & $21(1.3-39)$ & $78(50-128)$ \\
\hline Reversed & $209(173-271)$ & $139(102 \cdot 212)$ & $101(77-131)$ & $81(70-123)$ & $75(61-100)$ \\
\hline \multicolumn{6}{|l|}{ RD $(\%):$} \\
\hline PTFE & $2.2(1.6 \mathrm{~m} 2.7)$ & $1.9(0.3-2.3)$ & $0.4(0.3-0.8)$ & $0.5(0.3-0.8)$ & $2.2(1.1-3.0)$ \\
\hline Reversed & $2.8(1.8-3.7)$ & $3.5(2.4-4.6)$ & $1.7(1.6-2.9)$ & $1.5(1.1-2.5)$ & $1.8(1.3-2.5)$ \\
\hline \multicolumn{6}{|l|}{ Al $\left(\mathrm{mm}^{2}\right)$} \\
\hline PTFE & $2.12(1.21-4.34)$ & $0.77(0.14-0.87)$ & $0.17(0.12-0.30)$ & $0.16(0.09-0.27)$ & $0.64(0.20-1.05)$ \\
\hline Reversed & $3.06(2.23-4.72)$ & $1.20(0.63-1.48)$ & $0.90(0.551 .17)$ & $0.78(0.57-1.32)$ & $0.63(0.32-0.84)$ \\
\hline \multicolumn{6}{|l|}{$\mathrm{PSV}(\mathrm{cm} / \mathrm{s})$} \\
\hline PTFE & $103(82-127)$ & $81(62-109)$ & $81(60-97)$ & $71(53-87)$ & $71(56-105)$ \\
\hline Reversed & $107(82-144)$ & $97(74-149)$ & $80(58-97)$ & $63(51-73)$ & $91(59 \cdot 133)$ \\
\hline
\end{tabular}


Figure 2: Median values and $25^{\text {th }}$ and $75^{\text {th }}$ intervals of diameter (DI), distension (DIST), rellative distension ( $R D$ ), and area-increase (AI) measured at the proximal (Prox), mid (Mid) and distal (Dist) segments of the grafts and the inflow (Infl) and outflow (Outfl) arterial segments, $\left({ }^{*}, \mathrm{p}<0.05\right)$.
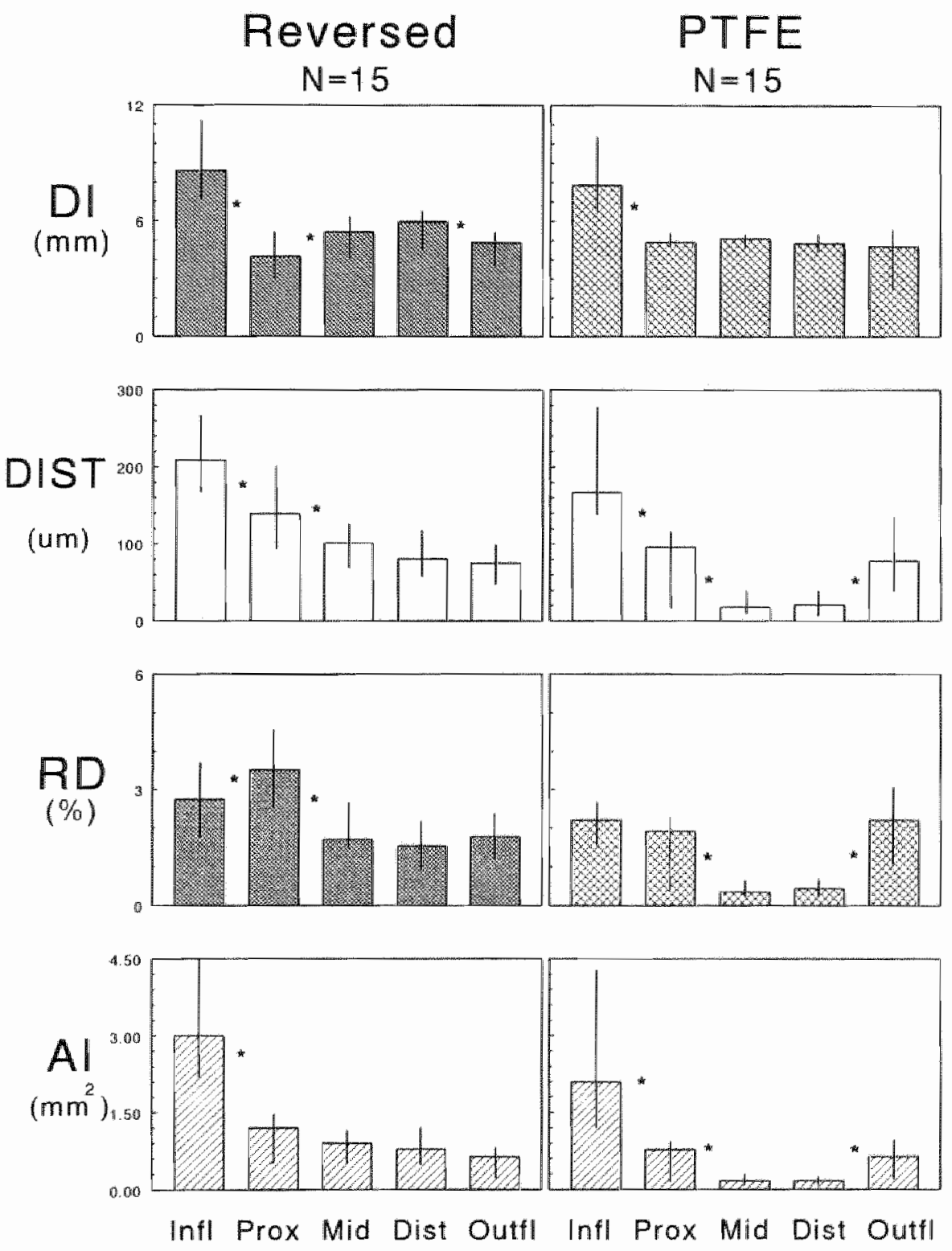
Figure 3: Median values and $25^{\text {th }}$ and $75^{\text {th }}$ percentile intervals of peak systolic velocity (PSV) for the PTFE and reversed saphenous vein graft, measured at defined sites in the graft (prox, mid and distal) and the inflow (Infl) and outflow (Outl) arterial segments, $(*, p<0.05$ ).

\section{$\operatorname{PSV}(\mathrm{cm} / \mathrm{s})$}
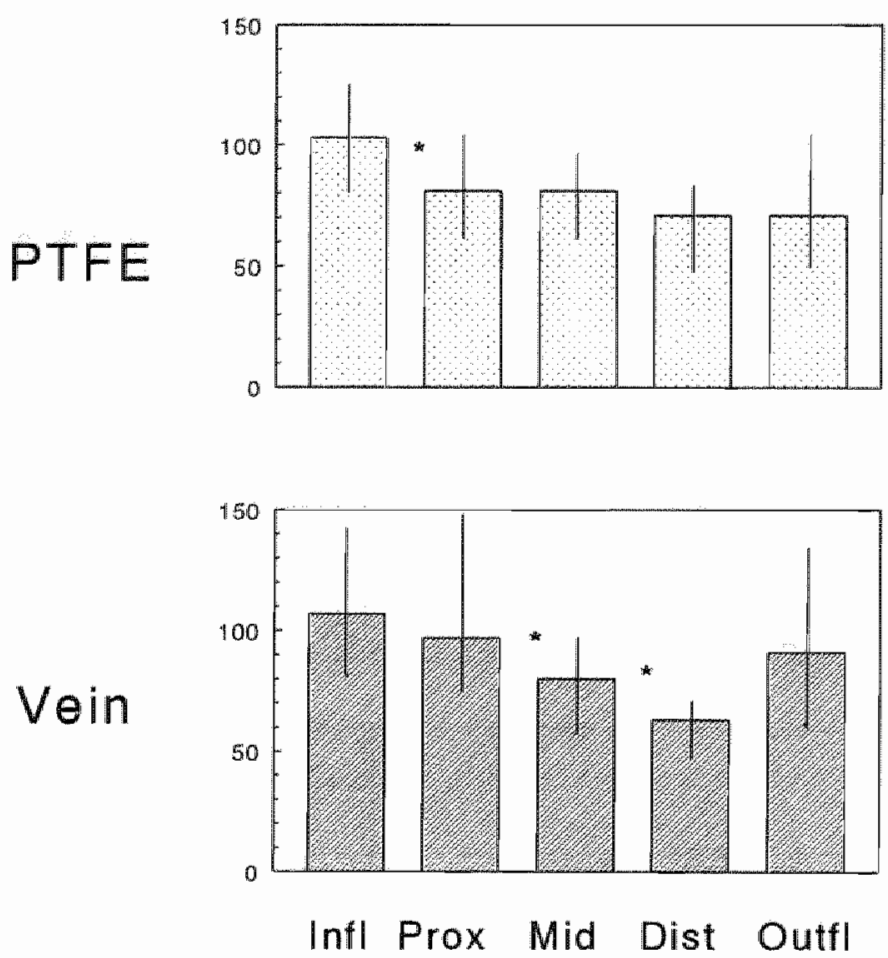

PTFE group. A significant decrease in diameter was observed between the arterial inflow segments $(7.9 \mathrm{~mm})$ and the proximal segments of the graft $(4.9 \mathrm{~mm}, \mathrm{p}<0.05)$. As expected, no change in diameter was found along the prosthetic grafts. Around the distal anastomoses no significant size differences were found. Around the proximal anastomoses no significant differences were apparent in RD. In the course of the PTFE grafts a decrease in RD was found between the proximal segments of the grafts and the middle segments (1.9\% vs $0.4 \%, \mathrm{p}<0.05)$, but no further decrease was found from the middle segments to the distal segments. An increase in RD was observed from the distal graft segments to the arterial outflow segments $(p<0.05)$. 
A decrease in distension was observed between the inflow segment and the proximal graft segment (167 vs $96 \mu \mathrm{m}$ ) and from the proximal to mid graft (96 vs $18 \mu \mathrm{m}$, $\mathrm{p}<0.05$ ). From the mid-graft segments to the distal segments no changes in distension were found. An increase in distension was observed in the distal anastomoses ( $21 \mathrm{vs}$ $78 \mu \mathrm{m}, \mathrm{P}<0.05$ ). A decrease in All was observed between the arterial inflow segments and proximal graft segments $\left(2.1\right.$ vs $\left.0.77 \mathrm{~mm}^{2}, \mathrm{p}<0.05\right)$ and a further decrease was encountered from proximal to midgraft $\left(0.77 \mathrm{vs} 0.16 \mathrm{~mm}^{2}, \mathrm{p}<0.05\right)$. Around the distal anastomoses an increase in AI was observed $\left(0.16 \mathrm{vs} 0.64 \mathrm{~mm}^{2}, \mathrm{p}<0.05\right)$. Peak systolic velocity decreased in the proximal anastomoses (103 vs $81 \mathrm{~cm} / \mathrm{s}, \mathrm{p}<0.05)$. A stable pattern of PSV was found along the prosthetic grafts, and no changes were observed around the distal anastomoses.

Reversed saphenous vein group: The proximal graft diameter $(4.1 \mathrm{~mm})$ was smaller as compared to the diameter of the arterial inflow segments $(8.6 \mathrm{~mm}, \mathrm{p}<0.05)$. The effect of reversed tapering is illustrated by a gradual increase in diameter from proximal $(4.1 \mathrm{~mm})$ to distal $(6.0 \mathrm{~mm}, \mathrm{p}<0.05)$ in these grafts. A difference in diameter was observed around the distal anastomoses (6.0 in the distal part of the grafts ws 4.9 $\mathrm{mm}$ in the arterial outflow segments, $\mathrm{p}<0.05$ ). An increase in RD was found between the inflow arterial segment $(2.8 \%)$ and proximal graft segments $(3.5 \%, \mathrm{p}<0.05)$. A gradual decrease in RD was found from proximal $(3.5 \%)$ to distal $(1.5 \%, \mathrm{p}<0.05)$ in the grafts. Around the distal anastomoses no significant differences in RD could be observed. A decrease in distension was observed between the inflow segment and the proximal graft segment ( 209 vs $139 \mu \mathrm{m}$ ) and between the proximal graft segment and the mid-graft segment ( 139 vs $101 \mu \mathrm{m}, \mathrm{p}<0.01$ ). Between the mid-graft segments and the distal graft segments and around the anastomoses no differences in distension were observed. The Area-increase (AI) was larger in the inflow arterial segments as compared to the proximal segments of the grafts $\left(3.0 \mathrm{vs} 1.2 \mathrm{~mm}^{2}, \mathrm{p}<0.05\right)$. No change in AI was observed along the grafts. Around the distal anastomoses no significant differences in AI were apparent. Within the proximal anastomoses of the reversed vein grafts no changes in PSV were observed. A decrease in PSV was observed along the grafts (99 vs $63 \mathrm{~cm} / \mathrm{s}, \mathrm{p}<0.05$ ). Around the distal anastomoses no changes in PSV were observed.

\section{DISCUSSION}

In the present study we investigated the dimensions and elastic properties around the anastomoses of PTFE and saphenous vein grafts in humans with a new ultrasound system, Vessel Wall Doppler Tracking. We observed higher values of distension in the proximal segments of the PTFE grafts compared to the mid- and distal segments which is surprising, since homogeneous intrinsic elastic properties in prosthetic graft material seemed more likely. Due to the high distension values in the proximal grafts segments, the values for $\mathrm{RD}$ and $\mathrm{AI}$ were also higher in this segment. The values for distension and relative distension in the mid-graft and distal graft segments of the PTFE grafts 
are comparable to values from in vitro assessment of distension of PTFE grafts, reporting values of one-sixth of femoral artery values ${ }^{5,19,28}$. Theoretically, the high values of distension in the proximal graft segment may be the effect of differentiation of pulse wave reflection ${ }^{22,27}$. The proximal segments of the grafts could be a site where the pulse wave, reflected from the periphery, augments systolic pressure, thereby increasing pulse pressure values at this particular point, leading to higher distensions $^{22,26}$. However, this mechanism is not likely, since the length of the graft is many times shorter as the wavelength of the pulse wave. Presumably, the increase of peak systolic pressure due to pulse wave reflection will have a general effect in the graft. Another possible explanation may be the interaction between the arterial inflow segment and the proximal graft segment. The distension of the inflow arterial segments may influence the distension of the most proximal graft segments, since these parameters were assessed quite close to the anastomosis, within $1 \mathrm{~cm}$ from the proximal anastomoses. To test this hypothesis, we correlated distension values of inflow arteries and proximal graft segments. The result is depicted in figure 4.

Figure 4: Scatterplot of distension values of the inflow arterial segments (X-axis) and the proximal graft segments ( $\mathrm{Y}$-axis). Linear regression analysis revealed a positive correlation between distension values measured at these sites.

\section{Distension}

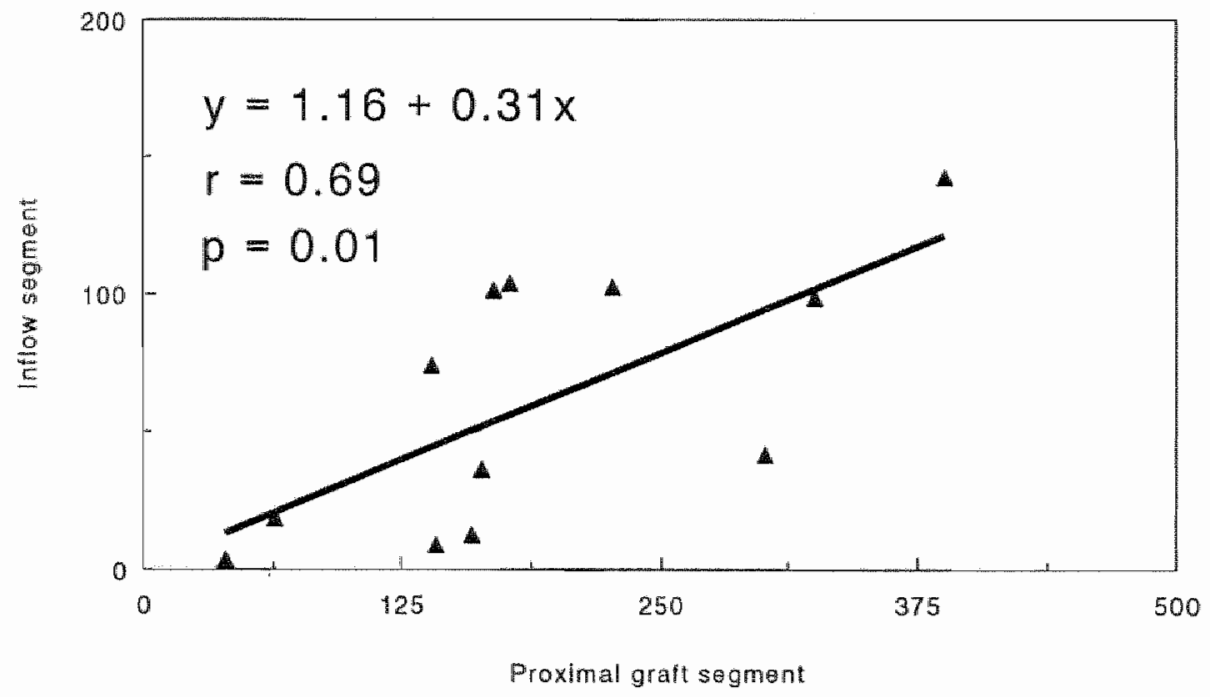


Linear regression analysis revealed a significant correlation between the distension values measured at these two different sites $\left(r=0.69, p=0.01, y=1.31+0.31^{\text {* }} \mathrm{x}\right.$ ). This supports the concept that the distension of the proximal graft segments is influenced by the distension of the inflow arterial system. The tendency of lower distemsion values in the inflow segments of the PTFE group as compared to the reversed vein group is a further indication that elastic properties of the prosthesis and of the inflow arteries close to the anastomosis are influenced by each other, indicating artery-graft interaction. In another study from our institute, the elastic profiles of different graft arteriovenous fistulas were assessed with the use of VWDT in a similar fashion (chapter 7$)^{29}$. Substantially lower values for Al and RD were found in the brachial artery of patients with a PTFE interposition graft as compared to patients with a saphenous vein interposition graft for the construction of a vascular access. Since in that study the patients were randomly assigned to either the PTFE or saphenous group, differences in the intrinsic elastic properties of the brachial artery are unlikely and cannot explain the lower values for the elastic properties in the PTFE group. Therefore, it seems that the distension of the brachial artery close to the arterial anastomosis of patients with a PTFE graft is restricted by the stiffness of the prosthesis. This observation supports the concept that the vessel segments close to the anastomosis are interrelated with respect to elastic properties, indicating graft-artery interaction.

The consequence of the relatively high distension values at the proximal graft segments is that the differences in elastic properties around the proximal anastomoses of the PTFE grafts are less pronounced than one would expect. The mechanical interaction between native arterial system and the PTFE graft attenuates the difference in intrinsic elastic properties to some extent.

At the distal anastomoses of the PTFE grafts an increase in the elastic parameters was observed. In vivo flow studies demonstrated that a sudden increase in compliance is associated with flow disturbances like increased particle residence time and flow stasis, suggesting low shear ${ }^{7,30}$. Low shear rate has been associated with increased intimal thickening by numerous investigators ${ }^{2,31.34}$. Therefore, the increase in the elastic parameters at the distal anastomoses of the PTFE grafts may explain the predisposition of intimall hyperplasia to develop at this site $e^{9,14}$.

In the reversed saphenous vein bypass grafts a gradual decrease in distension was observed along the entire vascular reconstruction. The most prominent finding in this group is the decline in $\mathrm{Al}$ in the proximal anastomoses. However, due to the increase in diameter along the graft the capacity to store blood volume, represented by AI, remained stable in the course of the graft. The sudden decrease in Al in the proximal anastomoses of reversed saphenous vein bypasses coincides with the frequent occurrence of stenosis at this site . $^{11,35}$.

The capacity to store blood volume during the cardiac cycle is a measure for the hemodynamic function of the graft. As a vascular conduit, the bypass has to adequately manage pulsatile flow ${ }^{3}$. This condition seems to be fulfilled by the reversed saphenous vein graft. The decline in AI along the prosthetic graft indicates that the 
capacity to store blood volume in the distal part of the graft is low. In the reversed saphenous vein graft also a decrease in PSV values is observed along the grafts, which can be attributed to the increase in diameter along the grafts. With the use of long prosthetic grafts to construct bypasses to infrapopliteal and crural arteries, a further loss of pulsatile energy might occur. This may explain the more pronounced difference in patency rates between PTFE and saphenous vein grafts at the below-knee level. The length of the PTFE graft may be the limiting factor rather than crossing the knee joint 36-3\%. In the development of new prosthetic graft materials the ability of maintaining hemodynamic capacity along the entire length of the graft should be of major concern. The hypothesis that a mismatch in elastic properties contributes to the development of intimal hyperplasia stems from the frequent occurrence of this phenomenon at anastomoses of grafts ${ }^{1,2,8,9,12,19,39-42}$. A mismatch in elastic properties may lead to vessel wall injury, thereby initiating a vascular response ${ }^{1}$. In addition, it leads to a site of excessive mechanical stretching at the anastomoses under pulsatile conditions, which may promote smooth muscle cell proliferation ${ }^{43-44}$. In the present study notable differences were observed around the anastomoses of the PTFE and reversed saphenous vein bypass graft. At this moment we can only speculate on the influence of the differences around the anastomoses of distension, RD and AI on the occurrence of intimal hyperplastic stenoses. A prospective analysis correlating quantitative differences in elastic properties with the occurrence of stenosis is necessary to address this question.

In summary, the dimensions and elastic properties of PTFE and saphenous vein bypass grafts in humans were assessed in vivo at defined sites in the graft and native arterial system, in order to obtain a mechanical profile. Higher distension values were found in the proximal segments of PTFE grafts as compared to the distal segments. This may be explained by the interaction between the native artery and the proximal graft segments, which is suggested by the positive correlation between distension of the inflow arterial segments and the proximal graft segments. At the distal anastomoses of the PTFE grafts an increase in distension and area-increase was observed. In the reversed saphenous vein grafts a decrease in distension and AI was observed around the proximal anastomoses. Around the distal anastomoses no differences in elastic parameters were observed in the saphenous vein group. 


\section{REFERENCES}

1. Abbott WM, Megerman J, Hasson JE, L"Italien G, Warnock DF. Effect of compliance mismatch on vascular graft patency, $J$ Vasc Surg $1987 ; 5: 376-382$.

2. Bassiouny HS, White $S$, Glagow S, Choi E, Giddens DP, Zarins CK. Anastomotic intmal hyperplasia: Mechamical injury or flow induced. $J$ Vasc Surg 1992; 15:708-717.

3. Baird RN, Abbott WM. Pulsatile blood-flow in arterial grafts. Lancet 1976; October 30:948-950.

4. Wu MH, Shi Q, Sauvage LR, et al. The direct effect of graft compliance mismatch per se on development of host arterial intimal hyperplasia at the anastomotic interface. Ann Vasc Surg 1993; 7:156-168.

5. Rodgers VGJ, Teodon MF, Brant AM, Borovetz HS. Characterization in vitro of the biomechanical properties of anastomosed host artery-graft combinations. $J$ Vasc Surg 1986 ; 4:396-402.

6. Okuhn SP, Connelly DP, Calakos N, Ferrell L, Man-Xiang P, Goldstone J. Does compliance mismatch allone cause neointimal hyperplasia? $J$ Vasc Surg 1989; 9:35-45.

7. Stewart SFC, Lyman DJ. Effects of a vascular graft/natural artery compliance mismatch on pusatile flow. I Biomech 1992; 25:297-310.

8. Abbott WM, Megerman J. Adaptive responses of arteries to grafting. $J$ Vasc Surg $1989^{*}$ 9:377-379.

9. Echave V, Koomick AR, Haimov M, Jacobson JH. Intimal hyperplasia as a complication of the use of the polytetrafluoroethylene graft for femoral-popliteal bypass. Surgery 1979; 86:791-798.

10. Madras PN, Ward CA, Johnson WR, Singh PI. Anastomic hyperplasia. Surgery 1981; 90:922-923.

11. Berkowitz HD, Greenstein S, Barker CF, Perloff LJ. Late failure of reversed vein bypass grafts. Ann Surg 1989; 210:782-786.

12. Swedberg SH, Brown BG, Sigley R, Wight TN, Gordon D, Nicholls SC. Intimal fibromuscular hyperplasia at the venous anastomosis of PTFE grafts in hemodialysis patients. Circulation 1989; 80:1726-1736.

13. Jenkins AMcL, Buist TAS, Glover SD. Medium-term follow-up of forty autogenous vein and forty polytetrafluorethylene (Gore-Tex) grafts for vascular access. Surgery 1980; 88:667-672.

14. Sottiurai VS, Sue SL, Feinberg II EL, Bringaze WL, Tran AT, Batson RC. Distal anatstomotic intimal hyperplasia: Biogenesis and etiology. Eur J Vasc Surg 1988; 2:245-256.

15. Ferrel M, Fuster $\mathrm{V}$, Gold HK, Chesebro JH. Choosing appropriate experimental animal model for the prevention of restenosis. Circulation 1992; 85:1630-1631.

16. Clowes AW, Reidy MA. Prevention of stenosis after vascular reconstruction: Pharmacologic control of intimal hyperplasia - A review. I Vasc Surg 1991; 6.885-891.

17. McBride W, Lange RA, Hillis LD. Restenosis after successfull coronary angioplasty. Pathophysiology and prevention. New Eng J Med 1988; 318:1734-1737.

18. Lye CR, Sumner DS, Hokanson DE, Strandness DE. The transcutaneous measurement of the elastic properties of the human saphenous vein femoropopliteal bypass graft. Surg Gynecol Obsiet 1975; 141:891-895.

19. Hokanson DE, Strandness DE. Stress-strain characteristics of various arterial grafts. Surg Gynecol Obstet 1968; 57-60.

20. Hoeks APG, Brands PJ, Smeets FAM, Reneman RS. Assessment of distensibility of superficial arteries. Ultrasound Med Biol 1990; 16:121-128.

2]. Hofstra L, Ermers EJM, Langeveld APM, Hoeks APG, Kitslatar PJEHM. Vessel Wall Doppler Tracking: A new technique to assess vessel wall compliance. $J$ Vasc Tech 1993; 17.65-68.

22. O'Rourke MF. Arterial stiffness, systolic blood pressure, and logical treatment of arterial. hypertension. Hypertension 1990; 15:339-347. 
23. Reneman RS, Merode van $T$, Brands PJ, Hoeks APG. Inhonogeneities in arterial wall properties under nomal and pathological conditions. J Hypertens 1992; 10,535-539.

24. Imholz BPM, Settels $\mathrm{J}_{3}$, Meiracker van der $\mathrm{AH}$, Wesseling $\mathrm{KH}_{3}$, Wieling $\mathrm{W}$. Non-invasive continuous finger blood pressure neasurement during orthostatic stress compared to intra-arterial pressure. Cardiovasc Res 1990; 24:214-221.

25. Murgo $\mathbb{J P}_{y}$. Westerhof $\mathrm{N}$, Giolma $\mathrm{JP}$, Altobelli $\mathrm{SA}$. Aortic input impedance in normal man: Relationship to pressure wave forms. Circulation 1980; 62:105-116.

26. ORourke MF. Systolic blood pressure: arterial compliance and early wave reflection, and their modification by antihypertensive therapy. $\mathcal{J}$ Hum Hypertens $1989 ; 3: 47-52$.

27. Kelly RP, Gibbs HH, ORourke MF, et al. Nitroglycerin has more favourable effects on left ventricular afterload than apparent from measurement of pressure in a peripheral artery. Eur Hear: J 1990; 11:138-144.

28. Pourdeyhimi $B$, Wagner D. On the correlation between the failure of vascular grafts and their structural and material properties: A critical analysis. I Biomed Mat Res $1986 ; 20: 375-409$.

29. Hofstra L, Bergmans DCCI, Hoeks APG, Kitslaar PJEHM, Leunissen KML, Tordoir JHM. Mismatch in elastic properties around anastomoses of interposistion grafts for hemodialysis access. JASN $1994,5: 1243-1250$.

30. Shu MCS, Noon GP, Hwang NHC. Flow profiles and wall shear stress distribution at a hemodialysis venous anastomosis: preliminary study. Biorheology 1987; 24:723-735.

31. Zarins CK, Bomberger RA, Glagov $S$. Local effects of stenoses: Increased flow velocity inhibits atherogenesis. Circulation 1981; 64:11221-11227.

32. Friedman MH, Bargeron CB, Deters OJ, Hutchins GM, Mark FF. Correlation between wall shear and intimal thickness at a coronary artery branch. Atherosclerosis 1987; 68:27-33.

33. Kamiya $A$, Togawa $T$. Adaptive regulation of wall shear stress to flow change in the canine carotid artery. Am J Physiol 1980; 239:H14-H21.

34. Rittgers SE, Karayannacos PE, Guy JF, et al. Velocity distribution and intimal proliferation in autologous vein grafts in dogs. Circ Res 1978; 42:792-801.

35. Berkowitz HD, Fox $A D$, Deaton $D H$. Reversed vein graft stenosis: Early diagnosis and management. J Vasc Surg 1992; 15:130-142.

36. Prendiville EJ, Yeager A, O'Donnell TF, et al. Long-term results with the above-knee popliteal expanded polytetrafluoroethylene graft. J Vasc Surg 1990; 11:577-524.

37. Michaels JA. Choice of material for above-knee temoropopliteal bypass graft. Br I Surg 1989; $76: 7-14$.

38. Veith FJ, Gupta SK, Ascer E, et al. Six year prospective multicenter randomized comparison of autologous saphenous vein and polytetrafluoroethylene grafts in infrainguinal arterial reconsituctions. I Vasc Surg 1986; 3:104-114.

39. Kidson J $\mathrm{G}_{*}$ Abbott WM. Low compliance and arterial graft occlusion. Circulation 1978; $58: 11-14$.

40. Werner $\mathrm{OS}$, Wiegand $\mathrm{V}$, Tebbe $\mathrm{U}$, Krewzer $\mathrm{H}$. Contrary effects of acefylcholine on coronary arteries and aortocoronary venous grafts in man. Eur Heart $J 1989 ; 10: 86-91$.

41. LoGerfo $\mathbb{F W}$, Quist WC, Nowak MD, Crawshaw HM, Haudenschild CC. Downstream anastomotic hyperplasia. A mechanism of failure in Dacron arterial grafts. Amn Surg 1983; $197: 479-483$

42. Sottiurai VS, Yao IST, Flinn WR, Batson RC. Intimal hyperplasia and neointima: An ultrastructural analysis of thrombosed grafts in humans. Surgery 1983; 93:809-817.

43. Predel $H_{G}$, Yang $Z$, Von Segesser $L$, Turina M, Buhler FR, Luscher TF. Implications of pulsatile stretch on growth of saphenous veiru and mammary artery smooth muscle. Lancet $1992 ; 340.878-879$.

44. Leung DYM, Glagov S, Mathews MB. Cyclic stretching stimulates synthesis of matrix components by arterial smooth muscle cells in vitro. Science $1976 ; 191.475-477$. 


\title{
MISMATCH IN ELASTIC PROPERTIES AROUND ANASTOMOSES OF INTERPOSITION GRAFTS FOR HEMODIALYSIS ACCESS
}

\author{
L Hofstra MD, DCJJ Bergmans, APG Hoeks PhD, PJEHM Kitslaar MD PhD, \\ KML Leunissen MD PhD and JHM Tordoir MD PhD
}

Adapted from the Journal of the American Society of Nephrology 1994; 5: 1243-1250

\section{ABSTRACT}

Background: Arterio-venous fistulas for hemodialysis access, constructed with the use of interposition grafts, are often complicated by intimal hyperplastic stenosis, mainly occurring at the venous anastomosis. In the current study we quantified mismatch in elastic properties around the arterial and venous anastomoses of graft AV filstulas in humans in order to find clues for the predisposition of intimal hyperplasia to develop at the venous anastomosis.

Methods: The elastic properties of graft AV fistulas of 31 hemodialysis patients were investigated with the use of Vessel Wall Doppler Tracking, two weeks after construction. Nine saphenous vein (SV) grafts, 8 expanded-PTFE (ePTFE) grafts and 14 stretch-PTFE (SPTFE) grafts were measured at the arterial inflow segment, the proximal graft segment, the distal graft segment and the venous outflow segment. Area-increase (AI), representing the capacity of the vessel wall to store blood volume, and relative distension (RD), representing the strain, were calculated from diameter and distension.

Results: A decrease in AI was observed in the arterial anastomoses of all graft types. An increase in AI was found in the venous anastomosis of ePTFE and SPTFE grafts. Higher values for $\mathrm{AI}$ and $\mathrm{RD}$ were found at the proximal and distal graft segments of the saphenous vein grafts when compared to the prosthetic grafts. In the sPTFE grafts the level of AI was maintained along the graft, while in the ePTFE grafts a decrease in AI was found.

Conclusion: In the arterial anastomoses of arteriovenous fistulas a decline in the capacity to store blood volume was observed. By contrast, an increase in capacity to store blood volume was found in the venous anastomoses. Since the latter condition is associated with flow disturbances, like enthanced particle residence time and low shear rate, it may contribute to the predisposition of intimal hyperplasia to develop at the venous site. 


\section{INTRODUCTION}

Patients requiring hemodialysis due to end-stage renal failure depend on a proper function of the vascular access, to provide sufficient flow during dialysis ${ }^{1}$. An increasing number of these patients receive an interposition graft in the usually secondary construction of an arterio-venous (AV) fistula ${ }^{1-3}$. The reported $50 \%$ revision rate of the graft AV fistulas during the first post-operative year, illustrates the susceptibility of this type of vascular access to develop complications and leads to an increased hospitalisation ${ }^{2,3}$. The main cause for the failure of the vascular access is graft stenosis due to intimal hyperplasia, jeopardizing graft flow and causing high venous pressure $^{1-4}$. Stenotic intimal hyperplasia frequently occurs at the site of the venous anastomosis and rarely develops at the arterial anastomosis ${ }^{2,3,-10}$. The incidence of stenoses developing at the venous anastomosis may be caused by the release of growth factors in the graft due to puncturing ${ }^{3,4,11}$. The upstream release of growtli factors may lead to proliferation of vascular smooth muscle cells (VSMC) at the site of the venous anastomosis ${ }^{12}$. However, since stenoses are not diffusely distributed along the efferent vein but localized at the anastomosis, other contributing factors are likely. A possible mechanism is mismatch in elastic properties around the anastomoses ${ }^{7,10,13-15}$. Mismatch in elastic properties leads to excessive mechanical stretch at the anastomoses ${ }^{13}$, which may promote smooth muscle cell replication ${ }^{16-19}$. Furthermore, the excessive mechanical stretch may lead to localized vessel wall injury ${ }^{13,20}$, initiating a vascular response. Another way by which compliance mismatch may affect intimal hyperplasia, is the influence on flow. The effect of an abrupt change in compliance on flow characteristics has been studied with the use of flow models ${ }^{21-23}$. A sudden decrease in compliance did not lead to flow disturbances whereas a sudden increase in compliance resulted in enhanced particle residence time and flow separation, suggesting low shear conditions. Numerous reports demonstrated an increased intimal thickening in areas of low shear stress ${ }^{22-28}$, probably by affecting the growth control function of the endotheliurn ${ }^{29-31}$.

Quantitative information on elastic properties around the anastomoses of interposition grafts is scarce. The elastic properties of graft AV fistulas of hemodialysis patients with the use of Vessel Wall Doppler Tracking ${ }^{32,33}$ were measured, two weeks after construction. Three different graft types were investigated: autologous saphenous vein grafts, expanded polytetrafluoroethylene (ePTFE) grafts, and a new PTFE graft with stretch properties (stretch-PTFE). The elastic properties were assessed at predefined sites in the graft, the arterial inflow segment and the venous outflow segment. The aim of the study was to compare the peri-anastomotic mismatch in elastic properties between the arterial and venous anastomoses in order to find clues for the predisposition of intimal hyperplasia to develop at the venous anastomosis. 


\section{MATERIALS AND METHODS}

\section{Patients}

A total of 31 patients was examined. In 25 patients the construction of a vascular access using interposition grafts was a secondary procedure. Previous arteriovenous fistulas at the usual sites, mostly Brescia Cimino fistulas, had failed. In the remaining 6 patients the use of an interposition graft was a primary choice due to the absence of a suitable vein. The proper function of the graft was tested with the use of a Duplex scan before the patients entered the study. Patients with evidence of graft related stenoses were excluded from this study, since a stenosis could alter the hemodynamics of the graft by influencing pulse wave reflections ${ }^{34}$. Thirty-one consecutive patients entered the study. In the first half of the study period patients were randomly assigned to either ePTFE ( $n=8$, mean age $51 \pm 20$ years) or saphenous vein implantation $(n=9$, mean age: $53 \pm 17$ years). In the second half of the study period only stretch-PTTE grafts were used ( $n=14$, mean age $56 \pm 15$ years). All grafts were implanted in a subcutaneous loop tunnel in the forearm between the brachial artery and the vein. The arterial and venous anastomoses were constructed at the site of the elbow in an end-toside fashion with running 7-0 polypropylene (Prolene) sutures.

\section{Measurements of the elastic properties}

The measurements of the elastic properties of the graft AV fistulas were performed two weeks after construction. Patients were measured in the supine position after an acclimatization time of 20 minutes. The elastic properties of the graft, the brachial artery and venous outflow segment were assessed with the use of Vessel Wall Doppler Tracking (VWDT). This system has been described in detail elsewhere (chapter 3 and $4)^{32,33}$. From distension (in $\mu \mathrm{m}$ ) and diameter (in $\mathrm{mm}$ ) the following parameters were calculated:

Relative Distension $(R D)=\frac{\Delta D}{D} * 100(\%)$

Area - Increase $(A I)=\frac{\pi \Delta D * D}{2}$

Relative distension (RD) gives the fractional diameter increase. Area-increase represents the capacity of the vessel wall to store blood wolume during cardiac cycle ${ }^{35}$. Usually, $\mathrm{RD}$ and $\mathrm{Al}$ are corrected for pulse pressure, resulting in the distensibility coefficient and the cross-sectional compliance, respectively ${ }^{36,37}$. Animal studies demonstrated a drop in pressure along AV-fistulas from $120 \mathrm{mmHg}$ in the arterial inflow segment to $50 \mathrm{mmHg}$ in the venous outflow segment ${ }^{38}$. This indicates that noninvasively obtained pressure values with the use of Finapress or Dynamap cannot 
represent the pressure values along the graft. Therefore, it was decided to use RD and Al to represent the elastic properties of the arterial wall. RD and AI were averaged from the 3-5 recorded heartbeats per measurements. The variation coefficient for RD and $\mathrm{AI}$ within the measurement was always less than $5 \%$.

In each graft measurements were performed proximal $(1 \mathrm{~cm}$ from the proximal anastomosis) and distal ( $1 \mathrm{~cm}$ from the distal anastomosis). The inflow artery was measured $1 \mathrm{~cm}$ from the proximal anastomosis, the outflow vein was measured $1 \mathrm{~cm}$ from the distal anastomosis (Figure 1).

Figure 1: Sites of measurements in the graft and in- and outflow segments. The measurements were performed within a distance of 1 centimeter from the anastomoses.

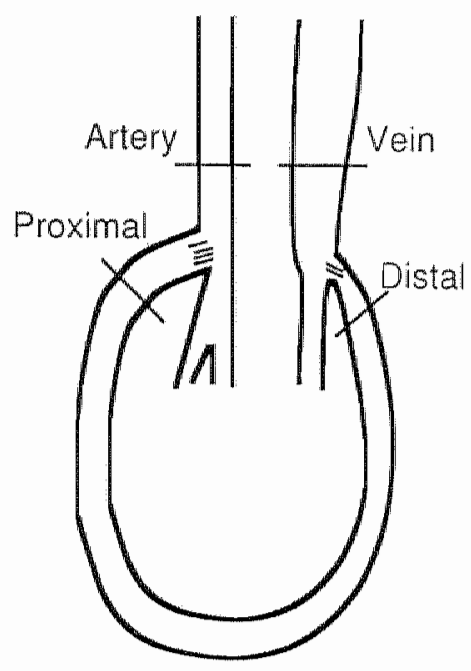

\section{ANALYSIS}

Data are presented as medians and $25^{\text {th }}$ and $75^{\text {th }}$ percentile intervals. Within the groups the values of diameter, RD, and AI measured at the defined sites in the graft and in the in- and outflow venous segments, respectively, were compared using the Wilcoxonsigned-rank test. Between the groups the values of the parameters measured at the defined sites were compared using the Mann-Whitney test. Linear regression analysis was used to correlate variables. A p-value of less than 0.05 was accepted as level of statistical significance.

\section{RESULTS}

The patient characteristics were not different between the groups (Table I). The results of measurement of diameter, RD and AI measured in the three different groups are summarized in Table II and depicted in Figure 2 to 5. 
Table : Patient characteristics of the different groups $(\mathrm{SV}=$ Saphenous wein graft, sPTTE stretch PTFE, ePTFE = expanded PTFE).

\begin{tabular}{lccc}
\hline & SV Grafts & sPTFE Grafts & ePTFE Grafts \\
\hline Age (years) & $54(17)$ & $56(15)$ & $54(21)$ \\
Male/Female & $7 / 2$ & $5 / 9$ & $5 / 3$ \\
\hline
\end{tabular}

Table II

Brachial Artery Proximal Distal Vein

\begin{tabular}{lllll}
\hline Diameter: & & & & \\
SV & $4.8(4.4-5.3)$ & $4.5(3.2-6.6)$ & $3.6(2.7-6.6)$ & $6.3(2.8-8.0)$ \\
sPTFE & $5.1(4.1-5.6)$ & $4.4(4.1-4.6)$ & $4.5(4.1-4.9)$ & $6.2(3.4-8.6)$ \\
EPTFE & $5.8(5.2-6.7)$ & $4.9(4.8-5.7)$ & $4.9(4.7-5.7)$ & $4.3(2.7-5.1)$
\end{tabular}

Relative Distension:

$\begin{array}{lllll}\text { SV } & 5.7(4.5-9.7) & 3.5(2.7-8.0) & 9.0(3.4-12.9) & 5.6(3.0-15.9) \\ \text { SPTFE } & 4.1(2.5-6.0) & 2.8(1.6-3.4) & 1.6(1.0-3.4) & 4.0(2.0-6.4) \\ \text { ePTFE } & 3.4(1.8-5.8) & 1.8(1.1-2.4) & 1.1(0.5-2.3) & 4.8(0.9-9.5)\end{array}$

Area Increase:

$\begin{array}{lllll}\text { SV } & 2.1(1.2-4.0) & 1.1(0.9-2.8) & 1.4(1.3-3.3) & 3.1(1.0-6.5) \\ \text { SPTFE } & 1.8(1.0-2.6) & 0.7(0.4-1.1) & 0.7(0.3-1.0) & 1.8(1.1-3.5) \\ \text { EPTFE } & 1.4(1.0-4.3) & 0.7(0.5-1.2) & 0.4(0.2-0.8) & 0.9(0.3-\mathbb{1 1 . 6})\end{array}$

\section{Saphenous vein group $(n=9)$.}

No differences in diameter were observed around the andstomoses and no changes in diameter along the graft were found (Table II, Figure 2). A large increase in RD from proximal to distal in the graft was observed $(p<0.05)$. A decrease in AI was found in the arterial anastomosis $(p<0.05)$. No change in Al along the graft was observed and no difference in AI around the venous anastomoses was found. 
Figure 2: Saphenous vein grafts. Median values and $25^{\text {th }}$ and $75^{\text {th }}$ percentile intervals of diameter (Dl), relative distension (RD) and area-increase (AD) measured at the proximal (Prox), mid (Mid) and distall (Dist) segments of the grafts and the artery (Art) and vein segments $(*, p<0.05)$.
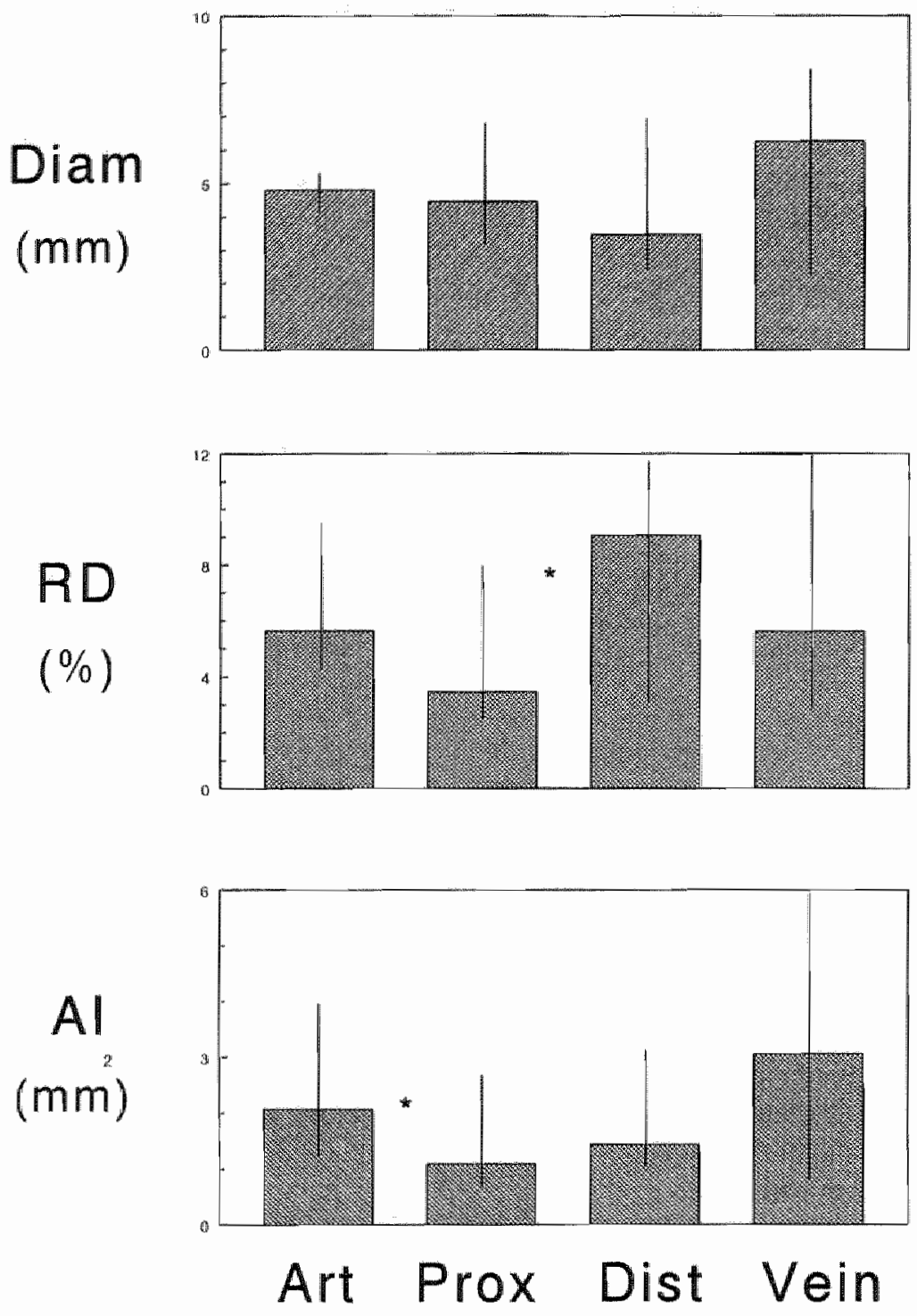


\section{e-PTFE group $(n=8)$}

A decrease in diameter was observed in the arterial anastomoses $(p<0.05)$; along the graft and around the venous anastomoses no differences in diameter were found (Table II, Figure 3). A decrease in RD in the arterial anastomoses was shown ( $<<0.05)$; along the graft and around the venous anstomoses no differences were observed. A decrease in AI was observed in the arterial anastomoses ( $p<0.05$ ) and along the graft ( $p<0.05$ ). Around the venous anastomoses an increase in Al was observed $(p<0.05)$.

Figure 3: expanded PTFE grafts. Median values and $25^{\text {th }}$ and $75^{\text {th }}$ percentile intervals of diameter (DI), relative distension (RD) and area-increase (AI) measured at the proximall (Pros), mid (Mid) and distal (Dist) segments of the grafts and the artery (Art) and vein segments, $\left({ }^{*}, p<0.05\right)$.
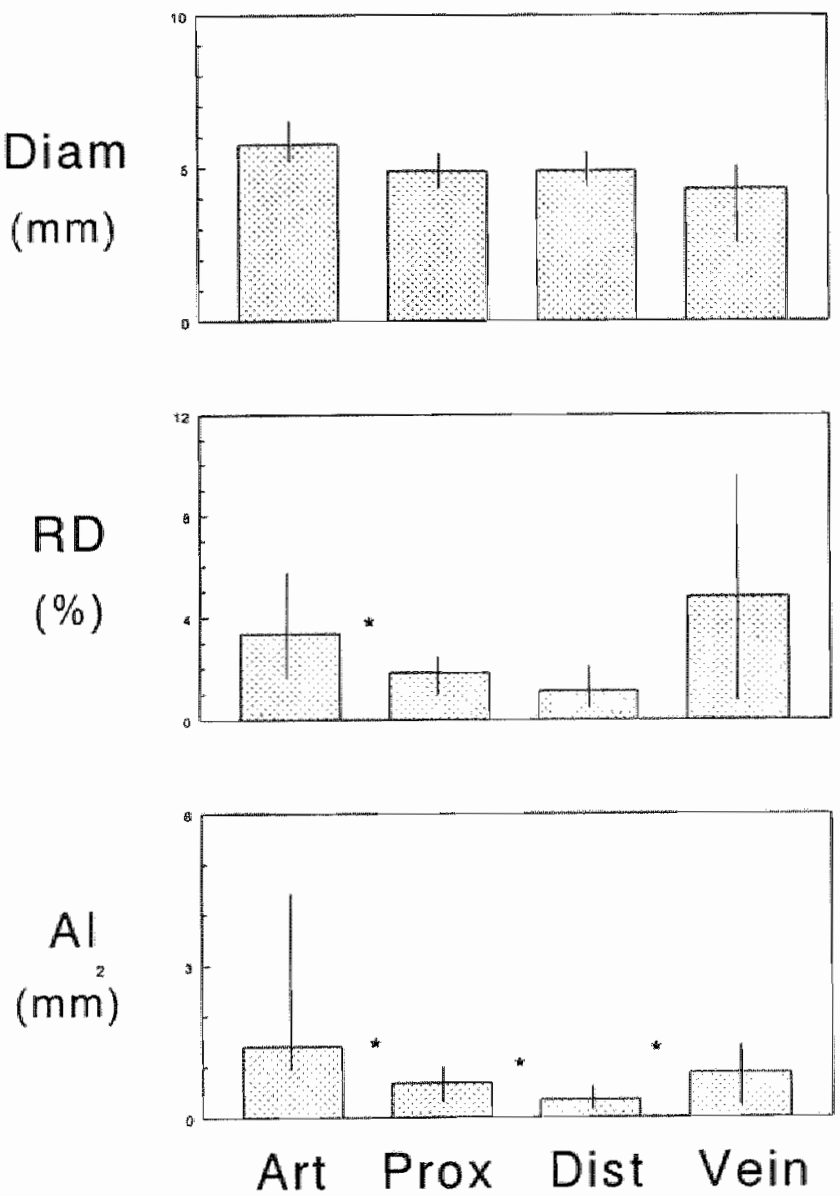


\section{Stretch PTRE group $(\mathrm{n}=14)$}

Around the arterial anastomoses and along the grafts no differences in diameter were observed, but an increase in diameter was found around the venous anastomoses (Table I, Figure 4). No differences in RD were observed around the arterial anastomoses and along the graft. RD increased around the venous anastomoses $(p<0.05)$. A decrease in Al was observed around the arterial anastomoses $(\mathrm{p}<0.05)$, but an increase was found around the venous anastomoses ( $\mathrm{p}<0.05$ ). Along the grafts no changes in AI were shown.

Figure 4: stretch PTFE grafts. Median values and $25^{\text {th }}$ and $75^{\text {th }}$ percentile intervals of diameter (DI), relative distension (RD) and area-increase (AI) measured at the proximal (Prox), mid (Mid) and distal (Dist) segments of the grafts and the artery (Art) and vein segments, (* , $p<0.05$ ).
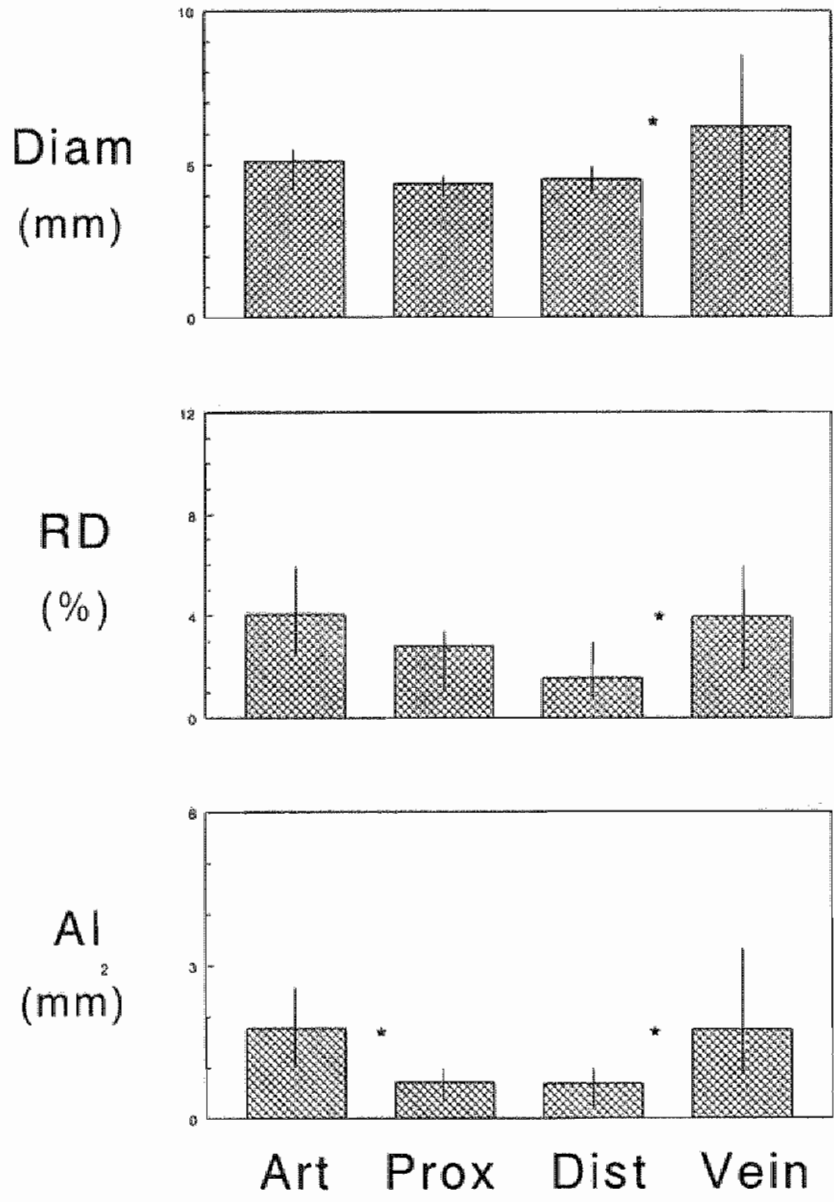


\section{COMPARISON BETWEEN THE GROUPS}

\section{Relative Distension}

$\mathrm{RD}$ was higher in the SV group in the proximal and distal graft segment as compared to both the ePTFE group and the stretch-PTFE group ( $<<0.05$ ) (Table $\mathbb{I I}$, Figure 5). Between the ePTFE group and the stretch-PTFE group no differences were found in the graft. In the arterial inflow segment RD was higher in the SV group as compared to the ePTFE group $(\mathrm{p}<0.05)$. Between the SV group and the stretch-PTFE group and between the two types prosthetic grafts no differences were found in RD in the arterial inflow segments. In the venous outflow segments no differences in RD were found between the three groups.

Figure 5: Bar graphs demonstrating the results of measurements of Relative Distension (RD) assessed at the defined sites in the grafts and host vessels, for all graft types ( $*, p<0.05$ ). Data are presented as medians and $25^{\text {th }}$ and $75^{\text {th }}$ percentile intervals. ( $\mathrm{PPTFE}=$ stretch PTFE, $\mathrm{SV}=$ saphenous vein, $\mathrm{ePTFE}=$ expanded $\mathrm{PTFE}$ )

\section{Relative Distension}

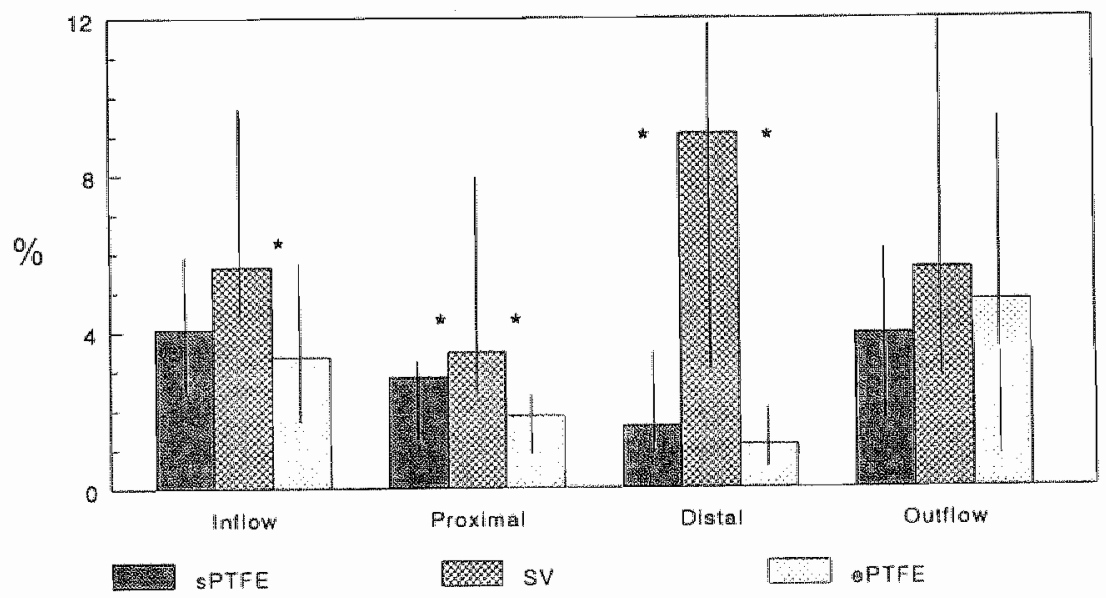

\section{Area Increase}

AI was higher in the SV group in the proximal and distal graft segments as compared to both the ePTFE group and the stretch-PTFE group ( $<<0.05$ ) (Table II, Figure 6), indicating a better ability to store blood volume during the cardiac cycle. Between the ePTFE group and the stretch-PTFE group no differences were found in the graft. In the arterial inflow segment no differences were found in AI between the groups. In the venous outflow segments $\mathrm{AI}$ was lower in the efferent vein segments in the ePTFE group as compared to both the SV-group and the stretch.PTFE group $(p<0.05)$. 
Figure 6: Bar graphs demonstrating the results of measurements of Area-Increase (AI) assessed at defined sites in the grafts and host vessels, for all graft types $\left({ }^{*}, \mathrm{p}<0.05\right)$. Data are presented as medians and $25^{\text {th }}$ and $75^{\text {th }}$ percentile intervals. (sPTFE $=$ stretch PTFE, SV = saphenous vein, ePTFE $=$ expanded PTFE)

\section{Area Increase}

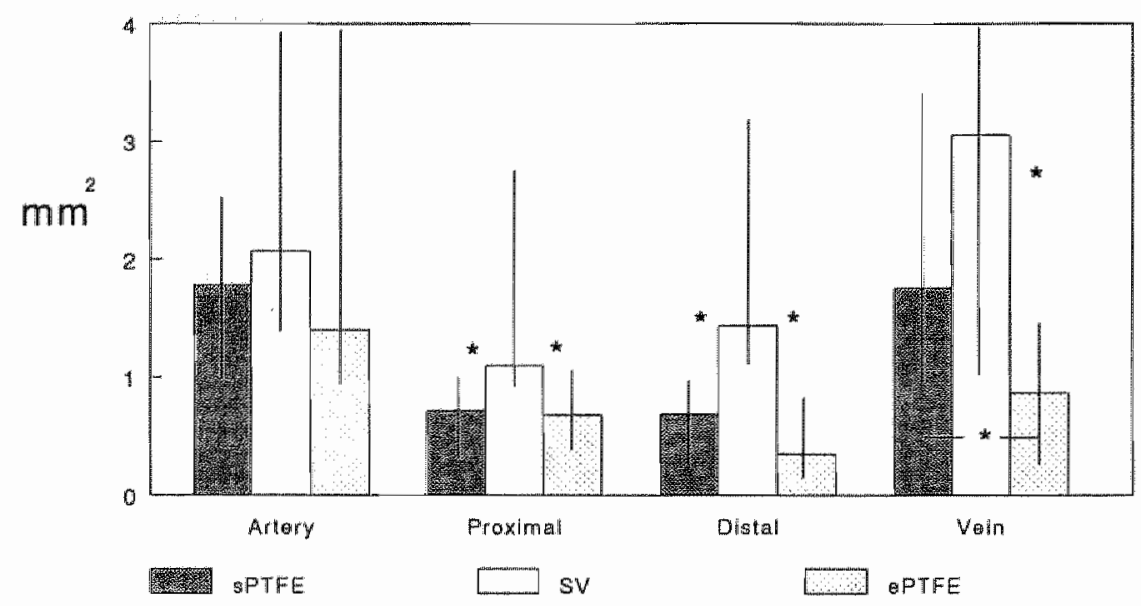

Figure 7: Scatterplot showing the relation between vein RD and distal graft RD (only PTFE grafts). A positive correlation was observed $(\mathrm{p}<0.05)$, suggesting vein graft interaction.

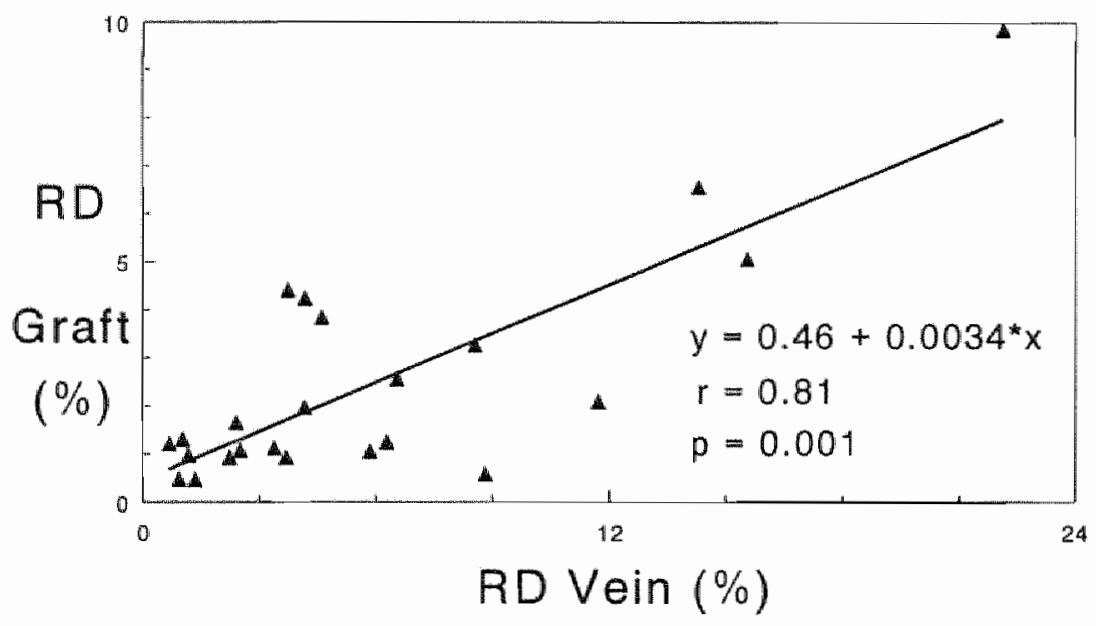




\section{Graft-vein interaction.}

To study a possible interaction between the dimensions and elastic properties of the vein and the PTFE (stretch and expanded) graft, we correlated the RD values of the vein segment with $\mathrm{RD}$ values for the distal graft segment (Figure 7). A positive relation between vein $R D$ values and distal graft $R D$ values was found $(p<0.05$, linear regression). Between vein diameter and distal graft distension a negative correlation was observed $(\mathrm{p}<0.05)$.

\section{DISCUSSION}

The major finding of the present study is that mismatch in elastic properties around the arterial and venous anastomoses of human AV-fistulas has a different character. In the arterial anastomosis a decline in AI (area increase) was found, indicating a sudden drop in the capacity to store blood volume. By contrast, in the venous anastomosis an increase in the capacity to store blood volume was encountered in the stretch-PTFE and EPTFE group. Since an abrupt increase in the capacity to store blood volume is associated with disturbances in flow, like enhanced particle residence time and flow stasis, it may contribute to the predisposition of intimal hyperplasia to develop at the venous anastomose ${ }^{21}$. The stasis of flow, caused by the sudden increase in capacity to store blood volume, may lead to a concentration of platelets and upstream released growth factors at a point just distal from the venous anastomoses, possibly initiating smooth muscle cell replication ${ }^{3,23,39}$. The repeated damage of the graft due to puncturing may enhance the upstream release of growth factors. The expected stagnation of flow at this particular site indicates a low wall shear rate at this point. This condition is associated with increased intimal thickening, as has been demonstrated in many studies ${ }^{22-28}$. The mechanism by which low shear conditions promote intimal thickening may be of influence on the growth control function of the endothelium ${ }^{29.31}$.

A limitation of the use of elastic parameters like Al and RD is that pulse pressure differences are not corrected for. However, the comparison of the elastic parameters within the grafts and around the anastomoses is independent of the local pulse pressure, assuming that pulse pressure does not change over the short segment considered.

A recent study demonstrated that pulsatile stress initiates vascular smooth muscle cell (VSMC) proliferation in human saphenous vein but not in internal mammary artery ${ }^{16}$, indicating a difference between the proliferative response of the arterial and venous smooth muscle cells to this physical stress. This suggests that the excessive stretch at the arterial and venous anastomoses due to the mismatch in elastic properties may lead to proliferation of VSMC at the venous anastomosis, but not at the arterial anastomosis. A possible contributing mechanism may be the different effect of elongation on the excessive stress encountered at the arterial and venous anastomosis, respectively. 
A noncompliant stiff graft does not have the possibility to elongate during the cardiac cycle. This indicates that elongation of the arterial inflow segment during the systolic phase approximates the arterial segment and the graft, thereby decreasing the effect of mechanical stretch. At the venous anastomoses the elongation leads to separation, leading to increase in mechanical stretch. This indicates that mismatch in compliance may have a different effect on the extent of the excessive mechanical stretching encountered at the arterial and distal anastomoses, respectively, due to the opposite effect of elongation at these sites. The new stretch-PTFE graft has the possibility to elongate during the cardiac cycle and may therefore decrease the effect of excessive mechanical stretching at the venous anastomosis ${ }^{40}$. This may lead to better primary patency rates for stretch-PTFE grafts as compared to non-compliant grafts.

Placement of an interposition graft in the construction of a vascular access leads to an enormous pressure- and flow increase at the site of the efferent vein, which may contribute to the development of vessel wall injury ${ }^{41}$. Mismatch around the anastomoses of interposition grafts, leads to impedance mismatch, thereby reducing the amount of pulsatile energy ${ }^{20,42}$. Therefore, placement of a stiff graft probably reduces the pulsatile stress and flow in the efferent vein, which may prevent the occurrence of intimal stenoses at this site. On the other hand, placement of a stiff graft increases peri-anastomotic mismatch in elastic properties, which may promote intimal thickening at the anastomoses, especially at the venous site, as is indicated by our data. The complexity of hemodynamics in AV fistulas is illustrated by the interaction of the distal end of the graft and the venous outflow segment. Since the elastic properties of the graft and the vein were assessed quite close to the anastomoses (within $1 \mathrm{~cm}$ ), the elastic properties of the graft may be influenced by the elastic properties of the vein. This is supported by the finding that a positive correlation was found between RD values obtained in the PTFE grafts and in the vein, as depicted in figure 8. The dimensions of the vein may also be of influence on the distension of the distal graft segments. The pulse wave arriving at a large diameter vein will not be reflected at this point. However, when the distal graft segment is anastomosed to a small diameter vein, part of the pulse wave will be reflected, leading to higher distensions in the distal graft. The presence of this type of interaction at the venous anastomosis of graft AV fistulas is suggested by the negative correlation between vein diameter and distal graft relative distension (Figure 8).

Recently, modifications of the conventional techniques for the construction of distal PTFE anastomoses have been introduced in peripheral bypass surgery, using anastomotic vein patches or cuffs ${ }^{43,44}$. Patency rates of ePTFE grafts anastomosed with these vein patches or cuffs at the crural vessels are promising ${ }^{44}$. Theoretically, the vein patches or cuffs may improve the abrupt change in compliance encountered in conventional anastomoses. However, the interposition of collars or cuffs with a large diameter may result in more flow disturbance due to the increase of hemodynamic capacity (equation 2). Therefore, in the design of modifications in anastomotic vein patches, the achievement of a gradual change in elastic properties in the anastomoses needs to be addressed. 
Figure 8: Scatterplot demonstrating the relation between vein diameter and distal graft relative distension. A negative correlation was observed between these parameters $(p<0.05)$.

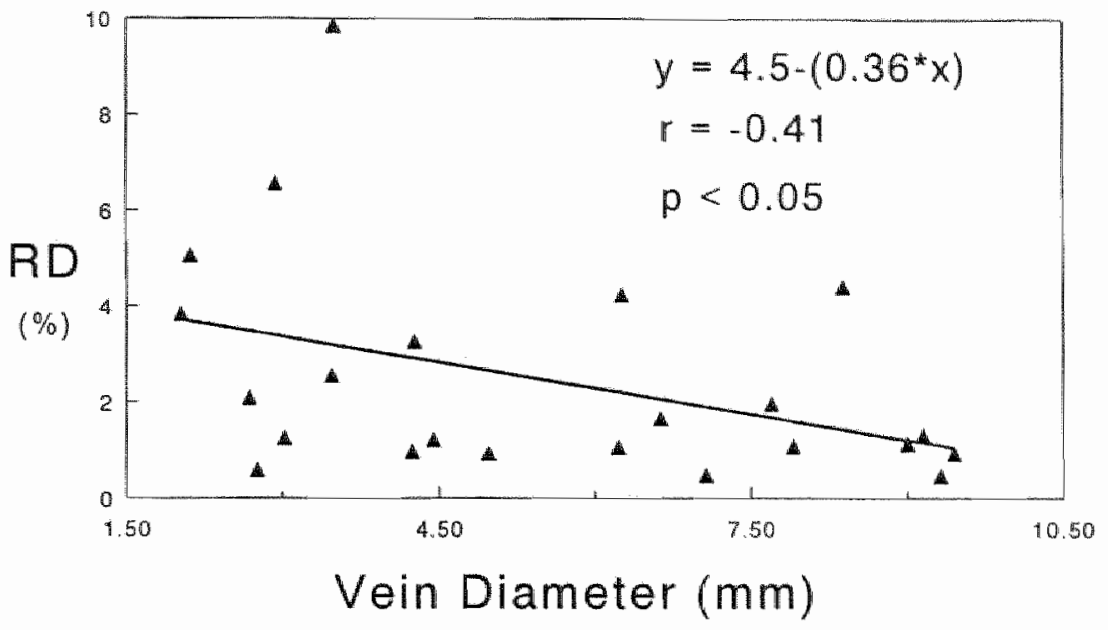

The higher values in the graft for RD and $\mathrm{AI}$ for the $\mathrm{SV}$ group as compared to the prosthetic materials indicate advantageous hemodynamic properties of the autologous graft $^{20}$. These findings confirm the results of a previous study from our institution, comparing ePTFE and saphenous vein bypass grafts in the lower limb. The beneficial elastic properties of the saphenous vein grafts resulted in a better match around the venous anastomosis, which may be an explanation for the better primary patency rates for saphenous vein grafts as compared to ePTFE grafts when used as a vascular access $^{2}$. The new stretch-PTFE graft showed slightly better elastic properties as compared to the ePTFE graft. In the stretch-PTFE graft the area-increase (AI) was maintained along the graft, in contrast to the ePTFE grafts, where a decrease was observed. This indicates a better preservation of pulsatile energy of the stretch-PTFE grafts as compared to the ePTFE grafts. However, this did not result in a better match around the venous anastomoses. A higher $\mathrm{Al}$ was found in the venous outflow segments in the stretch-PTFE group, indicating a better management of pulsatile flow at this point. This may contribute to a better hemodynamic enviromment of this flow segment, possibly leading to a decrease in the development of flow-induced hyperplastic lesions in the ouflow segments of stretch-PTFE grafts?

In conclusion, different characteristics were found for peri-anastomotic mismatch in elastic properties between the arterial and venous anastomoses of graft AV-fistulas in hemodialysis patients. A decline in area-increase, representing the capacity of the vessel wall to store blood volume, was found in the arterial anastomosis, while in the venous anastomosis an augmentation in area-increase was observed in the prosthetic grafts. Since the latter condition may lead to flow disturbances, like increased particle residence time and low shear stress, it may contribute to the predisposition of intimal byperplasia to develop at the venous anastomoses. 


\section{REFERENCES}

1. Windus DW. Permanent vascular access: a nephrologist's view. Am I Kidney Dis 1993; $21: 457.471$

2. Jenkins AMcL, Buist TAS, Glover SD. Medium-lerm follow-up of forty autogenous vein and forty polytetrafluorethylene (Gore-Tex) grafts for wascular access. Surgery 1980; 88.667-672.

3. Swedberg SH, Brown BG, Sigley R, Wight TN, Gordon D, Nicholls SC. Intimal fibromuscular hyperplasia at the venous anastomosis of PTFE grafis in hemodialysis patients. Circulation $1989 ; 80: 1726-1736$.

4. Rehkter $M$, Nicholls $S_{\text {, Ferguson } M}$, Gordon $D$. Cell proliferation in human arteriovenous fistulas use for hemodialysis. Arterioscler Thromb 1993; 13:609-617.

5. Sothurai VS, Yao JST, Flinn WR, Batson RC. Intimal hyperplasia and neointima: An ultrastructural analysis of thrombosed grafts in humans. Surgery 1983; 93:809-817.

6. Madras PN, Ward CA, Johnson WR, Singh Pl. Anastomic hyperplasia. Surgery 1981; 90:922-923.

7. Bassiouny HS, White $\mathrm{S}$, Glagov $\mathrm{S}$, Choi $\mathrm{E}_{\mathrm{x}}$ Giddens DP, Zarins CK. Amastomotic intimal hyperplasia: Mechanical injury or flow induced. I Vasc Swrg 1992;15:708 717 .

8. LoGerfo FW, Quist $W_{\text {, }}$ Nowak MD, Crawshaw HM, Haudenschild CC. Downstream anastomotic hyperplasia. A mechanism of failure in Dacron arterial grafts. An Surg 1983; $197: 479-483$.

9. Echave $\mathrm{V}$, Koornick AR, Haimow M, Jacobson JH. Intimal hyperplasia as a complication of the use of the polytetrafluoroethylene graft for femoral-popliteal bypass. Surgery 1979; $86.791-798$.

10. Sottiurai VS, Sue SL, Feinberg II EL, Bringaze WL, Tran AT, Batson RC. Distal amastomotic intimal hyperplasia: Biogenesis and etiology. Eur J Vasc Surg 1988; 2:245-256.

11. Zacharias RK, Kirkman TR, Kenagy RD, Biowen-Pope DF, Clowes AW. Growth factor production by polytetrafluoroethylene vascular grafts. $J$ Vasc Surg $1988 ; 7.606-610$.

12. Liu MW, Roubin GS, King III SB. Restenosis after coronary angioplasty. Potential biologic determinants and tole of intimal hyperplasia. Circulation 1989; 79.1374-1387.

13. Abbott WM, Megerman $J_{*}$ Hasson JE, LItalien $G$, Warnock DF. Effect of compliance mismatch on vascular graft patency. $J$ Vasc Surg 1987; 5:376-382.

14. Okuhn SP, Connelly DP, Calakos N, Ferrell L, Man-Xiang P, Goldstone J. Does compliance mismatch alone cause neointimal hyperplasia? J Vasc Surg 1989; 9.35-45.

15. Kidson $1 \mathrm{G}$, Abbotl WM. Low compliance and arterial graft occlusion. Circulation 1978; $58 \cdot 1 / 14$.

16. Predel $\mathrm{HG}_{2}$ Yang $\mathbb{Z}_{\text {, }}$ Von Segesser $L$, Turina M, Buhler FR, Luscher TF. Implications of pulsatile stretch on growth of saptienous vein and mamnary artery smooth muscle. Lancet 1992; $340: 878-879$.

17. Friedman MH. Some atherosclerosis may be a consequence of the normal adaptive response to shear. Atherosclerosis $1990 ; 82: 193-196$.

18. Leung DYM, Glagow S, Mathews MB. Cyclic stretching stimulates synthesis of matrix components by arterial smooth muscle cells in vitro. Science 1976, 191:475-477.

19. Sotturai VS, Kollross P, Glagov S, Zarins CK, Mathews MB. Morphologic alteration of cultured arterial smooth muscle cells by cyclic stretching. I Surg Res $1983 ; 35: 490-497$.

20. Baird RN, Abbott WM. Pulsatile blood-flow in arterial grafts. Lancet 1976; October $30: 948 \times 950$.

21. Stewart SFC, Lyman DJ. Effects of a vascular graft/natural artery compliance mismatch on pusatille flow. J Biomech 1992; 25:297-310.

22. Zarins $\mathrm{CK}$, Bomberger RA, Glagov $S$. Local effects of stenoses: Increased flow velocity inhibits atherogenesis. Circulation 1981; 64:11221-1/227. 
23. Zarins $\mathrm{CK}$, Giddens DP, Bharadvaj $\mathrm{BK}$, Sotturat VS, Mabon RF, Glagov $\mathrm{S}$. Carotid bifurcation atherosclerosis. Quantitative correlation of plaque localization with flow velocity profiles and wall shear siress. Circ Res $1983 ; 53: 502-514$,

24. Asakura T, Karino T. Flow patterns and spatial distribution of atherosclerotic lesions in human coronary arteries. Circ Res 1990; 66:1045-1066.

25. Cashin WL, Sammarco ME, Nessim SA, Blankenhorn DH. Accelerated progression of atherosclerosis in coronary vessels with minimal lesions that are bypassed. New Eng $I \mathrm{Med}$ $1984 ; 311: 824-828$.

26. Sterpetti AV, Cucina A, Santoro L, Cardillo B, Cavallaro A. Modulation of nrterial smooth muscle cell growth by hemodynamic forces. Eur J Vasc Surg 1992; 6:16-20.

27. Kohler TR, Jawien A. Flow affects development of intimal hyperplasia after arterial injury in rats. Arterioscler Thromb 1992; 12:963-971.

28. Kohler TR, Kirkman TR, Kraiss LW, Zierler BK, Clowes AW. Increased blood tlow inhibits. neointimal hyperplasia in endothelialized vascular grafts. Circ Res 1991; 69:1557 1565.

29. Buga GM, Gold ME, Fukuio JM, Ignarro LJ. Shear stress-induced release of nitric oxide from endothelial cells grown on beads. Hypertension 1991; 17:187-193.

30. Hsieh HJ, Li NQ, Frangos IA. Shear stress increases endohelial platelet-derived growth factor mRNA levels. Am J Physiol 1991; 260:H642-H646.

31. Cooke JP, Rossitch E, Andon NA, Loscalzo J, Dzau VJ. Flow activates an endothelial potassium channel to release an endogenous nitrovasodilator. $/$ Clin Invest $1991 ; 88: 1663-16$ 71.

32. Hoeks APG, Brands PJ, Smeets FAM, Reneman RS. Assessment of distensibility of superficial arteries. Uitrasound Med Biol 1990; 16:121-128.

33. Hofstra L, Ermers EJM, Langeveld APM, Hoeks APG, Kitslaar PJEHM. Vessel Wall Doppler Tracking: A new technique to assess wessel wall compliance. J Vasc Tech 1993; 17:65-68.

34. ORourke MF. Arterial stiffness, systolic blood pressure, and logical treatment of arterial bypertension. Hypertension $1990 ; 15: 339-347$.

35. Reneman RS, Merode van T, Brands PJ, Hoeks APG. Inhomogeneities in arterial wall properties under normal and pathological conditions. I Hypertens $1092 ; 10: 535$. 539.

36. Hofstra L, Willigers JM, Huvers EC, al. Short-term variations in elastic properties of at muscular artery in humans. Clin Sci 1993; 50:472-480.

37. Hofstra L, Bergmans DCJ, Hoeks APG, Tordoir JHM, Kitslaar PJEHM. Inhomogenueties in elastic properties of saphenous vein arterial bypass grafts in humans. Eur J Wasc Surg 1994 ; $40.300-310$.

38. Fillinger MF, Reinitz ER, Schwartz RA, et al. Graft gemetry and venous intimal-medial hyperplasia in arteriovenous loop grafts. J Vasc Surg 1990; 11:556-566.

39. Nerem RM, Girand PR. Hemodynamic influences on wascular endothelial biology. Toxicologic: Pathology $1990 ; 18.572-582$.

40. Pärsson $\mathbb{H}$, Jundzill W, Hallberg E, Thöne J, Norgren L. Acute thrombogenicily and 4 wecks: healing properties of a new stretch-ePTFE graft. Eur J Vase Surg 1993; 7:63-70.

41. Fry DL. Certain chemorheologic considerations regarding the blood vascular interface with particular reference to coronary artery disease. Circulation 1969; XXXXX and XI: WV3.IV59.

42. O'Rourke MF. Steady and pulsatile energy losses in the systemic circulation under normal conditions and in simulated arterial disease. Cardiowasc Res 1967; 1:313-326.

43. Tyrrell MR, Chester JF, Vipond MN, Clarke GH, Taylor RS, Wolfe JHN. Experimental evidence to support the use of interposition vein collars/patches in distal PTFE anastomoses. Eur J Vasc Surg 1990; 495-101.

44. Taylor RS, Loh A, McFarland RJ, Cox M, Chester JF. Improved technique for polyletrafluoroethylene bypass grafting: long-term results wsing anastomotic vein patches. Br J Surg 1992 ; 79.348-354. 



\title{
CHAPTER 8
}

\section{THE DIMENSIONS AND ELASTIC PROPERTIES OF HUMAN SAPHENOUS VEIN GRAFTED INTO THE ARTERIAL CIRCULATION ARE STABLE OVER TIME}

\author{
L Hofstra, DCJJ Bergmans, APG Hoeks, JHM Tordoir, PJEHM Kitslaar. \\ (submitted)
}

\begin{abstract}
Background. Structural changes of saphenous veins used as a bypass grafts include generalised intimal thickening and replacement of vascular smooth muscle cells by collagen and fibroblasts in the media. This may be the result of adaptation of the vein to arterial pressure and flow conditions. We investigated the possible influence of the structural adaptations on local elastic properties of venous peripheral bypass grafts in patients. In addition, local diameter changes of the grafts with time were measured. Methods. In 17 patients receiving a reversed saphenous vein bypass graft the local dimensions and elastic properties of the graft and native arteries were assessed with the use of Vessel Wall Doppler Tracking (VWDT). Measurements were performed at $2,6,12$ and 26 weeks after construction of the bypass.

Results. In local strain (in \%) and cross-sectional area increase $\left(\mathrm{mm}^{2}\right)$ no changes with time were observed in the graft and native arterial system. In the proximal graft segments an increase in diameter with time was observed (4.6 vs $5.2 \mathrm{~mm}, p<0.05$ ). Also in the outflow artery an increase in diameter with time was observed (4.9 vs 5.1 $\mathrm{mm}, \mathrm{p}<0.05$ ).

Conclusions. Our data indicate that the elastic properties of the saphenous vein grafted into the arterial circulation remain stable within the first 6 months after implantation. An increase in diameter in the proximal graft segments of the reversed saphenous vein grafts was observed. Since in the most proximal part of the graft the highest flow velocities are present, the structural dilatation may reflect an adaptational response to decrease shear rate at this point.
\end{abstract}

\section{INTRODUCTION}

The grafting of a saphenous vein into the arterial circulation leads to sudden changes in pressure as well as flow conditions. Local increase in pressure and flow occurs, and these physical stresses become pulsatile. This abrupt change in pressure and flow 
conditions may lead to functional as well as structural adaptations ${ }^{\mathrm{j}-4}$. The ability of large arteries to undergo structural adaption to changed flow and/or pressure conditions has been demonstrated by many investigators ${ }^{5-9}$. The role of the endothelium in the adaptional responses seems crucial. An increase in flow results in a functional and structural adaptation ${ }^{8,9}$, initiated by an increase in shear stress, probably sensed by the endothelial cells ${ }^{10,11}$. In vitro studies indicate that the mechanism by which structural adaptation occurs, may be shear stress induced release of growth factors, like PDGF and TGF-a, by the endothelium, possibly regulated by a shear responsive element ${ }^{12-15}$. Functional changes after alteration in shear rates are suggested by several studies $6,7,13,14,16$. High shear stress leads to an increase in the release of NO and substance-P by the endothelium, both resulting in vasodilatation. The time course of functional changes of the saphenous vein after grafting have been studied in a canine mode $1^{4,17}$. A decrease in endothelium dependent relaxation after the administration of acetylcholine (Ach) was reported indicating endothelial dysfunction of the venous graft, which has also been demonstrated in the saphenous vein when used as coronary bypass in humans ${ }^{17,18}$. However, responses to the administration of two other endothelium dependent relaxants showed a recovery to control values after 2 weeks, suggesting at least a partial recovery of the endothelial function.

Structural changes of the human saphenous vein after grafting can be divided into acute and chronic changes ${ }^{2,19-23}$. Acute changes include endothelial denudation and deposition of platelets, fibrin and leucocytes in the intima and edema, smooth muscle cell necrosis and hemorthage in the media. Chronic changes include generalized intimal thickening and the partial replacement of VSMC by collagen and fibroblasts in the media.

The observed functional and structural responses of the saphenous vein graft may alter the dimensions and the elastic properties with time and therefore may influence the hemodynamic function of the graft ${ }^{14}$. The time course of changes in elastic properties of saphenous veins has been reported in animal studies ${ }^{2,2,4}$. An upward shift was found in the pressure-diameter relation of veins after grafting with the use of an in vitro technique to assess the elastic properties ${ }^{2}$. In vivo assessment of the elastic properties of veins grafted into the arterial circulation of dogs, demonstrated no apparent change with time. This was confirmed in a clinical study ${ }^{2}$. However, the compliance values assessed at different sites along the graft were averaged, thereby excluding the evaluation of changes in local elastic properties due to tapering effects ${ }^{25}$.

In previous studies by our group the dimensions and elastic profiles of newly inserted human reversed saphenous vein grafts were reported, as assessed with the use of Vessel Wall Doppler Tracking, at defined sites in the graft and the arterial in- and outflow segments ${ }^{25,32}$. The use of both a fractional parameter (strain) and a capacitive parameter (compliance) was essential to give a proper mechanical profile of the reversed vein grafts. The aim of the present study was to investigate the local changes of the dimensions and elastic properties of these vein grafts within the first 6 months after implantation. 


\section{MATERLALS AND METHODS}

\section{Patients}

Patients with arterial insufficiency of the lower extremity as manifested by disabling claudication, restpain and/or tissue loss and receiving a reversed saphenous vein bypass graft were considered candidates for our study. Thirty-two consecutive patients received a reversed saphenous vein bypass during the study period (January 1992 August 1993). In three patients the vein grafts occluded within one month after implantation due to outflow problems. In seven patients a stenotic process occurred within the study period of six months. The presence of a possible stenosis was detected by Duplex scan before every session and was based on generally accepted Duplex criteria $^{26}$. The diagnosis of a hemodynamically significant stenosis was confirmed by angiogram. Although these grafts were surgically revised to maintain patency, these patients were excluded from the study since a stenosis could alter the hemodynamics of the graft by influencing pulse wave reflections ${ }^{27,28}$. In five patients the assessment of elastic properties was not possible at the first session due to hematoma formation and/or wound leakage. The remaining 17 patients were measured at strict time intervals after operation $(2,6,12$ and 26 weeks post-operatively). The autologous grafts were implanted using standard techniques and were inserted in an end-to-side fashion with running 6-0 Prolene sutures.

\section{Measurements of the elastic properties}

The elastic properties of the vein graft and host artery were assessed with the use of Vessel Wall Doppler Tracking (VWDT) (chapter 3 and 4$)^{29,30}$.

From distension (in $\mu \mathrm{m}$ ) and diameter (in $\mathrm{mm}$ ) the following parameters were calculated:

$$
\text { Relative Distension }(R D)=\frac{\Delta D}{D} * 100(\%)
$$

$$
\text { Area-Increase }(A I)=\frac{\pi \Delta D * D}{2}
$$

Relative distension (RD) represents the local strain of the vessel wall. Area-increase (AI) represents the capacity of the vessel to store and to release temporarily blood volume during the cardiac cycle ${ }^{31}$. Usually these parameters are corrected for pulse pressure, resulting in the distensibility coefficient (DC) and compliance coefficient (CC), respectively. In a previous study we correlated DC and CC values of the common femoral artery calculated with local invasive pressure measurements and digital beat-to-beat pressure measurements (Finapres, volume clamp technique), obtained in patients undergoing peripheral bypass surgery (chapter 5$)^{25}$. Although we observed reasonable correlation between $D C$ values calculated with local invasive 
pressure measurements and Digital Finapres measurements ( $r=0.93$ for $D C$ and $r=0.92$ for CC) we decided not to correct for pulse pressure, since pulse pressure behavior in a bypass may be unpredictable. Validation studies of the VWDT system demonstrated that the variation coefficient for distension of thick-walled medium-sized arteries, like the common femoral artery, lies between 10-15\% for young healthy volunteers (chapter 4). This substantial variation in elastic properties probably depends on the vasomotor tone of the active vessell. In diameter less variation was observed in this study, illustrated by a variation coefficient of $2-4 \%$. The variation coefficient for the carotid artery, an elastic artery, lies between $5-10 \%$. We believe that the variation coefficient of the elastic parameters for diseased femoral arteries and vein bypasses will not exceed the variation of healthy muscular arteries, and probably lies between $5-10 \%$.

In each graft measurements were performed in the proximal graft segment $(1 \mathrm{~cm}$ from the proximal anastomosis), in the middle segment, and in the distal graft segment (1 $\mathrm{cm}$ from the distal anastomosis). The inflow artery was measured $1 \mathrm{~cm}$ from the proximal anastomosis, the outflow artery was measured $1 \mathrm{~cm}$ from the distal anastomosis. The patients were measured at these sites $2,6,12$, and 26 weeks after operation.

At the same predefined sites in the graft and the arterial "n- and outflow arterial segments, peak systolic velocity was determined by placement of a Doppler sample midstream in the vessel.

Patients were measured in the supine position after an acclimatisation period of 20 minutes. All patients gave a written informed consent before entering the study. The study was approved by the institutional medical ethical committee.

\section{ANALYSIS}

Data are presented as medians and $25^{\text {th }}$ and $75^{\text {th }}$ percentile intervals. The changes in time for the values for the different parameters obtained at the defined sites were analysed with the use of the Friedman-test (two-way ANOVA). A p-value of less than 0.05 was accepted as level of statistical significance.

\section{RESULTS}

The patient characteristics are summarized in table I. Note that most grafts were anastomosed at a point below-knee. 
Table I: Patient characteristics and sites of anastomoses.

\section{Reversed SV (N=17)}

$\begin{array}{lcc}\text { Male } & & 12(69 \%) \\ \text { Female } & & 5(31 \%) \\ \text { Age } & \text { (Yrs) } & 68(\mathrm{SD} 8.8) \\ \begin{array}{l}\text { Diabetic } \\ \text { Clinical stage : }\end{array} & 5(29 \%) \\ & \text { II } & \\ & \text { III } & 5(28.6 \%) \\ & \text { IV } & 6(38.1 \%) \\ & \text { IV } & 6(33.3 \%)\end{array}$

Proximal Anastomosis :

Common Femoral Artery

$11(66.7 \%)$

Superficial Femoral Artery

$6(33.3 \%)$

Distal Anastomosis :

Popliteal Artery (above knee)

$4(19.0 \%)$

Popliteal Artery (below knee)

$11(66,7 \%)$

Crural

$2(14.3 \%)$

\section{Diameter}

The results of diameter measurement are summarized in table II and depicted in Figure 1. As the graph shows, an increase in diameter with time could be observed in the proximal graft segment $(p=0.05)$ and the afterial ouflow segment ( $p=0.05$, Friedman two-way Anova). In the mid- and proximal graft segments and the arterial inflow segments no change in diameter was observed. 
Table II: Results of the measurements of diameter (mm) at the predefined sites in the graft (proximal, mid and distal) and in the in- and outflow arterial segments, assessed at 2, 6, 12 and 26 weeks after implantation of the saphenous vein graft. Data are presented as medians and 25 th and 75 th percentile intervals. ${ }^{*}=p<0.05$, significant change with time, Friedman, two-way Anova).

2 weeks

\section{Site:}

Inflow

Proximal *

Mid

Distal

Outflow *

$$
7.4(7.1-10.6)
$$$$
7.4(6.0-10.8)
$$$$
4.3(3.2-5.1)
$$$$
5.0(4.1 .5 .7)
$$$$
5.7(4.8-6.7)
$$$$
5.2(4.9-5.8)
$$$$
5.3(3.7-8.0)
$$

6 weeks

12 weeks

8.1. $(5.6-12.0)$

$8.6(6.9-10.7)$

$4.7(3.9-5.4)$

$5.2(4.7-5.9)$

$5.6(4.1-6.6)$

$5.1(4.4-6.2)$

$6.2(4.8-7.1)$

$5.8(4.7-6.9)$

$5.6(5.3-6.2)$

Figure 1: Median walues of diameter (DI) assessed after 2, 6, 12 and 26 weeks at the proximal (Prox), mid (Mid) and distal (Dist) segments of the grafts and the inflow (Infl) and outflow (Outf) arterial segments. (* $\quad$ p<0.05, Friedman two-way ANOVA).

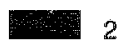

2

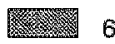

612

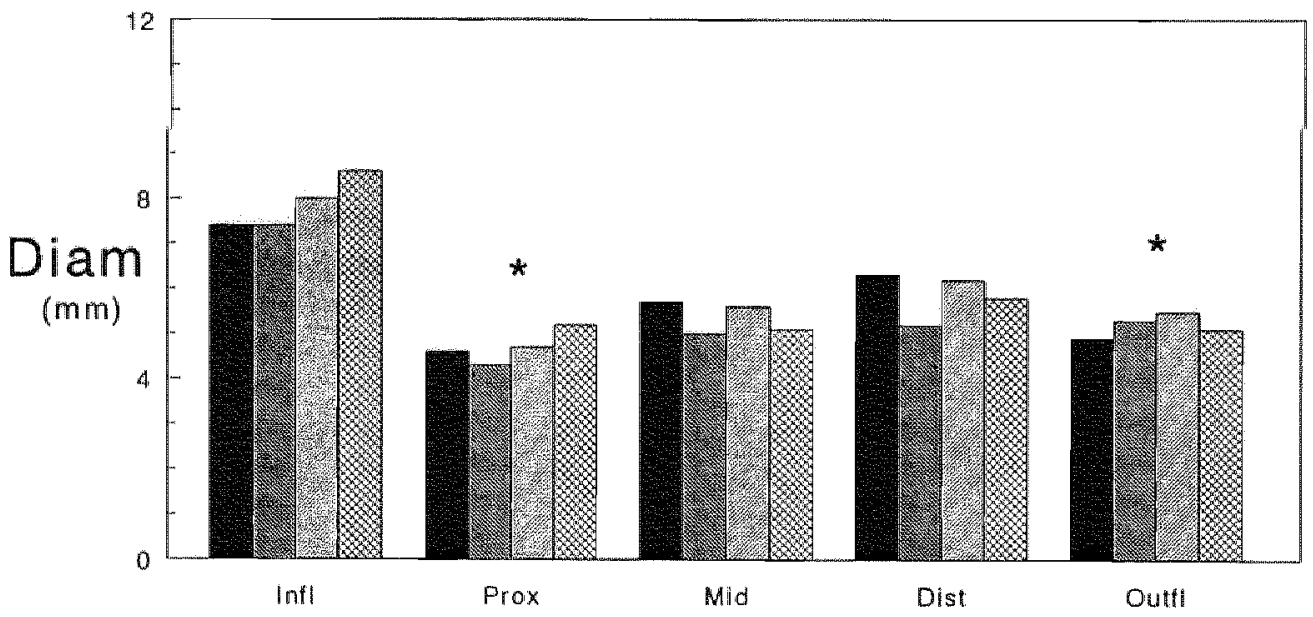




\section{Relative distension}

In $R D$, representing the local strain of the graft, no change with time was observed at the three different sites in the grafts (Table III, Figure 2). Also in the arterial inflowand outflow segments no changes in RD were shown within 6 months after operation. segments no change in diameter was observed.

Table III: Results of the measurements of relative distension (RD in \%) at the predefined sites in the graft (proximal, mid and distal) and in the in and outflow arterial segments, assessed at $2,6,12$ and 26 weeks after implantation of the saphenous vein graft. Data are presented as medians and 25 th and 75 th percentile intervals. No significant changes with time were observed.

2 weeks $\quad 6$ weeks 12 weeks 26 weeks

\begin{tabular}{lllll}
\hline Site: & & & & \\
Inflow & $2.6(1.8-3.9)$ & $2.5(1.8-3.9)$ & $2.0(1.4-3.1)$ & $2.4(1.8-3.7)$ \\
Proximal & $3.9(2.4-4.6)$ & $5.2(2.8-7.5)$ & $3.4(2.9-5.2)$ & $3.5(2.2-4.7)$ \\
Mid & $2.0(1.5-3.4)$ & $2.7(1.9-4.4)$ & $3.3(2.1-4.8)$ & $2.4(1.5-2.8)$ \\
Distal & $1.5(0.9-3.0)$ & $2.1(1.6-3.6)$ & $1.3(1.1-2.3)$ & $1.6(1.0-2.1)$ \\
Outflow & $1.4(1.1-2.9)$ & $1.2(0.7-1.8)$ & $2.0(1.3-2.3)$ & $1.9(1.2-2.1)$ \\
\hline
\end{tabular}

Figure 2: Bar graphs demonstrating the results of measurements of relative distension (RD) assessed at the defined sites in the grafts and host arteries. Data are presented as medians. No significant changes with time were observed.
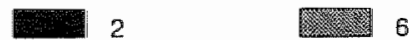

6

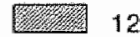

12

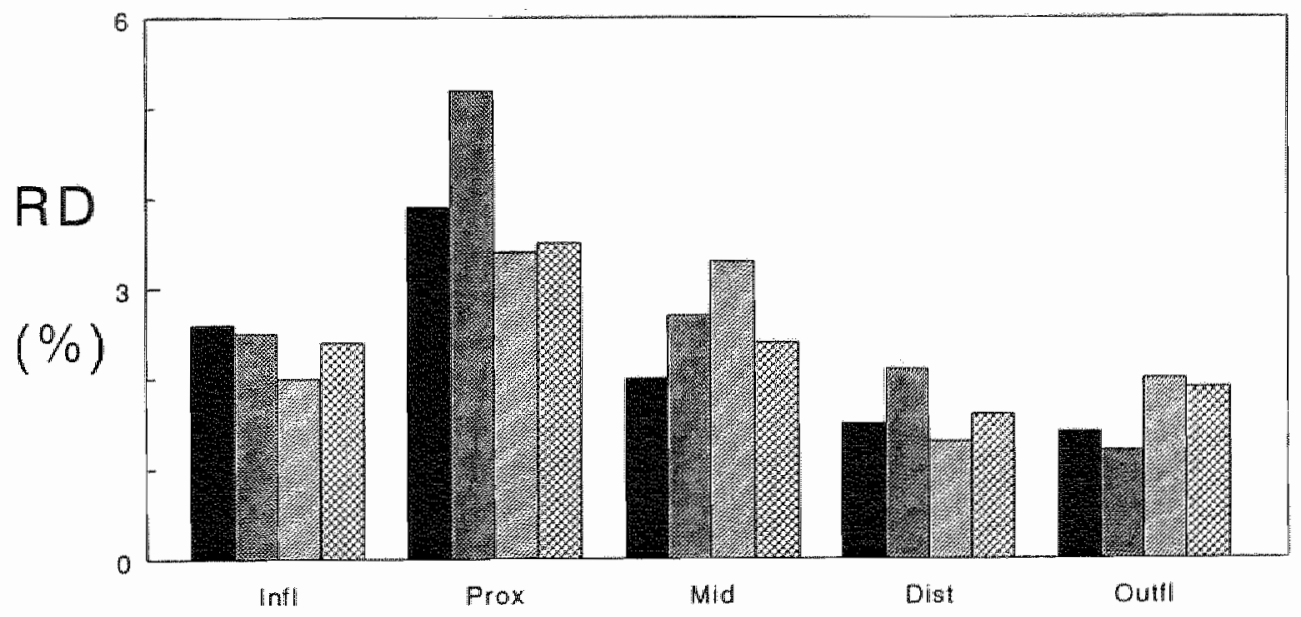




\section{Area-increase}

In Al, representing the capacity of the vessel wall to store blood volume during the cardiac cycle, no change was observed in the proximal graft segments $(p=0.19$, Friedman two-way Anova). In the mid- and distal graft segments and the arterial inand outflow segments also no changes in AI with time could be observed (Table IV, Figure 3).

Table IV: Results of the measurements of cross-sectional area-increase $\left(\mathrm{mm}^{2}\right)$ at the predefined sites in the graft (proximal, mid and distal) and in the in- and outflow arterial segments, assessed at $2,6,12$ and 26 weeks after implantation of the saphenous vein graft. Data are presented as medians and 25 th and 75 th percentile intervals. No significant changes with time were observed.

2 weeks $\quad 6$ weeks $\quad 12$ weeks $\quad 26$ weeks

\begin{tabular}{lllll}
\hline Site: & & & & \\
Inflow & $2.2(1.1-4.0)$ & $2.1(1.4-3.3)$ & $1.9(1.0-2.8)$ & $2.3(1.3-3.6)$ \\
Proximal & $1.6(1.1-2.0)$ & $2.0(1.1-3.4)$ & $1.7(1.2-2.1)$ & $1.8(1.2-2.3)$ \\
Mid & $1.4(1.0-1.7)$ & $1.3(1.0-2.3)$ & $1.9(1.3-2.4)$ & $1.2(0.8-1.3)$ \\
Distal & $0.9(0.6-1.4)$ & $1.0(0.9-1.9)$ & $0.8(0.5-1.4)$ & $0.8(0.6-1.3)$ \\
Outflow & $0.8(0.5-1.4)$ & $0.6(0.3-1.1)$ & $1.2(0.8-1.3)$ & $0.8(0.6-1.0)$ \\
\hline
\end{tabular}

Figure 3: Bar graphs demonstrating the results of measurements of the cross-sectional Area Increase (AI) assessed at defined sites in the grafts and host arteries. Data are presented as medians. No significant changes with time were observed.

2

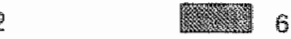

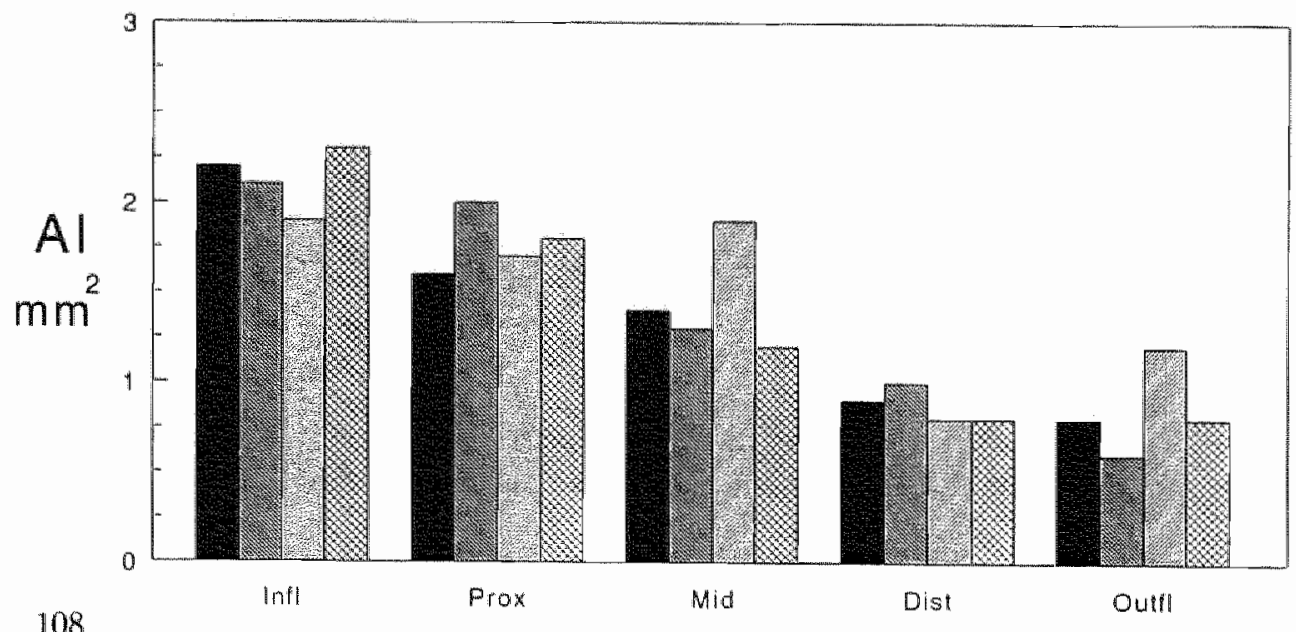




\section{Peak Systolic Velocity}

Peak systolic velocity in the proximal graft segments was higher as compared to PSV values in the mid- and distal portions of the grafts ( $<<0.05$, Mann-Whitney). With time, no changes were observed in as well the different sites of the graft as the arterial in- and outflow segments (Figure 4).

Figure 4: Median values of peak systolic velocity $(\mathrm{PSV}, \mathrm{cm} / \mathrm{s})$ measured at the defined sites in the graft and the in- and outflow arterial segments.
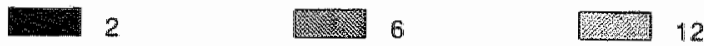

26

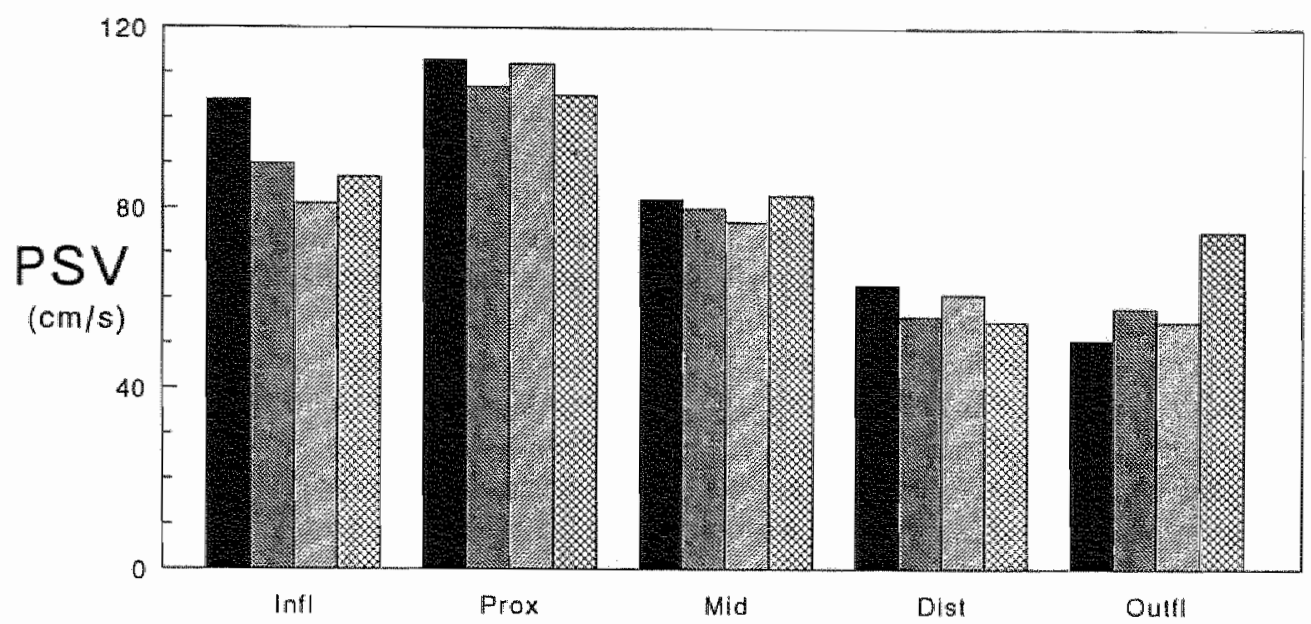

\section{DISCUSSION}

The goal of the current study was to evaluate changes over time of the dimensions and the local elastic properties of human saphenous vein after grafting into the arterial circulation. The major finding of our study is that the diameter of the proximal graft segments and of the arterial outflow segments increased within the first 6 months after operation, indicating an adaptation of these segments to the new flow and pressure conditions. Furthermore, the local elastic properties, as represented by relative distension and area-increase, are preserved with time along the entire graft. These findings indicate that the hemodynamic function of the graft is sustained within the first 6 months after operation.

\section{Dimensions}

Numerous studies suggested that changes in flow conditions of large arteries result in structural and/or functional adaptation in order to maintain the shear stress at a certain level ${ }^{5-9,12-14,16}$. High shear stress levels therefore should lead to diameter increase of the 
vessel. Due to the reversal of the saphenous vein in the construction of a bypass, the proximal part of the graft is the narrowest segment. This leads to high flow velocities in this part of the graft resulting in high shear stress levels sensed by the endothelial cells $^{33}$, which is illustrated by the significantly highter peak systolic velocity values in the proximal graft segment as compared to the mid- and distal segments. Our finding that the diameter of the proximal graft segments increases in the post-operative period, therefore, supports previous findings that vessels tend to maintain the shear rate at a certain level. Studies evaluating structural adaptation due to flow changes were always performed on large conduit arteries. Our data indicate that the human saphenous vein also has the ability to adapt to flow conditions. A possible mechanism may be the shear-stress dependent release of PDGF or TGF by the endothelium ${ }^{i 2-14}$. In the outflow arterial segments also an increase in diameter was observed, which may also be related to the increase in flow velocity in this segment, due to the restoration of flow after the construction of the bypass. The midgraft- and distal graft segments did not undergo considerable dimensional changes with time, which may be related to the lower flow velocities in these graft segments.

Studies evaluating the chronic structural changes after grafting demonstrated generalized intimal thickening, necrosis and replacement of vascular smooth muscle cells (VSMC) by fibroblasts and collage $\mathrm{n}^{2,19-2.3}$. This indicates an increase in wall thickness and loss of elastic components in the vessel wall, both of which are associated with a decrease of the elastic properties. Our data suggest that the local elastic properties assessed at predefined sites in the saphenous vein graft do not undergo considerable changes in the first 6 months after placement in the arterial system. The stable elastic properties of the saphenous vein graft with time may indicate that the decrease in elastic properties due to structural changes may be compensated for by an increase due to flow-induced functional adaptation. Another reason for the unchanged elastic properties of the graft with time may be the restricted ability of human saphenous vein to adapt to the new flow and pressure conditions. In studies evaluating the structure of the saphenous vein before grafting, pre-existing disease was observed in a large precentage of patients, consisting of intimal thickening and fibrosis of the media ${ }^{34,35}$. We observed similar findings in spare saphenous vein segments of patients undergoing peripheral bypass surgery. Functional testing of the saphenous vein segments in an organ chamber between an isometric force transducer revealed that segments showing media fibrosis had a blunted response to serotonine, indicating loss of contractile reactivity of VSMC in these segments (unpublished data). Therefore, functional adaptation in the graft due to flow increase may also be blunted, and may explain the lack of improvement of elastic properties of the grafts. The pre-existing pathology of the saphenous vein may also restrict the ability of the vein graft to undergo structural adaptation with time. In vein grafts with pre-existing media fibrosis proliferation of VSMC may also be limited. Since proliferation of VSMC is regarded as the most important feature in structural adaptation of large vessels, the ability of the diseased segments to adapt to the new environment may therefore be blunted ${ }^{36-40}$. Another factor restricting the ability of the saphenous vein bypass grafts to show 
functional adaptation to the new hemodynamic environment may be that about one third of the patients were diabetics. Diabetes mellitus leads to non-enzymatic changes of the elastic components of the media, leading to media sclerosis. This process leads to stiffening of vessels, probably limiting functional changes ${ }^{41}$.

The finding that the elastic properties of saphenous vein grafts remain stable with time supports the results from animal studies and from a clinical study ${ }^{2.24}$. In these studies, the fractional increase in diameter per unit of pressure was assessed at different segments of the graft. These values were avaraged to obtain a mean value for the graft. No apparent change with time was observed in both the animal and the clinical study. Our data indicate that large differences in RD, a fractional parameter, occur along the graft, due to the effect of reversed tapering. Therefore, we believe that changes of the local strain have to be assessed per graft segment and cannot be averaged from values obtained at different sites in the graft.

Studies investigating the functional changes of canine saphenous vein after grafting, demonstrated a partial recovery of endothelium-dependent relaxation ${ }^{17}$. This recovery occurred in the first two weeks after grafting. Since the first measurements of the elastic properties were performed two weeks after operation, we may have missed the early functional improvement. Also in another study recovery of the endothelium dependent relaxations were observed ${ }^{4}$.

In summary, no apparent changes were observed in the local elastic properties of human saphenous vein grafted into the arterial circulation. An increase in diameter with time was observed in the proximal graft segment, suggesting remodeling in this part of the graft. A possible mechanism explaining the increase in diameter may be high shear rate induced structural adaptation. In the arterial outflow segments also an increase in diameter with time was observed, which also may be a flow induced adaptational process. Our data suggest that the hemodynamic function of saphenous vein grafts in humans is stable during the first 6 months after operation. 


\section{REFERENCES}

1. Dobrin PB. On the roles of deformation, tension, and wall stress as critical stimuli eliciting myointimal/medial hyperplasia. I Vasc Surg 1991; $581-582$.

2. Dobrin PB, Littooy FN, Golan J, Blakeman B, Fareed J. Mechanical and histological changes in canine vein grafts. IJ Surg Res $1988 ; 44: 259-265$.

3. Dobrin $\mathrm{PB}$, Littooy FN, Endean ED. Mechanical factors predisposing to intimal hyperplasia and medial thickening in autogenous vein gratts. Surgery 1989; 105:393-400.

4. Miller VM, Reigel MM, Hollier LH, Vanhowtte PM. Endothelium-dependent responses in autogenous femorall veins grafted into the arterial circulation of the dog. I Clin Invest 1987; 80:1350-1357.

5. Casthin WL, Sanmarco ME, Nessim SA, Blankenhorn DH. Accelerated progression of atherosclerosis in coronary wessels with minimal lesions that are bypassed. New Eng $J$ Med $1984 ; 311: 824-828$.

6. Rubanyi GM, Freay AD, Kauser $\mathrm{K}$, Johns A, Harder DR. Mechanoreception by the endothelium: Mediators and mechanisms of pressure- and flow-induced vascular responses. Blood Vessels 1900; 27:246-257.

7. Tesfamariam $B$, Cohen RA. Inhibition of adrenergic vasoconstriction by endothelial cell shear stress. Circ Res 1988; 63:720-725.

8. Kamiya A, Togawa T. Adaptive regulation of wall shear stress to flow change in the canine carotid artery. Am J Physiol 1980; 239:H14-H21.

9. Langille BL, ODonnell $F$. Reductions in arterial diameter produced by chronic decreases in blood flow are endothelium-dependent. Science 1986:231:405-407.

10. Helmlinger $G$, Geiger $R V$, Schreck $S$, Nerem RM. Effects of pulsatile flow on cultured wascular endothelial cell morphology. J Biomech Eng 1991; 113:123-131.

11. Nerem RM, Girard PR. Hemodynamic influences on vascular endothelial biology. Toxicologic Paihology 1990; 18:572-582,

12. Hsieh HJ. Li NQ, Frangos JA. Shear stress increases endothelial platelet-derived growth factor mRNA levels. Am I Physiol 1991; 260:H642-11646.

13. Cooke JP, Rossitch E, Andon NA, Loscalzo J, Dzau VJ. Flow activates an endothelial potassium channel to release an endogenous nitrovasodilator. $J$ Clin Invest 1991; 88:1663-1671.

14. Buga GM, Gold ME, Fukuto JM, Ignarro LJ. Shear stress-induced release of nitric oxide from endothellal cells grown on beads. Hypertension 1991; 17:187-193.

15. Resmick N, Collins T, Atkinson W, Bonthron DT, Dewey CF, Gimbrone MA. Platelet-derived growth factor B chain contains a cis-acting fluid shear-stress-responsive element. Proc Nat Acad Sci U SA 1993; 90:4591-4595.

16. Ralevic $V$, Milner $P$, Hudlick $O$, Kristek $F$, Burnstock $G$. Substance $P$ is released from the cndothelium of normal and capsaicin-treated rat hind-limb vasculature, in vivo, by increased flow. Circ Res 1990; 66:1178-1183.

17. Ishii $T$, Okadome $K$, Komori $K$, Odashiro ' $T$, Sugimachi $K$. Natural course of endothelium-dependent and -independent responses in autogenous femoral veins grafted into the arterial circulation of the dog. Circ Res 1993; 72:1004-1010.

18. Lischer TF, Diederich $D$, Siebeenman $\mathbb{R}$, et al. Difference between endothelium-dependent relaxation in arterial and venous coronary bypass grafts. New Eng J Med 1988; 319:462-467.

19. Dilley $\mathrm{RJ}$, McGeachie JK. Prendergast $\mathrm{FJ}$. A review of the histologic changes in vein-to-artery grafts, with particular reference to intimal hyperplasia. Arch Surg 1988; 123:691-696.

20. Fuchs JCA, Mitchener IS, Hagen PO. Postoperative changes in autologous vein grafts. Ann Surg 1978; 188:1-15.

21. Dilley RJ, McGeachie IK, Tennant M. Vein to artery grafts: a morphological and histochemical study of the histogenesis of intimal hyperplasia. Aust $N Z J$ Swrg 1992; 62:297-303. 
22. Adcock GD, Adcock OT, Wheelet JR, et al. Arterialization of reversed autogenous vein gratis: Quantitative light and electron microscopy of canine jugular wein grafts harvested and implanted by standard or inproved techmiques. I Vasc Surg 1987; 6:283-295.

23. Milroy $C M$, Scot DJA, Beardi DD, Horrocks $M$, Bradfield NWB. Histological appearances of the long saphenous vein. I Pathology 1989; 159:311-316.

24. Cambria RP, Brewster DC, Hasson J, Megerman J, Warnock DF, Ablbot WM. The evolution of morphologic and biomechanical changes in reversed and in situ vein grafts. Ann Surg 1987; 205:167-174.

25. Hofstra L, Bergmans DCJJ, Hoeks APG, Tordoir JHM, Kitslaar PJEHM. Assessmen of inhomogeneities in elastic properties of in situ and reversed saphenous vein grafts in humans. Eur J Vasc Surg 1994; 8:100-105.

26. Buth J, Disselhoff B, Sommeling C, Stam L. Colot-flow duplex criteria for grading stenosis in infrainguinal vein grafts. $J$ Vasc Surg $1991 ; 14: 716-728$.

27. O'Rourke MF. Arterial stiffness, systolic blood pressure, and logical treatment of arterial hypertension. Hypertension 1990; 15:339-347.

28. Kelly RP, Gibbs HH, O'Rourke MF, et al. Nitroglycerin has more favourable effects on lefl ventricular afterload than apparen from measurement of pressure in a peripherat artery. Eur Heart J 1990; 11:138-144.

29. Hoeks APG, Brands PJ, Smeets FAM, Reneman RS. Assessment of distensibility of superficial arteries. Ultrasound Med Biol 1990; 16:121-128.

30. Hofstra L, Ermers EMM, Langeveld APM, Hoeks APG, Kitslaar PJEHM. Vessel Wall Doppler Tracking: A new technique to assess vessel wall compliance. $J$ Vasc Tech 1993; 17:65-68.

31. Reneman RS, Merode van T, Brands PJ, Hoeks APG. Inhomogeneities in arterial wall properties under normal and pathological conditions. J Hyperiens 1992; 10.S35-S39.

32. Hofstra L. Willigers JM, Huvers FC, et al. Short-term variations in elastic properties of : muscular artery in humans. Clin Sci 1993; 50:472-480.

33. Belkin M, Mackey WC, McLaughlin R, Umphrey SE, ODonnell TE. The variation in vein graft flow welocity with luminall diameter and outflow level. $J$ Vase Surg 1992; 15:991 -999.

34. Marin ML, Veith FJ, Panetta TF, et al. Saphenous vein biopsy: A predictor of wein graft failure. J Vasc Surg 1993; 18:407-415.

35. Panetta TF, Marin ML, Veith FJ, et al. Unsuspected preexisting saphenous vein disease: An unrecognized cause of vein bypass failure. $J$ Vase Surg 1992; 15:102-112.

36. Clowes AW, Reidy MA. Prevention of stenosis after vascular reconsiruction: Pharmacologic control of intimal hyperplasia. A review. J Vasc Surg 1991; 6:885-891.

37. Clowes AW, Clowes MM, Fingerle J, Reidy MA. Kinetics of cellular proliferation after arterial injury. $V$.Role of acute distension in the induction of smooth muscle cell proliferation. Lab Invest 1989; 60:360-364

38. Liu MW, Berk $\mathrm{BC}$. Restenosis following coronary balloon angioplasty. Role of smooth muscle cell prolferation. Trends Cardiovasic Med 1991; 1:107.111.

39. Liu MW, Roubin GS, King III SB. Restenosis after coronary angioplasty. Potential biologic determinants and role of intimal hyperplasia. Circulation 1989; 79:1374-1387.

40. Schwartz SM, Ross R. Cellular proliferation in atherosclerosis and hypertension. Prog Cardiovasc Dis 1984; 26:355-372.

41. Cairns SA, Woodcock JP, Marshall AI. Early arterial lesions in maturity onset diabetes mellitus detected by an ullrasound technique. Diabetologia $1978 ; 14: 107-111$. 



\title{
ANASTOMOTIC INTIMAL HYPERPLASIA IN PROSTHETIC ARTERIO-VENOUS FISTULAS FOR HEMODLALYSIS IS ASSOCIATED WITH INITIAL HIGH SHEAR RATE AND NOT WITH MISMATCH IN ELASTIC PROPERTIES
}

L Hofstra, DCJJ Bergmans, KML Leunissen, APG Hoeks, PJEHM Kitslaar, MJAP Daemen, and JHM Tordoir

(submitted)

\begin{abstract}
Background. Stenotic intimal thickening at the venous end of prosthetic arterio-venous (AV) fistulas for hemodialysis has been associated with peri-anastomotic mismatch in elastic properties and low shear rates. In a prospective way, we investigated the role of these factors on the occurrence of intimal hyperplasia in prosthetic AV fistulas in hemodialysis patients.

Methods. In 24 hemodialysis patients, the elastic properties were assessed in the distal graft and the outflow vein post-operatively, with the use of Vessel Wall Doppler Tracking (VWDT), a non-invasive ultrasound technique. In addition, local peak shear rate (PSR) was calculated from diameter (VWDT) and peak systolic velocity. The initial mismatch around the venous anastomoses and local PSR were correlated with the occurrence of stenoses during follow-up ( 2 years). The detection of a stenosis was performed with both Duplex uitrasound and angiography. Furthermore, surgically derived stenotic tissue samples were histologically examined with respect to endothelial cell coverage of the lumen.
\end{abstract}

Results. In 4 cases a stenosis developed in the venous anastomosis, in 8 cases in the venous outflow segment and in 4 cases at both sites. A better initial match in elastic properties around the venous anastomosis was observed in the fistulas developing a stenosis at this site as compared to the non-stenotic fistulas $(\mathrm{p}<0.05)$. The initial local PSR values at the site of the later stenosis were higher in the fistulas developing a stenosis as compared to the non-stenotic fistulas $(p<0.05)$. Histologic examination of stenotic tissue samples derived from these patients $(n=11)$ revealed only partial coverage of the lumen with endothelial cells (mean $48 \%$ ).

Conclusions. The occurrence of stenosis in prosthetic AV fistulas for hemodialysis in or adjacent to the venous anastomoses is associated with a high initial peak shear rate 
but not with a mismatch in elastic properties. A possible mechanism may be a denudating effect of excessive high shear on venous endothelial cells, thereby initiating intimal thickening.

\section{INTRODUCTION}

Arterio-venous fistulas constructed with the use of interposition grafts are often complicated by the development of occlusive intimal thickening, mostly occurring at the venous anastomoses ${ }^{1-4}$. The repair of these stenotic lesions leads to a mean hospitalisation time of one month a year for these patients ${ }^{2,3}$. The reasons for the high incidence of stenoses developing at the venous anastomoses are unclear. Studies evaluating the influence of varying levels of shear rate on intimal thickening reported conflicting data. In animal studies increased intimal thickening was found in areas with low shear rates, indicating that low shear rates may induce the intimal thickening ${ }^{5-12}$. A possible factor contributing to low shear rates at a site just downstream from the venous anastomosis may be the sudden increase in the capacity to store blood volume at this site ${ }^{13}$, leading to flow disturbances like flow separation and stasis ${ }^{14}$. On the other hand, very high shear rates damage the endothelial cells covering the lumen and may therefore result in vessel wall injury, possibly initiating intimal hyperplasia ${ }^{15.16}$. The latter concept is supported by animal studies evaluating intimal thickening in the venous outflow segments of arterio-venous fistulas. The most severe intimal thickening was observed in areas with the highest flow velocities ${ }^{17,18}$.

A second mechanical condition affecting intimal growth may be a difference in elastic properties around anastomoses, also called compliance mismatch ${ }^{12,19-22}$. This leads to points of excessive mechanical stretching, possibly resulting in vessel wall injury. Furthermore, excessive mechanical stretching may induce vascular smooth muscle cell replication, as has been demonstrated in in vitro model $\mathrm{s}^{23-26}$. However, an association between intimal thickening and compliance mismatch has not been convincingly demonstrated so far $r^{20}$.

In the present study, vessel wall elastic properties were measured around the venous anastomoses of polytetrafluoroethylene (PTFE) arterio-venous fistulas in hemodialysis patients. These measurements were performed within two weeks after the construction of the AV fistula, with the use of Vessel Wall Doppler Tracking (VWDT) ${ }^{27,28}$. In addition, peak systolic velocity (PSV) was measured at defined sites in the graft and in the inflow- and outflow vessels. From diameter, measured with VWDT, and PSV the peak shear rate (PSR) was calculated, an approximation of the actual shear rate exerted on the endothelial cells covering the lumen of the vessel wall. Furthermore, stenotic tissue specimens were harvested in the patients developing a stenosis during follow-up necessitating surgical repair. These specimens were histologically evaluated with respect to the endothelial cell coverage of the lumen, determined with the use of immunostaining (ULEX Europeus). The aim of the present study was to define the 
influence of both mismatch in elastic properties around the anastomosis and peak shear rate on the occurrence of occlusive intimal hyperplasia in or adjacent to the venous anastomoses in hemodialysis patients with a prosthetic AV fistula. In addition, the possible influence of shear rate on the presence of endothelial cells covering the lumen was evaluated.

\section{MATERIALS AND METHODS}

\section{Patient clinical profile}

Twenty-four consecutive patients receiving a hemodialysis graft $\mathrm{AV}$ fistula with the use of a PTFE prosthesis (WL GORE, Flagstaff, Arizona, USA) entered the study (December 1991 - December 1993). Generally, the construction of the fistula with the use of interposition grafts was a secondary procedure. In 4 patients the construction of a graft AV fistula was a primary choice, due to the absence of suitable veins in the forearm for the creation of a Brescia Cimino fistula. In all patients the arterial and venous anastomoses were constructed at the level of the elbow. The brachial artery served as the inflow segment; as outflow segments served the basilic, the cephalic or the cubital veins. The grafts were implanted in a loop configuration in the forearm.

\section{Measurement of the elastic properties.}

The diameter and distension of the vessel and graft segments were measured with the use of Vessel Wall Doppler Tracking (VWDT) ${ }^{27,28}$. This system combines B-mode imaging (ATL, Ultramark IV, Englewood, USA) and off-line data processing, which offers the possibility to assess the distension and diameter accurately at defined sites in the graft, the inflow artery and the efferent vein. In vitro studies showed that VWDT is able to detect distensions as low as $1 \mu \mathrm{m}$, indicating that the expected low distension values of the PTFE grafts can be measured properly. The recording time of 4 seconds per registration allows measurement of distension $(\Delta D)$ and internal diastolic diameter (D) during 3.5 consecutive heartbeats. The values of these consecutive beats were averaged in this study. From the diameter and distension the following parameters were calculated:

$$
\text { Relative Distension }(R D)=\frac{\Delta D}{D} * 100(\%)
$$

$$
\text { Area-Increase }(A I)=\frac{\pi \Delta D * D}{2}
$$

Relative distension gives the strain of the vessel during the cardiac cycle. Areaincrease represents the capacity of the vessel to store blood volume during the cardiac cycle. Generally, the parameters are corrected for pulse pressure resulting in the 
distensibility coefficient and compliance coefficient, respectively ${ }^{29}$. In studies evaluating the pressure distribution in graft AV fistulas it was shown that mean pressure and pulse pressure decrease along the graft and within the anastomoses ${ }^{17,18}$. The extent of the decrease waries with graft geometry. This implicates that valid pressure values can only be obtained with the use of invasive pressure measurements at all sites investigated. Since this would be unethical, we decided not to use pulse pressure in the equations.

Diameter and distension were assessed in the distal gralt $1 \mathrm{~cm}$ proximal from the venous anastomoses, in the venous anastomoses, and in the efferent vein, $1 \mathrm{~cm}$ distal from the venous anastomosis (Figure 1). The positioning of the cursor line at these particular sites was facilitated by repeated imaging of the anastomotic complex with B-mode.

Figure 1: Schematic drawing of a venous anastomosis of an arteriovenous fistula. Most of the stenoses developed at the site of the anastomoses (A) or in the venous outflow segment just distal from the anastomosis, within $1 \mathrm{~cm}(\mathrm{~V})$.

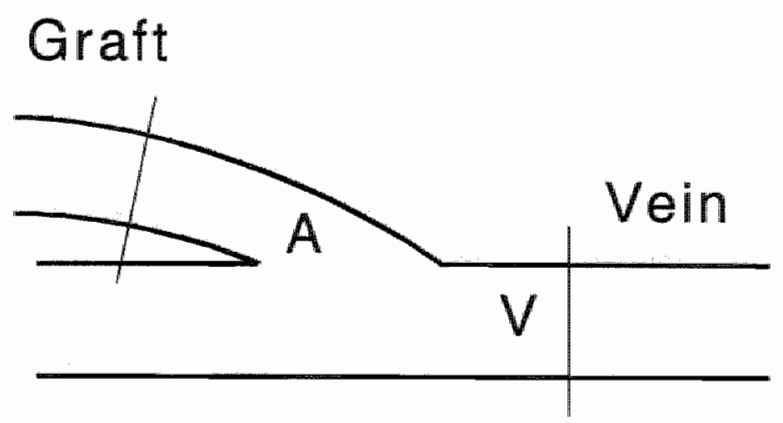

Since we attempted to evaluate the influence of mismatch in elastic properties around anastomoses on the occurrence of intimal hyperplasia, we indexed the values for AI and RD around the anastomoses, resulting in the match factor. Also for diameter a match factor was calculated, in order to obtain insight in the size differences around the anastomoses. The match factors for the different parameters were calculated in the following way:

Match factor $=$ value efferent vein $/$ value distal graft

A perfect match is considered to be present when the match factor is one. A mismatch value higher than 1 implicates an increase in the parameter within the anastomotic area, while a value lower than 1 implicates a decrease of the parameter in the direction of blood flow. 


\section{Determination of Peak Shear Rate (PSR)}

PSR was calculated from peak systolic velocity (PSV) and diameter. Peak systolic velocity was measured by placement of a Doppler sample midstream in the vessel at an angle of $60^{\circ}$. At the same location diameter was assessed with the use of VWDT. Diameter measurements with the use of VWDT have been validated in a previous study. The variation coefficient for diameter varied between 3 to $5 \%$, indicating low variation in diameter assessment with the use of this system ${ }^{30}$. PSV and diameter were assessed in the distal graft ( $1 \mathrm{~cm}$ from the anastomosis), within the venous anastomoses, and in the venous outflow segments (within $1 \mathrm{~cm}$ from the anastomoses). From PSV and diameter, PSR was calculated with the use of a modification of the HaagenPoisseuille formula:

Peak Shear Rate $(\mathrm{PSR})=\mathrm{n} *$ Peak Systolic Velocity/Diameter

The value for $\mathrm{n}$ depends on the shape of the velocity profile. When a parabolic laminar flow pattern is present, the value for $n$ is 4 . When the flow pattern is blunted, the value for $\mathrm{n}$ increases. Detailed information on velocity patterns in vivo was not available, and we therefore decided to use $n=4$ in the calculation of PSR. Especially in the anastomotic area high blood velocities are present, probably resulting in complex flow patterns. Therefore, PSR can only give an approximation of the actual shear forces exerted on the inner layer of the vessel wall. Some investigators calculate mean shear rate from diameter and volume flow, also assessed with the use of ultrasound ${ }^{5,6}$. Besides difficulties in calculating volume flow with the use of ultrasound in $A V$ fistulas, we believe that peak shear rate may give a better representation of the pulsatile character of the stress exerted on the endothelial cells ${ }^{31.33}$. In another study (chapter 11) we observed a negative correlation between peak shear rate and subendothelial VSMC proliferation, indicating that peak shear rate may have physiological importance. Therefore it was decided to use this parameter in the current study.

Most patients were measured within 2 weeks after the construction of the AV fistula. In some cases the measurements were delayed due to wound leakage or heamatoma formation. These patients were measured within 4 weeks after operation. All patients were measured in the supine position after an acclimatisation period of 20 minutes. At strict time intervals $(2,6$ and 12 weeks, and every 3 months thereafter) a Duplex scan of the arteriovenous fistula was performed for the detection of possible stenoses. When a stenosis was detected with Duplex, an angiogram was made to confirm the diagnosis. The study was approved by the medical ethical committee of the University Hospital of Maastricht. All patients gave written informed consent before entering the study.

\section{Histologic examinations}

Stenotic tissue was harvested for histologic evaluation in patients developing a stenosis necessitating repair with an interposition graft. These tissue specimens were fixed overnight in $10 \%$ phosphate buffered formalin, processed according to routine histologic 
procedures and paraffin-embedded. Serial sections ( 5 um thick) were cut and placed on gelatin coated glass slides. To identify endothelial cells, Ulex Europeus agglutinin (1:500 dilution, Vector Labs, Burlingame, CA, USA) was used. After blocking of the endogenous peroxidase activity with $0.3 \% \mathrm{H}_{2} \mathrm{O}_{2}$, sections were incubated with the lectine antibody (1:250, $45 \mathrm{~min}$., DAKO) after predigestion with pepsin $(1 \mathrm{mg} / \mathrm{ml}, 30$ min.). Subsequently, the sections were incubated with an anti-Ulex Europeus lectine peroxidase complex (1:100, DAKO). As the chromogen 3,3' diamino-benzidine was used. As a negative control spare saphenows vein segments were used, obtained from patients undergoing peripheral bypass surgery. The degree of endothelial cell cowerage was estimated by dividing the circumference of the lumen covered by endothelial cells by the total luminal circumference.

\section{ANALYSIS}

Data are presented as medians and 25 th and 75 th percentile intervals. To compare differences between groups, the Mann-Whitney-U test was used. The local initial mechanical and flow conditions of the fistulas developing a stenosis at either the venous anastomosis or the efferent vein were compared with the conditions of the fistulas without a stenosis at these locations. Since the initial mechanical and flow conditions were assessed at well defined sites in the anastomotic complex, good correlation of these local conditions with the site of the later stenosis was possible. To test which of the mechanical factors showed an independent correlation with the occurrence of intimal thickening, multiple regression analysis was performed. Mechanical factors showing a correlation with the occurrence of intimal thickening with a $\mathrm{p}$-value $<0.10$ were included in a stepwise multiple regression model. A pvalue lower than 0.05 was accepted as level of statistical significance.

\section{RESULTS}

In the 24 patients, a total of 20 stenoses developed in 16 fistulas in the perianastomotic area at the venous site during the follow-up period (mean 12.2 \pm 8.7 (SD) months); in 8 patients no fistula stenosis was found during the study period. In 4 fistulas a stenosis occurred only at the venous anastomosis. In 8 cases a stenosis developed only in the efferent vein adjacent to the anastomosis (within $1 \mathrm{~cm}$ from the anastomosis, Figure 1) and in 4 fistulas stenoses developed at both sites. This results in a total of 8 stenoses in the venous anastomosis and 12 in the efferent vein adjacent to the anastomosis (Table I). In all patients with a stenosis repair of the stenotic area was necessary to reestablish a sufficient flow for dialysis treatment, indicating that the stenosis was occlusive or subocclusive. Stenoses occurring at sites more downstream of the efferent vein $(n=4)$ were not included in this study, because of the difficulty to correlate the initial mechanical and flow information with the site of these stenoses. 
Table I: Patient Characteristics.

\section{Age}

Sex

Primary/Secundary Fistula
$61(39-68)$

11 male/13 female

$4 / 20$

\section{Stenoses at the venous anastomoses}

The initial relative distension (RD) values in the venous anastomoses were higher (Table II) in the fistulas developing a stenosis in the venous anastomoses as compared to the fistulas without stenosis development at this site $(2.5$ vs $1.0 \%, \mathrm{p}<0.05)$. No differences in initial diameter match and diameter at the anastomoses were observed between the groups. The initial match factors for Al and RD (ARM and RDM respectively, Table II, Figure 2) were closer to 1 in the stenotic fistulas as compared to the fistulas without a stenosis at this site (1.5 vs 5.1 for Al and 1.2 vs 2.6 for RD, $\mathrm{p}<0.05$ ), indicating a better initial match in elastic properties around the venous anastomoses in stenotic fistulas. Higher initial values for PSR were found in the anastomoses of stenotic fistulas as compared to the fistulas without a stenosis (308 vs $2121 / \mathrm{s}, \mathrm{p}<0.05$, Figure 3).

Table II: Vaiues for the different parameters measured at the venous anastomosis, two weeks after construction, for the AV fistulas with a later stenosis at this point (stenotic) and the fistulas without a stenosis (non-stenotic) at this site during follow-up. $\mathrm{RD}=$ relative distension, $D I A M=$ diameter, $A R M=$ match factor area increase, $\mathrm{RDM}=$ match factor relative distension, $\mathrm{PSR}=$ Peak shear rate. Values are presented as medians and $25 \mathrm{th}$ and $75 \mathrm{th}$ percentile intervals.

VENOUS ANASTOMOSIS

$\begin{array}{cc}\text { Stenotic } & \text { Nonstenotic } \\ (m=8) & (n=16)\end{array}$

P-value

$(n=8)$

$1.0(0.4-1.6)$

0.02

$\mathrm{RD}(\%)$

$2.5(1.5-3.2)$

$3.5(3.1-4.5)$

0.82

DIAM (mm)

$4.1(3.6-4.4)$

$5.1(2.8-8.4)$

0.005

ARM

$1.5(0.8-2.7)$

$2.6(2.0-5.0)$

0.01

RDM

$1.2(0.9-2.2)$

$212(168-276)$

0.02 
Figute 2: Bar graph showing the initial values for the match factor in area increase (ARM) for the fistulas developing a stenosis (stenotic) and non-stenotic fistulas. In the fistulas with a later stenosis at the wenous anastomoses as well as fistulas with a later stenosis in the venous outflow segment a more ideal match in area increase was observed $\left({ }^{*}, p<0.05\right.$, MannWhitney).

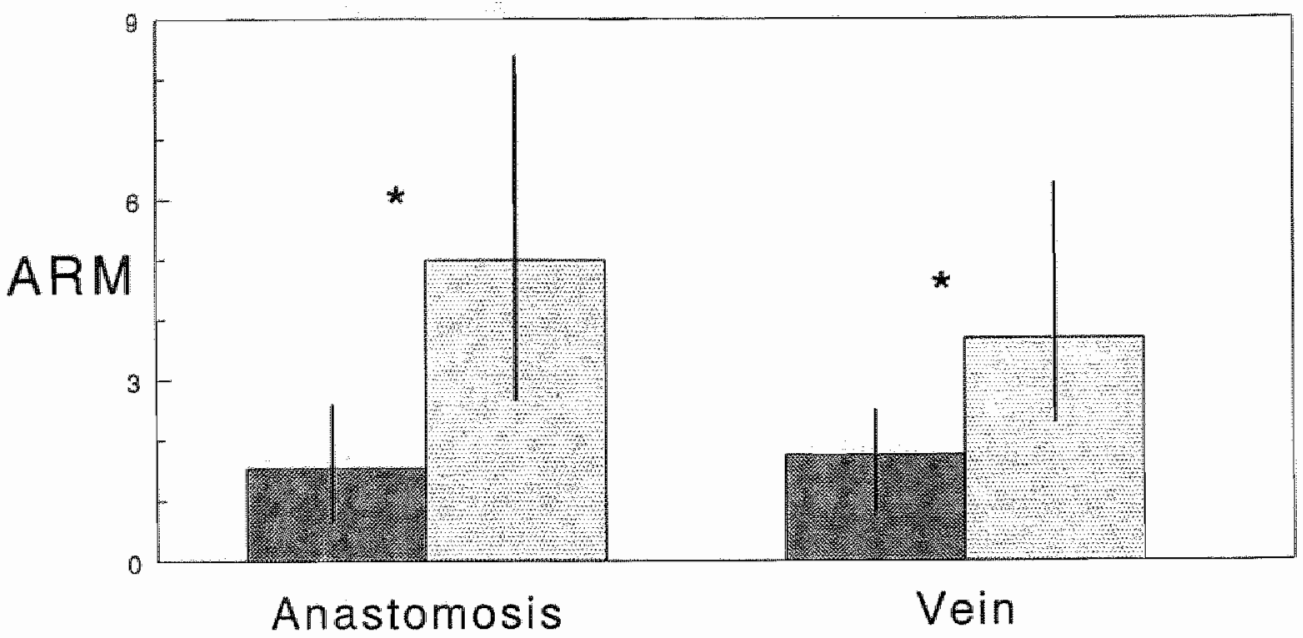

Table III: Values for the different parameters measured in the efferent vein just downstream the anastomosis, two weeks after construction, for the arterio-venous fistulas with and without a later stenosis at this point. $R D=$ relative distension, $D I A M=$ diameter, $A R M=$ match factor area increase, $\mathrm{RDM}=$ match factor relative distension, $\mathrm{PSR}=$ Peak shear rate. Values are presented as medians and 25 th and 75 th percentile intervals.

\section{EFFERENT VEIN}

Stenotic
$(\mathrm{n}=12)$$\quad \begin{gathered}\text { Non-stenotic } \\ (\mathrm{n}=12)\end{gathered}$

P-value

$\begin{array}{lccc}\text { RD }(\%) & 4.2(3.4-14.3) & 3.7(1.3-6.5) & 0.34 \\ \text { DIAM (mm) } & 4.2(2.9-8.3) & 6.3(4.2-7.9) & 0.34 \\ \text { ARM } & 1.8(0.7-2.6) & 3.7(2.2-6.2) & 0.04 \\ \text { RDM } & 1.2(0.9-2.2) & 2.5(1.8-4.2) & 0.05 \\ \text { PSR }(1 / \mathrm{s}) & 272(1.43-331) & 99(60-219) & 0.04\end{array}$




\section{Stenoses in the efferent vein}

No differences in initial relative distension and vein diameter (Table III) were found between the fistullas developing a stenosis in the efferent vein (within $1 \mathrm{~cm}$ from the anastomosis) and the fistulas without a stenosis at this site. Also no differences in diameter match around the venous anastomoses were observed between the groups. The initial match values for AI and RD (ARM and RDM, Table III, Figure 2) around the venous anastomosis were closer to 1 in the fistulas with a later stenosis in the efferent vein as compared to the non-stenotic fistulas (1.8 vs 3.7 for ARM and 1.2 vs 2.5 for RDM, $\mathrm{p}<0.05$ ). Initial PSR values in the efferent vein were higher in the fistulas with a later stenosis as compared to the fistulas without a stenosis in this area ( 272 vs $991 / \mathrm{s}, \mathrm{p}<0.05$, Figure 3).

Figure 3: Bar graph showing the initial values for PSR at the anastomoses and venous outflow segments for the fistulas developing a stenosis (stenotic) and the non-stenotic fistulas. Higher values for the fistulas with a later stenosis were observed at both sites $\left({ }^{*}, p<0.05\right.$, MannWhitney).

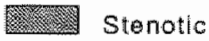

Norstenotic

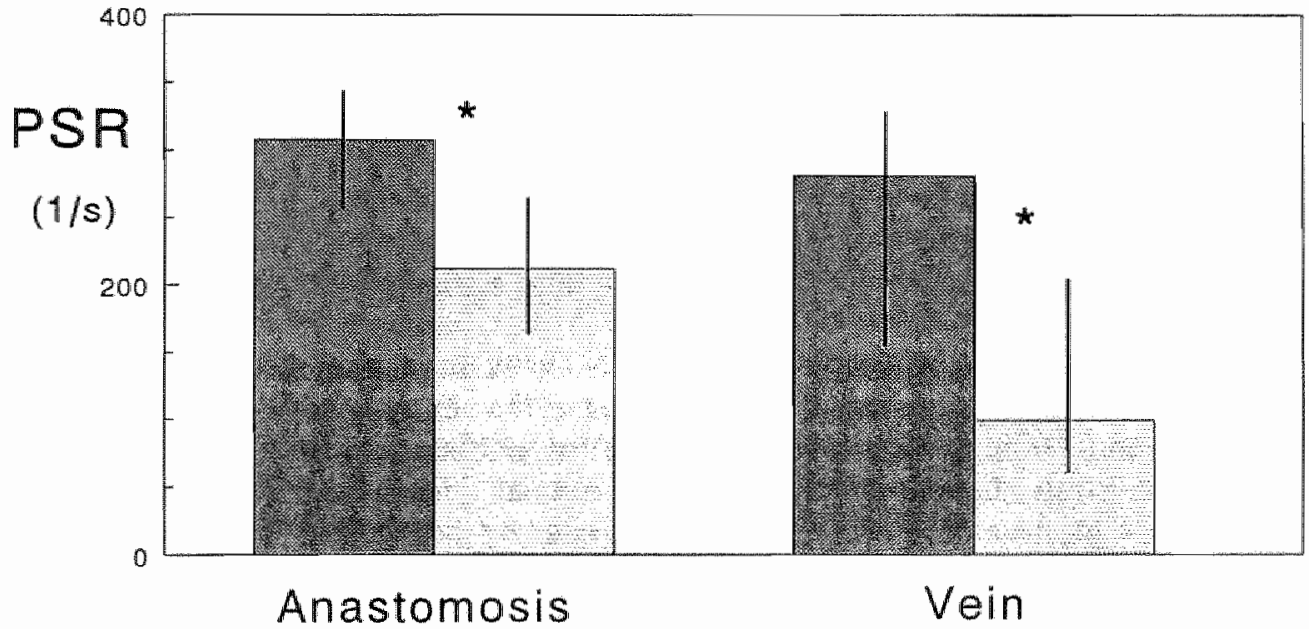

\section{Regression analysis}

Multiple regression analysis showed that an increase in initial PSR values was independently correlated with the occurrence of (sub)-occlusive intimal thickening ( $r=-$ $0.55, \mathrm{p}<0.05$ ) at both the venous anastomosis and the efferent wein. In addition, an RD match (RDM) closer to 1 around the venous anastomoses, indicating a better match, was correlated with the occurrence of a stenosis $(r=0.41, p<0.05)$. For match in Al (ARM) no independent correlation was found. 


\section{Histologic examinations}

In 9 cases the repair of the stenotic venous anastomosis was performed with the use of an interposition graft, which allowed examination of the stenotic lesions. A total of 11 stenotic specimens were derived from the anastomoses or the efferent vein adjacent to the anastomoses. In all samples the stenotic lesion consisted mainly of smooth muscle cells and extra-cellular matrix material. The mean percentage of endothelial cells covering the lumen was $48 \%$. In the control saphenous vein specimens ( $n=15$ ) a mean percentage of endothelial cells covering the lumen was $95 \%$.

\section{DISCUSSION}

The present study contains two major findings. First, the occurrence of stenotic intimal hyperplasia in prosthetic AV fistulas in humans is associated with initial high peak shear rate at the site of the later stenosis, indicating that high shear rates may initiate the development of stenotic intimal hyperplasia at the venous anastomoses of AV fistulas for hemodialysis. Second, a better initial match in strain around the venous anastomosis was found in fistulas developing a stenosis in this area, indicating that mismatch in elastic properties around anastomoses of prosthetic graft AV fistulas does not contribute to the initiation of stenotic intimal hyperplasia.

\section{Peak shear rate and intimal thickening}

In the stenotic fistulas higher PSR values were observed at the venous anastomoses and the outflow venous segments as compared to the non-stenotic fistulas. This suggests that high shear rates may initiate the development of intimal thickening in arterio-venous fistulas used for hemodialysis. These observations support the results of earlier studies investigating the effects of flow on cultured endothelial cells $\mathrm{s}^{15,16}$. Swelling, deformation, and finally denudation was observed in the cultured EC, suggesting serious EC injury. In animall studies evaluating the effect of varying levels of flow on the occurrence of intimal thickening at the venous outflow segment of AV fistulas, more intimal thickening was observed in fistulas with the highest flow velocities at this site ${ }^{18,34}$. This indicates that intimal thickening may be initiated by excessive high shear levels, which is also suggested by the data from the present study. This seerns to be in contrast with numerous other investigations, reporting that low shear rate promotes intimal thickening ${ }^{5.12,35}$. Several points have to be considered when comparing the effects of shear rate on intimal thickening, including the range of shear rate investigated, the possible difference between the regulation of intimal thickening in animals and humans, and the different response of arteries and veins to unphysiological shear rate. In some studies, the effect of a decreased flow was compared with the effect of normal arterial flow ${ }^{36,37}$. This indicates that the range of shear rates investigated lies between normal and low, which is a different range as compared to the level in our study. In normal arteries peak systolic velocities between 60 to $120 \mathrm{~cm} / \mathrm{s}$ are present, leading to substantially lower shear rate levels. In the venous anastomoses of an AV-fistula, peak systolic velocity values as high as $300-350 \mathrm{~cm} / \mathrm{s}$ can be measured, 
indicating excessive high shear rate levels. This implies that the shear rate magnitude found in the present study is far beyond physiological values. Therefore, comparison of the results of different studies has to be performed with regard to the range of shear rate values investigated.

Another point which has to be considered is the use of animal models in studies investigating the effects of flow on intimal thickening. In animal models intimal hyperplasia does not proceed to subocclusive or occlusive stenotic lesions, but is restricted in its extent ${ }^{38,39}$. The changes in intimal thickening that are found with flow wariation in animal models may be just an adaptational process. The factors involved in the regulation of intimal thickening in experimental animals may therefore be dissimilar to the factors that induce occlusive intimal lesions in humans. Our study overcomes this disadvantage, since we studied (sub)occlusive intimal hyperplasia in hemodialysis patients. A third consideration may be the use of different vessel types in studying the proliferative process. Some investigators use PTFE grafts, and measure the thickness of the neo-intima at different flow levels ${ }^{5,33}$. Another model which is often used is the balloon catheter denudated carotid artery in the rat or baboons $s^{6,41-43}$. In the present study, the intimal stenotic lesions occurred at the venous anastomoses or the venous outflow segment, which is adjacent to the PTFE graft but not in the graft. The excessive high shear rates in arteriovenous fistulas may be tolerated by arteries and arterial endothelial cells, while veins and venous endothelial cells undergoing these shear rate magnitudes may be damaged. This is supported by the data from the histologic examinations of the stenotic samples derived from the venous anastomoses of the fistulas in our patient group. The mean degree of endothelial cell coverage of the lumen was $48 \%$, indicating partial denudation of endothelial cells in these vessel segments, indicative for a denudating effect of excessive shear rates at the venous anastomoses and efferent vein of prosthetic AV fistulas in humans.

In low shear areas intimal thickening probably is induced by endothelial cells, sensing the forces exerted by blood flow ${ }^{44.51}$. In case of low shear, endothelial cells release growth promoting factors, leading to intimal thickening, in order to reestablish a certain level of shear rate ${ }^{8,10,11,36}$. The reversed process, structural adaptive vessel dilatation with increased flow, has also been described ${ }^{32,53}$. Our working hypothesis is that within a certain spectrum of shear rate, intimal thickening (leading to a decrease in vessel diameter) or dilatation in response to changes in flow are physiologic adaptational processes to regulate the shear rate levels sensed by endothelial cells $^{10,11,52,53}$. However, when shear rate levels exceed the upper limit of this spectrum, denudation may occur, leading to intimal thickening rather than adaptive structural dilatation. Despite similar flow conditions, structural dilatation is observed at the arterial site of AV fistulas whereas intimal thickening develops at the venous site. This suggests that the upper limit of this spectrum probably is higher for arteries than for veins. 


\section{Mismatch in elastic properties and intimal thickening}

The compliance mismatch hypothesis was first postulated in the seventies, and stems from numetous observations made by vascular surgeons, that anastomotic areas of peripheral bypasses as well as arteriovenous fistulas are predisposed to the development of intimal hyperplasia ${ }^{1-4,12,49-22,54}$. It was hypothesized that a mismatch in elastic properties leads to a point of excessive mechanical stretching resulting in wall injury and in the initiation of vascular smooth muscle cell (VSMC) replication ${ }^{20,23,25,26,55}$. Furthermore, an increase in compliance is associated with flow disturbances like flow stasis and enhanced particle residence time, which may promote the development of intimal thickening ${ }^{14}$. In a previous study we observed a rise in area-increase within the venous anastomoses, while area-increase dropped in the arterial anastomoses ${ }^{13}$. Since the first condition is associated with flow disturbances and enhanced particle residence time, we postulated that this might be the reason for the predisposition of intimal hyperplasia to develop at the wenous anastomoses ${ }^{14}$. The results of the present study suggest that the postulated mechanism does not play a role in the development of stenotic intimal hyperplasia at the venous anastomoses of PTFE AV fistulas. Our data clearly indicate that an increased mismatch in elastic properties does not lead to the occurrence of intimal hyperplasia in AV fistulas in humans. On the contrary, we found that an increased mismatch in strain seems to protect against the development of a stenosis, since according to our definition, the peri-anastomotic match in strain (RD) was far from the ideal value in the non-stenotic groups. A possible explanation may be that an advantageous effect of a proper match in elastic properties around the venous anastomoses of stenotic AV fistulas is prepondered by the influence of excessive high peak shear rate resulting from the construction of an arteriovenous fistula.

Uswally, relative distension (RD) and area-increase (AI) are corrected for pulse pressure, resulting in cross-sectional compliance and distensibility coefficient, respectively. There are two reasons why it was decided to use RD and AI instead of the corrected parameters. First, invasively obtained pressure measurements in loop AVfistulas in dogs have demonstrated that a large drop in pressure is present along the grafts and within the anastomoses ${ }^{17}$. This indicates that non-invasively obtained pulse pressure values obtained at one site in the vascular system cannot give a proper estimation of pulse pressure in the whole system. A second reason for the use of AI and RD is that the compliance mismatch hypothesis is based on the thought that perianastomotic differences in strain and differences in cross-sectional area increase, possibly lead to local mechanical stress and/or flow disturbances ${ }^{20}$. The force leading to strain and cross-sectional area increase (i.e. pulse pressure) is of a lesser importance. Therefore, it seems justified to use RD and AI to represent the local elastic properties and to calculate peri-anastomotic mismatch in elastic properties.

\section{Clinical Implications}

According to the findings of the present study, one should aim at decreasing initial peak shear rate at the venous site in constructing an $\mathrm{AV}$-fistula. This may be achieved 
with the use of $4-7 \mathrm{~mm}$ tapered grafts which results in decreased peak systolic velocities at the venous end of graft $A V$ fistulas ${ }^{17}$. In addition, the use of wide venous cuffs in the construction of the venous anastomosis may help in decreasing peak shear rate in the efferent vein just downstream the anastomosis ${ }^{5657}$. Our data indicate that differences in elastic properties around anastomoses cannot be regarded as a causal factor in the occurrence of anastomotic intimal thickening in human graft AV fistulas. Therefore, the use of stiff prosthetic graft materials is not discouraged by the outcome of our study. Application of the findings of the present study to other clinical manifestations of intimal hyperplasia, like restenosis after PTCA and stenosis in peripheral or coronary bypass grafts, has to be performed with caution ${ }^{42,58,59}$. Flow characteristics in coronary arteries and peripheral bypass grafts differ substantially from AV fistula flow, indicating quite different magnitudes of shear rate. In addition, intimal thickening in coronary arteries following PTCA may differ from intimal thickening observed at graft-vein jumctions in AV fistulas, due to differences in structure and function between arteries and veins/PTFE grafts ${ }^{26,600}$.

In summary, the results of the present study indicate that the occurrence of occlusive or subocclusive intimal thickening at the venous anastomoses and venous outflow segments of AV fistulas for hemodialysis access is associated with initial high peak shear rate at these sites. This suggests that high shear rate may initjate intimal hyperplasia in AV fistulas in humans. A possible mechanism may be an injurous effect of high shear on the venous endothelial cells leading to denudation, which is supported by the finding that the lumen of the stenotic lesions derived from these patients is only partly covered with endothelial cells. In addition, in the fistulas developing stenoses a more ideal initial match in elastic properties around the venous anastomoses was found. This strongly argues against a contribution of mismatch in elastic properties to intimal thickening in graft AV fistulas in humans. To improve patency rates of arteriovenous fistulas with the use of interposition grafts attention has to be focused on decreasing initial peak shear rate at the venous anastomoses and the efferent vein. 


\section{WEFRENCES}

1. Windus DW. Permanent vascuitar access: a nephrologist's view. Am $J$ Kidney Dis 1993; $21: 457-471$.

2. Jenkins AMcL, Bust TAS, Glover SD. Mediam-term follow-up of forty autogenous vein and forty polytetrafluorethylene (Gore-Tex) grafts for vascular access. Surgery 1980; 88:667-672.

3. Swedberg SH, Brown BG, sigley $\mathrm{R}$, Wight TM, Gordon D, Nicholls SC. Intimal fibromuscular hyperplasia at the venous anastomosis of PTFE grafts in hemodualysis patients. Circulation 1989, 80:1726-1736.

4. Tordoir $\mathbb{N H M}$, Herman JM, Kwan TS, Diderich PM. Long-term follow-up of the polytetraftuoroethylene (PTFE) prosthesís as an arteriovenous fistula for hemodialysis. Eur J Vasc Surg $1988 ; 2: 3-7$.

5. Kohler TR, Kirkman TR, Kraiss LW, Zierler BK, Clowes AW. Increased blood flow inhibits neointimal hyperplasia in endothelialized vascular grafts. Circ Res 1991; 69:1557-1565.

6. Kohler TR, Jawien A. Flow affects dewelopment of intimal hyperplasia after arterial injury in rats. Arterioscler Thromb 1992; 12:963-971.

7. Zarins CK, Bomberger RA, Glagov S. Local effects of stenoses: Increased flow velocity inhibits atherogenesis. Circulation 1981; 64:11221-11227.

8. Zarins CK, Zatina MA, Giddens DP, Ku DN, Glagov S. Shear stress regulation of artery lumen diameter in experimental atherogenesis. J Vasc Surg 1987; 5:413-420.

9. Zarins CK, Giddens DP, Bharadvaj BK, Sottiurai VS, Mabon RF, Glagov S. Carotid bifurcation atherosclerosis. Quantitative correlation of plaque localization with flow velocity profiles and wall shear stress. Circ Res 1983; 53:502-514.

10. Friedman MH, Bargeron CB, Deters OJ, Hutchins GM, Mark FF. Correlation between wall shear and intimal thickness at a coronary artery branch. Atherosclerosis $1987 ; 68: 27-33$.

11. Friedman $\mathrm{MH}$. Some atherosclerosis may be a consequence of the normal adaptive response to shear. Aherosclerosis 1990; 82:193-196.

12. Bassiouny HS, White S, Glagow S, Choi E, Giddens DP, Zarins CK. Anastomotic intimal hyperplasia: Mechanical injury or flow induced. J Vasc Surg 1992; 15:708-717.

13. Hofstra L, Bergmans DCCJ, Hoeks APG, Kitslaar PJEHM, Leunissen KML, Tordoir JHM. Mismatch in elastic properties around anastomoses of interposistion grafts for hemodialysis. access. JASN 1994; 45:45-55.

14. Stewari SFC, Lyman DJ. Effects of a vascular graft/natural artery compliance mismatch on pusatile How. J Biomech 1992:25:207-310.

15. Fry DL. Certain chemorheologic considerations regarding the blood vascular interface with particular reference to coronary artery disease Circulation 1969; XXXIX and XI.TV38-IV59.

16. Fry DL. Acute vascular endothelial changes are associated with increased blood velocity gradients. Circ Res 1968; 22:165-197.

17. Fillinger MF, Reinitz ER, Schwartz RA, et al. Graft geometry and venous intimal-medial hyperplasia in arteriovenous loop grafts. I Vasc Surg 1990; 11:556-566.

18. Fullinger MF, Reinitz ER, Schwartz RA, Resetarits DE, Paskanik AM, Bredenberg CE. Beneficial effects of banding on venous intimal-medial hyperplasia in arteriovenous loop grafts. Am I Surg 1989; 158:87-94.

19. Kidson IG, Abbott WM. Low compliance and arterial graft occlusion. Circulation 1978; $58: 11-14$.

20. Abbott WM, Megerman $\mathbb{~}$, Hasson JE, LYtalien $G$, Warnock DF. Effect of compliance mismatch on vascular graft patency. J Vasc Surg 1987; 5:376-382.

21. Abbott WM, Megeman J. Adlaptive responses of arteries to grafting. I Vasc Surg 1989; 9:377-379.

22. Baird RN, Abbott WM. Pulsatile blood-flow in arterial grafts. Lancet 1976; October $30: 948.950$ 
23. Leung DYM, Glagov S, Mathews MB. Cyclic stretching stimulates synthesis of matrix components by arterial smooth muscle cells in vitro. Science 1976:191:475-477.

24. Sumpio BE, Banes AJ, Levin $L G$ Johnson $\mathrm{G}$. Mechanical stress stimulates aortic endothelial cells to proliferate. J Vase Surg 1987; 6.252-256.

25. Leung DYM, Glagov S, Mathews MB. Elastin and collagen accumulation in rabbit ascending aorta and pulmonary trunk during postnatal growth. Correlation of cellular synthetic response with medial tension. Circ Res 1977; 41:316-323.

26. Predel HG, Yang Z, Von Segesser L, Turina M, Buhler FR, Luscher TF. Implications of pulsatille stretch on growth of saphenous vein and mammary artery smooth muscle. Lamcet $1992 ; 340: 878-879$.

27. Hoeks APG, Brands PJ, Smeets FAM, Reneman RS. Assessment of distensibility of superficial arteries. Ultrasound Med Biol 1990; 16:121-128.

28. Hofstra L, Ermers EMM, Langeveld APM, Hoeks APG, Kitslaar PJEHM. Vessel Wall Doppler Tracking: A new technique to assess vessel wall compliance. $J$ Vasc Tech 1993; 17:65-68.

29. Reneman RS, Merode van $T$, Brands PJ, Hoeks APG. Inhomogeneities in arterial wall properties under normal and pathological conditions. J Hypertens 1992; 10:535-539.

30. Hofstra L, Willigers JM, Huvers FC, et al. Short-term variations in ellastic propenties of a mescular artery in humans. Clin Sci 1993; 50:472-480.

31. Ojha M, Johnston KW, Cobbold RS. Evidence of a possible link between poststenotic dilatation and wall shear stress. I Vasc Surg 1990; 11:127-135.

32. Okadome $\mathbb{K}$, Yukizane T, Mii S, Fukuda A, Sugimachi $\mathbb{K}$. Correlation of longterm results of femoropopliteal autogenous vein grafts with shear stress variation. In situ or reversed graft? J Cardiovasc Surg Torino 1989; 30:932-935.

33. Nerem RM, Girard PR. Hemodynamic influences on vascular endothelial biology, Toxicologic Pathology 1990; 18:572-582.

34. Dobrin PB. On the roles of deformation, tension, and wall stress as critical stimuli eliciting myointimal/medial hyperplasia. J Vasc Surg 1991; $581-582$.

35. Wallenstein $\mathrm{S}$, Zucker $\mathrm{C}$, Fleiss F. Some statistical methods useful in circulation research. Circ Res $1980 ; 47: 1-9$.

36. Langille BL, O'Donnell F. Reductions in arterial diameter produced by chronic decreases in blood flow are endothelium-dependent. Science 1986; 231:405-407.

37. Langille BL, Bendeck MP, Keelley FW. Adaptations of carotid arteries of young and mature rabbits to reduced carotid blood flow. Am J Physiol 1989; 256:H931-H039.

38. Ferrel $M$, Fuster $V$, Gold $\mathrm{HK}$, Chesebro JH. Choosing appropriate experimental animal model for the prevention of restenosis. Circulation 1992;85:1630-1631.

39. Clowes AW, Reidy MA. Prevention of stenosis after vascular reconstruction: Pharmacologic control of intimal hyperplasia - A review. I Vasc Surg 1991; 6.885-891.

40. Okadome $\mathrm{K}$, Miyazaki $\mathrm{T}$, Onohara $\mathrm{T}$, Yamamura $\mathrm{S}$, Sugimachi $\mathrm{K}$. Hemodynamics and the development of anastomotic intimal hyperplasie of the polytatrefluoroethylene grafts in dogs. Int Angiol 1991; $10: 238-243$.

41. Clowes AW, Clowes MM, Fingerle J, Reidy MA. Kinetics of cellular proliferation after arterial injury. V.Role of acute distension in the induction of smooth muscle cell proliferation. Lab Invest 1989: 60:360-364.

42. Clowes $\mathrm{AW}$, Clowes $\mathrm{MM}$, Verge $\mathrm{SC}$, et al. Heparin and cilazaprill together inhibit injury-induced intimal hyperplasia. Hypertension 1991; 18://65-1/69.

43. Clowes AW, Reidy MA, Clowes MM. Mechanisms of stenoses after arterial injury. Lab Imvest $1983 ; 49: 208-215$.

44. Cooke JP, Rossitch E, Andon NA, Loscalzo J, Dzau WJ. Flow activates an endothelial potassium channel to release an endogenous nitrowasodilator. J Clin Invest 1991; 88:1663-16$7 \%$. 
45. Buga GM, Gold ME, Fukuto JM, Ignamo LJ. Shear stress-induced release of nitric oxide from endothelial cells grown on beads. Mypertensiow 1991; 17:187-193.

46. Hsich HJ, LINQ, Frangos JA. Shear stress increases endothelial platelet-derived growth factor mRNA Ulevels. Am J Physiol 1991; 260:H642-H646.

47. Tesfamariam B, Cohen RA. Inhibition of adrenergic vasoconstriction by endothelial cell shear stress. Circ Res 1988; 63:720-725.

48. Rubanyi CM, Freay $A D$, Kauser K, Johns $A$, Harder DR. Mechanoreception by the endothelium: Mediators and mechanisms of pressure- and flow-induced vascular responses. Blood Vessels $1990 ; 27: 246-257$.

49. Resnick N, Collins $T$, Atkinson W, Bonthron DT, Dewey CF, Gimbrone MA. Platelet-derived growth factor B chain contains a cis-acting fluid shear-stress-responsive element. Proc Natl Acad Sci U S A 1993; 90:4591-4595.

50. DePaola N, Gimbrone MA, Davies PF, Dewey CF. Vascular endothelium responds to fluid shear stress gradients. Arteriascler Thromb 1992; 12:1254-1257.

51. Shen $J_{y}$ Luscinskas FW, Conolly A, Dewey CF, Gimbrone MA. Fluid shear stress modulates cytosolic free calcium in vascular endothelial cells. Am J Cell Physiol 1992; 31:c384-c390.

52. Kamiya A, Ando J, Shibata M, Masuda H. Roles of fluid shear stress in physiological regulation of vascular structure and function. Biorheology 1988; 25:271-277.

53. Kamiya A, Togawa T. Adaptive regulation of wall shear stress to Jow change in the canine carotid artery. Am J Physiol 1980; 239:H14-H21.

54. Madras PN, Ward CA, Johnson WR, Singh PI. Anastomic hyperplasia. Surgery 1981; $90: 922.923$.

55. Sottiurai VS, Kollross P, Glagov S, Zarins CK, Mathews. MB. Morphologic alleration of cultured arterial smooth muscle cells by cyclic stretching. I Surg Res 1983; 35:490-497.

56. Taylor RS, Loh A, McFarland RJ, Cox M, Chester JF. Improved technique for polytetrafluoroethylene bypass grafting: long-term results using anastomotic wein patches. BrJ Swrg 1992; 79:348-354.

57. Tyrrell MR, Wolfe JHN. New prosthetic venous collar anastomotic technique: combining the best of other procedures. Br J Surg 1991; 78:1016-1017.

58. Liw MW, Roubin GS, King III SB. Restenosis after coronary angioplasty. Potential biologic determinants and rolle of intimal hyperplasia. Circulation 1989; 79:1374-1387.

59. Cashin WL, Sanmarco ME, Nessim SA, Blankenhorn DH. Accelerated progression of atherosclerosis in coronary vessels with minimal lesions that are bypassed. New Eng J Med 1984; $311: 824-828$.

60. Luscher TF, Diederich $\mathrm{D}$, Siebeenman $\mathrm{R}$, at al. Difference between endothelium-dependent relaxation in arterial and wenous coronary bypass grafts. New Eng $J$ Med 1988; 319:462-467. 


\title{
MECHANICAL FACTORS PREDISPOSING TO INTIMAL HYPERPLASLA IN PERIPHERAL BYPASS GRAFTS CONSTRUCTED WITH THE USE OF AUTOLOGOUS VEIN; A PROSPECTIVE ANALYSIS
}

\author{
L Hofstra, APG Hoeks, JHM Tordoir, DCJ Bergmans, MJAP Daemen, \\ PJEHM Kitslaar. \\ (submitted)
}

\section{ABSTRACT}

Background. Failure of peripheral bypass grafts constructed with the use of saphenous vein is mainly caused by the formation of stenosis due to intimal hyperplasia. Mechanical factors such as compliance mismatch around anastomoses and unphysiological shear rate have been implicated to contribute to the development of intimal hyperplasia but their actual role remains uncertain. The present study was conducted to investigate the role of these mechanical factors on the occurrence of intimal hyperplasia in peripheral bypasses.

Methods. Patients receiving a peripheral bypass for occlusive arterial disease of the leg were included $(n=43)$. The bypass was constructed using either the reversed $(n=28)$ or the in situ vein technique $(n=15)$. Within 2 weeks after construction local dimensions and elastic properties of vessel segments were assessed in the graft and adjacent vessel segments at defined sites, with the use of Vessell Wall Doppler Tracking, a non-invasive ultrasound technique. A match factor was calculated by indexing elastic properties and dimensions of graft and native artery around the anastomoses. A perfect match is considered when the match factor is 1 . In addition, peak shear rate (PSR) was calculated from diameter and peak systolic velocity (PSV), assessed at corresponding sites. The local initial match in elastic properties and dimensions and PSR values were correlated with the occurrence of stenoses during follow-up. The presence of stenoses was established with Duplex surveillence, made every 3 months after construction of the bypass. The occurrence of a stenosis was always confirmed by an angiogram.

Results. In 7 cases a stenosis developed at the proximal anastomosis, in 4 cases at the distal anastomosis and in 3 cases in the course of the graft. Bypasses without a stenosis at the proximal anastomosis showed a better initial peri-anastomotic match in strain $(1.1$ vs $1.5, \mathrm{p}<0.05)$ and a better initial diameter match $(0.68$ vs $0.38, \mathrm{p}<0.05)$ 
as compared to the bypasses with a stenosis at this point during follow-up. Regression analysis showed that only an initial local high PSR was independently correlated with the occurtence of stenosis at the proximal anastomosis. At the distal anastomosis no differences in initial peri-anastomotic match in elastic properties and flow characteristics were observed between the bypasses with and without a stenosis at this site. Histologic examination of the stenoses $(\mathrm{n}=6)$ demonstrated only partial covering ( $50 \%$ ) of the remaining lumen with endothelial cells, indicating denudation.

Conclusions. Our data suggest that a greater mismatch in strain and a poor diameter match contribute to the development of intimal hyperplasia. In addition, it is suggested that a high initial peak shear rate initiates the development of intimal hyperplasia in the proximal anastomosis of venous femorodistal grafts. A possible mechanism may be a damaging effect of high shear on venous endothelium, leading to partial denudation.

\section{INTRODUCTION}

The main cause for failure of peripheral bypass grafts in the first post-operative year is the formation of stenosis due to intimal hyperplasia ${ }^{1}$. The development of a stenosis may jeopardize the function of the graft and may finally lead to occlusion ${ }^{2}$. Platelet aggregation $^{3,4}$, endothelial cell dysfunction ${ }^{5}$, damage of the vessel wall media ${ }^{6}$ and a variety of growth factors ${ }^{3,7}$ have all been alleged to play a role in the development of intimal thickening, at least in animal models. In addition, mechanical factors such as compliance mismatch ${ }^{8-10}$ and unphysiological shear rates ${ }^{11-15}$ may play a role in the formation of a stenosis.

Since the anastomoses are predisposed to the development of a stenosis, many researchers hypothesized that a mismatch in elastic properties between graft and native arteries might be an important contributing factor ${ }^{1,8,16-18}$. Excessive mechanical stretch at the anastomoses due to mismatch may lead to vessel wall injury and may initiate the replication of vascular smooth muscle cells (VSMC), the dominant cell type in the intimal lesion. In animal models a correlation between compliance mismatch and intimal hyperplasia was never demonstrated ${ }^{8,19}$. However, occlusive intimal hyperplasia has never been observed in animal models, which may explain the absence of a correlation between mismatch in elastic properties and intimal hyperplasia ${ }^{20,21}$. Another factor affecting intimal growth is flow. A low shear rate in arteries is associated with increased intimal thickening, as has been demonstrated by numerous investigators ${ }^{11,12,22 \cdot 24}$. On the other hand, more intimal thickening was observed at the venous site of AV fistulas in dogs in areas with the highest flow velocities ${ }^{14,25}$. The influence of shear rate on the occurrence of intimal hyperplasia in saphenous vein bypass grafts in humans could not be investigated so far, due to the absence of suitable techniques to assess shear rate in vivo accurately.

The present prospective study was conducted to investigate the influence of both a mismatch in elastic properties and shear rate on the occurrence of intimal hyperplasia in saphenous vein peripheral bypass grafts in humans. In a group of patients who 
underwent peripheral bypass surgery, the elastic properties of the saphenous vein grafts and the host arteries were assessed at defined sites in a non-invasive way, with the use of Vessel Wall Doppler Tracking, an ultrasound technique. By using this method, we were able to calculate mismatch in elastic properties around the anastomoses ${ }^{26}$. Furthermore, peak shear rate, calculated from diameter and peak systolic velocity was assessed at corresponding sites in the graft and adjacent vessel segments ${ }^{27}$. The measurements took place within 2-4 weeks after the construction of the bypass. The initial mechanical and flow conditions of the vein grafts were correlated with the occurrence of (sub)occlusive intimal hyperplasia in the post operative period. In addition, histologic examination of stenotic lesions was performed to find clues for the etiology of the stenosis.

\section{MATERIALS AND METHODS}

\section{Patient clinical profile}

Forty-three consecutive patients receiving a saphenous vein bypass graft to reestablish a sufficient blood flow to the lower limb entered the study (august 1991-august 1993). The majority of the patients were operated for limb threatening ischaemia (Table I). In 28 patients the reversed vein technique was used and in 15 patients the in situ technique. Before inclusion in the study, a Duplex examination was performed to ascertain that the the graft was free of stenotic lesions or incompletely removed valves $^{2}$. A stenotic lesion may alter the hemodynamics of the graft by influencing pulse wave reflections ${ }^{28,29}$. Therefore these patients had to be excluded.

Table I: Characteristics of the patients with and without a stenosis.

\begin{tabular}{|c|c|c|c|}
\hline & Stenosis & No stenosis & $P$ value \\
\hline Sex (male/female) & $9 / 5$ & $16 / 13$ & 0.35 \\
\hline Age (Years) & $67(60-74)$ & $71(64-78)$ & 0.24 \\
\hline $\begin{array}{l}\text { Fontaine } \\
\text { II } \\
\text { III } \\
\text { IV }\end{array}$ & $\begin{array}{l}4 \\
5 \\
5\end{array}$ & $\begin{array}{c}8 \\
11 \\
10\end{array}$ & 0.93 \\
\hline Diabetes & 4 & 12 & 0.34 \\
\hline
\end{tabular}




\section{Detection of stenoses during the study period}

At 6, and 12 weeks and every 3 months thereafter a Duplex scan was performed as part of a surveillance program in the hospital. When the Duplex scan revealed a stenosis, angiography was performed to assess the severity of the stenotic lesion. A decision to perform surgical correction of the stenotic lesion was based on the outcome of both the Duplex scan and angiography.

\section{Measurement of the elastic properties and calculation of match}

The diameter and distension of the vessel and graft segments were measured with the use of Vessel Wall Doppler Tracking (VWDT). A detailed description of this ultrasound system is given elsewhere (chapter 3 and 4$)^{30-32}$. From diameter (D in $\mathrm{mm}$ ) and distension ( $\Delta \mathrm{d}$ in $\mu \mathrm{m}$ ) the following parameters were calculated:

$$
\begin{aligned}
& \text { Relative Distension }(R D)=\frac{\Delta D}{D} * 100 \% \\
& \text { Area-increase }-\frac{\pi \Delta D * D}{2}
\end{aligned}
$$

Relative distension (RD in \%) represents the local strain of the vessel wall during the cardiac cycle. Area-increase ( $\mathrm{AI}$ in $\mathrm{mm}^{2}$ ) is calculated as the increase in cross-sectional area during cardiac cycle and represents the capacity of the vessel to store and release blood volume. With the use of B-mode imaging measurements were performed at defined sites in the graft and adjacent vessel segments by using the anastomosis as a landmark ${ }^{26}$.

Since we aimed at investigating the influence of mismatch in elastic properties around anastomoses on the development of intimal hyperplastic stenoses, the values for RD, AI and diameter around the anastomoses were indexed. The calculation of the indices were performed as follows:

Match factor = value distal / value proximal from the anastomosis

A perfect match is considered to be present when the match factor is 1 . A value lower than 1 indicates a loss of the value of parameter in the anastomosis, while a value higher than 1 indicates an increase of the value of the parameter within the anastomosis. 


\section{Calculation of peak shear rate}

A relliable method to perform in vivo shear rate measurements in humans is not available at this moment. Therefore, shear rate can only be estimated from flow parameters and diameter. Usually, mean shear rate is calculated from the HaagenPoisseuille formula ${ }^{11.12}$. However, studies evaluating the effect of steady and pulsatile flow on the lining and the shape of endothelial cells demonstrated that the pulsatile component of shear rate may be of more importance than the mean level ${ }^{3-35}$. Furthermore, in another study evaluating the effect of flow on proliferation in human stenotic tissue, we observed a negative correlation between peak shear rate and proliferation, which also indicates that the pulsatile component of shear rate may be an important determining factor (chapter 11$)^{27}$. We therefore decided to calculated peak. shear rate from a modification of the Haagen-Poisseuille formula in the following way:

Peak shear rate $(1 / \mathrm{s}, \mathrm{PSR})=\mathrm{n} *$ peak systolic velocity/diameter

Peak systolic velocity was determined from the doppler sample placed midstream under an angle of $60^{\circ}$. Diameter was measured with the use of VWDT. The calculation of PSR with the modification of the Haagen-Poisseuille formula is based on the assumption that flow is laminar and the velocity profile is parabolic. Since one can only speculate on the presence of such conditions in the bypass grafts, PSR can only give a rough approximation of the actual shear stresses exerted on the vessel wall. The value for $\mathrm{n}$ varies between 4 and 8 for normal arterial flow and increases when flow velocity increases. The determination of diameter with the use of the B-mode image is not very accurate. Therefore, we used the diameter values obtained from VWDT. A validation study showed a low coefficient of variation $(2-4 \%)$ in the assessment of diameter with this system ${ }^{32}$.

\section{Histologic examimations}

When a stenotic lesion of hemodynamic importance occurred within the graft necessitating surgical repair with the use of interposition grafts, a stenotic tissue sample was obtained for histologic examination. These specimens were processed according to routine histologic procedures and paraffin-embedded. Serial sections were cut and placed on gelatin coated glass slides. To identify endothelial cells, Ulex Europeus agglutinin (1:500 dilution, Vector Labs, Burlingame, CA, USA) was used. After blocking of the endogenous peroxidase activity with $0.3 \% \quad \mathrm{H}_{2} \mathrm{O} 2$ and predigestion with pepsin $(1 \mathrm{mg} / \mathrm{ml}, 30 \mathrm{~min})$, sections were incubated with the lectin antibody $(1: 250,45 \mathrm{~min}$, DAKO). Subsequently, the sections were incubated with an anti-Ulex Europeus lectine peroxidase complex (1:100, DAKO). As the chromogen 3,3 diamino-benzidine was used. The degree of endothelial cell coverage was estimated by dividing the surface of the lumen with endothelial cells by the total luminal surface. 


\begin{abstract}
ANALYSIS
Data are presented as medians and $25^{\text {th }}$ and $75^{\text {th }}$ percentile intervals. To compare results between different groups, the Mann-Whitney-U test was used. Multiple regression analysis was used to determine the relation between the local initial mechanical and flow characteristics and the occurrence of a stenosis at a certain site. A p-value of less than 0.05 was accepted as a level of statistical significance.
\end{abstract}

\title{
RESULTS
}

During the follow-up period stenotic lesions developed in 14 grafts (Table II). In 7 cases the lesion developed in or adjacent to the proximal anastomoses, in 4 cases within the distall anastomosis and in 3 cases in the course of the graft. Since measurements of the elastic properties and flow focused on locations around the anastomoses, the development of focal stenoses in or directly adjacent to the proximal and distal anastomoses could be correlated with the initial mechanical and flow characteristics. In the remaining 3 cases, the stenoses were randomly distributed along the entire grafts. Reliable correlation of these stenoses with mechanical and flow conditions with respect to localisation is therefore difficult. Since coupling of local flow and mechanical parameters is essential in this study, these stenoses were not included in the study. The majority of the stenoses in the proximal anastomosis occurred in the reversed vein bypass group ( $84 \%$, Table II). No differences in characteristics were observed between the stenotic and non-stenotic bypass patients (Table I).

Table II: Distribution of stenosis in the reversed and in situ saphenous wein grafts

\begin{tabular}{lccc}
\hline & $\begin{array}{c}\text { Reversed } \\
(\mathrm{n}=28)\end{array}$ & $\begin{array}{c}\text { In Situ } \\
(\mathrm{n}=15)\end{array}$ & Total \\
\hline Proximal Anastomosis & 6 & 1 & 7 \\
Graft & 1 & 2 & 3 \\
Distal Anastomosis & 2 & 2 & 4 \\
\hline
\end{tabular}

\section{Local elastic properties and stenosis}

A summary of the results is presented in Table III and IV. No differences in initial RD and Al values measured at the proximal and distal graft segments were observed between the bypasses with and without a stenosis at these sites. A smaller initial diameter of the proximal graft segments was observed in the bypasses with a later stenosis at this site as compared to the non-stenotic bypasses ( 3.2 vs $4.4 \mathrm{~mm}, \mathrm{p}<0.05$ ). 
Table III: The outcome of different mechanical parameters in the patients with and without a stenosis in or adjacent to the proximal anastomosis of the venous bypass. Data are presented as medians and 25 and 75 th percentile intervals.

\begin{tabular}{lccc}
\hline & Proximal stenosis & $\begin{array}{c}\text { No stenosis } \\
\text { proximal } \\
(\mathrm{n}=36)\end{array}$ & P Value \\
& $(\mathrm{n}=7)$ & $4.4(3.7-5.6)$ & \\
\hline Vein diameter $(\mathrm{mm})$ & $3.2(2.8-4.3)$ & $0.65(0.43-0.84)$ & 0.03 \\
Diameter match & $0.38(0.26-0.58)$ & $3.2(1.5-4.1)$ & 0.03 \\
RD $(\%)$ & $3.5(2.5-4.5)$ & $1.1(0.6-1.4)$ & 0.35 \\
RD match & $1.5(1.2-2.4)$ & $0.92(0.54-1.38)$ & 0.03 \\
AI $\left(\mathrm{mm}^{2}\right)$ & $0.68(0,52-1,12)$ & $0.36(0.16-0.79)$ & 0.45 \\
AI match & $0.31(0.08-0.50)$ & $105(77-131)$ & 0.39 \\
PSV $(\mathrm{cm} / \mathrm{s})$ & $127(70-211)$ & $99(64-145)$ & 0.32 \\
PSR $(1 / \mathrm{s})$ & $143(55-338)$ & & \\
\hline
\end{tabular}

Table IV: The outcome of different mechanical parameters in the patients with and without a stenosis in or adjacent to the distal anastomosis of the venous bypass. Data are presented as medians and 25 and 75 th percentile intervals.

\begin{tabular}{lccc}
\hline & Distal stenosis & $\begin{array}{c}\text { No stenosis } \\
\text { distal } \\
(\mathrm{n}=39)\end{array}$ & P Value \\
& $(\mathrm{n}=4)$ & & \\
\hline Vein diameter(mm) & $3.8(2.4-5.1)$ & $4.6(3.6-6.4)$ & 0.18 \\
Diameter match & $0.6(0.5-0.9)$ & $0.7(0.6-0.90)$ & 0.46 \\
RD $(\%)$ & $2.3(1.4-4.7)$ & $2.0(1.2-3.6)$ & 0.67 \\
RD match & $0.9(0.8-1.2)$ & $0.8(0.4-1.2)$ & 0.32 \\
Al $\left(\mathrm{mm}^{2}\right)$ & $0.68(0.22-1.03)$ & $0.68(0.48-1.14)$ & 0.59 \\
Al match & $0.4(0.2-0.7)$ & $0.3(0.2-0.5)$ & 0.66 \\
PSV $(\mathrm{cm} / \mathrm{s})$ & $100(45-136)$ & $67(53-83)$ & 0.31 \\
PSR $(1 / \mathrm{s})$ & $124(35-224)$ & $56(39-94)$ & 0.61 \\
& & & \\
\hline
\end{tabular}




\section{Peri-anastomotic match in elastic properties and stenoses}

\section{Proximal anastomosis}

No difference in initial peri-anastomotic match in AI was observed between the stenotic and non-stenotic bypasses (Table III). A better initial match in RD (1.1. vs 1.5 , $p<0.05$, Figure 1$)$ and diameter $(0.65$ vs $0.38, p<0.05$, Figure 1$)$ around the proximal anastomosis was observed in the bypasses without a later stenosis at this site as compared to the non-stenotic bypasses. Between the stenotic and non-stenotic bypasses no differences were observed in initial local peak systolic velocity (PSV). Also in initial local peak shear rate (PSR) no differences were observed between the groups (Table III). In the bypass group with a proximal stenosis, higher PSR and PSV values were measured at the site of the later stenoses as compared to the distal segments of the bypass (PSR: 145 vs $621 / \mathrm{s}, \mathrm{P}<0.05$; PSV: 127 vs $80 \mathrm{~cm} / \mathrm{s}, \mathrm{p}<0.05$, Wilcoxon signed rank test). Multiple regression analysis, including mismatch and flow parameters, demonstrated that only a high initia] local PSR at the proximal anastomosis independently correlated with the occurrence of a stenosis at this point $(p<0.05)$.

Figure 1: Bar graph showing the differences in match in strain and diameter around the proximal anastomosis between the bypasses with and without a stenosis at this point.

Stenotic
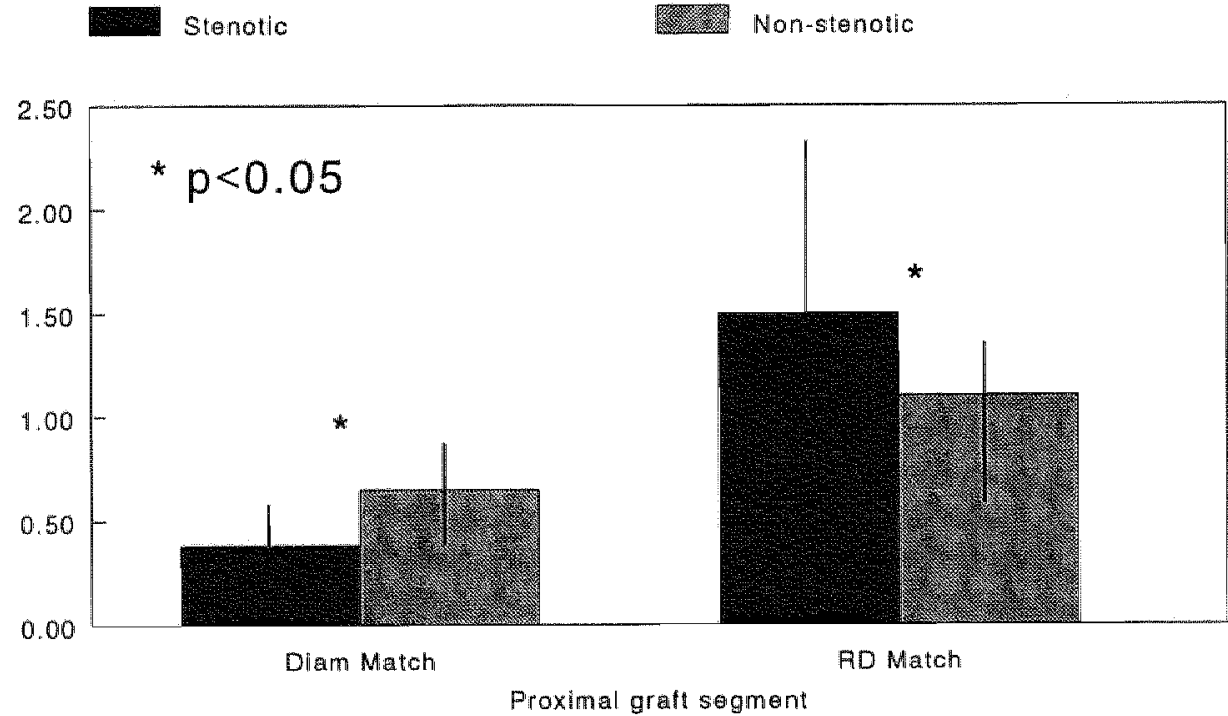

\section{Distall anastomosis}

No differences in initial peri-anastomotic match in AI, RD and diameter were observed between the bypasses with and without a later stenosis at the distal anastomosis. Also in PSR and PSV, no differences were observed between the bypasses with and without a stenosis at the distal graft end (Table IV). 


\section{Histologic examinations}

In 6 cases repair of the proximal stenotic lesions was performed with the use of an interposition graft, allowing harvesting of stenotic material. Histologic evaluation revealed a focal stenotic mass consisting mainly of vascular smooth muscle cells and matrix, confirming the hyperplastic nature of the material. The mean coverage of endothelial cells of the lumen was $50 \%$.

\section{DISCUSSION}

The goal of the present study was to correlate initial mechanical factors, like perianastomotic mismatch in elastic properties and flow characteristics, with the occurrence of stenosis during follow-up in peripheral saphenous vein bypass grafts. For the proximal anastomosis, a better initial match in local strain and diameter was observed in the bypasses without a stenosis at this site during follow-up as compared to the stenotic bypasses. This suggests that mismatch in strain and diameter may play a role in initiating the development of an anastomotic stenosis. Furthermore, multiple regression analysis showed that a high initial local peak shear rate at the proximal graft segment was associated with the occurrence of a stenosis at this site during follow-up. This suggests that high shear rate initiates intimal hyperplasia in venous grafts.

\section{Mismatch in elastic properties and stenosis}

The compliance mismatch hypothesis stems from numerous observations reporting a high incidence of stenosis within or adjacent to the anastomoses in peripheral bypasses and in arteriovenous fistulas $1,8,14,16,17,25 ; 36,39$. Theoretically, a point of excessive mechanical stretching is created when vessels with different elastic properties are anastomosed ${ }^{8}$, which may lead to vessel wall injury. A greater initial mismatch in strain was found in peripheral bypasses with a stenosis in the proximal anastomosis during follow-up as compared to the bypasses without a stenosis at this point. The local initial strain values were equal in the proximal graft segments in both groups, suggesting that mismatch in strain had to be the contributing factor rather than local mechanical conditions. A point of interest is that strain increased within the proximal anastomoses of the stenotic bypasses. The median value for the mismatch was 1.5 , indicating a $50 \%$ increase in relative strain. In vitro studies have demonstrated that cyclic stretching of vessel segments results in proliferation of smooth muscle cells and production of extra-cellular matrix, important events in the development of intimal thickening ${ }^{40-42}$. In addition increased proliferation of VSMC was observed after cyclic stretching, in venous segments as compared to arterial segments, indicating that veins may be more susceptible to repetitive strain than arteries ${ }^{40}$. Thus, the mismatch in relative strain between the inflow artery and the proximal vein segments, resulting in excessive repetitive cyclic strain at the site of the proximal anastomosis, may contribute to the development of intimal thickening in human saphenous vein bypass grafts. 
Another contributing factor may be the influence of a mismatch in compliance on flow ${ }^{43}$. A sudden increase in compliance has been associated with flow disturbances like flow stasis and increased particle residence time, suggesting low shear. In the present study, the majority of stenoses developed at the proximal anastomoses. At this point, a sudden decrease in compliance is present, which is not associated with flow disturbances and probably will not lead to low shear conditions. At the distal anastomosis, no differences were observed in peri-anastomotic mismatch in elastic properties between the bypasses with and without a stenosis at this point. A possible explanation may be that the number of stenosis at this point is too small for statistical analysis.

Smaller vessel diameters were found in the vein grafts with a stenosis at the proximal anastomosis as compared to the non-stenotic bypasses. Diameter mismatch was also greater in the stenotic bypasses. We do not know whether the occurrence of stenotic lesions in segments with a small diameter during the follow-up period is caused by the fact that intimal thickening in these bypasses leads more rapidly to subocclusive or occlusive stenotic lesions. Recurrence of symptoms will return faster and Duplex surveillance will demonstrate higher velocities in narrow bypasses with a certain stenotic mass as compared to large diameter grafts. As a consequence, angiography and surgical intervention may be performed in relatively early stages in the development of the intimal hyperplastic stenoses. The finding that bypasses with a proximal stenosis had smaller initial diameters indicates that in case of a small caliber saphenous vein, the in situ technique may be preferable over the reversed technique.

\section{Flow characteristics and stenosis}

In the bypasses with a stenosis at the proximal anastomosis, higher initial peak shear rate values were found at the proximal graft segments as compared to other regions of the bypass. In addition, multiple regression analysis showed that a high initial local peak shear rate value correlated with the occurrence of a stenosis at the proximal anastomosis during follow-up. This suggests that a high initial peak shear rate initiates stenosis due to intimal thickening in saphenous vein bypass grafts. The majority of the stenosis at the proximal anastomosis occurred in the reversed saphenous vein bypass group, which confirms observations from other groups $s^{1,16}$. The highest initial flow velocities and peak shear rates are present in the most proximal part of the graft due to the small diameter at this point (equation 3). Histologic examinations of the stenotic tissue samples showed that the lumen of the stenosis was only partly covered with endothelial cells. This indicates that denudation of endothelial cells was present at the time of harvesting the stenotic sites. Since PSV and PSR values at the site of the stenosis just prior to intervention will even be further increased as compared to the initial high values, the reason for denudation may be excessive high shear rate ${ }^{44,45}$. This has been previously observed in a similarly conducted study by our group on AV fistulas ${ }^{46}$. The occurrence of stenosis at the venous anastomoses of hemodialysis graft AV fistulas was associated with high initial PSR and PSV values, and also denudation was found in stenotic areas. 
Since denudation is an established method to initiate intimal thickening in animal ves$\operatorname{sels}^{47.48}$, one might speculate that at least the initiation of intimal thickening is due to denudation mediated by high shear rate. This seems to be in contrast with observations from many animal studies, reporting increased intimal thickening in areas of low shear $^{11,12}$. However, some differences between experimental animal models and human saphenous vein bypass grafts may explain the discrepancy. First, in most animal models the influence of varying levels of shear on intimal thickening is studied in arteries, whereas in the present study the influence of shear on intimal thickening in veins was studied. Venous endothelium may be more susceptible to high shear as compared to arterial endothelium as has been suggested by some authors ${ }^{14,25}$. A second reason may be that the biology of human intimal thickening differs from intimal thickening in animals ${ }^{20,21,49}$. In animal models intimal thickening is limited and never leads to occlusion, which is quite different from occlusive intimal thickening as found after vascular intervention in humans. The observation that the occurrence of stenosis at the proximal anastornosis is associated with initial high peak shear rate may explain why small sized veins have a lower graft patency ${ }^{50,51}$. Due to a small diameter, peak systolic velocity will be high, resulating in a high peak shear rate level. Therefore, a certain critical vein diameter may result in peak shear rate levels, which are not well tolerated by venous endothelial cells. This may result in endothelial cells damage and eventually denudation, which may initiate intimal thickening.

In conclusion, our data suggest that a high initial mismatch in strain and a poor diameter match may contribute to the development of proximal anastomotic intimal hyperplasia in saphenous vein peripheral bypass grafts in humans. In addition, the development of intimal hyperplasia at the proximal anastomosis of these grafts was associated with increased flow velocities and high peak shear rates, suggesting that high shear contributes to the development of intimal hyperplasia in vein grafts. A possible mechanism may be a damaging effect of high shear on venous endothelium, leading to partial denudation, thereby initiating the development of a stenosis. 


\section{REFERENCES}

1. Berkowitz HD, Greenstein $S$, Barker $C F$, Perloff $L$. Late failure of reversed vein bypass grafts. A,sw Surg 1989; 210:782-786.

2. Buth $J$, Dissellioff $B$, Somineling C, Stam L. Color-flow duplex criteria for grading stenosis in infrainguinal wein grafts. $\int$ Vasc Surg $1991 ; 14: 716-728$.

3. Lit MW, Roubin GS, King III SB. Restenosis after coronary angioplasty. Potential biologic determinants and role of imtimal hyperplasia. Circulation 1989; 79:1374-1387.

4. Fingerle J, Johnson $\mathrm{R}$, Clowes AW, Majesky MW, Reidy MA. Role of platelets in smooth muscle cell proliferation and migration after vascular injury in rat carotid artery. Proc Natl Acad Sci U S A 1989; 86:8412*8416.

5. Lischer TF. Endothelial control of vascular tone and growth. Clin Exp Hypertens 1990; 12:897.902.

6. Clowes AW, Clowes MM, Fingerle J, Reidy MA. Kinetics of cellular proliferation after arterial injury. $V$. Role of acute distension in the induction of smooth muscle cell proliferation. Lab Invest 1989; 60:360-364.

7. Clowes $\mathrm{AW}$, Reidy MA. Prevention of stenosis after vascular reconstruction: Pharmacologic control of intimal hyperplasia - A review. J Vasc Surg 1991; 6:885-891.

8. Abbott WM, Megerman J, Hasson JE, L'Ttalien $G$, Warnock DF. Effect of compliance mismatch on vascular graft patency. $J$ Vasc Surg 1987; 5:376-382.

9. Abbott WM, Megerman J. Adaptive responses of arteries to grafting. $J$ Vasc Surg 1989 ; $9.377-379$.

10. Kidson $1 G$, Abbott WM. Low compliance and arterial graft occlusion. Circulation 1978; 58:11-14.

11. Kohler TR, Jawien A. Flow affects dewelopment of intimal hyperplasia after arterial injury in rats. Arterioscler Thromb 1992; 12:963-971.

12. Kohler TR, Kirkman TR, Kraiss LW, Zierler BK, Clowes AW. Increased blood flow inwibits neointimal hyperplasia in endothelialized wascular grafts. Circ Res 1991; 69:1557-1565.

13. Fry DL. Certain chemorheologic considerations regarding the blood vascular interface with particular reference to coronary artery disease. Circulation 1969; XXXIX and XI:IV38-IV59.

14. Fillinger MF, Reinitz ER, Schwartz RA, et al. Graft geometry and venous intimal-medial hyperplasia in arteriovenous loop grafts. $J$ Vasc Surg 1990; 11:556-566.

15. Sottiurai VS, Kollross $P$, Glagov $S$, Zarins CK, Mathews MB. Morphologic alteration of cultured arterial smooth muscle cells by cyclic stretching. J Surg Res 1983; 35:490-497.

16. Berkowitz HD, Fox $\mathrm{AD}$, Deaton DH. Reversed vein graft stenosis: Early diagnosis and management. J Vasc Surg 1992; 15:130-142.

1.7. Echave W, Koornick AR, Haimov M, Jacobson JH. Intimal hyperplasia as a complication of the use of the polytetrafluoroethylene graft for femoral-popliteal bypass. Surgery 1979; $86: 791-798$.

18. Madras PN, Ward CA, Johnson WR, Singh PI. Anastomic hyperplasia. Surgery 1981; 90:922-923.

19. Okuhn SP, Connelly DP, Calakos N, Ferrell L, Man-Xiang P, Goldstone J. Does compliance mismatch alone cause neointimal hyperplasia? $J$ Vasc Surg 1989; 9:35-45.

20. Ferrel M, Fuster $\mathrm{V}$, Gold $\mathrm{HK}_{\mathrm{K}}$ Chesebro $\mathrm{JH}$. Choosing appropriate experimental animal model for the prevention of restenosis. Circulation 1992; $85: 1630-1631$.

21. McBride W, Lange RA, Hillis $L D$. Restenosis after successful coronary angioplasty. Pathophysiology and prevention. New Eng J Med 1988; 318:1734-1737.

22. Zarins CK, Giddens DP, Bharadvaj BK, Sottiurai VS, Mabon RF, Glagov S. Carotid bifurcation atherosclerosis. Quantitative correlation of plaque localization with flow velocity profiles and wall shear stress. Circ Res 1983; 53:502-514. 
23. Zarins CK, Bomberger RA, Glagov S. Local effects of stenoses: Increased now velocity inhibits atherogenesis. Circulation 1981;64:11221-11227.

24. Zarins CK, Zatina MA, Giddens DP, Ka DN, Glagov S. Shear stress regulation of artery dumen diameter in experimental atherogenesis. J Vasc Surg 1987; 5:413-420.

25. Fillinger MF, Reinitz ER, Schwartz RA, Resetarits DE, Paskanik AM, Bredenberg CE. Beneficial effects of banding on venous intimal-medial hyperplasia in arteriovenous loop grafts. Am J Surg 1989; 158:87-94.

26. Hofstra L, Bergmans DCJ, Hoeks APG, Tordoir JHM, Kitslaar PJEHM. Assessment of inhomogeneities in elastic properties of in situ and reversed saphenous vein grafts in humans. Eur J Vasc Surg 1994; 8:100-105.

27. Hofstra L, Tordoir JHM, Kitslaar PJEHM, Hoeks APG, Daemen M MP. High shear rate mediated denudation decreases proliferation in human stenotic lesions derived from arterio-venous fistulas and peripheral bypass grafts. Circulation 1994; 100:100-105.

28. ORourke MF. Arterial stiffness, systolic blood pressure, and logical treatment of arterial hypertension. Hypertension 1990; 15:339-347.

29. Kelly RP, Gibbs HH, O'Rourke MF, et al. Nitroglycerin has more favourable effects on left ventricular afterload than apparent from measurement of pressure in a peripheral artery. Eur Heart I 1990; 11:138-144.

30. Hoeks APG, Brands PJ, Smeets FAM, Reneman RS. Assessment of distensibility of superficial arteries. Ultrasound Med Biol 1990; 16:121-128.

31. Hofstra L, Ermers EJM, Langeveld APM, Hoeks APG, Kislaar PJEHM. Vessel Wall Doppler Tracking: A new technique to assess vessel wall compliance. J Vasc Tech 1993; 17:65-68.

32. Hofstra L, Willigers JM. Huvers FC, et al. Short-term variations in elastic properties of a muscular artery in humans. Clin Sci 1993; 50:472-480.

33. Helmlinger $G$, Geiger $\mathbb{R V}$, Schreck $S$, Nerem RM. Effects of pulsatile flow on cultured vascular endothelial cell morphology. J Biomech Eng 1991; 113:123-131.

34. Ojiha M. Wall shear stress temporal gradient and anastonotic intimall hyperplasia. Circ Res 1994; $74: 1227-1231$.

35. DePaola N, Gimbrone MA, Davies PF, Dewey CF. Vascular endothelium responds to fluid shear stress gradients. Arterioscler Thromb 1992; 12:1254-1257.

36. Jenkins AMcL, Buist TAS, Glover SD. Medium-term follow-up of forty autogenous vein and forty polytetraillorethylene (Gore-Tex) grafts for vascular access. Surgery 1980;88:667-672.

37. Sottiurai VS, Sue SL, Feinberg II EL, Bringaze WL, Tran AT, Batson RC. Distal anastomotic intimal hyperplasia: Biogenesis and etiology. Eur J Vasc Surg 1988;2:245-256.

38. Swedberg SH, Brown BG, Sigley R, Wight TN, Gordon D, Nicholls SC. Intimal fibromuscular hyperplasia at the venous anastomosis of $\mathrm{PTFE}$ grafts in hemodialysis patients. Circulation $1989 ; 80: 1726-1736$.

39. Tordoir JHM, Herman JM, Kwan TS, Diderich PM. Long-term follow-up of the polytetrafluoroethylene (PTFE) prosthesis as an arteriovenous fistula for hemodialysis. Eur $J$ Vasc Surg $1988 ; 2: 3-7$.

40. Predel $H_{G}$, Yang $Z$, Von Segesser $L$, Turina $M$, Buhler FR, Luscher TF. Implications of pulsatile stretch on growth of saphenous vein and mammary artery smooth muscle. Lancet 1992; $340: 878-879$.

41. Leung DYM, Glagow S, Mathews MB. Elastin and collagen accumulation in rabbit ascending aorta and pulmonary trunk during postuatal growth. Correlation of cellular synthetic response with medial tension. Circ Res 1977; 41:316-323.

42. Leung DYM, Glagov $\mathrm{S}$, Mathews MB. Cyclic stretching stimulates synthesis of matrix components by arterial smooth muscle cells in vitro. Science 1976; 191:475-477.

43. Stewart SFC, Lyman DJ. Effects of a vascular graft/natura! artery compliance mismatch on pusatile flow. I Biomech 1992; 25:297-310. 
44. Reidy MA. Biology of disease. A reassessment of endothelial injury and arterial lesion formation Lab lnvest 1985; $53: 513-520$.

45. Fry DL. Acute vascular endothelial changes are associated with increased blood welocity gradients. Circ Res 1968; 22:165-197.

46. Hofstra L, Bergmans DCJ, Leunissen KML, Hoeks APG, Kitslaar PJEHM, Tordoir JHM. Anastomotic intimal hyperplasia in prosthetic arteriomenous hemodialysis access fistulas is associated with high shear rate and not with mismatch in elastic properties. JASN 1994; 100:100-105.

47. Buga OM, Gold ME, Fukuto JM, lgnarro LJ. Shear stress-induced release of nitric oxide from endothelial cells grown on beads. Hypertension 1991; 17:187-193.

48. Daemen MJAP, Lombardi DM, Bosman FT, Schwartz SM. Angiotensin II induces smooth muscle oll proliferation in the normal and injured rat arterial wall. Circ Res 1991; $68: 450-456$.

49. O'Brien ER, Alpers $C E$, Stewart DK, et al. Proliferation in primary restenotic coronary atherectomy tissue. Implications for antiproliferative therapy. Circ Res 1993; 73:223-231.

50. Wengerter KR, Veith KJ, Gupta SK, Ascer E, Rivers SP. Influence of vein size (diameter) on infrapopliteal reversed vein graft patency. J Vasc Surg 1990; 11:525-531.

51. Wengerter KR, Yang PM, Veith FJ, Gupta SK, Panetta TF. A twelve-year experience with the popliteal-to-distal artery bypass: The significance and management of proximal disease. $J$ Vasc Surg 1992; 15:143-151. 


\title{
HIGH SHEAR RATE MEDIATED DENUDATION DECREASES PROLIFERATION IN HUMAN STENOTIC LESIONS DERIVED FROM ARTERIO-VENOUS FISTULAS AND PERIPHERAL BYPASS GRAFTS
}

L Hofstra, JHM Tordoir, PJEHM Kitslaar, APG Hoeks, MJAP Daemen.

(submitted)

\begin{abstract}
Background. Vascular interventions are often complicated by the development of intimal thickening, leading to stenosis. Proliferation is considered to be one of the key events in the development of an intima. There has been extensive research on the growth regulation of the intima in animals, but information on the biology of intimal thickening in humans is scarce.

Methods. We studied the proliferation patterns of 35 human stenotic lesions, derived from either peripheral bypasses $(n=18)$ or hemodialysis $A V$-fistulas $(n=17)$ with the use of KI-67, an antibody to a proliferating cell nuclear antigen. In addition, proliferation was assessed in 13 saphenous vein control specimens. Furthermore, peak shear rate was calculated from peak systolic velocity and diameter, both assessed non invasively with the use of ultrasound, in an attempt to study the influence of local flow characteristics on the proliferation patterns in the stenotic lesions.

Results. Proliferation rates were less than $0.2 \%$ in control vessels and were elevated in stenotic tissue. In both the AV-fistula and the bypass stenoses, prolliferation was higher in the area just below the endothelium as compared to intimal regions adjacent to the media (AV-fistulas: 3.6 vs $1.1 \%$ and bypasses: 3.5 vs $2.0 \%, p<0.01$ ). Multiple regression analysis showed that the extent of subendothelial-intimal proliferation was independently correlated with the endothelial cell coverage of the lumen $(-1=0.74$, p<0.01). For local peak shear rate, the age of the lesion and graft material (PTFE or vein) no independent correlations with subendothelial proliferation were found. Local peak shear rate was negatively correlated with endothelial cell coverage of the stenosis $(r=-0.61, p<0.05)$. Proliferation in the different vessel layers showed no differences between the bypass and the AV-fistula group. From the intima to the adventitia a gradually increasing percentage of proliferating cells could be identified as endothelial cells, indicating neovascularisation.
\end{abstract}


Conclusions. These data indicate that cell proliferation in human stenotic tissue, derived from $\mathrm{AV}$ fistulas and peripheral bypass grafts, is increased as compared to control vessels and is concentrated in subendothelial-intimal areas. Furthermore, the extent of subendothelial-intimal proliferation is correlated with the presence of endothelial cell coverage of the lumen. In addition, a high shear rate was correlated with an decreasing endothelial cell coverage of the lumen, suggesting that denudation of EC may be the mechanism by which high shear rate results in decreasing DNA synthesis in the underlying VSMC.

\section{INTRODUCTION}

Failures of vascular reconstructions are mainly caused by the development of stenotic lesions, often located at the anastomoses ${ }^{1.5}$. The incidence of stenoses in the first postoperative year varies from $20-30 \%$ in femorodistal bypass grafts to $50-60 \%$ in hemodialysis arterio-venous fistulas when constructed with the use of interposition grafts $^{6-8}$. Proliferation of vascular smooth muscle cells (VSMC) is thought to be the dominant cellular event in the development of an intima ${ }^{5,9,10}$. The kinetics of this proliferative response are well described in animal studies ${ }^{11}$. The biology of human intimal hyperplastic lesions may be different and possibly more complex $x^{9,10,12,13}$. However, information on proliferation in human stenotic lesions is scarce.

In recent studies, the proliferative response of VSMC in humans was investigated in restenotic coronary tissue ${ }^{13}$, peripheral artery restenotic lesions ${ }^{14}$ and stenoses derived from $\mathrm{AV}$ fistulas ${ }^{10}$. In comparable stenotic lesions very high (up to $20 \%$ ) and very low $(0-0.5 \%)$ proliferation indices were reported. Consequently, the exact contribution of VSMC proliferation to restenosis in humans still remains unclear. A difficulty of the reported studies may be the use of PCNA as the marker for proliferation. Overestimation of the proliferation index with this marker has been demonstrated, and may explain the reported high proliferation indices ${ }^{15}$. A difficulty of evaluating atherectomy derived stenotic tissue may be the possible influence of sampling error, giving underestimation of the contribution of proliferation ${ }^{13}$. The use of another proliferation marker, KI-67 may provide an easier and mote reliable method to determine proliferative activity in tissue samples ${ }^{\mathrm{B}-18}$.

One of the factors that influence the growth of an intimal lesion is local flow. A decrease in flow is associated with increased intimal thickening ${ }^{19-25}$. The mechanism by which flow affects intimal hyperplasia may be its influence on the release of PDGF and EDRF, which has been demonstrated in in vitro studies ${ }^{26-28}$. In humans, accelerated atherosclerosis has been reported in bypassed coronary vessels, which have almost zero flow ${ }^{29}$. However, information on the possible correlation between flow and intimal growth in humans lesions is lacking. Another factor influencing proliferation is the presence of endothelial cells. In animal models, denudation of arteries initiates proliferation of VSMC in the media and subsequently in the intima. ${ }^{30,31}$. On the other hand, in in vitro studies elevated proliferation was observed in non-denuded areas with 
high levels of EC DNA synthesis, suggesting a stimulatory effect of activated endothelial cells on VSMC proliferation ${ }^{32-35}$. The role of endothellial cells in proliferation in human stenotic lesions derived from patients with $A V$ fistulas and peripheral bypasses has never been established.

The aim of the present study was to determine the distribution and time course of proliferation in human stenotic lesions. Furthermore, the influence of local flow characteristics on the proliferative reponse in the stenoses was studied. Since arteriovenous fistulas are an example of a high flow system, and a peripheral bypass an example of a low flow system, we hypothesized that the extent and pattern of replication in stenotic lesions derived from these two types of vascular reconstructions might be different, i.e. a high proliferation in the peripheral bypass and low proliferation in the AV fistula. In a consecutive series of patients receiving an hemodialysis arteriovenous fistula or a femorodistal bypass, flow characteristics were determined 2 weeks after construction at numerous sites in the graft and in the in- and outflow vessel segments, with the use of ultrasound techniques. At a later time point, the local flow characteristics were assessed at the site of the stenosis in patients developing stenoses in the graft or at the anastomoses, necessitating surgical intervention. After harvesting of the stenotic vessel segments, proliferation was assessed in different layers of the stenosis, with the use of KI-67. Local flow characteristics were correlated with the extent of proliferation in the stenotic vessel segments. In addition, endothellal cell coverage of the stenotic lumen was correlated with the extent of proliferation.

\section{MATERIALS AND METHODS}

\section{Tissue Specimens}

During the study period, from January 1992 to June 1994, 48 reinterventions were performed following construction of either an arteriovenous fistula or a peripheral bypass in the surgery department of the University Hospital of Maastricht or the Catharina Hospital of Eindhoven. In 13 cases the vascular conduit was corrected by patch plasty at the site of the stenosis. Since collection of stenotic tissue in these cases was impossible without performing extra surgical procedures, which might jeopardize the succes of the reintervention, it was decided not to obtain tissue specimens from this group of patients. In the remaining 35 cases surgical repair was performed by placement of an interposition graft, allowing the collection of the stenotic process and adjacent vessel segments. In all cases the stenotic lesion was focal and apparantly narrowing or occluding the lumen. 


\section{PATIENT CLINICAL PROFILE}

\section{Patients with an arterio-venous fistula}

This group consisted of 9 men and 6 women. Mean age was 56 years, ranging from 37 to 76 years. Repair of the AV fistula was performed after an average time of 10.4 months, varying from 3 to 27 months. The diagnosis of a stenosis was based on Duplex ultrasound criteria and confirmed by fistulography. In all patients the occurrence of a stenosis was associated with an increase in venous pressure and/or low flow of the fistula during hemodialysis, necessitating reintervention. In one patient a second reintervention was performed during the study period and in one patient two stenotic lesions were derived from different sites in the vascular conduit, resulting in a total number of 17 stenotic samples $(\mathrm{n}=17$ ). In 12 cases, the stenotic samples were derived from the efferent vein of either Brescia-Ciminino fistulas $(n=2)$ or fistulas constructed with the use of interposition grafts $(n=10)$. In 5 cases the stenotic sample was derived from the venous anastomosis of a PTFE interposition graft.

\section{Patients with a peripheral bypass}

This group of patients with a femorodistal bypass graft, consisted of 12 men and 4 women. Mean age was 64 years, ranging from 54 to 77 years. Reintervention was performed after an average time of 4.5 months, varying from 1 to 24 months. The diagnosis of a stenosis was based on generally accepted Duplex criteria and confirmed by angiography ${ }^{36}$. Patients with a graft at risk underwent repair of the stenotic segment. In most of these patients the occurrence of a stenosis was associated with a recurrence of symptoms. In two patients stenotic tissue was derived from two different sites in the graft, making the total number of stenotic vessel specimens in this group $18(n=18)$. In 10 cases the stenotic tissue was derived from reversed saphenous vein grafts, in 6 cases from in situ saphenous vein grafts and in 2 cases from a PTFE graft. Stenotic samples were derived from the proximal anastomosis $(n=11)$, midgraft $(n=5)$, and from the distal anastomosis $(n=2)$.

\section{Controls}

From patients receiving an AV fistula $(\mathrm{n}=6)$ or a peripheral bypass graft $(\mathrm{n}=9)$ with the use of saphenous vein, spare vein segments were derived and used for the assessment of proliferation.

\section{Tissue Staining with KI-67}

Cell proliferation was determined using KI-67, an antibody to an antigen expressed in all phases of the cell cycle, except G0 and the early part of G1. The KI-67 antigen is localized at the periphery of the chromosome scaffold and cellular cortex ${ }^{15}$. The exact function of this antigen in the process of replication has not been determined so far, but a reaction of the KI-67 antibody with nuclear proteins has been established ${ }^{15}$. Furthermore, the proliferation indices determined with $\mathrm{KI}-67$ and $3 \mathrm{H}$-thymidine are closely correlated ${ }^{16,18}$. 


\section{Staining Protocol}

Immediately after harvesting, the tissue specimens were carefully processed to preserve the sections intact and to prevent loss of endothelial cells covering the lumen. The tissues were fixed overnight in $10 \%$ phosphate buffered formalin, processed according to routine histologic procedures and paraffin-embedded, 5- $\mu \mathrm{m}$-thick serial sections were cut and placed on gelatin coated glass slides. After deparafinizing the sections and blocking of endogenous peroxidase activity with $0.3 \% \mathrm{H}_{2} \mathrm{O}_{2}$, the slides were placed in a $0.01 \mathrm{M}$ citrate buffer, $\mathrm{pH} 6.0$ and boiled during 5 minutes in a microwave oven. After subsequent washes in $\mathrm{H}_{2} \mathrm{O}$ and tris buffered saline (TBS), the slides were incubated with a mouse anti KI-67 monoclonal antibody (MIB, Immunotech, Apeldoorn, The Netherlands) during 60 minutes at room temperature at a dilution of 1:100, followed by incubation with biotinylated sheep anti-mouse IgG (1:250; DAKO) at room temperature for 30 minutes. Sections were then labeled for 30 minutes with an Avidin/Biotin peroxidase complex (Vectastain - ABC kit, Vector Labs, Builingame, CA, USA) using 3,3' diaminobenzidine as the chromogen. The sections were counterstained with hematoxilin, dehydrated through graded series of alcohols and mounted. A piece of human small intestine was used as a positive control in all staining sessions. As an internal positive control we used one stenotic AV fistula segment, which showed consistent positive staining during all sessions. As a negative control the staining procedure was performed without addition of the primary antibody. Furthermore, a spare saphenous vein segment was used as a negative control, showing no proliferation troughout the different staining sessions.

To identify endothelial cells, Ulex Europeus agglutinin I (1:500 dilution, Vector Labs, Burlingame, CA, USA) was used. After blocking of endogenous peroxidase activity with $0.3 \%, \mathrm{H} 2 \mathrm{O} 2$ sections were incubated with the lectin antibody $(1: 250,45$ min., DAKO) after predigestion with pepsin $(1 \mathrm{mg} / \mathrm{ml}, 30 \mathrm{~min})$. Subsequently, the sections were incubated for 45 minutes with an anti-Ulex Europeus lectine peroxidase complex (1:100, DAKO). As the chromogen, 3,3'diamino-benzidine was used.

\section{Cell Counting}

Tissue sections were investigated by light microscopy at $\times 400$ magnification using at standard field size. Cells containing dark nuclear staining with KI-67 were considered as positive cells ${ }^{16,17}$. In order to obtain insight in the distribution of the proliferative response in the intima, cells were counted separately in subendothelial-intimal and medial-intimal areas. Furthermore, medial and adventitial areas were counted (Figure 1). All cell counting was performed with an ocular grid by two investigators ( $\mathrm{LH}$ and MD). In each of the vessel layers, 4 at random selected fields were counted. The proliferation index, defined as the total number of positive cells divided by the total cell number, was calculated for each layer. In the stenotic lesions derived from PTFE grafts, no medial proliferation index was calculated. To assess the contribution of angiogenesis in the proliferative response a separate index for positive endothelial celis was calculated. Since cell counting was performed with the use of standard field size, the total number of cells per field can be used as a measure for the cell content in the different vessel layers. The degree of endothelial cell coverage of the lumen was 
estimated by using the Ulex Europeus stained sections and was calculated by dividing the surface of the lumen covered by endothelial cells by the total luminal surface. Tissue processing and all cell counting was performed with the investigators blinded to the clinical information.

\section{Measurement of the flow characteristics}

Since we attempted to determine the influence of the initial as well as the actual local flow characteristics on proliferation, peak systolic velocity (PSV) and peak shear rate (PSR) were assessed in vivo at numerous sites in the graft and in the in- and outflow segments with special attention to sites with a predisposition to develop intimal lesions, like the anastomoses. PSV was assessed with the use of Duplex ultrasound (ATL, Ultramark IV, Advanced Technology Laboratories, USA) with a doppler sample placed midstream at defined sites in the vascular conduit. The diameter was determined at the same defined sites in the graft and in- and outflow arterial segments with the use of Vessel Wall Doppler Tracking (VWDT). This system has been described in detail elsewhere (chapter 3 and 4$)^{37,38}$. Validation studies showed a coefficient of variation of $2-4 \%$ in the determination of diameter of a medium-sized muscular artery with the use of this system (chapter 4$)^{39}$.

From PSV and diameter, peak shear rate (PSR) was calculated, based on the HaagenPoiseuille formula for an assumed symmetric parabolic velocity profile ${ }^{25}$ :

$\operatorname{PSR}=\mathrm{n} *$ PSV/diameter $(1 / \mathrm{s})$

The local flow characteristics, determined 2 weeks after construction of the vascular conduit and 1-2 weeks before surgical repair of the stenosis, were used for analysis and correlation with proliferative patterns.

\section{ANALYSIS}

Data are presented as means and standard deviations. To compare results between the groups, the Mann-Whitney-U test was used. To compare proliferation between different cell layers within stenoses, the Wilcoxon test was performed. To test which factors showed an independent correlation with proliferation in the stenosis a multiple regression model was used. Linear regression analysis was used to define correlations between different parameters. When the data suggested a non-linear relation, non-linear regression analysis was used to define the relationship. A p-value of less than 0.05 was accepted as level of statistical significance. 


\section{RESULTS}

\section{Patient- and flow characteristics}

The patient characteristics are summarized in table I. No differences in mean age were observed between the groups. Surgical repair of the vascular conduit in patients with AV-fistulas was performed on the average 10.9 months after reconstruction, and in bypass patients after an average time of 4.5 months ( $p=0.002)$. Two weeks after operation mean PSV and PSR were higher at the site of stenosis in the AV fistula group as compared to the bypass group $(p=0.002$ and $p=0.05$ ). However, no differences in PSV and PSR were observed shortly before correction of the stenotic segment.

Table I: Patient- and flow characteristics. Both the initial and final (before harvesting) values of peak systolic velocity (PSV) and peak shear rate (PSR) are presented (mean(SD)).

\begin{tabular}{lccc}
\hline & $\begin{array}{c}\text { Bypass } \\
(\mathrm{n}=18)\end{array}$ & $\begin{array}{c}\text { AV fistula } \\
(\mathrm{n}=17)\end{array}$ & P Value \\
\hline & $64(12)$ & $46(21)$ & $\mathrm{ns}$ \\
Age (years) & $12 / 4$ & $9 / 6$ & $\mathrm{~ns}$ \\
Male/Female & $4.5(5.1)^{*}$ & $10.4(7.6)$ & $\mathrm{p}=0.002$ \\
Age Graft (months) & $124(96)^{*}$ & $341(60)$ & $\mathrm{p}=0.002$ \\
Initial PSV (cm/s) & $291(90)$ & $375(71)$ & $\mathrm{ns}$ \\
Final PSV (cm/s) & $52(28)$ & $78(29)$ & $\mathrm{p}=0.05$ \\
Initial PSR (1/s) & $132(59)$ & $115(60)$ & $\mathrm{ns}$ \\
Final PSR (1/s) & & & \\
\hline
\end{tabular}

\section{Proliferation}

In all stenotic samples KI-67 positive cells were observed, indicating a proper expression of this proliferation marker in the vessel specimens (Figure 1). In the control vein segments proliferation was almost zero (less than $0.2 \%$, data not shown) in the different cell layers.

A summary of the results is presented in Table II. The degree of endothelial cell coverage of the lumen was approximately $50 \%$ in both groups (5136 cells counted), with a proliferation index in the endothelium covering the stenosis of $2.9 \%$ in the AV fistula group and $3.5 \%$ in the bypass group $(p=0.31$, Table II). No differences in proliferation index were observed between the AV fistula group and the bypass group (Table II) in the subendothelial-intimal areas ( 7234 cell counted), medial-intimal areas (8371 cells counted), medial areas (3893 cells counted) and adventitial areas (61.24 
cells counted). In both the AV fistula group and the bypass group subendothelialintimal proliferation was higher as compared to medial-intimal proliferation (3.6\% vs 1.1 and 3.5 vs $2.0 \%$, respectively, $\mathrm{P}<0.05$ ). In the adventitia, relatively high proliferation indices were found (7.5\% for AV fistula stenoses and $4.2 \%$ for bypass stenoses, $p=0.26$ ). For the whole group, endothelial cell (EC) proliferation, increased from $0.3 \%$ in the subendothelial sections to $3.5 \%$ in the adventitia. This suggests increasing angiogenesis from the lumen to the outer layers of the vessel specimens.

Table II: Labeling fraction (\%) of KI-67 positive cells in the different layers of the stenosis. Data are presented as means $( \pm S D$ ). The total labeling fraction and the percentage proliferating vascular smooth muscle cells (VSMC) and endothelial cells (EC) are presented.

\begin{tabular}{lll}
\hline Proliferation (\%) & $\begin{array}{c}\text { Bypass } \\
(\mathrm{n}=18)\end{array}$ & $\begin{array}{c}\text { AV-fistula } \\
(\mathrm{n}=17)\end{array}$ \\
\hline $\begin{array}{l}\text { subendothelial intima } \\
\text { total }\end{array}$ & $3.5(3.9)$ & $3.6(3.6)$ \\
VSMC & $3.3(3.5)$ & $3.3(3.6)$ \\
EC & $0.2(0.6)$ & $0.3(1.0)$ \\
medial intima & & \\
$\quad$ total & $2.0(1.8)$ & $1.1(1.5)$ \\
VSMC & $1.2(1.8)$ & $0.9(1.2)$ \\
EC & $0.8(1.8)$ & $0.2(0.5)$ \\
media & & \\
total & $2.6(2.7)$ & $1.7(3.9)$ \\
VSMC & $1.3(2.1)$ & $0.7(1.4)$ \\
EC & $2.3(2.2)$ & $1.0(2.9)$ \\
adventitia & & \\
total & $4.2(3.5)$ & $7.5(6.7)$ \\
VSMC & $2.3(2.0)$ & $2.6(2.8)$ \\
EC & $1.9(2.0)$ & $4.9(6.6)$ \\
\hline
\end{tabular}


Figure 1: Photomicrograph of an anti-MIB stained section of a stenosis derived from the venous anastomosis of an AV-fistula. Dark-brown stained nuclei are positive.

a. Detail of the subendothelial intimal area. Note that most of the positively stained cells are lacalized in the intima adjacent to the lumen.

b. Detail of the media/adventitia area. Note that most of the positive nuclei are endothelial cells covering small vessels. ( $L=l u m e n, I=i n t i m, M=$ media, $A=a d v e n t i t i a$, magnification $\times 400$ ).
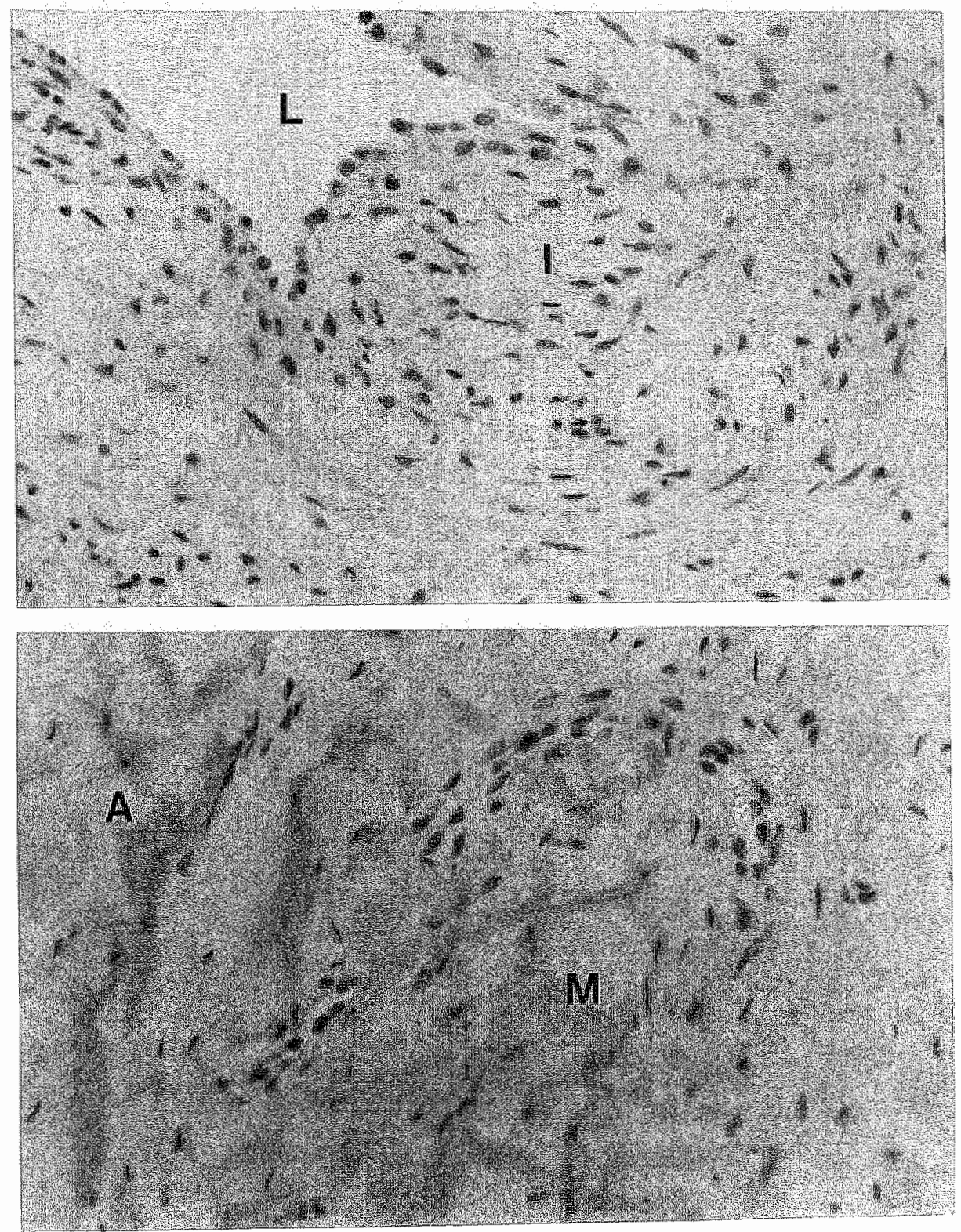
Figure 2: Photomicrograph of an anti-Ulex Europeus stained section of an AV fistula.

a. Detail of the intima and adjacent media. Note that the coverage of the lumen with endothelial cells is almost $100 \%$ and that the media contains many vessels.

b. Detail of the media/adventitia area. The stain visualizes the high vascularity of this region. ( $L=$ =lumen, $I=$ intima, $M=$ media, $A=a d v e n t i t i a$, magnification $\times 200$ and $\times 400$ respectivêly).
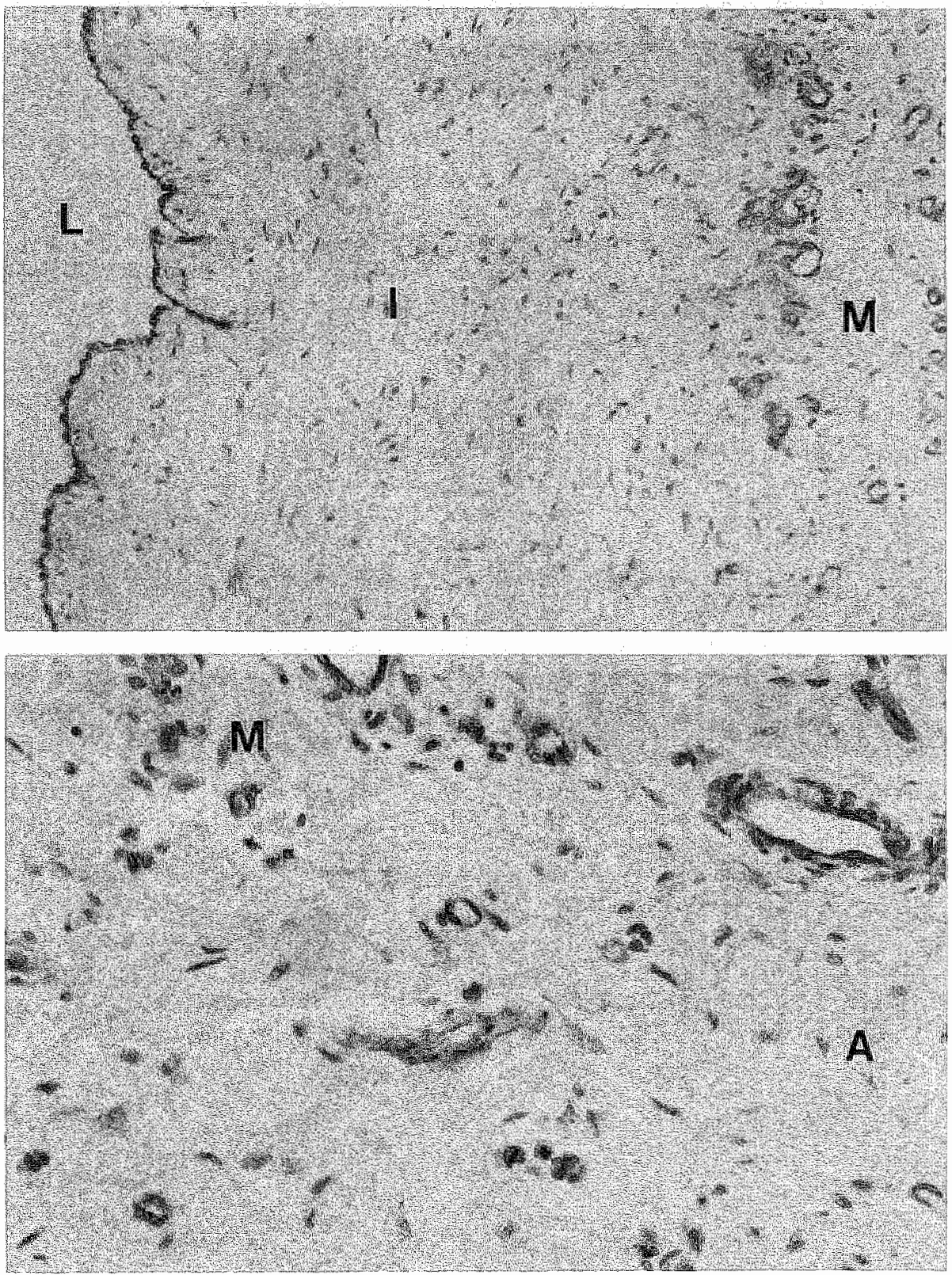


\section{Correlations}

Since no differences in proliferation patterns were found between AV fistulas and peripheral bypasses, they were treated as one group in correlating different parameters with proliferation. A multiple regression model was used to identify factors independently correlating with subendothelial-intimal proliferation, including endothelial cell coverage of the lumen of the stenosis, age of the lesion, peak shear rate at the site of the stenosis and graft type (vein or PTFE). The only factor independently influencing subendothelial-intimal cell proliferation was endothelial cell coverage (Table III). A positive correlation was found between endothelial coverage and subendothelial-intimal proliferation $(r=0.74, p=0.001$, Figure 3a). The final PSR could not be identified as an independent factor. However, when correlating PSR solely with subendothelial-intimal cell proliferation, a negative correlation was observed (non linear regression analysis, $\mathrm{r}=-0.67, \mathrm{p}<0.05$ Figure $3 \mathrm{~b}$ ). Therefore, a relation between endothelial cell coverage and peak shear rate was sought. Linear regression analysis demonstrated a negative correlation between these parameters (Figure 3c), suggesting that high shear results in loss of endothelial cell coverage, i.e., denudation (PTFE excluded since no endothelial cells are present in these specimens). A positive correlation was observed between proliferation of endothelial cells covering the stenosis and subendothelial-intimal cell proliferation $(y=1.4+0.47 * X, r=0.54$, $\mathrm{p}<0.01 \%$. The age of the stenosis could not be identified as an independent factor influencing proliferation, indicating that no distinct time course of proliferation is present in human stenotic tissue (Figure 3d).

Table III: Different parameters with a possible influence on subendothelial proliferation were included in a multiple regression model. From the $95 \%$ confidence limits it is shown that only the percentage of endothelial cells covering the lumen can be considered as an independent factor influencing subendothelial proliferation $(E C=$ endothelial cell, $P S R=$ peak shear rate, age $=$ age of the stenosis).

\begin{tabular}{lcc}
\hline factor & slope & $95 \%$ confidence limits \\
\hline ET cell coverage & 0.06 & $0.03 \cdots 0.08$ \\
$\log$ (PSR) & -0.3 & $-2.0-1.3$ \\
$\log (\mathrm{age})$ & -0.9 & $-2.1-0.2$ \\
\hline
\end{tabular}


Figure 3a: The relationship between the degree of coverage of the lumen by endothelial cells (EC) and subendothelial-intimal (SI) proliferation.

6 bypass

4 Shunt

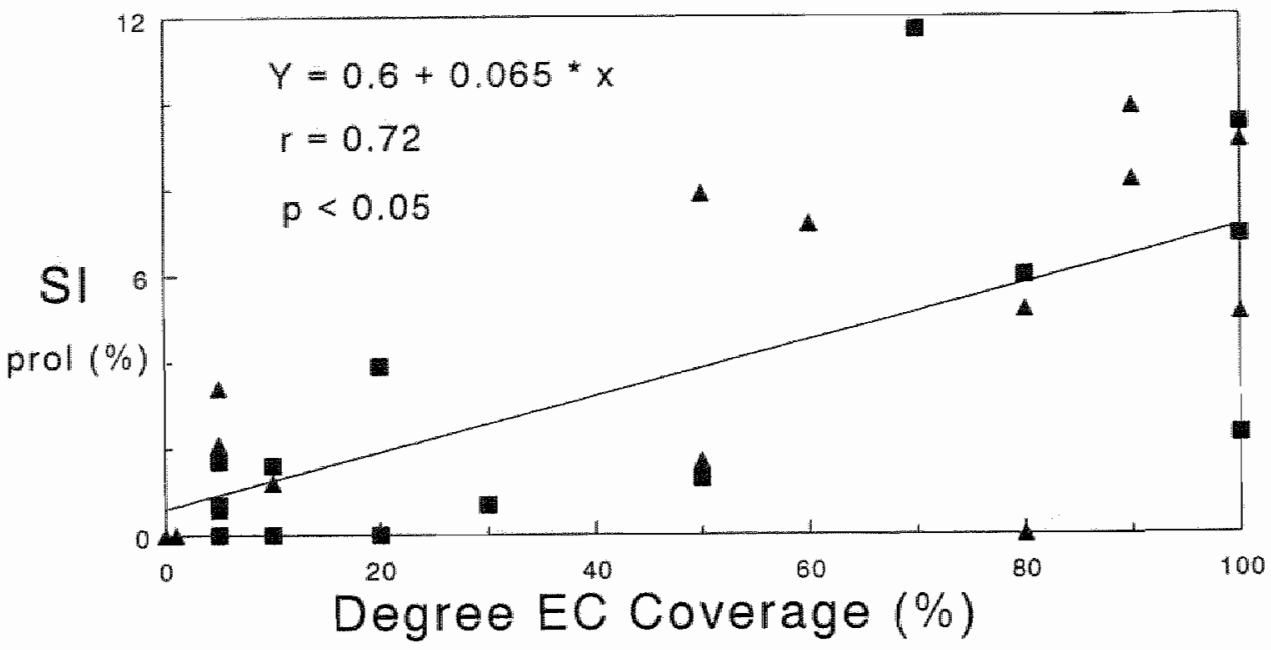

Figure 3b: The relationship between peak shear rate (PSR) and subendothellial-intimal (Sl) proliferation. Nonlinear regression analysis revealed a decreasing proliferation with increasing shear rate.

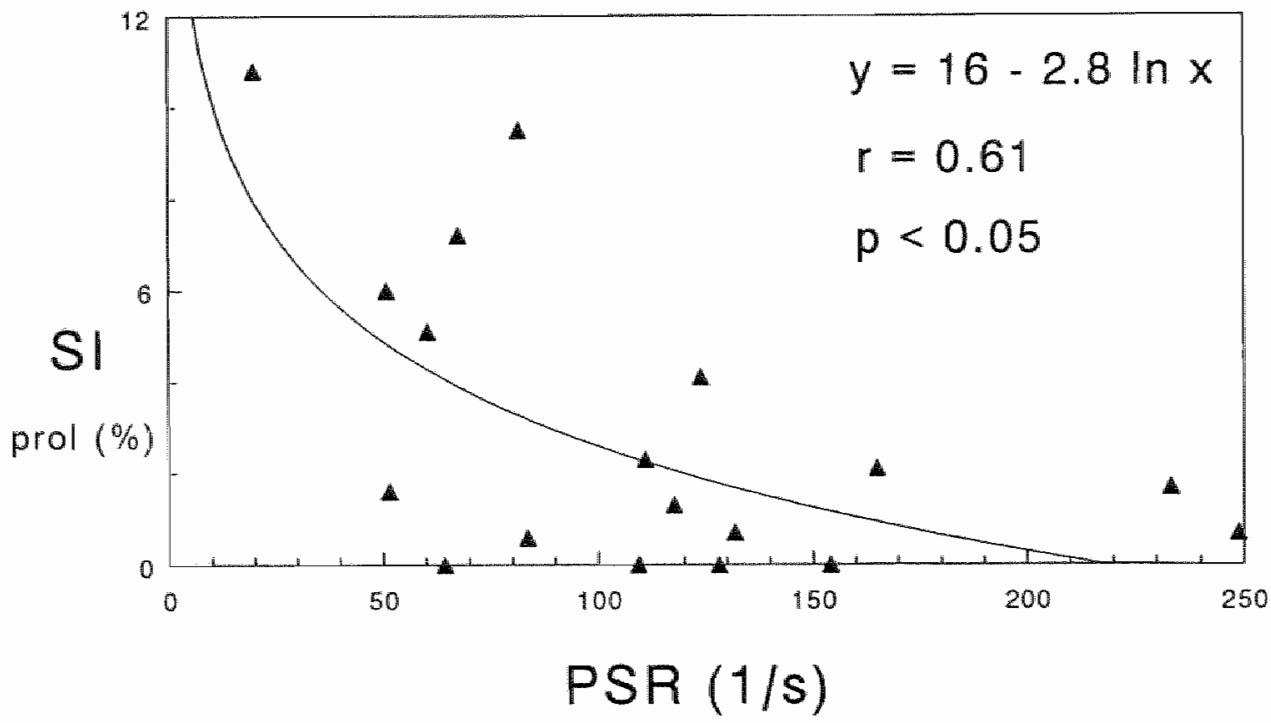


Figure 3c: The relationship between PSR and endothelial cell coverage of the lumen within the stenosis (PTFE grafts excluded). With increasing shear rate, endothelial cell coverage becomes less, indicaling denudation.

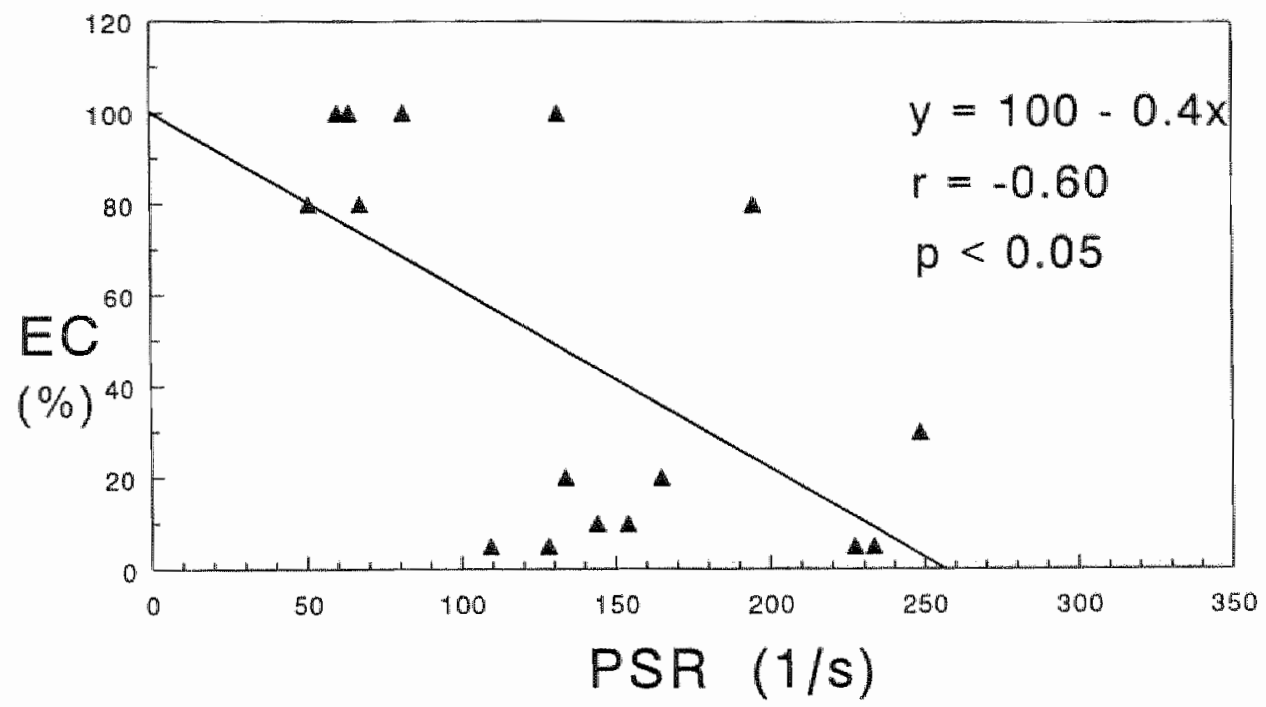

Figure 3d: The time course of subendothelial-intimal (SI) proliferation. The highest values of SI proliferation are observed in early developing stenoses. However, no significant correlation with time was observed.

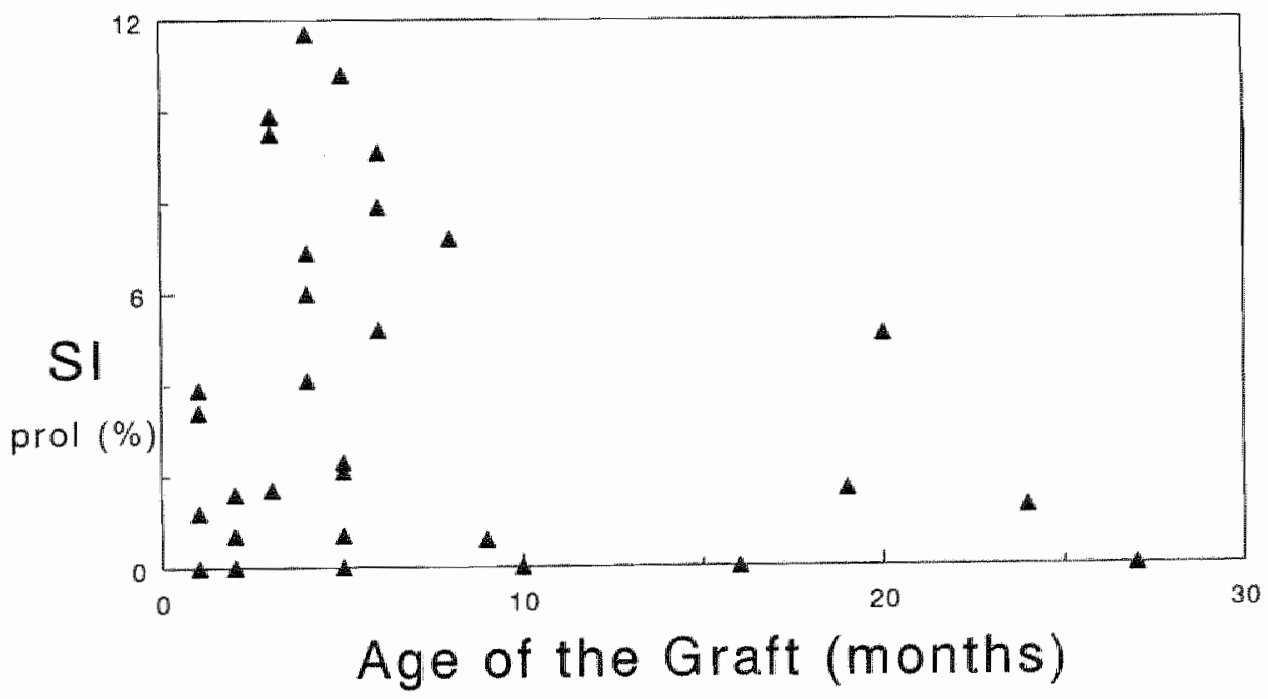




\section{DISCUSSION}

The present study has three interesting findings. First, it shows increased proliferation in human vascular stenotic lesions derived from $A V$ fistulas and peripheral bypass grafts, determined with the use of KI-67. Furthermore, our data suggest a stimulating role of the endothelium on proliferation in the intima, since proliferating KI-67 positive cells are mainly present in the area adjacent to the lumen and the degree of endothelial coverage of the lumen is correlated with subendothelial-intimal proliferation. In addition, with increasing peak shear rates, a decreasing endothelial cell coverage of the lumen was observed, suggesting that excessive high shear rate leads to denudation. This would imply an indirect inhibitory effect of high shear rate on proliferation in subendothelial areas by means of denudation.

\section{Proliferation in human stenotic tissue}

The contribution of proliferation of VSMC on the development of stenoses after vascular intervention in humans remains uncertain. In animal models stimulation and inhibition of replication of vascular smooth muscle cells by numerous pharmacological agents has been reported ${ }^{11,40-49}$. However, administration of these agents in patients undergoing vascular intervention failed to show beneficial effects ${ }^{9,12.50}$, indicating that extrapolation of findings in animal models to the human situation may be restricted and that proliferation patterns may differ between human and animal stenotic lesions ${ }^{9,12,13}$. Therefore, more information on cell proliferation in human stenotic lesions is required to address this question. In the present study we defined replication in stenotic tissue with the use of the marker KI-67. This proliferation marker has been validated with the use of BrdU labeling and gains acceptance as a prognostic marker in cancer research ${ }^{15-17}$. The advantage of studying surgically harvested stenotic tissue from anastomoses of $\mathrm{AV}$ fistulas and peripheral bypasses is that the tissue samples are well defined and cannot be confused with non-stenotic vessel segments. This excludes the possibility of sample errors, as may be encountered in studies evaluating atherectomy derived tissue, reporting very low and very high replication rates ${ }^{13,14}$. The replication rates in the different vessel layers as found in the present study (1.1 to $3.6 \%$ for the intima) are, however, also considerably lower as compared to the ones found in another study evaluating proliferation in AV fistula stenoses ${ }^{10}$. In that study the marker PCNA was used and proliferation rates as high as $15.20 \%$ were observed in the intima. High proliferation rates were also observed in a study using PCNA in the evaluating of proliferation in restenotic tissue after PTCA ${ }^{14}$. The use of PCNA may lead to overestimation of proliferation, as has been observed in validation studies, and may explain the reported high replication rates. The use of KI-67 may give a better representation of proliferation as compared to PCNA ${ }^{16,18}$.

\section{The endothelium and proliferation}

In the present study replication was markedly higher in the subendothelial-intimal areas as compared to the medial-intimal layer, which has also been observed in animal studies $^{25}$. In addition, a positive correlation was found between the degree of endothelial 
cell coverage of the lumen and proliferation indices in the subendothelial area (Figure 3a). This strongly suggests, that the endothelial cells covering the lumen of human stenotic lesions have a stimulating influence on proliferation. The data as depicted in Figure 3a, suggest that below an endothelial cell coverage of 30-40\% subendothelialintimal proliferation is very limited (mean $0.53 \pm 0.86 \%$ ), while a coverage over $40 \%$ is associated with significantly higher proliferation indices (mean $4.54 \pm 3.29 \%$, $\mathrm{p}<0.01$, Mann-Whitney-U test). In vitro studies have demonstrated that endothelial cells can release a variety of growth regulating factors ${ }^{11,51,53.5}$. Endothelium-derivedrelaxing-factor (EDRF), heparin, and prostacyclin (PGI-2) can be released by endothelial cells and may inhibit VSMC replication ${ }^{26-28,54-57}$. Growth-promoting factors released by the endothelium are platelet-derived-growth-factor (PDGF) and angiotensin-II (AGII) $28,51,58$. The effect of the endothelium on the growth response of VSMC probably depends on the balance between growth stimulating and inhibiting factors ${ }^{55.57}$. From our observation it can be concluded that the endothellum, when present, promotes replication, indicating a dysbalance between stimulating and inhibiting factors in favor of stimulation. This has been described previously in an in vitro study, using porcine aortic organ cell cultures ${ }^{32}$. In a recently published study, using human saphenous vein organ culture, also higher proliferation indices where found in the intima with an intact endothelial cell layer as compared to denuded vein cultures ${ }^{33}$. The results of this in vitro study are in concordance with the results from the present study. We found a positive correlation between proliferation of endothelial cells covering the stenosis and subendothelial-intimal proliferation. Proliferation of endothelial cells covering the stenosis suggests that these cells are not in their normal quiescent state. This may be due to partial denudation caused by high flow velocities, resulting in a disruption of cell-cell interaction between endothelial cells, initiating proliferation in order to reestablish a confluent monolayer ${ }^{59}$. The proliferative state of the endothelial cells may be related with a loss of growth inhibitory function, resulting in high subendothelialintimal proliferation as is suggested by the positive correlation between proliferation of endothelial cells covering the lumen of the stenosis and subendothelial-intimal proliferation. This hypothesis is supported by an in vitro study, reporting increased proliferation of VSMC in areas covered with proliferating endothelial cells ${ }^{34,35}$.

\section{Peak Shear Rate and Proliferation}

The influence of flow characteristics on the development of intimal hyperplasia has been extensively investigated in animal models, showing that low shear conditions lead to increased intimal thickening, while high shear rate inhibits the development of intimal thickening ${ }^{19-25}$. We therefore hypothesized that the extent and distribution of proliferation may differ between stenotic lesions derived from AV fistulas (relatively high-flow system) and peripheral bypasses (relatively low-flow system). However, we found no apparent differences in proliferation between stenotic tissue derived from these two groups, suggesting that volume flow may not be a determining factor in proliferation. The PSR values just before repair of the stenosis (Table I) showed similar values in the group AV fistulas and bypasses. To establish a possible effect of flow on VSMC replication, the PSR values just before harvesting were correlated with 
subendothelial proliferation. A negative correlation was found between final PSR and subendothelial proliferation index $(Y=16-2.8 \ln (P S R), r=0.67, p<0.05$, Figure 3b), but multiple regression analysis revealed that final PSR was not an independent determinant of subendothelial proliferation. Therefore, we hypothesized that shear rate might have an indirect effect on proliferation through its influence on the endothelial cells.

Linear regression analysis showed that with increasing shear rate, endothelial cell coverage decreases, suggesting a denudating effect of high shear rate. The calculation of PSR, based on the Haagen - Poisseille formula, can only give a rough estimation of the actual shear forces exerted on the endothelial cell layer, since a parabolic symmetric velocity profile is assumed. It is likely that in the systolic phase the local velocity profile is blunted, especially in narrowed segments. Therefore, the PSR as calculated in this study gives an underestimation of the actual PSR. However, the negative correlation between PSR and endothelial cell coverage of the lumen indicates that PSR may be of physiologic importance. Peak shear rate possibly gives a better characterization of the local pulsatile shear rate conditions than does mean shear rate, which has been used by other investigators ${ }^{24}$. This is supported by findings in an animal study, where no correlation was observed between mean shear stress and proliferation $^{24}$. Our data support the hypothesis that high shear rate inhibits the development of intimal thickening. The exact mechanism by which shear rate influences replication is unclear. Many authors and our data suggest a key role of the endothelium in this mechanism, which is supported by the finding that shear rate can initiate the release of EDRF and can lead to an increase in endothelial PDGF mRNA level $\mathrm{s}^{26.28}$. In addition, variation in shear rate levels results in modification of the structure of endothelial cells $s^{60-62}$.

No independent significant correlation between proliferation index and age of the conduit was observed. The highest values of proliferation indices in the subendothelial-

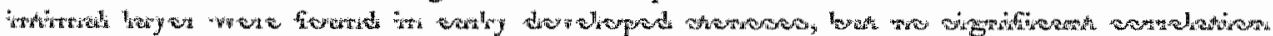
with time was demonstrated $(p=0.10$, Figure $3 d$ ), which confirms the findings of other studies evaluating proliferation in human stenotic tissue ${ }^{10,13,14}$. This suggests that a small but continuously elevated proliferation is present rather than a high peak in proliferation.

In the present study neovascularisation was observed in the stenotic lesion as well as in the media and adventitia. From the lumen to the adventitia, an increasing proportion of proliferating cells were identified as endothelial cells, covering microvessels. Angiogenesis thas been observed previously in human stenotic lesions ${ }^{10}$. The close correlation of subendothelial-intimal proliferation with the degree of endothellial cell coverage and the large percentage of proliferating endothelial cells covering microvessels in the stenosis, indicate that endothelial cells may be a major source for growth factors influencing proliferation patterns in human stenotic lesions. The exact contribution of angiogenesis to the development of stenotic lesions and atherosclerosis is unclear, but certainly deserves further investigation. 
In summary, a $0.9-3.7 \%$ proliferation rate was observed in well defined human stenotic tissue, derived from severely or occluded peripheral bypasses or AV-fistulas, with the use of KI 67. Subendothelial proliferation in the intima was positively correlated with the presence of endothelial cells covering the lumen, suggesting at stimulating role for endothelial cells on subendothelial-intimal proliferation. In addition, with increasing peak shear rate, a decrease in endothelial cell coverage of the lumen was observed, indicating that denudation occurs in areas of excessive high shear. This may indicate that high shear tate has an indirect inhibitory effect on proliferation by means of denudation.

\section{ACKNOWLEDGEMENT}

We are indebted to Jean Willigers for the technical assistance. We thank Petra Aarts and Anique Janssen for excellent technical support. We thank Dr J Buth and Dr M Idu for supplying us with samples from the Catharina Hospital Eindhoven. 


\section{REFEPENCES}

1. Harris PL, Veith FJ, Shanik GD, Nott D, Wengerter KR, Moore DJ. Prospective randomized comparisoin of in situ and reversed infrapopliteal vein grafts. Br J Surg 1993; 80:173-176.

2. Berkowit HD, Greenstein S, Barker CF, Perloff LJ. Late falure of reversed vein bypass griffts. Awn Surg 1989; 210:782-786.

3. Taylor $\mathbb{L M}$, Edwards JM, Porter JM. Present status of reversed vein bypass grafting: Five-year resulis of a modern series. J Vasc Surg 1990; 11:193-206.

4. Jenkins AMcL, Buist TAS, Glover SD. Medium-term follow-up of forty autogenous vein and forly polytetrafluorethylene (Gore-Tex) grafis for vascular access. Surgery 1980; 88:667-672.

5. Swedberg SH, Brown BG, Sigley $\mathrm{R}$, Wight TN, Gordon D, Nicholls SC. Intimal fibromuscular hyperplasia at the venous anastomosis of PTFE grafts in bemodialysis patients. Circulation $1989 ; 80: 1726-1736$

6. Berkowitz HD, Fox AD, Deaton DI. Reversed vein graft stenosis: Early diagnosis and management. J Vasc Surg 1992; 15:130-142.

7. Harris PL, How TV, Jones DR. Prospectively randomized clinical trial to compare in situ and reversed saphenous vein grafts for femoropopliteal bypass. Br J Surg 1987; 74:252-255

8. Tordoit JHM, Herman JM, Kwan TS, Diderich PM. Long-term follow-up of the polytetrafluoroethylene (PTFE) prosthesis as an arteriovenous fistula for hemodialysis. Eur $J$ Vasc Surg $1988 ; 2: 3-7$.

9. Liu MW, Roubin GS, King III SB. Restenosis after coronary angioplasty. Potential biologic determinants and role of intimal hyperplasia. Circulation 1989; 79:1374-1387.

10. Rehkter M, Nicholls S, Ferguson M, Gordon D. Cell proliferation in human arteriovenous fistulas use for hemodiallysis. Arterioscler Thromb 1993: 13:609-617.

11. Clowes AW, Reidy MA. Prevention of stenosis after vascular reconstruction: Pharmacologic control of intimal hyperplasia - A review. I Vasc Surg 1991; 6:885-891.

12. Ferrel M, Fuster V, Gold HK, Chesebro JH. Choosing appropriate experimental animal model for the prevention of restenosis. Circulation 1992; 85:1630 1631.

13. OBrien ER, Alpers CE, Stewart DK, et al. Proliferation in primary restenotic cononary atherectomy tissue. Implications for antiproliferative therapy. Circ Res 1993; 73:223-231.

14. Pickering JG, Weir L, Jekanowski J, Kearny MA, Isner JM. Proliferative activity in peripheral and coronary atherosclerotic plaque among patients undergoing percutaneous revascularisation. J Clin Invest 1993; 91:1469-1480.

15. Verheyen $\mathrm{R}$, Kuypers HH, Schlingeman RO, ell al. Ki-67 detects a nuclear matrix-associated proliferation-related antigen. $J$ Cell Science 1989; $92: 123-130$.

16. Sasaki K, Matsumara K, Tsuji T, Shinozaki Ha, Takahashi M. Relationship between labeling. indices of Ki-67 and BrdUrd in human maligmant turnors. Cancer 1988; 62:989-993.

17. Veronese SM, Gambacorta M, Gottardi O, Scanzi F, Ferrari M, Lampertico P. Proliferation index as a prognostic marker in breast cancer. Cancer 1993; 71:3926-3931.

18. Van Dierendonck $\mathrm{JH}_{\mathrm{s}}$ Wijsman $\mathrm{JH}$, Keyzer $\mathrm{R}$, Van De Velde CJH, Conelisse $\mathrm{CJ}$. Cell-cycle-telated staining palterns of anti-proliferating cell nuclear antigen monoclonal antibodies- Comparison with BRDUrd labeling and KI-67 staining. Am I Pahol 1991; $138: 1165-1172$.

19. Zarins CK, Bomberger RA, Glagov S. Local effects of stenoses: Increased flow velocity inhibits atherogenesis. Circulation 1981; 64:11221-1/227.

20. Zarins CK, Giddens DP, Bharadvaj BK, Sottiarai VS, Mabon RF, Glagov S. Carotid bifurcation atherosclerosis. Quantitative correlation of plaque localization with flow velocity profiles and wall shear stress. Circ Res 1983; 53:502-514.

21. Asakura T, Karino T. Flow patterns and spatial distribution of atherosclerotic lesions in human coronary arteries. Circ Res 1990; 66:1045-1066. 
22. Friedman MH, Bargeron CB, Detters OJ, Hutchins GM, Mark FF. Correlation between wall shear and intimal thickness at a coronary artery branch. Aheroscterosis $1987 ; 68.27-33$.

23. Sterpeti AV, Cucina A, Santoro L, Cardillo B, Cavallaro A. Modulation of arterial smocth muscle cell growth by hemodynamic forces. Eur J Vasc Surg 1992; 6:16-20.

24. Kohler TR, Jawien A. Flow affects development of intimal hyperplasia after arterial injury in rats. Arterioscler Thromb 1992; 12:963-971.

25. Kohler TR, Kirkman TR, Kraiss LW, Zierler BK, Clowes AW. Increased blood flow inhibits neointimal hyperplasia in endothelialized vascular grafts. Circ Res 1991; 69:1557-1565.

26. Cooke JP, Rossitch $\mathrm{E}_{3}$ Andon NA, Loscalzo J, Dzau VI. Flow activates an endothelial potassiun channel to release an endogenous nitrovasodilator. J Clin Imes 1991; 88:1663-16. 71.

27. Buga GM, Gold ME, Fukuto JM, Ignarro La. Shear stress-induced release of nitric oxide from endothelial cells grown on beads. Hypertension 1991: 17:187-193.

28. Hsieh HJ, Li NQ, Frangos JA. Shear stress increases endothelial platelet-derived growth factor mRNA levels. Am J Physiol 1991; 260:H642-H646.

29. Cashin WL, Sanmarco ME, Nessim SA. Blankenhom DH. Accelerated progression of atherosclerosis in coronary vessels with minimal lesions that are bypassed. New Eng $J$ Med $1984 ; 311.824-828$.

30. Clowes AW, Reidy MA, Clowes MM. Mechamisms of stenoses after arterial injury. Lab Invest $1983 ; 49: 208-215$.

31. Gordon D, Schwartz SM. Cell proliferation in human atherosclerosis. Trends Cardioyasc Med 1991; Januaryl February:24-28.

32. Koo EWY, Gotlieb AI. Endothelial stimulation of intimal cell proliferation in a porcine aortic organ culture. Am J Pathol 1989; 134:497-503.

33. Allen KE, Varty $K$, Jones $L$, Sayers RD, Bell PRF, London NJM. Human venous endothelium can promote intimal hyperplasia in a paracrine manner. I Vasc Surg 1994; 19:577-584.

34. Mey de JGR, Dijkstra EH, Vrijdag MJJF. Endothelium reduces DNA synthesis in isolated arteries. Am I Physiol 1991; 260:H1-H7.

35. De Mey JGR, Schiffers PM. Effects of the endothelium on growth responses in arteries. $J$ Cardionasc Pharmacol 1993; 21:s22-s25.

36. Buth J, Disselhoff B. Sommeling C, Stam L. Color-flow duplex criteria for grading stenosis in infrainguinal wein grafts. J Vasc Surg 1991; 14:716-728.

37. Hoeks APG, Brands PI, Smeets FAM, Reneman RS. Assessment of distensibility of superficial arteries. Ultrasound Med Biol 1990; 16:121-128.

38. Reneman RS, Merode van T, Brands PJ, Hoeks APG. Inhomogeneities in arterial wall properties under nomal and pathological conditions. J Hypertens 1992; 10:S35-S39.

39. Hofstra L, Willigers JM, Huvers $\mathrm{FC}$, et al. Short-term variations in elastic properties of a muscular artery in humans. Clin Sci 1993; 50:472-480.

40. Daemen MJAP, Lombardi DM, Bosman FT, Schwartz SM. Angiotensin II induces smooth muscle cell proliferation in the nomal and injured tat arterial wall. Circ Res 199 ; $68: 450 \cdot 456$.

41. Powell JS, Clozel JP, Muller RKM, et al. Inhibtors of angiotensin-converting enzyme prevent myointimal proliferation after vascular injury. Science 1989; 245:186-188.

42. Vashiht $R$, Sian M, Franks PJ, OMalley MK. Long-term reduction of intimal hyperplasia by the selective alpha-1 adrenergic antagonist doxazosin. Br J Surg 1992; 79:1285-1288.

43. Powell IS, Rouge M, Muller RK, Baumgariner HR. Cilazapril suppresses myointimal. proliferation after vascular injury: effects on growth factor induction in vascular smooth muscle cells. Basic Res Cardiol 1991; 86:65-74.

44. Mitsuka M, Nagae M, Berk BC. Nat-H+ exchange inhibiors decrease neointimal fomation after rat carotid injury. Effects on smooth muscle cell migration and proliferation. Circ Res $1993 ; 73: 269-275$ 
45. Kranzhöfer $R$, Schirmer J, Schömig $A$, et al. Suppresion of neointimal thickening and smooth muscle cell proliferation ater arterial injury in the rat by inhibitors of $\mathrm{Na}+\mathrm{H}+$ exchange. CirC Res 1993; 73:264-268.

46. Kleef van EM, Smits JFM, Mey de JGR, el al. a1-Adrenoreceptor blockade reduces the angiotensin II -induced vascular smooth muscle cell in the rat thoracic aorta and carotid artery. Circ Res 1992; 70:1122-1127.

47. Jawien A, Bowen-Pope DF, Lindner V, Schwartz SM, Clowes AW. Platelet-derived growth factor promotes smooth muscle migration and intimal thickening in a rat model of balloon angioplasty. J Clin Invest 1992; 89.507-511.

48. Dryjski M, Mikat E, Bjornsson TD. Inhibition of intimal hyperplasia after arterial injury by heparins and heparinoid. J Vasc Surg 1988; 8:623-633.

49. Clowes $\mathrm{AW}$, Clowes $\mathrm{MM}$, Vergel $\mathrm{SC}_{\text {s }}$ et al. Heparin and cilazapril together inhibit injury-induced intimal hyperplasia. Hypertension 1991; 18:1165-1169.

50. McBride W, Lange RA, Hillis LD. Restenosis after successful coronary angioplasty. Pathophysiology and prevention. New Eng J Med 1988; 318:1734-1737.

51. Ross R. The pathogenisis of atherosclerosis - An update. New Eng J Med 1986; 314:488-499.

52. Ralevic $V$, Milner $P$, Hudlicka $O$, Kristek $F$, Burnstock $G$. Substance $P$ is released from the endothelium of normal and capsaicin-treated rat hind-limb vasculature, in vivo, by increased flow. Circ Res 1990; 66:1178-1183.

53. Ross R. Atheroselerosis: A defense mechanism gone awry. Am J Pathol 1993; 143:987-1002.

54. Rubanyi GM, Freay AD, Kauser $K$, Johns A, Harder DR. Mechanoreception by the endothelium: Mediators and mechanisms of pressure- and flow-induced vascular responses. Blood Vessels 1990; $27: 246-257$.

55. Lisscher TF. Imbalance of endothelium-derived relaxing and contracting factors. A new concept in hypertension? Am I Hypertens 1990; 3:317-330.

56. Limanni A, Fleming T, Molina R, et al. Expression of genes for platelet-derived growth factor in adult human venous endothelium. A possible non-platelet-dependent cause of intimal hyperplasia in vein grafts and perianastomotic areas of vascular prostheses. $J$ Vasc Surg 1988; 7:10-20.

57. Furchgott RF, Vanhoutte PM. Endothelium-derived relaxing and contracting factors. FASEB J 1989; $3: 2007-2018$.

58. Schwartz CJ, Valente AJ, Sprague EA, Kelly JL, Nerem RM. The pathogenesis of atherosclerosis: An overview. Clin Cardial 1991; 14:1-16.

59. Schwartz SM, Liaw L. Growth control and morphogenesis in the development and pathology of arteries. I Cardiovasc Pharmacol 1993; $21: 331-549$.

60. Langille $B L$, Reidy $M$, Kline R. Injury and repair of endothelium at sites of flow disturbances near abdominal artic coarctations in rabbits. Arierioscler Thromb 1988; 6:146-154.

61. Gotllieb AI, Langille BL, Wong MKK, Kim DW. Sructure and function of the endothelial cytoskeleion. Lab Invest 1991; 65:123-137.

62. Langille $\mathrm{BL}$, Graham JJ, Kim D, Gotlieb Al. Dynamics of shear induced redistribution of F-actin in endothelial cells in viwo. Arterioscler Thromb 1991; 6:1814-1820. 


\section{GENERAL DISCUSSION}

\section{MECHANICAL AND FLOW CHARACTERISTICS AFFECTING INTIMAL HYPERPLASTA IN PERIPHERAL BYPASS GRAFTS AND GRAFT ARTERIO VENOUS FISTULAS IN HUMANS}

The principal goal of the studies described in this thesis was to clarify the role of perianastomotic mismatch in elastic properties and unphysiological flow conditions on the occurrence of stenotic intimal thickening in peripheral bypasses and graft arteriovenous fistulas. Based on the literature, we hypothesized that an increase in perianastomotic mismatch in elastic properties leads to an increase in the occurrence of stenoses. In addition, we hypothesized that a low shear rate in these vascular reconstructions results in stenotic intimal thickening.

The first step to investigate the role of mechanical factors in the occurrence of stenotic intimal thickening in peripheral bypasses and graft AV fistulas was to test the applicability of Vessel Wall Doppler Tracking (VWDT) in the assessment of elastic properties of these vascular reconstructions. The use of the B-mode image in the positioning of the measurements turned out to be crucial in the determination of elastic properties at defined sites in the vascular systems. By using the anastomosis as a landmark, the assessment of differences in elastic properties around anastomoses was possible, allowing the quantification of peri-anastomotic mismatch in elastic properties. For the first time, assessment of elastic profiles of peripheral bypass grafts and graft AV fistulas was possible, indicating that VWDT is a promising and very useful new tool to obtain insight in the mechanics of vascular reconstructions. In the first chapters (chapter 5-8); we studied the elastic behavior of peripheral bypasses and arteriovenous fistulas constructed using different techniques and graft materials. In addition, we tried to assess local flow characteristics in peripheral bypasses and arterio-venous fistulas at corresponding sites. One of the limitations in the measurement of wall shear rate with the use of uitrasound is that the determination of vessel diameter on a B-mode image is inaccurate. Since VWDT provides accurate determination of diameter, the calculation of peak shear rate was possible. This provided a rough estimate of the actual shear stresses exerted on the vessel wall. 
A second step was to correlate initial peri-anastomotic mismatch and local flow conditions with the occurrence of stenosis in peripheral bypasses and AV fistulas during follow-up. It was observed that the occurrence of stenotic intimal thickening in arteriovenous fistulas is associated with high shear rate and not with a mismatch in elastic properties (chapter 9). In addition, a high initial locall peak shear rate in venous peripheral bypass grafts was associated with the accurrence of stenotic intimal thickening during follow up. A greater initial peri-anastomotic mismatch in strain was observed in the proximal anastomoses of bypasses developing a stenosis as compared with the bypasses without a stenosis.

\section{MISMATCH IN ELASTIC PROPERTIES AND INTIMAL THICKENING}

In the AV fistula group no association was observed between a greater perianastomotic mismatch in elastic properties and intimal thickening. In the bypass group, a greater peri-anastomotic mismatch in local strain at the proximal anastomosis was associated with stenotic intimal thickening. However, for the distal anastomosis no association between peri-anastomotic mismatch and the occurrence of stenoses was observed. In addition, multiple regression analysis, including flow- and mismatch parameters, demonstrated that only a high initial peak shear rate was correlated with the occurrence of intimal thickening. For a mismatch in peri-anastomotic strain no correlation with the occurrence of intimal lesions was found in the multiple regression model. The observations from the prospective studies in $\mathrm{AV}$ fisstulas and peripheral bypasses suggest that initial peri-anastomotic mismatch in elastic properties does not play a major role in the occurrence of intimal lesions in these vascular reconstructions. A possible explanation for the absence of a correlation between peri-anastomotic mismatch in elastic properties and stenotic intimal thickening may be that the differences in distension between graft and native vessels are less than one would expect from the intrinsic material properties. The observations in chapter 6 and 7 suggest that the distension of the graft close to the anastomosis is influenced by the distension of the native vessel and vice versa. Placement of a stiff graft in a compliant arterial system leads to a decrease in distension of the arterial segments close to the anastomosis. Or the other hand, the distension of the native vessel leads to passive distension of the adjacent graft segment. This suggests graft-native vessel interaction. This interaction between graft and native vessel system was observed when measuring elastic properties at a distance of approximately 1 centimeter from the anastomosis. One might speculate that more interaction between graft and native vessels is present at points closer to the anastomosis. Therefore, the actual difference in distension between graft and native vessel close to the anastomosis may be even less than was observed in our studies.

Another explanation for the absence of a correlation between peri-anastomotic mismatch in elastic properties and stenotic intimal thickening may be that the in vivo strain at the anastomosis is not enough to initiate the replication of VSMC and to 
stimulate the production of matrix by these cells. In in vitro studies, VSMC started to produce matrix material when exposed to repetitive cyclic stretching. However, the values of strain in these studies were around $20-25 \%$, which is very high when compared to the strain values found in our sindies. We observed strain values of $1-5 \%$ around the anastomosis, which may not be sufficient to initiate VSMC responses.

\section{FLOW CHARACTERISTICS AND INTIMAL THICKENING}

The finding that intimal thickening in the venous outflow segment of AV fistulas and in venous peripherall bypass grafts is associated with initial high peak shear rate levels seems to be in contrast with numerous studies demonstrating that increased intimal thickening occurs mainly in areas of low shear rate. There are several possible reasons for this apparent discrepancy. First of all, most investigators studied the effect of varying shear rates on intimal thickening after the initial injury had already occurred. This is quite different from the initial situation at the venous outflow segment of the $A V$ fistula and a saphenous vein bypass graft, where intact endothelium is present. Another point that has to be considered is the range of shear rates investigated. In some studies a comparison was made between the effect of a decreased flow and the effect of normal arterial flow. This indicates that the range of shear rates investigated lies between normal and low, which is different from the magnitude of the shear rate values encountered in AV fistulas. In the venous anastomoses of AV fistulas peak systolic velocity values as high as $300-350 \mathrm{~cm} / \mathrm{s}$ are present, indicating excessive high shear rate levels. In normal arteries peak systolic velocity varies between $60-120 \mathrm{~cm} / \mathrm{s}$, leading to substantially lower shear rate levels for the same vessel diameter. This implies that the shear rate values as found in AV fistulas are beyond physiological values. Also in the proximal segments of reversed saphenous vein grafts elevated peak systolic velocities may be present, since this is the narrowest segment in the graft. Another point which has to be considered, when comparing the results in this thesis with data from animal studies, is the fact that in animal studies intimal hyperplasia does not proceed to subocclusive or occlusive stenotic lesions, but is restricted in its extent. The changes in intimal thickening as found in the animal models may just be an adaptational process, and may therefore be dissimilar to occlusive intimal hyperplasia as found in humans.

Another consideration may be the use of different vessel types and reconstructions when studying the effect of varying flow on the development of intimal thickening. Balloon denudation in rat models are mostly performed in the carotid artery, whereas intimal thickening in AV fistulas in humans predominantly occurs at the site of the venous anastomoses or the efferent vein. At the arterial site or at the arterial anastomoses of the AV fistulas intimal thickening hardly develops despite similar flow conditions. This suggests that excessive high shear rates may lead to denudation in veins due to a high susceptibility of the venous endothelial cells to the injurous effect of shear stress. Some investigators have used PTFE grafts, and measured the thickness 
of the neo-intima within the graft at varying flow levels. Since initially PTFE grafts are not covered with endothelial cells and no media is present as the origin of the proliferating and migrating vascular smooth muscle cells, the mechanism of intimal thickening in this model has to be different. In addition, occlusive intimal hyperplasia associated with PTFE grafts hardly ever occurs within the graft, but develops at the site of the anastomoses. Therefore, studying intimal thickness within PTFE grafts at varying flow levels probably has limited relevance for the clinical situation.

The prospective studies on the influence of the initial flow characteristics on the occurrence of stenoses in AV fistulas and peripheral bypasses (chapter 9 and 10) showed that initial high local peak shear rate is associated with the occurrence of stenoses in the follow-up period. This seems to be in contrast with the observation in the study described in chapter 11, showing a decreased proliferation with increasing local peak shear rate, suggesting an inhibitory effect of high shear rate on the development of intimal thickening. When combining the results from these studies we propose the following hypothesis on the relation between flow characteristics and intimal thickening in human vascular grafts:

1. An initial high peak shear rate, as present in the venous anastomoses and efferent vein segments in AV fistulas and in the proximal segment of reversed saphenous vein bypass grafts, results in partial denudation and intimal damage in venous segments, thereby initiating a vascular response leading to local intimal thickening.

\section{High Shear Rate}
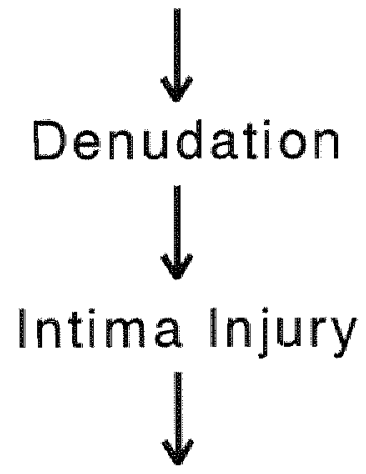

\section{Initiation Stenosis Formation}


2. A local high peak shear rate at the site of the stenosis inhibits proliferation of VSMC in the intima, possibly by a denudating effect on endothelial cells covering the lumen. Thus after the initiation of vascular injury by a high peak shear rate as discussed under 1 , the velocity by which the stenosis develops is inhibited by a high peak shear rate.

\section{High Shear Rate}
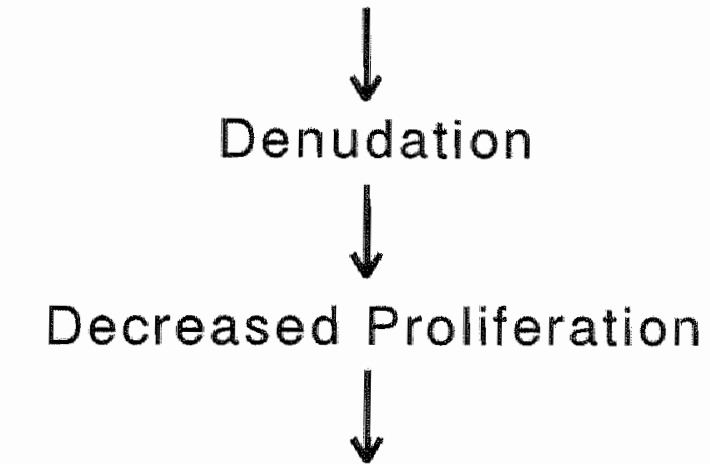

Inhibition Stenosis Formation

\section{LIMITATIONS OF THE STUDY}

The technique by which the studies were performed, Vessel Wall Doppler Tracking, has been validated in previous studies reported from our institution. In chapter 4 the data on short-term variations in elastic properties in the femoral artery in humans are presented. We found considerable variation with time, which could not be attributed to changes in pressure, indicating that active vessel wall behavior is responsible for the variation. Changes in vascular muscle tone may be the result of changes in flow and/or the activity of the local renine-angiotensin system (RAS) system. This study was performed in healthy young subjects. So far, we do not know whether short term variations in elastic properties are also present in saphenous vein bypass grafts, femoral and popliteal arteries in atherosclerotic patients, and brachial arteries and veins in hemodialysis patients.

A major restriction of the assessment of compliance and distensibility coefficient in peripheral bypass grafts and $\mathrm{AV}$ fistulas is the absence of local pulse pressure information. The calculation of compliance and distensibility based on non-invasively 
obtained pulse pressure values may be inaccurate. In chapter 5 we have used compliance and distensibilty (CC and DC), calculated with the use of digital blood pressure values obtained with Finapres. We observed a good correlation between DC and $\mathrm{CC}$ values of the common femoral artery obtained with either local intra-arterial measurements or Finapres values in patients with diseased vessels (see chapter 5). However, the use of blood pressure values remote from the assessment of distension is under discussion and has resulted in the development of new approaches to determine local pressure and vessel wall distensions simultaneously.

Another point is that the compliance mismatch theory is based on the thought that peri-anastomotic differences in strain and cross-sectional area-increase possibly lead to local mechanical stress and/or flow disturbances. The pressure leading to strain and cross-sectional area increase (i.e. pulse pressure) is of a lesser importance. Based on the arguments mentioned above we decided to use parameters not corrected for pulse pressure, like local strain (RD) and cross-sectional area-increase (AI) in the later studies of the thesis.

The assessment of shear rate in the human in vivo situation is difficult. We used peak shear rate, which can only give a rough estimation of the actual peak wall shear rates. With the use of a new ultrasound system to estimate wall shear rate in vivo in humans, we found an almost linear relationship between velocity in the center of the vessel and wall shear rate. These measurements were performed in the carotid artery in healthy volunteers under well-defined conditions. This implies that velocity in the center of the vessel is a major determinant of wall shear rate, and indicates that the use of PSR in this thesis was justified. The scaling factor may vary between different vascular territories and may be influenced by hemodynamic conditions.

\section{CLINICAL IMPLICATIONS}

The concept that high shear rates lead to denudation in peripheral saphenous vein bypass grafts and venous outflow segments of AV fistulas has implications for the method of construction of these vascular conduits. Modifications of operation techniques should aim at decreasing peak shear rate levels, thereby reducing the possible injurous effects of excessive high shear rate, at least in venous vessel segments. In constructing peripheral bypasses from saphenous vein material, the vascular surgeon is restricted by the dimensions of the vein and the length of the bypass. Theoretically, the in sitw technique, with its natural taper, overcomes the problem of high shear rate in the proximal graft segment and therefore seems to be the most ideal graft in terms of flow. In constructing AV fistulas, a decrease in flow velocity may be accomplished by the use of inversely tapered grafts (i.e. 4 to $7 \mathrm{~mm}$ ) and the construction of cuffs at the venous anastomosis.

The assessment of proliferation in human stenotic tissue revealed elevated proliferative activity and suggests an important contribution of proliferation of vascular smooth 
muscle cells to the development of intimal thickening. This implicates that inhibition of proliferation may help in decreasing the progress of intimal lesions. One might speculate that angiotensin converting enzyme (ACE) inhibitors, which do also decrease the activity of the peripheral RAS system, may help in preventing intimal growth by decreasing proliferation. In this study we also found a high level of proliferating endothelial cells in the stenosis, indicating neovascularisation. This finding certainly needs further investigation in order to clarify the role of neovascularisation in the process of intimal thickening. A better insight in this mechanism may help in defining therapeutic strategies to decrease the development of intimal thickening.

The clinical implication of the findings in this study for other clinical problems related to intimal hyperplasia, such as restenosis after PTCA, is unclear. Although the time course and incidence of intimal thickening in vascular grafts and after PTCA are similar, it is obvious that compliance mismatch cannot play a role in the initiation or perpetuation of intimal thickening after PTCA. The role of flow in the development of restenosis after PTCA in humans is still unclear, but may be further elucidated with the use of intravascular ultrasound techniques.

\section{FUTURE DIRECTIONS}

In studying the effect of mismatch in elastic properties more attention has to be focused on the region close to the anastomosis. One interesting observation from our study is that graft-vein or graft-artery interaction may occur in the regions adjacent to the anastomoses. More knowledge on this subject may help in constructing better anastomoses and may improve the development of vascular prostheses.

In the prospective studies, relating initial flow conditions to the occurrence of intimal hyperplasia, a rough approximation of shear rate, the peak shear rate, was used. Improved techniques, like the new ultrasound system to estimate wall shear rate in the human in vivo situation may further clarify the correlation between intimal thickening and flow, since a more detailed picture of velocity patterns is provided.

Another improvement may be the continuous on-line registration of vessel wall distension. This allows investigation of beat-to-beat changes in elastic behavior of vessels, which may help to increase our understanding of the function of medium-sized arteries in pressure and flow homeostasis. A different topic is the assessment of wall thickness with the use of ultrasound techniques. This may increase our knowlegde on the natural history of vascular disease leading to intimal thickening. In addition, the effect of pharmacological intervention in patients with vascular disease can be evaluated when accurate wall thickness measurement is possible. 



\section{MECHANICAL AND FLOW CHARACTERISTICS AFFECTING INTIMAL HYPERPLASIA IN PERIPHERAL BYPASSES AND GRAFT AV FISTULAS IN HUMANS}

In chapter 1 and 2 the background and principal goals of the thesis are described. The main goal of the studies was to investigate the role of mechanical factors in the development of intimal thickening in peripheral bypass grafts and arteriovenous fistulas in patients. The development of intimal thickening in these arterial reconstructions leads to hemodynamically significant stenoses in a large fraction of patients, often necessitating surgical interventions. This results in considerable morbidity and hospitalisation. More insight in the initiation and development of intimal thickening in peripheral bypass grafts and AV fistulas may help in designing new surgical approaches in order to optimize mechanical and flow conditions, thereby preventing the development of intimal hyperplasia. In addition, better understanding of the biology of intimal thickening in humans may help in developing pharmacological interventions that inhibit the development of intimal thickening.

\section{VESSEL WALL DOPPLER TRACKING}

Information on the elastic properties of peripheral bypasses and graft arteriovenous fistulas has een very difficult to obtain, since suitable systems to assess the dimensions at defined sites in the wascular system were absent. With the introduction of Vessel Wall Doppler Tracking (VWDT), combining B-mode imaging and off-line data processing, the in vivo measurement of elastic properties of vessels in humans at defined sites in a vasculat system has become possible. This possibility allows for the assessment of elastic properties around the anastomoses of vascular reconstructions. Quantification of peri-anastomotic differences in elastic properties (mismatch) is crucial to investigate its possible role in the development of anastomotic stenoses in vascular reconstructions.

In chapter 3 VWDT is described and the possible application of the technique in vascular research is discussed.

In chapter 4 the short-term variations in elastic properties of the common femoral artery were studied in 10 young volunteers without vascular disease. The principal finding of this study is that the elastic properties of this artery change considerably 
within a relatively short period of time. In addition, it was observed that the changes in elastic properties were not related to changes in local blood pressure, suggesting that changes in vascular smooth muscle tone are responsible for the variation of elastic properties of this medium sized artery.

\section{MISMATCH IN ELASTIC PROPERTIES AROUND ANASTOMOSES OF PERIPHERAL BYPASSES AND GRAFT AV FISTULAS IN HUMANS}

The function of the graft as a vascular conduit is to transport blood volume without the loss of pulsatile energy to provide sufficient blood flow in the periphery. The transport function of grafts is largely determined by its mechanical properties. In order to obtain basic information on the mechanical profiles of grafts, we started to assess the elastic properties of different graft types at defined sites in the graft and native vessels in peripheral bypasses and AV fistulas with the use of Vessel Wall Doppler Tracking. By using this method we were able to provide the first in vivo data on mismatch in elastic properties around anastomoses of vascular grafts in humans.

In chapter 5 the mechanical profiles of in situ and reversed saphenous vein grafts are presented. One of the principal findings of this sudy was that in the in situ graft a proper match in compliance was found around the proximal anastomosis in contrast to the reversed graft, where a large drop in compliance around the proximal anastomosis was observed. However, in the course of the graft compliance in the reversed saphenous vein graft was remarkably stable, whereas in the in situ grafts an important drop in compliance was found.

In chapter 6 the elastic properties of PTFE peripheral bypass grafts and matched saphenous vein grafts were compared. As expected, the distension values of saphenous wein grafts were higher as compared to PTFE grafts. An interesting finding in this study is, that distension in the proximal graft segment of PTFE grafts was higher as compared to the distal graft segments, which is remarkable, since PTFE prosthesis have homogeneous material properties throughout the graft. A possible explanation may be that distension of the inflow artery leads to a passive distension of the most proximal graft segments. The finding that distension values of the inflow segment are positively correlated with distension values of the proximal segments supports the hypothesis of an artery-graft interaction.

In chapter 7 the differences in peri-anastomotic mismatch in elastic properties between the arterial and venous anastomoses of graft AV fistulas for hemodialysis were compared in order to find clues for the predisposition of intimal hyperplasia to develop at the venous site. The principal finding of this study was that at the arterial anastomoses a decrease in compliance was observed, whereas a sudden increase in compliance was observed at the venous site. The latter condition is associated with increased particle residence time and flow disturbances, suggesting low shear rates. 
Since numerous animal studies reported increased intimal thickening in areas of low shear rate, we postulated that the sudden increase in compliance at the venous anastomoses of graft AV fistulas may be the reason for the predisposition of intimal hyperplasia to develop at this site. At the venous anastomosis of the AV fistulas graftnative vessel interaction was observed. We found that an increase in the distension of the outflow vein was associated with an increase in distension of the graft close to the anastomosis, suggesting that distension of the vein leads to a passive distension of the graft at the site of the anastomosis.

In chapter 8 the dimensions and elastic properties of femoro-distal saphenous vein grafts for obstructive arterial disease were studied with time. The goal of this study was to investigate possible structural and functional adaptive responses of the saphenous vein, when grafted into the arterial circulation. The main finding of this study was that the elastic properties of the vein graft are stable within the first 6 months after grafting. A slight increase in the diameter of the proximal graft segments was observed. Since in this segment the highest flow velocities are present, the increase in diameter may be a flow mediated adaptive response in order to decrease the high level of shear rate at this point.

\section{MECHANICAL INFLUENCES ON THE OCCURRENCE OF INTIMAL HYPERPLASIA IN PERIPHERAL BYPASS GRAFTS AND GRAFT AV FISTULAS IN HUMANS}

In chapter 9, the role of peri-anastomotic mismatch in elastic properties and flow conditions on the occcurrence of stenoses in graft AV fistulas was reported. As stated in chapter 7 , one of the hypotheses was that the sudden increase in compliance at the venous anastomosis would cause flow disturbances indicating low shear rate conditions, thereby leading to increased intimal thickening. However, the prospective analysis described in chapter 9 , showed that this mechanism does not play a role in the development of intimal thickening in graft AV fistulas. When correlating initial flow characteristics and peri-anastomotic mismatch in elastic properties with the incidence of intimal thickening at the venous anastomosis, we found that the occurrence of intimal hyperplasia was not associated with mismatch in elastic properties. On the contrary, an even better inititial match in elastic properties was observed in AV fistulas developing an intimal stenosis as compared to the AV fistulas that did not develop a stenosis. Another major finding in this prospective study was that local initial high shear rates at the site of the venous anastomosis or the efferent vein is associated with the occurrence of intimal thickening leading to stenosis. Histologic examination of the harvested stenotic tissue specimens revealed that the average coverage of the lumen with endothelial cells was approximately $50 \%$, indicating partial denudation of endothelial cells. The finding that denudation is present at the site of the stenosis suggests that high shear rate at the venous site leads to injury and erosion of endothelial cells, possibly initiating the process of intimal thickening. 
In chapter 10 the influence of mechanical factors on the accurrence of intimal hyperplasia in saphenous vein peripheral bypass grafts was studied prospectively. The proximal anastomosis of the graft was predisposed to the development of stenoses. In the grafts developing a stenosis at the proximal anastomosis during follow-up, a higher initial mismatch in strain around the anastomosis was observed than in grafts free of stenosis during follow-up. In addition, the initial diameter mismatch at the proximal anastomosis was larger in the grafts developing a stenosis.

Multiple regression analysis showed that a high initial peak shear rate at the proximal graft segment was associated with the occurrence of stenoses. In addition, in the grafts developing a stenosis, the highest initial flow velocities and peak shear rate levels were observed at the site of the later stenosis. This suggests that intimal thickening in venous grafts is associated with high shear rate rather than low shear rate. This observation is in concordance with our findings in AV fistulas (chapter 9). In the stenotic segments harvested from patients needing surgical intervention denudation was found in approximately the same extent as in the stenotic segments harvested from AV fistulas. This indicates that high shear rates also may play a role in the initiation of intimal hyperplasia in saphenous vein peripheral bypass grafts. This supports the concept that in venous segments excessive high shear rates are not very well tolerated and may lead to endothelial cell injury and denudation which in turn causes a response of the vessel wall initiating intimal thickening.

In chapter 11 the results of the assessment of cellular proliferation in stenotic segments derived from human AV fistulas and peripheral bypass grafts are reported. This is the first prospective study correlating initial flow conditions with the extent of proliferation in human stenoses. In addition, the distribution of proliferation in the stenotic segments was determined, since anatomically intact material was studied. The major finding of this study was that the extent of subendothelial proliferation was positively correlated with the percentage coverage of the lumen by endothelial cells, suggesting that the presence of endothelial cells in the stenotic lesion leads to promotion of proliferation rather than inhibition. This suggests that the endothelial cells covering the stenotic segments are dysfunctional and are unable to control cell proliferation in the vessel wall. A positive correlation was observed between proliferation of endothelial cells covering the lumen and subendothelial-intimal proliferation, suggesting that a proliferative state of the endothelial cells is associated with an imbalance between growth inhibition and promotion in favour of the latter. Peak shear rate was negatively correlated with endothelial cell coverage of the lumen, supporting the concept that an excessive high shear rate leads to endothelial cell injury, and even to denudation. Thus, high shear may have an indirect inhibitory effect on proliferation by means of denudation. 


\section{DE INVLOED VAN STROMINGSKARAKTERISTIEKEN (FLOW) EN EEN PLOTSELINGE VERANDERING IN ELASTISCHE EIGENSCHAPPEN (MISMATCH) OP HET ONTSTAAN VAN INTIMA HYPERPLASIE IN PERIFERE BYPASSES EN ARTERIO-VENEUZE FISTELS VOOR HEMODLA. LYSE}

In de hoofdstuk 1 en 2 zijn de achtergronden en vraagstellingen van het proefschrift beschreven. Het belangrijkste doel was de rol van mechanische factoren op het ontstaan van intima hyperplasie te onderzoeken bij patienten met een perifere arteriële bypass in het been of een arterio-veneuze fistel voor hemodialyse. De hypothese hierbij was dat door inhomogeniteit in elastische eigenschappen of door plaatselijke bloedstroom condities intima hyperplasie kan worden gestimuleerd. De ontwikkeling van intima hyperplasie in deze arteriële vaatreconstructies leidt tot hemodynamisch significante stenosen in een groot deel van de patienten, hetgeen chirurgische interventie noodzakelijk maakt. Dit resulteert in substantiële morbiditeit en hospitalisatie bij deze patienten. Meer inzicht in de initiatie en ontwikkeling van intima hyperplasie zou kunnen bijdragen tot het ontwerpen van nieuwe chirurgische benaderingen om de mechanische en flow condities van de reconstructies te optimalizeren en dit zal kunnen leiden tot een vermindering van de incidentie van intima hyperplasie. Ook kan een beter inzicht in de pathofysiologische processen welke leiden tot intima verdikking bijdragen aan de ontwikkeling van pharmacologische interventies, om de ontwikkeling van het proces te kunnen remmen.

\section{VESSEL WALL DOPPLER TRACKING}

Voor het meten van elastische eigenschappen van perifere bypasses en arterio-veneuze fistels ontbraken tot recent gesckikte meetsystemen. Met de introductie van Vessel Wall Doppler Tracking (VWDT) is het magelijk geworden om de dimensies en uitzetting van bloedvaten in vivo bij de mens te meten. Dit ultrageluids systeem combineert B-mode met off-line automatische detectie van de beweging van structuurovergangen, zoals de vaatwand. Hierdoor is het mogelijk om dimensies en elastische eigenschappen op gedefinieerde plaatsen in een vasculair systeem te meten. Op deze wijze kunnen de elastische eigenschappen rond de anastomosen van arteriële reconstructies worden bepaald. Deze informatie is essentieel om de rol van perianastomotische verschillen in elastische eigenschappen in het onstaan van stenosering te onderzoeken. In hoofdstuk 3 is het VWDT systeem beschreven en wordt de mogelijke rol van het systeem binnen de het vaatonderzoek bediscussieerd. 
In hoofdstuk 4 worden de korte termijn variaties in elastische eigenschappen van de arteria femoralis communis bij gezonde jonge vrijwilligers beschreven. De belangrijkste bevinding in het onderzoek is dat de elastische eigenschappen van deze grote musculaire arterie in een periode van omstreeks 30 minuten belangrijk kunnen veranderen. Deze variatie in elasticiteit was niet gerelateerd aan veranderingen in locale bloeddruk, hetgeen suggereert dat veranderingen in vaattonus verantwoordelijk zijn voor dit fenomeen.

\section{MISMATCH IN ELASTISCHE EIGENSCHAPPEN ROND ANASTOMOSEN VAN PERIFERE BYPASSES EN ARTERIO-VENEUZE FISTELS}

De belangrijkste functie van een vaattransplantaat (graft) is het transporteren van bloed volume met een zo gering mogelijk verlies van energie, om zo voldoende doorbloeding in de periferie te verzorgen. Deze transport functie wordt grotendeels bepaald door de mechanische eigenschappen van deze grafts. Om basale informatie over de mechanische eigenschappen te verkrijgen, werden de dimensies en de uitzetting van grafts en van het natieve vasculaire stelsel op gedefinieerde plaatsen gemeten met behulp van VWDT. Op deze wijze werden de eerste humane in vivo gegevens over mismatch in elastische eigenschappen rond de anastomosen van perifere bypassses en arterio-veneuze fistels verkregen.

In hoofdstuk 5 zijn de mechanische profielen van 'in situ' en omgekeerde veneuze bypasses in het been beschreven. In de in situ bypass werd een vloeiende overgang in compliantie rond de proximale anastomose gevonden, in tegenstelling tot de omgekeerde veneuze bypass, waar ter plaatse van de proximale anastomose een belangrijk verval in compliantie werd gemeten. Echter, van proximaal naar distaal in de graft was er een stabiel patroon in compliantie in de omgekeerde veneuze graft, terwijl de in situ bypass een belangrijk verval in compliantie liet zien.

In hoofdstuk 6 zijn de elastische eigenschappen van veneuze en prothetische (PTFE) bypass grafts met elkaar vergeleken. In vivo metingen bleken met het VWDT systeem goed mogelijk. Naar verwachting bleek de uitzetting van de veneuze bypass groter te zijn dan die van de PTFE bypass.

In hoofdstuk 7 zijn de verschillen in peri-anastomotische mismatch in elastische eigenschappen vergeleken tussen de arteriële en de veneuze anastomose van interpositie grafts voor hemodialyse. Het merendeel van de stenosen in deze AV fistels ontwikkelt zich in of rond de veneuze anastomose. Gevonden werd dat er in de arteriële anastomose een abrupte vermindering in compliantie bestaat, terwijl in de veneuze anastomose een abrupte toename in compliantie voorkomt. Een abrupte toename in compliantie is geassocieerd met veranderingen in stromingscondities, zoals stase en omkering van bloedstroom. Omdat in verschillende studies is aangetoond dat een trage flow is geassocieerd met een toename van intima hyperplasie, zou dit de verklaring 
kunnen zijn voor de predispositie van de veneuze anastomose tot het ontwikkelen van intima verdikking.

In hoofdstuk 8 zijn de dimensies en elastische eigenschappen van veneuze bypasses als functie van de tijd bestudeerd (tot 6 maanden na aanleggen). Gedurende deze periode werd geen verandering in elastische eigenschappen gevonden, hetgeen suggereert dat de elastische eigenschappen van de veneuze graft bewaard blijven gedurende de eerste 6 maanden na de aanleg ervan.

\section{DE INVLOED VAN MECHANISCHE EIGENSCHAPPEN OP HET ONTSTAAN VAN INTIMA HYPERPLASIE IN PERIFERE BYPASSES EN ARTERIO. VENEUZE FISTELS}

In hoofdstuk 9 zijn op prospectieve wijze de invloeden van peri-anastomotische mismatch in elastische eigenschappen en van stromingscondities op het ontstaan van intima verdikking in arterio-veneuze hemodialyse fistels bij patienten bestudeerd. Hierbij werden de initiële mismatch in elastische eigenschappen en stromingsparameters (gemeten 2 weken na aanleggen) gecorreleerd met het optreden van stenosering gedurende de follow-up periode tot 2 jaar. Uit de analyse bleek dat mismatch in elastische eigenschappen rond de anastomosen niet geassocieerd is met het onstaan van stenosering door intima hyperplasie. Tevens bleek dat een initiële hoge systolische bloedstroomsnelheid, gecorrigeerd voor diameter, geassocieerd is met het optreden van stenosering. Stenosen traden voor het overgrote deel op aan de veneuze zijde van de $A V$-fistels.

In hoofdstuk 10 werd een soortgelijke prospectieve analyse gedaan voor perifere bypasses in het arteriële systeem van het been. Een grote mismatch in relatieve rek en in einddiastolische diameter ter plaatse van de proximale anastomose van veneuze perifere bypasses bleek geassocieerd met het ontstaan van stenosering tijdens de nacontrole. Tevens bleek in de bypasses die een stenose ontwikkelden gedurende de follow-up periode de stenose te onstaan op de plaats met de initieel hoogste piek bloedstroomsnelheid. Dit laatste bevestigt de resultaten uit hoofdstuk 9. De data suggereren derhalve dat hoge initiële bloedstroomsnelheden in veneuze segmenten zou kunnen leiden tot stenosering door intima hyperplasie.

Proliferatie van gladde spiercellen wordt als een belangrijke stap beschouwd in de ontwikkeling van intima hyperplasie. In hoofdstuk 11 is de cellulaire proliferatie in een aantal stenotische segmenten bepaald, welke werden verkregen uit de patientenpopulaties zoals beschreven in de hoofdstukken 9 en 10 . Tevens werd de invloed van locale bloedstroomkarakteristieken op de cellulaire proliferatie bestudeerd. De gemiddelde proliferatie index van cellen in de stenose bleek zowel in de stenosen uit de bypass groep als uit de AV-fistel groep omstreeks 3.5\% te zijn, hetgeen veel hoger is dan in controle vaatsegmenten $(0-0.5 \%)$. Tevens werd een positieve correlatie gevonden 
tussen de mate van endotheelcel bekleding van de stenose en de subintimale proliferatie, hetgeen suggereerd dat de aanwezige endotheelcellen proliferatie bevorderen. Een andere belangrijke bevinding was de grote mate van vaatnieuwvorming in de stenotische segmenten. Op dit moment is nog onduidelijk in welke mate deze vaatnieuwvorning bijdraagt aan de ontwikkeling van stenosering. 


\section{DANKWOORD}

Niet in de laatste plaats maar toch meestal aan het einde van het van het dankwoord wordt het gezin van de promovendus bedankt. Erica, ondanks het feit dat veel heeft moeten wijken voor de promotie heb je me altijd volledig gesteund en heb je ons gezin gepromoveerd met 2 schatten van kinderen, waar ik dit boekje meteen voor zou inleveren.

Prof Dr PJEHM Kitslaar, beste Peter, gaarne wil ik je hartelijk bedanken voor de grote vrijheid en hulp die je me hebt gegeven voor het opzetten van onderzoek, ook al was het vaak naast de oorspronkelijke vraagstelling. Veel baat heb ik gehad bij je enorme nauwgezetheid en je gedrevenheid om het onderzoek te laten slagen. Onvergetelijk waren de ritten in de Peugeot 504 familiale, die helaas door claudicatio aan z'n einde is gekomen.

Prof Dr APG Hoeks, beste Arnold, aanvankelijk waren de denkstappen die je maakte voor mij onnavolgbaar en deed ik maar wat je me opdroeg. Later kwam ik toch wat dichter in de buurt van jouw uitzend frequentie, hetgeen geleid heeft tot zeer vruchtbare discussies over de resultaten van het onderzoek. Daarbij is de door jouw gretig aangehaalde kloof tussen clinici en basiswetenschappers hopelijk wat kleiner geworden.

Dr JHM Tordoir, beste Jan, tijdens de research periode heb ik altijd veel plezier beleefd aan het onderzoek met de AV fistels, het turbomodel voor de ontwikkeling intima hyperplasie, zoals het door jou treffend wordt genoemd. Wat je doet lijkt vaak laconiek, maar blijkt toch zeer toegewijd. Zowel binnen het onderzoek als erbuiten heb ik veel steun aan je gehad, ook wanneer het eens wat slechter ging.

Dr MJAP Damen, beste Mat, jouw expertise op het gebied van (re)-stenose heeft een belangrijke kwaliteit toegevoegd aan het onderzoek. Een zeer goede maar soms zeer lastige eigenschap van je is dat je altijd zeer kritisch blijft, waarbij je als een terrier aan je standpunten vasthoudt. Dat heeft me wel eens wat moedeloosheid bezorgd. Ondanks en ook dankzij die eigenschap zet ik de samenwerking in de toekomst graag met je voort.

JHM Willigers, beste Jean, high-tech onderzoek kan niet zonder high-tech ondersteuning. Bij calamiteiten op technisch gebied stond je altijd weer klaar, ook al was het soms slechts om een stekker in het juiste stopcontact te steken. Met een zeer speciaal gevoel kijk ik terug naar het fitten van sinusfuncties door onze data, het zogenaande 'snaken'. Veel dank voor deze Eysdense kwaliteiten. 
P Brands, beste Peter, ook jij stond altijd klaar in geval van technische problemen, met name wanneer Jean het ook niet meer wist. Veel dank voor de onvoorwaardelijke support tijdens het onderzoek.

DCJJ Bergmans, super Dennis, een ieder kan ik zonen van vlaaienbakkers uit Weert aanbevelen (vlaaien graag goed vasthouden). Als student-assistent heb je geweldig veel werk verzet bij het verwerken van de data-stroom en daardoor zeker een jaar 'gewonnen' voor het onderzoek. Niet alleen je werklust werkte aanstekelijk, maar ook je gevoel voor humor. Daarom vind ik het jaar dat jij er was het beste jaar van de research tijd. Ooit zal ik je verslaan met squash.

H Kurvers, beste Harry, 'a young man in a hurry', altijd geef je vol gas (helaas ook in mijn auto). Ondanks het feit dat je niet direct betrokken was bij het onderzoek, heb je er tocli veel aan bijgedragen, alleen al door je competatitieve natuur. Naast goede discussies hebben we steeds zeer veel pret gemaakt tijdens het onderzoek. Zeer fraaie herinneringen bewaar ik aan onze ski-congressen en de door mij geschreven en aan jouw gerichte fake-liefdesbrieven van vermeende minnaressen uit het verre Amerika.

Frank Huvers, Nicolaas Schaper, Boy Houben en Karel Leunissen, zeer gewaardeerd en ook zeer waardevol is de internistische bijdrage geweest aan het onderzoek. Van de bekende water-vuur verhouding tussen de heelkunde en interne is mij gelukkig niets gebleken.

De dames van het vaatlab, Edith, Yvonne, Monique, Ien en Laura, bedankt voor de jullie steun tijdens het leren echoën en de gezelligheid, waarvan ik met name het jaarlijkse Sinterklaas vieren zeer heb gewaardeerd. Yvonne en Nicole, jullie wil ik graag bedanken voor de altijd attente ondersteuning tijdens de gehele research periode.

De Nederlandse Hartstichting wil ik graag bedanken voor de financiële steun voor projecten als deze. Ook veel dank voor de ondersteuning van de verschillende congresbezoeken, welke mijn wetenschappelijke horizon zeker verbreed hebben. 


\section{CURRICULUM VITAE}

The author was born on June 251963 in Emmen, The Netherlands. After visiting primary school, he attended high school in Emmen (Christelijke Scholengemeenschap). In 1981 he entered Medical School at the University of Groningen; he graduated in 1989. From August 1989 to January 1991 he served as a medical officer in the Royal Dutch Army. From February 1991 to February 1994 he was a research fellow in the Vascular Laboratory, department of Surgery, and the department of Biophysics. During this period the work contained in this thesis was accomplished under the supervision of Prof PJEHM Kitslaar and Prof APG Hoeks. Part of the work was rewarded with European Society for Vascular Surgery Prize 1993, for the best original paper on clinical research and an Award lecture on the 12th Annual Meeting of the International Society of Blood Purification, 1994, Maastricht, The Netherlands. In September 1994 he started his training in Cardiology in the University Hospital of Maastricht (head: Prof HJJ Wellens). 



\section{LIST OF PUBLICATIONS}

\section{PUBLICATIONS RELATED TO THIS THESIS}

\section{Articles}

L Hofstra, EJM Ermers, APM Langeveldt, APG Hoeks, PJEHM Kitslaar. Vessel Wall Doppler Tracking: A new technique to assess vessel wall compliance. J Vase Tech 1993; 17:65-68.

L Hofstra, JM Willigers, ADM Kester, PJEHM Kitslaar, APG Hoeks. Short-term variations in elastic properties of a muscular artery in humans. Clin Science 1994; 86: $567-574$.

L Hofstra, DCJJ Bergmans, APG Hoeks, JHM Tordoir, PJEHM Kitslaar. Compliance and distensibility of the reversed saphenous vein graft. VASA 1993: $542 ; 40-41$.

L Hofstra, DCJJ Bergmans, APG Hoeks, JHM Tordoir, PJEHM Kitslaar. Assessment of inhomogenieties in elastic properties of in situ and reversed saphenous wein grafts in humans. Eur J Vasc Surg 1994; 8: 6701676.

L Hofstra, DCJJ Bergmans, APG Hoeks, PJEHM Kitslaar, KML Leunissen, JHM Tordoir. Mismatch in elastic properties around anastomoses of interposition grafts for hemodialysis access. JASN 1994; $5 ; 1243-1250$.

L Hofstra, JHM Tordoir, PJEHM Kitslaar, APG Hoeks, MJAP Daemen. The influence of peak shear rate on proliferation patterns in human stenotic lesions derived from arterio-venous fistulas and peripheral bypass grafts - A study using KI-67 (submitted).

L Hofstra, DCJJ Bergmans, JHM Tordoir, APG Hoeks, PJEHM Kitslaar. Elastic properties of PTFE and saphenous vein bypass grafts in humans (submitted).

PJ Brands, APG Hoeks, L Hofstra, RS Reneman. A non-invasive method to estimate wall shear rate using ultrasound. Ultrasound Med Biol. 1995: 2;171-185.

JHM Tordoir, L Hofstra, KML Leunissen, PJEHM Kitslaar. Early experience with stretch. polytetrafluoroethylene grafts for hemodialysis access surgery: results of a prospective randomized study (submilted).

L Hofstra, DCJJ Bergmans, PJEHM Kitslaar, KML Leunissen, MJAP Daemen, JHM Tordoir. The effect of shear rate and anastomotic mismatch in elastic properties on the development of stenosis in AV fistulas (submitted). 


\section{Abstracts}

L Hofstra, PJEHM Kitslaar, APG Hoeks, KML Leunissen, JHM Tordoir. Vaatwand conpliance in PTFE en veneuze grafts bij hemodialyse patienten. Voordracht chirurgendagen, Rotterdam, mei 1992.

L Hofstra, PJEHM Kitslaar, APG Hoeks, JHM Tordoir. Compliance in PTFE and saphenous vein grafts in hemodialysis patients. 16 th World Congress of the International Union of Angiology, Paris, september 1992 .

L Hofstra, PJEHM Kitslaar, APG Hoeks. Cyclic variation in compliance in the common femoral artery. 16 th World Congress of the International Union of Angiology, Paris, september 1992 .

L Hofstra, APG Hoeks, JHM Tordoir, PJEHM Kitslaar. Compliance en distensibiliteit in de omgekeerde vene graft. Voordracht Ned Vereniging voor Vaatchirurgie, Utrecht, oktober 1992.

F Huwers, L Hofstra, C Lange, A Hoeks, A Houben, P Kitslaar, P de Leeuw, A Krüseman, N Schaper. Carotid and femoral distensibility in uncomplicated non-insulin-dependent diabetes mellitus patients without atherosclerotic changes. Neth J Med 1993: 22: A91

F Huvers, L Hofstra, C Lange, A Hoeks, A Houben, P Kitslaar, P de Leeuw, A Krüseman, N Schaper. Venous distensibility and the venodilatory effect of nitroglycerin are not reduced in uncomplicated non-insulin-dependent diabetes mellitus. Eur J Clin Invest 1993; 23: A7.

F Huvers, L Hofstra, C Lange, A Hoeks, A Houben, P Kitslaar, P de Leeuw, A Krüseman, $\mathrm{N}$ Schaper. Distensibility of the arterial and venous system in non-insulin-dependent diabetes mellitus. Voordracht Ned Vereniging voor Diabetes Onderzoek, mei 1993.

L Hofstra, DCJJ Bergmans, PJEHM Kitslaar, APG Hoeks, JHM Tordoir. Compliance in PTFE ans saphenous vein grafts in hemodialysis patients. 4th Vascular symposium, Zürs, Austrita, februari 1993.

L. Hofstra, P Schiffers, JHM Tordoir, MJAP Daemen, JGR DeMey, PJEHM Kitslaar. Preexistente afwijkingen in de vena saphena magna: oorzaak voor het vroeg falen van de perifere bypass. Voordracht chirurgendagen, Amsterdam, mei 1993.

L Hofstra, DCJJ Bergmans, APG Hoeks, JHM Tordoir, PJEHM Kitslaar. Compliance and distensibility of the reversed saphenous vein graft. Voordracht Deutschen Gesellschaft für Gefaßchirurgie, Heidelberg, mei 1993.

L. Hofstra, DCJJ Bergmans, APG Hoeks, JHM Tordoir, PJEHM Kitslaar. Elastic properties of the saphenous vein graft: A comparison of the in situ and reversed technique in humans. VII th Annual Meeting of the European Society for Vascular Surgery, Barcelona, september 1993. 
JHM Tordoir, L Hofstra. Klinische resultaten en in vivo compliance metingen van stretchable PTFE AV protheses. Symposium Nieuwe Technieken en Materialen woor Henodialyse Toegang en CAPD Behandeling, Utrecht, april 1993.

L Hofstra, DCJJ Bergmans, APG Hocks, JHM Tordoir, PJEHM Kitslaar. Elastische eigenschappen van veneuze grafts; vergelijking van de in situ en omgekeerde vene graft bij de mens. SEOHS, Nijmegen, november 1993.

DCJ Bergmans, L Hofstra, APG Hoeks, JHM Tordoir, PJEHM Kitslaar. Compliance in PTFE en veneuze femoro-distale bypasses. Ned Tijdschr Geneeskd 1994, 21; 138 (21).

L Hofstra, APG Hoeks, KML Leunissen, DCJJ Bergmans, PJEHM Kitslaar, JHM Tordoir. Mismatch in elastic properties around anastomoses of interposition grafts for hemodialysis access. A Symposium on Hemodialysis Access IV, Orlando, mei 1994.

JHM Tordoir, L Hofstra, DCJJ Bergmans, APG Hoeks, KML Leunissen, PJEHM Kitslaar. Stretch PTFE grafts for hemodialysis access: improved hemodynamic performance and less complications compared to standard ePTFE grafts. A Symposiun on Hemodialysis Access IV, Orlando, mei 1994.

L Hofstra, PJEHM Kitslaar, APG Hoeks, JHM Tordoir, MJAP Daemen. Correlation of proliferation and shear rates in human stenotic lesions derived from AV fistulas and fenorodistal bypasses. Symposium on Intimal Hyperplasia, Maastricht, mei 1994.

PJEHM Kitslaar, L Hofstra, JHM Tordoir, APG Hoeks, MJAP Daemen. Het effect van peak shear rate op celproliferatie in stenosen in AV dialyse fistels en periphere arteriele bypasses. Chirurgendagen, Veldhoven 1994.

JHM Tordoir, L Hofstra, DCJJ Bergmans, APG Hoeks, KML Leunissen, PJEHM Kitslaar. Stretch PTFE prothesen voor hemodialyse toegangschirurgie: verbetering in hemodynamische eigenschappen en vermindering van complicaties in vergelijking tot standaard ePTFE grafts. Chirurgendagen, Veldhoven 1994.

JHM Tordoir, L Hofstra, KML Leunissen. Duplex scanning and compliance measurement of graft AV fistulas. Simposio de Actualicacao na Cirurgica dos Acessos Vasculares Parahemodialise, Lisabon, juli 1994.

L Hofstra, JHM Tordoir, APG Hoeks, PJEHM Kitslaar, MJAP Daemen. The effect of peak shear rate on proliferation patterns in human stenotic lesions derived from AV fistulas and peripheral bypass grafts. VIIth International Sypmposium on Vascular Biology, Heidelberg, august 1994. 


\section{OTHER PUBLICATIONS}

\section{Articles}

L Hofstra, E Boersma, SJ Ham. Penetrerende letsels van het abdomen op het eiland Curacao. Ned Tijdschr Gieneesk 1990; 134: 1046-48.

L. Hoftrtra, HH wan Woetden en R Deutman. Chemonucleolysis in the Herniated L3-LA Disk. Clin Orthop 1991; 269:151-156.

H de Swart, L Dijkman, L Hofstra, FW Bär, V van Ommen, J Tordoir, HJJ Wellens. A new hemostatic puncture closure device for the immedeate sealing of arterial puncture sites. Am J Cardiol 1993; $72: 445-449$.

MH Booster, RMH Wijnen, JP van Hooff, ATMG Tiebosch, HG Peltenburg, PM van den Berg-Loonen, MJPG van Kroonenburgh, T Verschuren, L Hofstra and G Kootstra. The role of the spicen in pancreas transplantation. Transplantation (in press).

\section{Abstracts}

HAJM Kurvers, L Hofstra, APG Hoeks, FAJM van de Wildenberg, PJEHM Kitslaar, MJHM Jacobs. Sympathetic dysfunction in Sudeck's dystrophy assessed by Vessel Wall Echo Tracking. Eur $\sqrt{ }$ Clin Inv 1992; 22: A8.

L Hofstra, HAJM Kurvers, FAJM van de Wildenberg, MJHM Jacobs, PJEHM Kitslaar. Veranderingen van vaatwandgedrag bij Sudeck-dystrofie. Ned Tijdschr Geneesk 1992; 136: 1428.

H de Swart, L Dijkman, L Hofstra, F Bär, V van Ommen, J Tordoir, H Wellens.A new hemostatic puncture closure device for the immediate sealing of arterial puncture sites. XIV th Congress of the European Saciety of Cardiology, Barcelona, september 1992.

L Hofstra, HAJM Kurvers, APG Hoeks, FAJM van de Wildenberg, MJHM Jacobs PJEHM Kitslaar. The influence of sympathetic dysfunction on compliance of the brachial artery in Sudeck"s dystrophy. 16th World Congress of the International Union of Angiology, Paris, september 1992 .

HAJM Kurvers, L Hofstra, FAJM van den Wildenberg, PJEHM Kitslaar, MJHM Jacobs. Bilateral sympathetic involvement in Sudeck's dystrophy assessed by Vessel Wall Doppler Tracking. 16th World Congress of the International Union of Angiology, Paris, september 1992.

L. Hofstra, L Dijkman, H de Swart, F Bär, V van Ommen. Resultaten van een nieuwe hemostatische vaatplug bij A. Femoralis-catheterisatie. Ned Tijdschr Geneesk 1993; 137: 627628. 
L Hofstra, HAJM Kurvers, JPL van der Plas, JHM Tordoir, MJHM Jacobs, BK Janewski, PJEHM Kitslaar. Klinische presentatie en diagnostiek van handarterieletsels door stompe traumata. Ned Tijdschr Geneesk 1993; $137: 628$.

H de Swart, L Dijkman, L Hofstra, F Bär, V van Ommen, J Tordoir, H Wellens. A new hemostatic puncture closure device for the immediate sealing of arterial puncture sites. Neth J Card 1992; $5: 73$.

$G$ van Ommen, J Tordoir, $F$ van der Veen, L Hotstra, $D$ Koster, H Wellens. A new hydrodynamic thrombectomy catheter for the removal of intravascular thrombus: First clinical results. XVth Congress of the European Society of Cardiology, Nice, september 1993.

PJ Brands, APG Hoeks, L. Hofstra. Een niet-invasieve methode voor shear-rate meting. Voordracht Nederlandse Vereniging Ultrageluid, Utrecht, Oktober 1993.

L Hofstra, P Schiffers, JHM Tordoir, MJAP Daemen, JGR De Mey, PJEHM Kitslaar. Preexistente afwijkingen in de vena saphena magna; oorzaak voor het vroeg falen van de perifere bypass? Chirurgendagen, Amsterdam, mei 1993.

JHM Tordoir, V van Ommen, EH van der Veen, L Hofstra, D Koster. Eerste resultaten van een nieuwe hydrodynamische trombectomie catheter. Chirurgendagen, Amsterdam, nuei 1993. 

Het verschijnen van dit proefschrift werd financieel ondersteund door:

W.L. Gore and Associates B.V.

LEO

Zambon

Servier

Wyeth

Pie Medical

Van der Laar Stichting 